\title{
CHEMILUMINESCENCE AND HIGH SPEED IMAGING OF REACTING FILM COOLING LAYERS
}

\author{
Thesis \\ Submitted to \\ The School of Engineering of the \\ UNIVERSITY OF DAYTON
}

In Partial Fulfillment of the Requirements for The Degree

Master of Science in Aerospace Engineering

\author{
By \\ Alanna Rose O’Neil \\ UNIVERSITY OF DAYTON \\ Dayton, Ohio
}

December, 2011 
CHEMILUMINESCENCE AND HIGH SPEED IMAGING OF REACTING FILM

COOLING LAYERS

Name: O’Neil, Alanna Rose

APPROVED BY:

Dr. Dilip Ballal

Advisory Committee Chairman

Hans von Ohain Distinguished Professor

Mechanical and Aerospace Engineering

Dr. Sukh Sidhu

Committee Member

Associate Professor

Mechanical and Aerospace Engineering

John G. Weber, Ph.D.

Associate Dean

School of Engineering
Dr. Scott Stouffer

Committee Member

Senior Research Engineer

Energy and Environmental Engineering
Dr. David Blunck

Committee Member

Mechanical Engineer

Air Force Research Laboratory
Tony E. Saliba, Ph.D.

Dean, School of Engineering \& Wilke Distinguished Professor 


\begin{abstract}
CHEMILUMINESCENCE AND HIGH SPEED IMAGING OF REACTING FILM COOLING LAYERS
\end{abstract}

Name: O’Neil, Alanna Rose

University of Dayton

Advisor: Dr. Dilip Ballal

The demand for more efficient and compact gas turbine engines has resulted in an increase in the operating temperatures and pressures and a decrease in combustor weight and size. These advances may result in incomplete combustion products entering the turbine section. The products can react with the air intended to cool the turbine vanes, and the resulting flame can cause damage to the engine. This study reports chemiluminescence measurements of flames and correlates these to heat release rate and the measured heat flux to a surface. To accomplish this, fuel rich combustion products are generated in a well-stirred reactor. The flow of products is directed over a flat plate with cooling air jets normal to the flow. Chemiluminescence data of the flames is obtained, along with high speed images, and temperature measurements of the flow inside the test section. Three film cooling geometries are studied: normal holes, fan shaped holes, and slot. Measurements are acquired at three equivalence ratios (1.3, 1.4, and 1.5) at three different blowing ratios $(M=1,4$, and 7$)$. 
It is found that the rate of heat release from the flame does not always trend the same as the heat transfer to the surface. It is also seen that a large reaction region does not always equate to high heat flux to the surface. If enough cooling air is present the surface is protected from the heat released from the flame 


\section{ACKNOWLEDGEMENTS}

To Scott Stouffer, your continual support has been amazing. The work environment you created has helped me gain confidence in my abilities and has been truly rewarding. Thank you for always making time for me and keeping me motivated. Most importantly thank you for all the life lessons you have shared with me over the past year and a half; all those insights and bits of wisdom are so deeply appreciated.

To David Blunck, thank you for the time spent sitting down and going through my thesis. Thank you for both your professional and personal advice. Your constant smile and cheerful demeanor has been greatly appreciated.

To Stan Kostka and Amy Lynch, both of you are a blast to spend time with; your upbeat attitudes and constant supply of snacks have kept me going through many stressful days. Thank you to both of you for giving me so much of your valuable time by sitting in the lab, talking through the camera program, dealing with computer problems, and figuring out how to best process data.

To Dr. Dilip Ballal and Dr. Sukh Sidhu, thank you both for being on my defense committee. The time you have both spent reading my thesis and offering insight has been greatly appreciated. Also, thank you to the Hons von Ohain Fellowship, which made graduate school a possibility. 
To Mike Arstingstall, thank you for all the time you spent with me sitting in the lab. Thank you for always answering my questions and for teaching me more than a thing or two about thinking creatively and problem solving.

To my family, Dad, Mom, John, Moreen, Erin, Kathleen, Margaret, and Jim: Though I may not have said so before, knowing that regardless of how I perform at work and school you will all still love me has been an amazing support.

Finally, to my husband, Brian, your unwavering love has been a wonderful blessing. Thank you for being young at heart; this attitude has kept me smiling and laughing, and from taking all of this too seriously. Thank you for constantly reminding me of the truly important things in life. 


\section{TABLE OF CONTENTS}

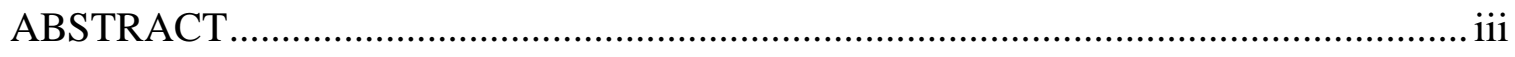

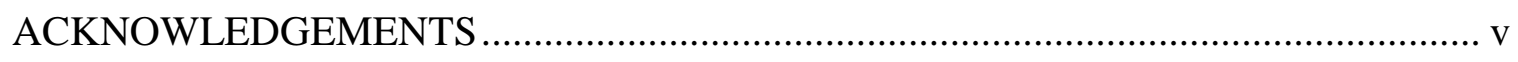

TABLE OF CONTENTS ................................................................................. vii

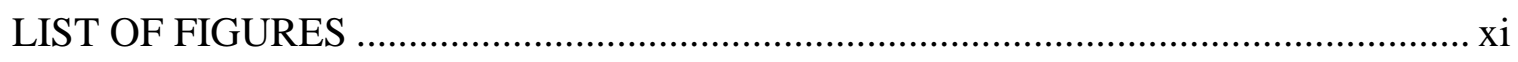

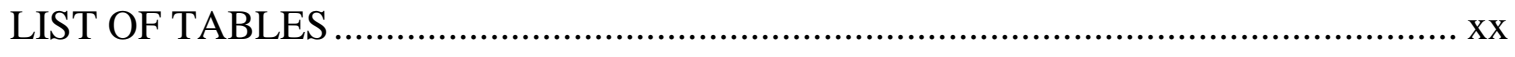

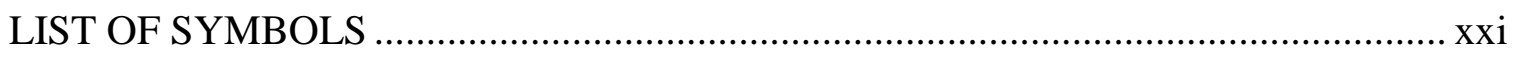

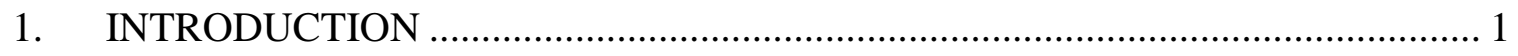

1.1. TURBINE FILM COOLING .............................................................. 1

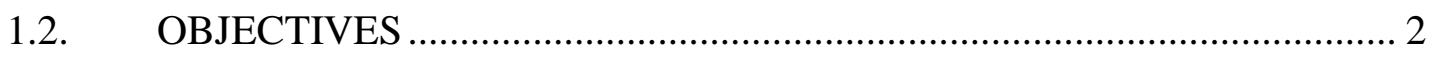

1.3. CHAPTER OUTLINE ................................................................. 2

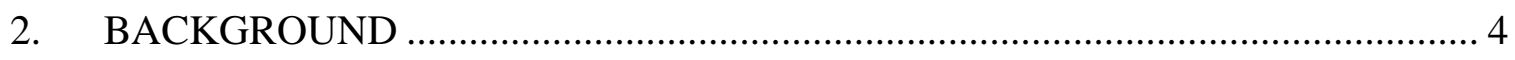

2.1. TURBINE FILM COOLING............................................................. 4

2.1.1. Potential for Reactions and Heat Transfer ................................................ 6

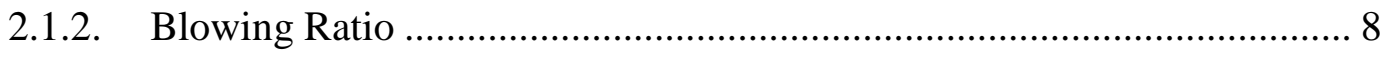

2.2. THE ULTRA COMPACT COMBUSTOR ……………………............. 9

2.3. AUTOIGNITION …………………………............................. 11

2.4. HEAT TRANSFER CALCULATION ……………................................ 11

2.5. EQUIVALENCE RATIO CALCULATION ............................................ 15 
2.6. HIGH SPEED IMAGING AND CHEMILUMINESCENCE ................... 16

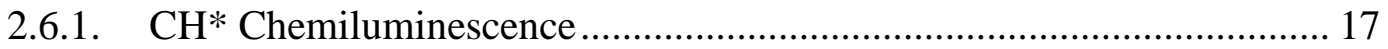

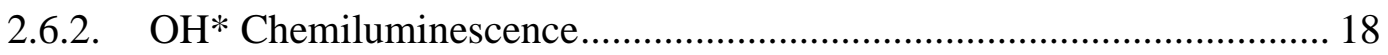

2.7. HEAT RELEASE RATE AND CHEMILUMINESCENCE .................... 19

2.8. LOCAL EQUIVALENCE RATIO AND CHEMILUMINESCENCE ...... 20

2.9. PREVIOUS RESEARCH IN FILM COOLING ................................. 21

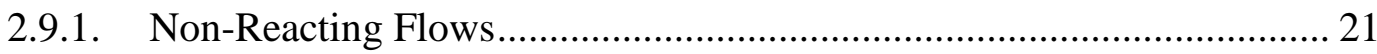

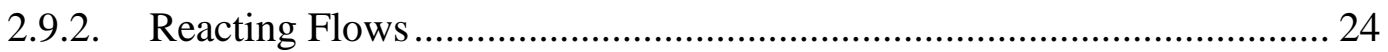

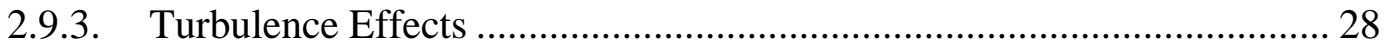

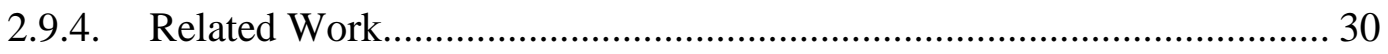

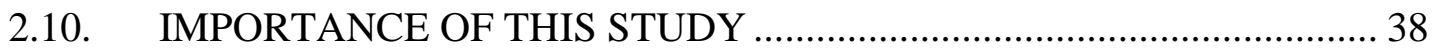

3. EXPERIMENTAL SETUP AND PROCEDURE ............................................. 39

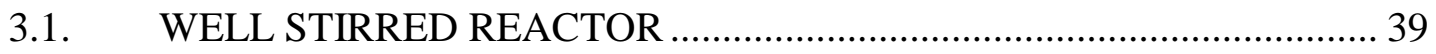

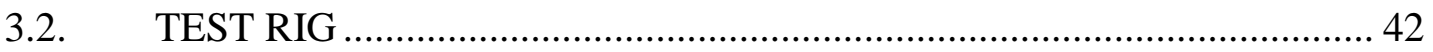

3.2.1. Transition and Flow Straightening Section ..................................... 43

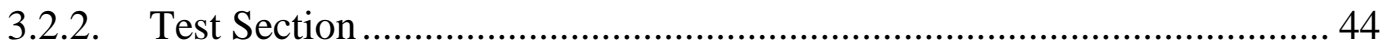

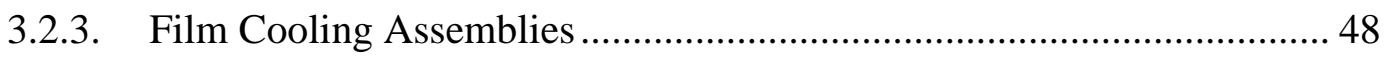

3.2.4. Heat Transfer Gauge Assemblies .................................................... 50

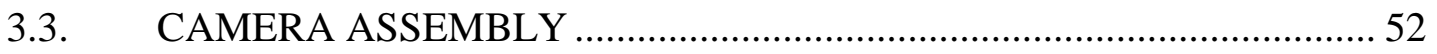

3.4. FUEL AND AIR CONTROL .......................................................... 53

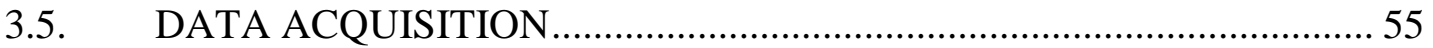

3.6. TEST PLAN AND PROCEDURE ..................................................... 56

3.7. IMAGE CAPTURE AND IMAGE PROCESSING SOFTWARE ............ 58 
4. EXPERIMENTAL RESULTS AND DISCUSSION ............................................ 60

4.1. HIGH SPEED IMAGES AND STABILITY ................................................ 60

4.2. CHEMILUMINESCENCE EMISSIONS - OH* AND CH*................... 62

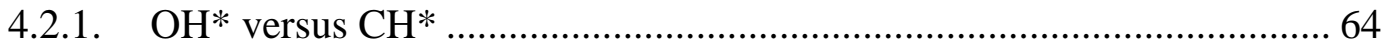

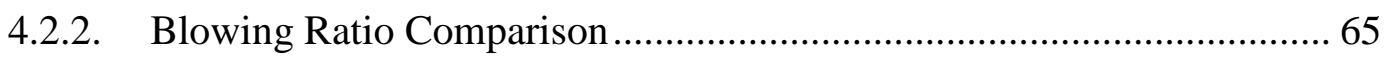

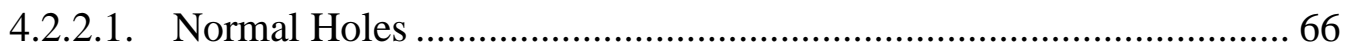

4.2.2.2. Fan Shaped Holes.......................................................................... 72

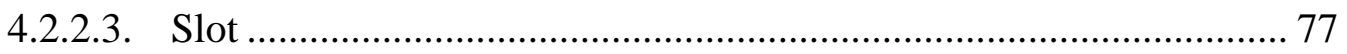

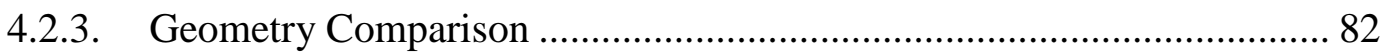

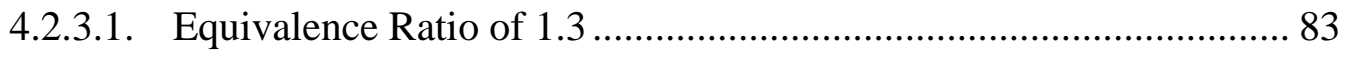

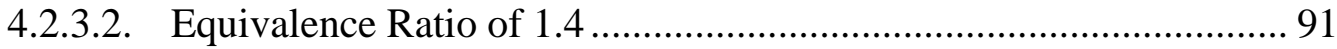

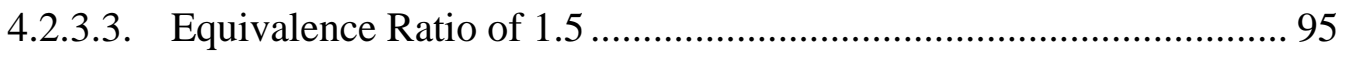

4.2.4. Equivalence Ratio Comparison ............................................................... 99

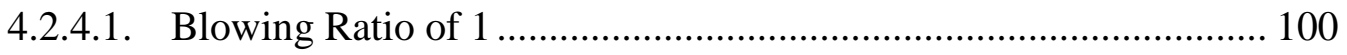

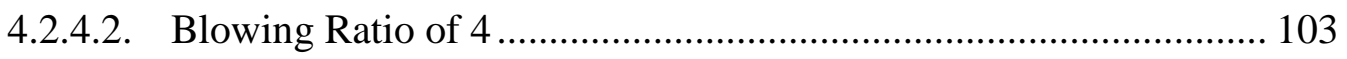

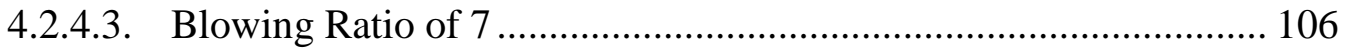

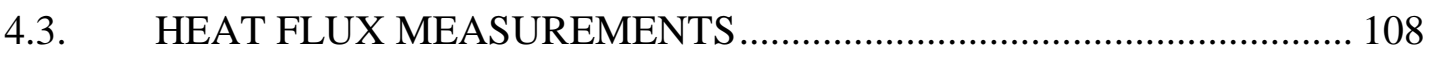

4.3.1. Equivalence Ratio and Blowing Ratio Comparison.............................. 109

4.3.1.1. Normal Holes ........................................................................... 110

4.3.1.2. Fan Shaped Holes...................................................................... 112

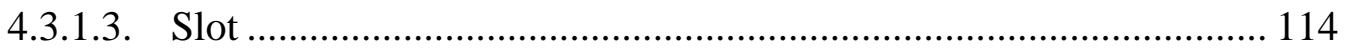

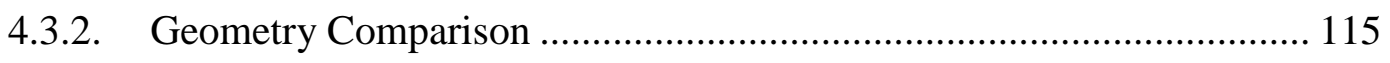

4.3.3. Heat Flux Gauge Location Discussion................................................. 120 
4.4. ANALYSIS OF HEAT FLUX AND RATE OF HEAT RELEASE ........ 122

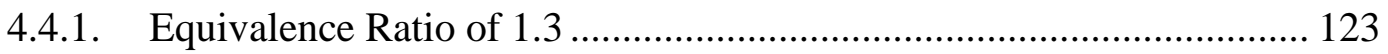

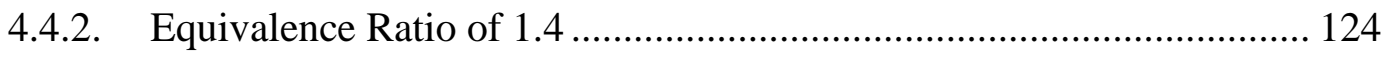

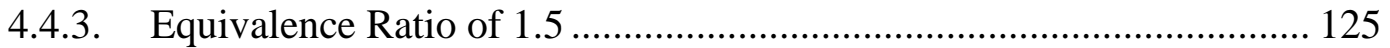

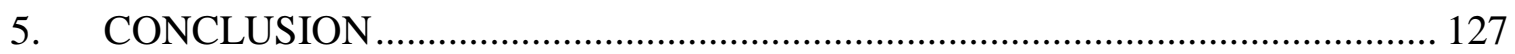

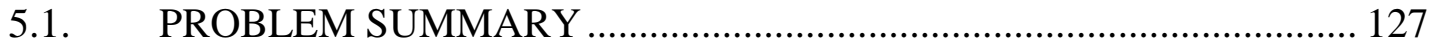

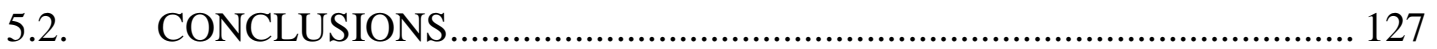

5.3. FUTURE WORK ..................................................................... 129

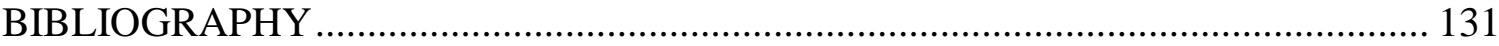

A. APPENDIX A - OH* EQUIVALENCE RATIO COMPARISON IMAGES ...... 136

B. APPENDIX B - $\mathrm{CH}^{*}$ IMAGES AND PLOTS ................................................. 141

C. APPENDIX C - FILM COOLING INSERTS ENGINEERING DRAWINGS .... 150

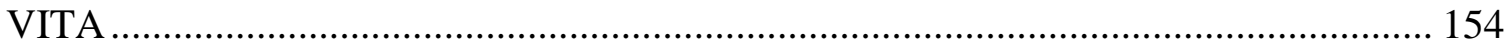




\section{LIST OF FIGURES}

Figure 2.1 Comparison between turbine inlet temperatures and blade material limits (6). 5

Figure 2.2 Secondary combustion in a traditional gas turbine engine (1) ......................... 7

Figure 2.3 Annular combustor (left) and UCC (right) (7) ............................................. 10

Figure 2.4 Least square line fit for thermal conductivity of Hastelloy-X® $\mathrm{X}$...................... 14

Figure 2.5 Heat release rate for the UCC compared to a conventional combustor (7) ..... 19

Figure 2.6 Cooling effectiveness field for a typical hole geometry (15) ......................... 22

Figure 2.7 Effect of injection angle on cooling effectiveness fields (15) ....................... 23

Figure 2.8 Potential local temperature rise due to reaction in the turbine (1) …….......... 25

Figure 2.9 Heat flux at $M=0.6$ and $M=2.0$ for reacting and non-reacting cooling flow

(3)

Figure 2.10 Numerical results of temperature profile of a reacting jet (3) ...................... 28

Figure 2.11 Local film cooling effectiveness for (a) cylindrical holes, (b) fan shaped holes, and (c) laidback fan shaped holes (17) .................................................. 29

Figure 2.12 Comparison of heat flux between reacting (air) and non-reacting (nitrogen)

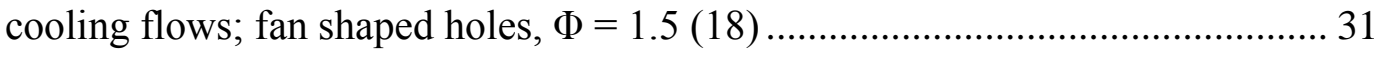

Figure 2.13 Comparison of heat flux between reacting (air) and non-reacting (nitrogen) cooling flows; normal holes, $\Phi=0.6$ (18) 
Figure 2.14 Heat flux, $\Phi=1.1$; upstream = offset normal, coolant = air, $\mathrm{M}=$ variable;

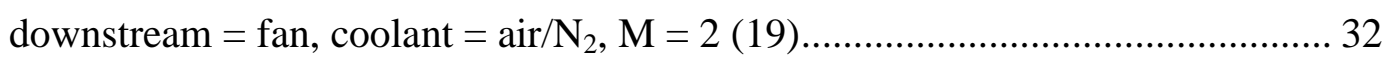

Figure 2.15 Heat flux, $\Phi=1.1$; upstream = slot, coolant = air, $\mathrm{M}=$ variable; downstream $=$ fan, coolant $=$ air $/ \mathrm{N}_{2}, \mathrm{M}=2$ (19) 32

Figure 2.16 Distance between wall and location of peak $\mathrm{OH}$ concentration at axial locations 0.75 and $3 \mathrm{~cm}$ downstream of the injection location $(20) \ldots \ldots \ldots \ldots \ldots \ldots . . . . . . . . .33$

Figure 2.17 Average $\mathrm{OH}$ measurements at $\Phi=1.1,1.2,1.3$, and 1.4 at $\mathrm{M}=4(20) \ldots \ldots . .33$

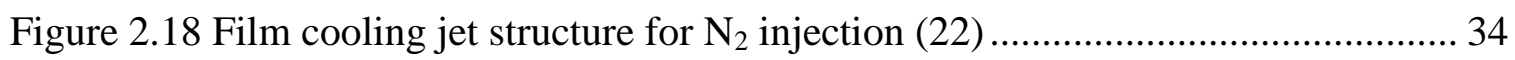

Figure 2.19 Temperature contours for $\Phi=1.5, \mathrm{M}=1$, air injection (22) ...................... 35

Figure 2.20 Temperature contours for $\Phi=1.5, \mathrm{M}=1, \mathrm{~N}_{2}$ injection (22) ..................... 35

Figure 2.21 Cooling effectiveness contours on the wall for $\Phi=1.5, \mathrm{M}=1$, air injection 36

Figure 2.22 Temperature contours for $\Phi>1, M=1$, fan shaped holes (23) .................. 37

Figure 2.23 Temperature contours for $\Phi=1.5, \mathrm{M}=2$, fan shaped holes (23) ............... 37

Figure 3.1 Lower half of the toroid with the jet ring in the WSR housing (19) ............. 41

Figure 3.2 Complete toroidal set up with the jet ring in the WSR housing (19) ............. 41

Figure 3.3 Test rig with sections identified (18) ................................................. 42

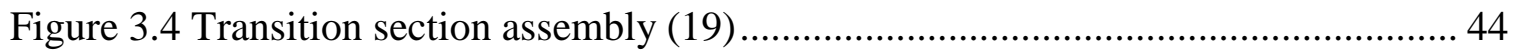

Figure 3.5 Single flow straightener disc (left) and flow straightener stack sitting on the

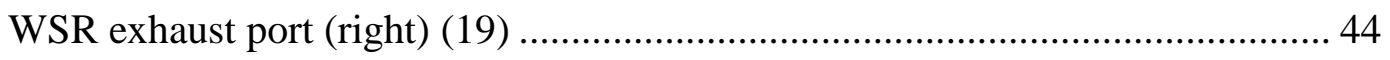

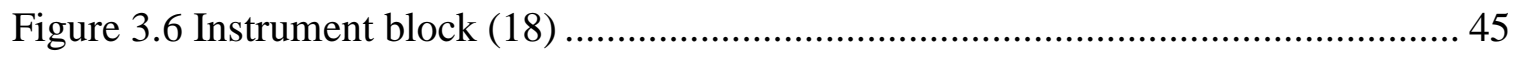

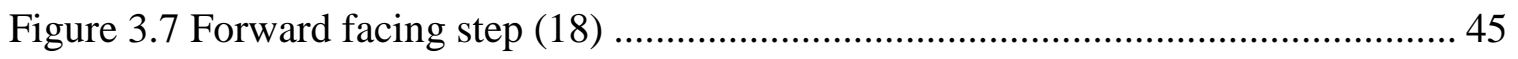

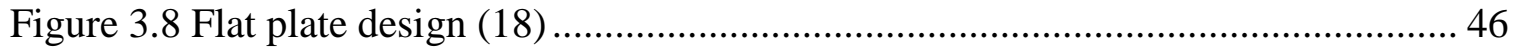




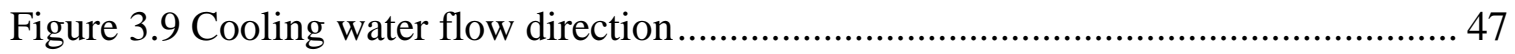

Figure 3.10 Cooling air assemblies with thermocouples inserted (18) ......................... 49

Figure 3.11 Cooling hole geometries used in this study ........................................ 50

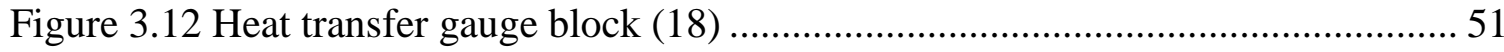

Figure 3.13 Heat transfer gauge labels and positions (19)....................................... 52

Figure 3.14 Camera assembly, mirror, and test section orientation............................. 53

Figure 3.15 Flow controllers for air, nitrogen, and fuel supplied to the test rig and WSR

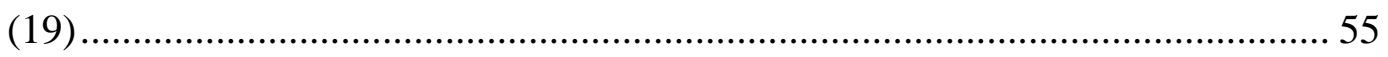

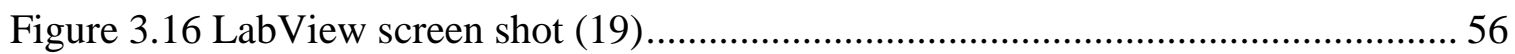

Figure 4.1 Four successive $\mathrm{OH}$ chemiluminescence images, $\Phi=1.4, \mathrm{M}=4$, normal holes

61

Figure 4.2 Flame normalized standard deviation for 1000 images, $\mathrm{OH}^{*}, \Phi=1.4, \mathrm{M}=4$,

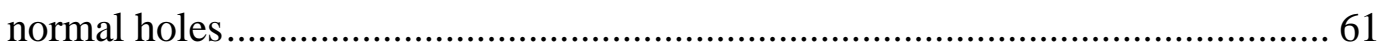

Figure 4.3 DaVis average chemiluminescence emissions image; $\mathrm{OH}^{*}, \Phi=1.4, \mathrm{M}=4$,

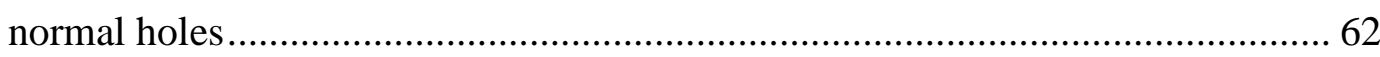

Figure 4.4 MATLAB chemiluminescence emissions image; $\mathrm{OH}^{*}, \Phi=1.4, \mathrm{M}=4$, normal holes 63

Figure 4.5 $\mathrm{OH}^{*}$ versus $\mathrm{CH}^{*}$ chemiluminescence images at $\Phi=1.4, \mathrm{M}=4$, normal holes

Figure 4.6 $\mathrm{CH}^{*}$ versus $\mathrm{OH}^{*}$ chemiluminescence average photon count plots, $\Phi=1.4, \mathrm{M}$ $=4$, normal holes 65

Figure 4.7 $\mathrm{OH}^{*}$ chemiluminescence images at blowing ratios, $\Phi=1.3$, normal holes.... 69

Figure $4.8 \mathrm{OH}^{*}$ chemiluminescence images at blowing ratios, $\Phi=1.4$, normal holes.... 70 
Figure $4.9 \mathrm{OH}^{*}$ chemiluminescence images at blowing ratio, $\Phi=1.5$, normal holes .... 70

Figure $4.10 \mathrm{OH}^{*}$ average photon count at blowing ratios, $\Phi=1.3$, normal holes .......... 71

Figure $4.11 \mathrm{OH}^{*}$ average photon count at blowing ratios, $\Phi=1.4$, normal holes .......... 71

Figure $4.12 \mathrm{OH}^{*}$ average photon count at blowing ratios, $\Phi=1.5$, normal holes .......... 72

Figure $4.13 \mathrm{OH}^{*}$ chemiluminescence images at blowing ratios, $\Phi=1.3$, fan shaped holes

Figure $4.14 \mathrm{OH}^{*}$ chemiluminescence images at blowing ratios, $\Phi=1.4$, fan shaped holes

Figure $4.15 \mathrm{OH}^{*}$ chemiluminescence images at blowing ratios, $\Phi=1.5$, fan shaped holes

Figure $4.16 \mathrm{OH}^{*}$ average photon count at blowing ratios, $\Phi=1.3$, fan shaped holes .... 76

Figure $4.17 \mathrm{OH}^{*}$ average photon count at blowing ratios, $\Phi=1.4$, fan shaped holes $\ldots . . .76$

Figure $4.18 \mathrm{OH}^{*}$ average photon count at blowing ratios, $\Phi=1.5$, fan shaped holes $\ldots . .77$

Figure $4.19 \mathrm{OH}^{*}$ chemiluminescence images at blowing ratios, $\Phi=1.3$, slot............... 79

Figure $4.20 \mathrm{OH}^{*}$ chemiluminescence images at blowing ratios, $\Phi=1.4$, slot................ 80

Figure $4.21 \mathrm{OH}^{*}$ chemiluminescence images at blowing ratios, $\Phi=1.5$, slot................ 80

Figure $4.22 \mathrm{OH}^{*}$ average photon count at blowing ratios, $\Phi=1.3$, slot ....................... 81

Figure $4.23 \mathrm{OH}^{*}$ average photon count at blowing ratios, $\Phi=1.4$, slot ....................... 81

Figure $4.24 \mathrm{OH}^{*}$ average photon count at blowing ratios, $\Phi=1.5$, slot ....................... 82

Figure $4.25 \mathrm{OH}^{*}$ chemiluminescence images for three geometries, $\Phi=1.3, \mathrm{M}=1 \ldots \ldots .85$

Figure $4.26 \mathrm{OH}^{*}$ chemiluminescence images for three geometries, $\Phi=1.3, \mathrm{M}=2 \ldots \ldots .86$

Figure $4.27 \mathrm{OH}^{*}$ chemiluminescence images for three geometries, $\Phi=1.3, \mathrm{M}=3 \ldots \ldots .86$

Figure $4.28 \mathrm{OH}^{*}$ chemiluminescence images for three geometries, $\Phi=1.3, \mathrm{M}=4 \ldots \ldots .87$ 
Figure $4.29 \mathrm{OH}^{*}$ chemiluminescence images for three geometries, $\Phi=1.3, \mathrm{M}=5 \ldots \ldots .87$

Figure $4.30 \mathrm{OH}^{*}$ chemiluminescence images for three geometries, $\Phi=1.3, \mathrm{M}=7 \ldots \ldots .88$

Figure $4.31 \mathrm{OH}^{*}$ average photon count for three geometries, $\Phi=1.3, \mathrm{M}=1 \ldots \ldots \ldots \ldots \ldots . . .88$

Figure $4.32 \mathrm{OH}^{*}$ average photon count for three geometries, $\Phi=1.3, \mathrm{M}=2 \ldots \ldots \ldots \ldots \ldots . . .89$

Figure $4.33 \mathrm{OH}^{*}$ average photon count for three geometries, $\Phi=1.3, \mathrm{M}=3 \ldots \ldots \ldots \ldots \ldots . . . .89$

Figure $4.34 \mathrm{OH}^{*}$ average photon count for three geometries, $\Phi=1.3, \mathrm{M}=4 \ldots \ldots \ldots \ldots \ldots . . . .90$

Figure $4.35 \mathrm{OH}^{*}$ average photon count for three geometries, $\Phi=1.3, \mathrm{M}=5 \ldots \ldots \ldots \ldots \ldots . .90$

Figure $4.36 \mathrm{OH}^{*}$ average photon count for three geometries, $\Phi=1.3, \mathrm{M}=7 \ldots \ldots \ldots \ldots . . .91$

Figure $4.37 \mathrm{OH}^{*}$ chemiluminescence images for three geometries, $\Phi=1.4, \mathrm{M}=1 \ldots \ldots .93$

Figure $4.38 \mathrm{OH}^{*}$ chemiluminescence images for three geometries, $\Phi=1.4, \mathrm{M}=4 \ldots \ldots .93$

Figure $4.39 \mathrm{OH}^{*}$ chemiluminescence images for three geometries, $\Phi=1.4, \mathrm{M}=7 \ldots \ldots 94$

Figure $4.40 \mathrm{OH}^{*}$ average photon count for three geometries, $\Phi=1.4, \mathrm{M}=1 \ldots \ldots \ldots \ldots \ldots . . . .94$

Figure $4.41 \mathrm{OH}^{*}$ average photon count for three geometries, $\Phi=1.4, \mathrm{M}=4 \ldots \ldots \ldots \ldots \ldots . . .95$

Figure $4.42 \mathrm{OH}^{*}$ average photon count for three geometries, $\Phi=1.4, \mathrm{M}=7 \ldots \ldots \ldots \ldots \ldots . . . .95$

Figure $4.43 \mathrm{OH}^{*}$ chemiluminescence images for three geometries, $\Phi=1.5, \mathrm{M}=1 \ldots \ldots 97$

Figure $4.44 \mathrm{OH}^{*}$ chemiluminescence images for three geometries, $\Phi=1.5, \mathrm{M}=4 \ldots \ldots 97$

Figure $4.45 \mathrm{OH}^{*}$ chemiluminescence images for three geometries, $\Phi=1.5, \mathrm{M}=7 \ldots \ldots .98$

Figure $4.46 \mathrm{OH}^{*}$ average photon count for three geometries, $\Phi=1.5, \mathrm{M}=1 \ldots \ldots \ldots \ldots \ldots . . .98$

Figure $4.47 \mathrm{OH}^{*}$ average photon count for three geometries, $\Phi=1.5, \mathrm{M}=4 \ldots \ldots \ldots \ldots \ldots . . .99$

Figure $4.48 \mathrm{OH}^{*}$ average photon count for three geometries, $\Phi=1.5, \mathrm{M}=7 \ldots \ldots \ldots \ldots \ldots . . .99$

Figure $4.49 \mathrm{OH}^{*}$ average photon count at equivalence ratios, $\mathrm{M}=1$, normal holes ..... 102

Figure $4.50 \mathrm{OH}^{*}$ average photon count at equivalence ratios, $\mathrm{M}=1$, fan shaped holes 102

Figure $4.51 \mathrm{OH}^{*}$ average photon count at equivalence ratios, $\mathrm{M}=1$, slot ................... 103 
Figure $4.52 \mathrm{OH}^{*}$ average photon count at equivalence ratios, $\mathrm{M}=4$, normal holes ..... 105

Figure $4.53 \mathrm{OH}^{*}$ average photon count at equivalence ratios, $\mathrm{M}=4$, fan shaped holes 105

Figure $4.54 \mathrm{OH}^{*}$ average photon count at equivalence ratios, $\mathrm{M}=4$, slot ................... 106

Figure $4.55 \mathrm{OH}^{*}$ average photon count at blowing ratios, $\mathrm{M}=7$, normal holes ........... 107

Figure $4.56 \mathrm{OH}^{*}$ average photon count at equivalence ratios, $\mathrm{M}=7$, fan shaped holes 108

Figure $4.57 \mathrm{OH}^{*}$ average photon count at equivalence ratios, $\mathrm{M}=7$, slot .................. 108

Figure 4.58 Station 1 average heat flux at blowing ratios for three equivalence ratios,

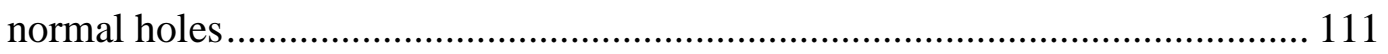

Figure 4.59 Station 2 average heat flux at blowing ratios for three equivalence ratios,

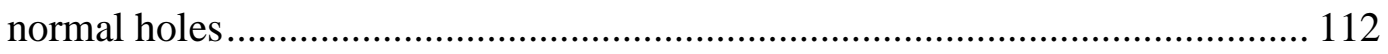

Figure 4.60 Station 1 average heat flux at blowing ratios for three equivalence ratios, fan

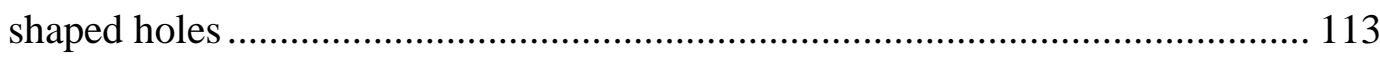

Figure 4.61 Station 2 average heat flux at blowing ratios for three equivalence ratios, fan shaped holes 113

Figure 4.62 Station 1 average heat flux at blowing ratios for three equivalence ratios, slot

Figure 4.63 Station 2 average heat flux at blowing ratios for three equivalence ratios, slot

Figure 4.64 Station 1 average heat flux at blowing ratios for three geometries at $\Phi=1.3$

Figure 4.65 Station 2 average heat flux at blowing ratios for three geometries at $\Phi=1.3$ 
Figure 4.66 Station 1 average heat flux at blowing ratios for three geometries at $\Phi=1.4$

Figure 4.67 Station 2 average heat flux at blowing ratios for three geometries at $\Phi=1.4$

Figure 4.68 Station 1 average heat flux at blowing ratios for three geometries at $\Phi=1.5$

Figure 4.69 Station 2 average heat flux at blowing ratios for three geometries at $\Phi=1.5$

Figure 4.70 Heat flux at varying blowing ratios for reacting and non-reacting flow, $\Phi=$

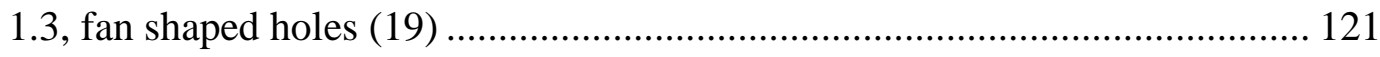

Figure 4.71 Station 1 average heat flux at blowing ratios for three geometries at $\Phi=1.3$

Figure 4.72 Station 2 average heat flux at blowing ratios for three geometries at $\Phi=1.3$

Figure A.1 $\mathrm{OH}^{*}$ chemiluminescence images at equivalence ratios, $\mathrm{M}=1$, normal holes

Figure A.2 $\mathrm{OH}^{*}$ chemiluminescence images at equivalence ratios, $\mathrm{M}=1$, fan shaped

holes

Figure A. $3 \mathrm{OH}^{*}$ chemiluminescence images at equivalence ratios, $\mathrm{M}=1$, slot....

Figure A.4 $\mathrm{OH}^{*}$ chemiluminescence images at equivalence ratios, $\mathrm{M}=4$, normal holes 
Figure A.5 $\mathrm{OH}^{*}$ chemiluminescence images at equivalence ratios, $\mathrm{M}=4$, fan shaped holes 138

Figure A.6 $\mathrm{OH}^{*}$ chemiluminescence images at equivalence ratios, $\mathrm{M}=4$, slot 139

Figure A.7 $\mathrm{OH}^{*}$ chemiluminescence images at equivalence ratios, $\mathrm{M}=7$, normal holes

Figure A.8 $\mathrm{OH}^{*}$ chemiluminescence images at equivalence ratios, $\mathrm{M}=7$, fan shaped holes 140

Figure A.9 $\mathrm{OH}^{*}$ chemiluminescence images at equivalence ratios, $\mathrm{M}=7$, slot 140

Figure B.1 $\mathrm{CH}^{*}$ average photon count for three geometries, $\Phi=1.3, \mathrm{M}=1$ 141

Figure B.2 $\mathrm{CH}^{*}$ average photon count for three geometries, $\Phi=1.3, \mathrm{M}=4$

Figure B. $3 \mathrm{CH}^{*}$ average photon count for three geometries, $\Phi=1.4, \mathrm{M}=1$

Figure B.4 $\mathrm{CH}^{*}$ average photon count for three geometries, $\Phi=1.4, \mathrm{M}=4$ 142

Figure B.5 $\mathrm{CH}^{*}$ average photon count for three geometries, $\Phi=1.4, \mathrm{M}=7$ 143

Figure B.6 $\mathrm{CH}^{*}$ average photon count for three geometries, $\Phi=1.5, \mathrm{M}=1$ 143

Figure B.7 $\mathrm{CH}^{*}$ average photon count for three geometries, $\Phi=1.5, \mathrm{M}=4$ 144

Figure B.8 $\mathrm{CH}^{*}$ average photon count for three geometries, $\Phi=1.5, \mathrm{M}=7 \ldots$ 144

Figure B.9 $\mathrm{CH}^{*}$ average photon count at blowing ratios, $\Phi=1.3$, normal holes. 145

Figure B.10 $\mathrm{CH}^{*}$ average photon count at blowing ratios, $\Phi=1.4$, normal holes 145

Figure B.11 $\mathrm{CH}^{*}$ average photon count at blowing ratios, $\Phi=1.5$, normal holes 146

Figure B.12 $\mathrm{CH}^{*}$ average photon count at blowing ratios, $\Phi=1.3$, fan shaped holes.. 146 Figure B.13 $\mathrm{CH}^{*}$ average photon count at blowing ratios, $\Phi=1.4$, fan shaped holes.. 147

Figure B.14 $\mathrm{CH}^{*}$ average photon count at blowing ratios, $\Phi=1.5$, fan shaped holes.. 147 Figure B.15 $\mathrm{CH}^{*}$ average photon count at blowing ratios, $\Phi=1.3$, slot 148 
Figure B.16 $\mathrm{CH}^{*}$ average photon count at blowing ratios, $\Phi=1.4$, slot.................... 148

Figure B.17 $\mathrm{CH}^{*}$ average photon count at blowing ratios, $\Phi=1.5$, slot.................... 149

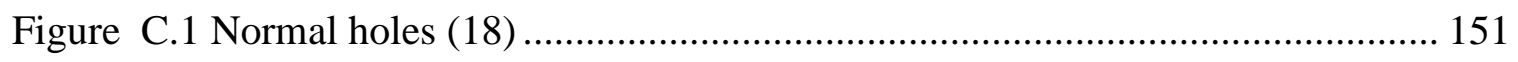

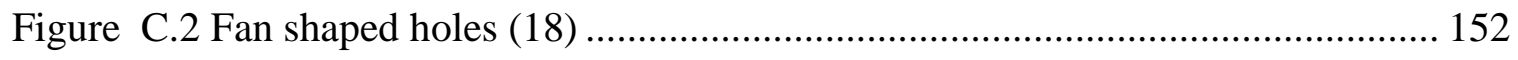

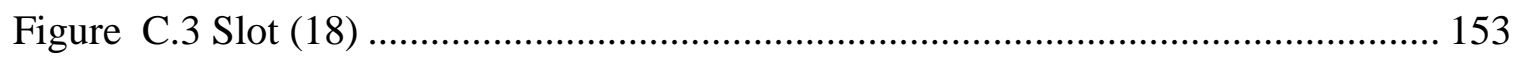




\section{LIST OF TABLES}

Table 2.1 Temperature and thermal conductivity for Hastelloy-X® (10) ....................... 13

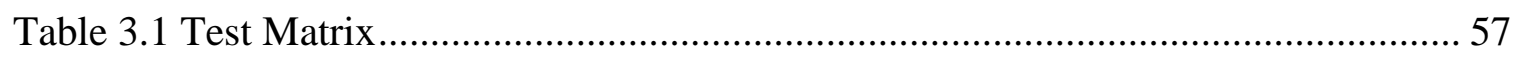

Table 4.1 Summary of blowing ratio comparison results for chemiluminescence data ... 65

Table 4.2 Summary of geometry comparison results for chemiluminescence data ......... 82

Table 4.3 Summary of equivalence ratio comparison results for chemiluminescence data 100

Table 4.4 Summary of equivalence ratio comparison results for heat flux data............ 109

Table 4.5 Summary of blowing ratio comparison results for heat flux data.................. 110

Table 4.6 Summary of geometry comparison results for heat flux data ...................... 116 


\section{LIST OF SYMBOLS}

\section{English Symbols}

$\begin{array}{lll}\mathrm{A} & = & \text { area }\left(\mathrm{m}^{2}\right) \\ \mathrm{a}_{0}, \mathrm{a}_{1} & = & \text { curve fit parameter } \\ \mathrm{C} & = & \text { constant of integration } \\ \mathrm{D} & = & \text { diameter } \\ \mathrm{Da} & = & \text { Damköhler number } \\ \mathrm{h} & = & \text { heat transfer coefficient }\left(\mathrm{W} / \mathrm{m}^{2}-\mathrm{K}\right) \\ \mathrm{H}^{*} & = & \text { heat release potential } \\ \mathrm{H}_{\mathrm{T}} & = & \text { total enthalpy }(\mathrm{J}) \\ \mathrm{k} & = & \text { thermal conductivity }\left(\mathrm{W} / \mathrm{m}^{2}-\mathrm{K}\right) \\ \mathrm{M} & = & \text { blowing ratio } \\ \dot{m} & = & \text { mass flow rate }(\mathrm{g} / \mathrm{min} ; \mathrm{g} / \mathrm{s}) \\ \mathrm{MW} & = & \text { molecular weight }(\mathrm{g} / \mathrm{mol}) \\ \mathrm{PR} & = & \text { pressure ratio } \\ \mathrm{Q} & = & \text { scaled heat flux }\left(\mathrm{W} / \mathrm{m}^{2}\right) \\ \mathrm{q} & = & \text { rate of heat transfer }(\mathrm{W}) \\ \mathrm{q}, & = & \text { heat flux }\left(\mathrm{W} / \mathrm{m}^{2}\right) \\ \mathrm{T} & = & \text { temperature }(\mathrm{K}) \\ \mathrm{U} & = & \text { velocity }(\mathrm{m} / \mathrm{s}) \\ \mathrm{X} & = & \text { distance }(\mathrm{m})\end{array}$

\section{Greek Symbols}

$\alpha=$ injection angle $\left(^{\circ}\right)$

$\gamma=$ heat capacity ratio 


$$
\begin{array}{lll}
\eta_{\mathrm{T}} & = & \text { Brayton Cycle thermal efficiency } \\
\rho & = & \text { density }\left(\mathrm{kg} / \mathrm{m}^{2}\right) \\
\tau_{\text {chem }} & = & \text { characteristic chemical time }(\mathrm{s}) \\
\tau_{\text {flow }} & = & \text { characteristic flow time }(\mathrm{s}) \\
\Phi & = & \text { equivalence ratio }
\end{array}
$$

\section{Subscripts}

$\begin{array}{lll}1 & = & \text { near-surface thermocouple location } \\ 2 & = & \text { deep thermocouple location; compressor inlet } \\ 4 & = & \text { turbine inlet } \\ \infty & = & \text { freestream } \\ \mathrm{c} & = & \text { coolant } \\ \text { cond } & = & \text { conduction } \\ \text { condi } & = & \text { condition } \\ \text { conv } & = & \text { convection } \\ \mathrm{f} & = & \text { film } \\ \text { rad } & = & \text { radiation } \\ \text { ref } & = & \text { reference } \\ \mathrm{s} & = & \text { surface } \\ \text { stoich } & = & \text { stoichimetric } \\ \mathrm{x} & = & \text { location }\end{array}$

\section{Abbreviations}

AFRL $=\quad$ Air Force Research Laboratory

ITB $=$ Inter-Turbine Burner

SLPM $=\quad$ Standard Liters Per Minute

UCC = Ultra-Compact Combustor

WSR $=$ Well Stirred Reactor 


\section{INTRODUCTION}

\subsection{TURBINE FILM COOLING}

For aerospace applications, the demands for greater thrust, increased combustion and thermal efficiencies, and reduced fuel consumption continue to increase for gas turbine engines. These requirements can be met through various methods, including operating at higher temperatures and pressures, increasing the combustor fuel-to-air ratio, and decreasing the size of the combustor. Higher temperatures necessitate the use of active turbine blade cooling, such as film cooling, to combat turbine hardware failure due to decreased strength of materials at high temperatures. Higher temperatures can also result in dissociation of combustion products into hydrogen and carbon monoxide $(1,2)$ and consequently the presence of incomplete combustion products within the turbine. Additionally, incomplete combustion products enter the turbine if the residence time within the combustor is small, due to reduced combustor size, or rice fuel-to-air ratio (3, 4). These incomplete combustion products in the turbine can react with the air used to cool the turbine blades, leading to destruction of turbine hardware. Reactions occurring close to the surface of the turbine blades can increase the heat transfer to the turbine hardware leading to significant damage. 


\subsection{OBJECTIVES}

This study investigates the effect of reactions in turbine film cooling using a well stirred reactor (WSR) to provide combustion products to the test section.

Chemiluminescence, heat release rate, and reaction zone location are correlated to the heat flux from the reacting boundary layer to the surface. The purpose of this study is to bridge the gap between heat flux measurements and actual flame characteristics and heat release rate. This research will help in the understanding of reacting boundary layers and how they relate to current combustion systems such as the UCC. The following data is collected and/or investigated as a part of this work:

- Chemiluminescence of $\mathrm{CH}$ and $\mathrm{OH}$ radicals

- Heat flux to the surface

- Flame spatial characteristics

- High speed images

\subsection{CHAPTER OUTLINE}

Chapter 2 contains background information pertinent to this study. Many of the topics briefly discussed in the introduction section are explained further. The background chapter includes information on important film cooling parameters, a literature review on previous and related film cooling work, heat transfer and equivalence ratio calculations, and discussions on auto-ignition, chemiluminescence, and heat release rate. The importance of this study is also addressed.

Chapter 3 contains an explanation of the experimental set-up including discussion of the reactor, the test rig, and the laboratory capabilities. The data acquisition methods and test procedure are also presented in this section. 
Chapter 4 presents the experimental data. This includes high speed images, chemiluminescence images, chemiluminescence photon count plots, and heat flux measurements. Important characteristics and trends are identified. This chapter also provides analysis and discussion of the data, providing a discussion of chemiluminescence plots and images in comparison to heat flux measurements and rate of heat release.

Finally, Chapter 5 offers a summary of the tests performed in this study and main conclusions that can be made from the analysis and discussion. Suggestions for future work are also presented in this chapter. 


\section{BACKGROUND}

\subsection{TURBINE FILM COOLING}

Film cooling is used to diminish heat transfer to the turbine hardware surface from the combustor exhaust flow. Film cooling in turbines today presents a way to extend the material life of the turbine blades as the increasingly high temperatures and reactions in the turbine cause premature material failure.

The thermal efficiency of engines increases with increasing turbine inlet temperatures. In gas turbine engines, the Brayton Cycle is used to predict the thermodynamic performance. Equation 1 provides the thermal efficiency of an ideal Brayton Cycle. This presents how an increase in the turbine inlet temperature, $T_{4}$, results in higher cycle efficiency (5).

$$
\eta_{T}=1-\frac{(P R)^{(\gamma-1) / \gamma}}{T_{4} / T_{2}}
$$

But, high inlet temperatures can cause premature material failure of the turbine hardware. Figure 2.1 shows how turbine inlet temperatures have continued to increase over the years. 


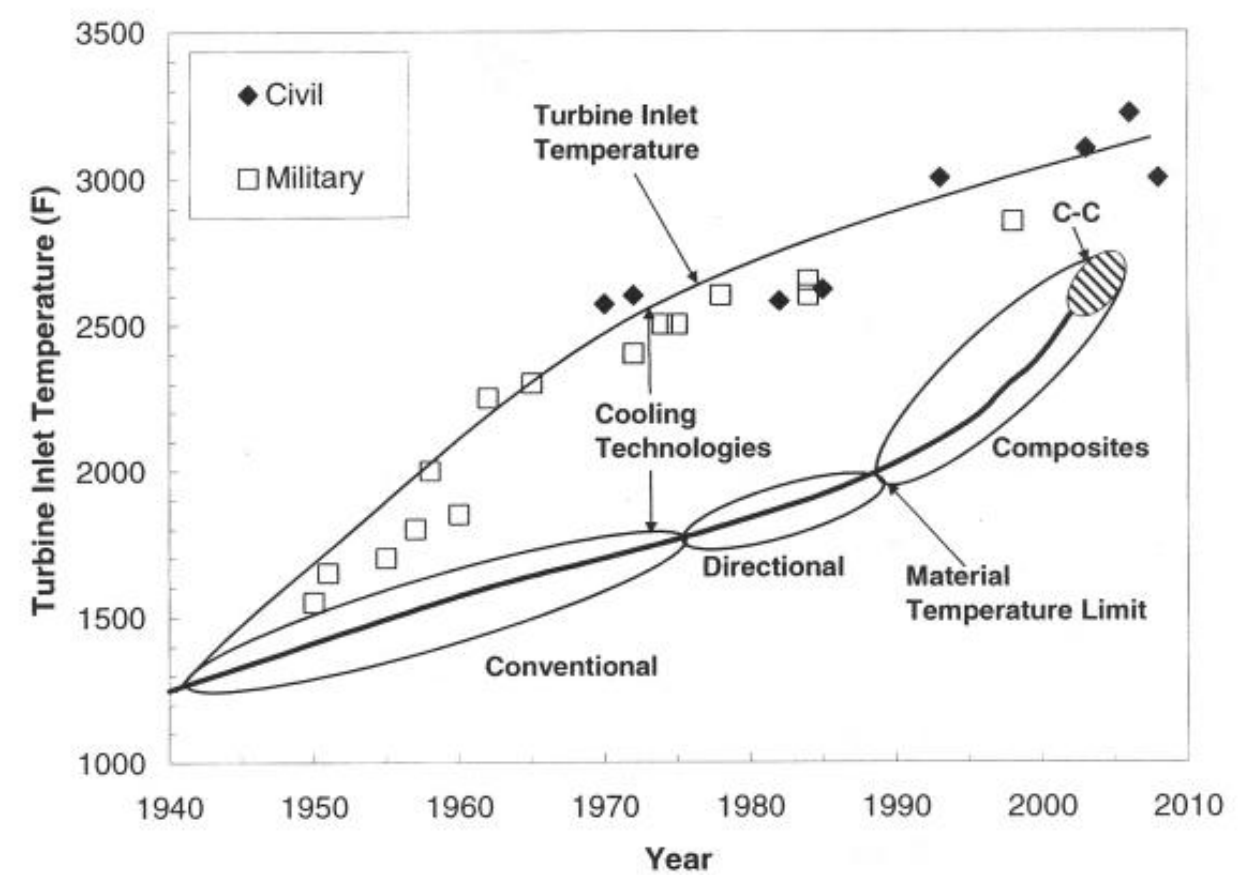

Figure 2.1 Comparison between turbine inlet temperatures and blade material

limits (6)

As inlet temperatures have increased above temperatures that will cause material failure within the engine, blades have been cooled actively using compressor bleed air. Initially blades were cooled by convective cooling by air flow through internal cooling channels. Later, turbines were designed with film cooling to force internal cooling air out through the blade surface using small holes. This creates a thin layer of air on the outer surface of the blade, forming a cooler barrier film between the blade and the high temperature freestream flow. Film cooling is the most popular method of active cooling, in which cooling air is injected through small holes in the turbine blades providing a cooling film over the surface of the blade. In absence of reactions, film cooling helps to shield blades from high enthalpy external flow in addition to internal cooling of blades. This cooling air can potentially increase the local heat transfer coefficient, though overall it is designed to decrease the heat transfer to the surface from the freestream flow. Film 
cooling can also affect the local heat transfer coefficient, $h$, causing it to increase due to flow effects. The free stream temperature increases to a greater extent due to reactions that occur.

It is seen in previous studies (4) that the introduction of cooling air into the fuel rich vitiated flow results in a significant increase in effective heat transfer coefficient, $h_{\text {eff }}$, for each cooling hole geometry due to reactions in the film. Using nitrogen as a cooling gas instead of air does not result in secondary combustion in the turbine, but it is not as readily available as air.

\subsubsection{Potential for Reactions and Heat Transfer}

In the past, gas turbine engines have been run at less than stoichiometric fuel to air ratios. Typically reactions were completed before leaving the combustor due to longer engines and the lower fuel to air ratios. As the requirement for higher efficiency engines has grown, the creation of engines that operate at close to stoichiometric fuel-toair ratios has increased. High operating fuel-to-air ratios can lead to the presence of unburned fuel in the turbine. The residence time and amount of oxidizer is not adequate to result in combustion of all of the fuel present. The introduction of cooling air into the high temperature fuel-rich turbine environment often leads to combustion which results in increase in the local heat transfer. Combustion in the turbine due to cooling air injection is illustrated below in Fig. 2.2. 


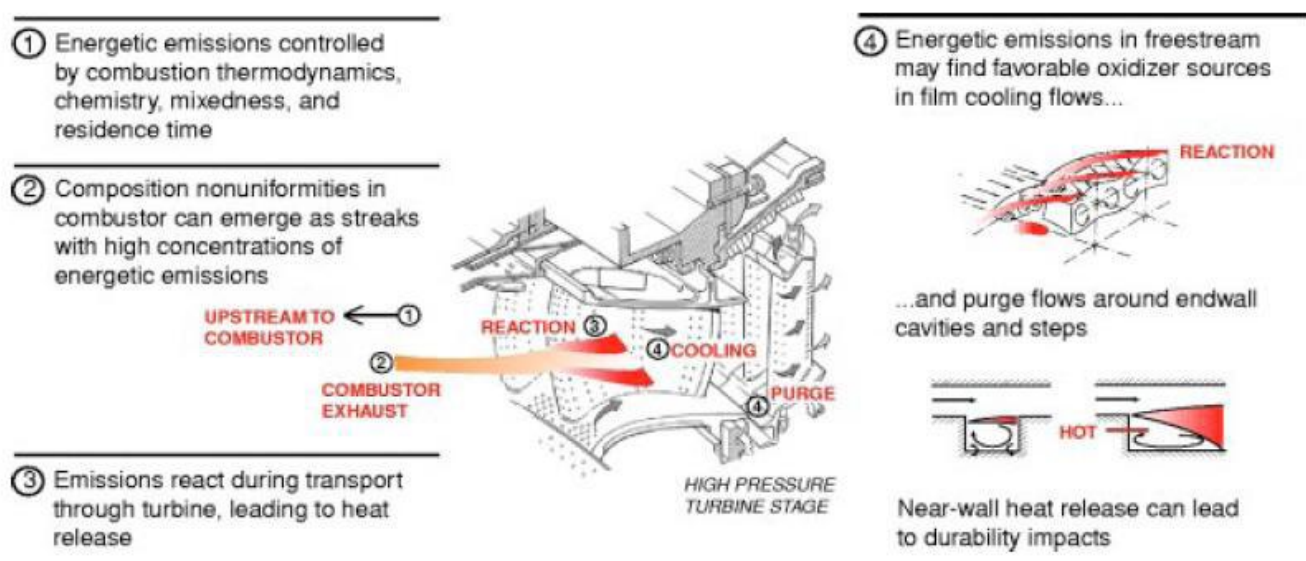

Figure 2.2 Secondary combustion in a traditional gas turbine engine (1)

Combustion close to the turbine blade surface creates a higher temperature environment. This combustion and high temperatures potentially damage the turbine vane material and can also decrease the effectiveness of the cooling film. It is necessary to find the best possible method for diminishing heat transfer to the surface and the resulting combustion from the injection of cooling air into the fuel-rich combustor exhaust flow.

The measurement of heat transfer to the surface is an important part of assessing the effectiveness of a specific film cooling scheme. The heat transfer per unit area for general fluid flow over a surface is calculated using the convective heat transfer equation:

$$
q^{\prime \prime}=h\left(T_{r e f}-T_{S}\right)
$$

Where $h$ is the convective heat transfer coefficient, $T_{r e f}$ is the driving temperature of the fluid, and $T_{S}$ is the temperature of the surface. Due to the dynamic nature of film cooling flow, temperature and heat transfer coefficient of the fluid can be difficult to quantify, especially in a reacting flow. 
Though film cooling can minimize the heat transfer, it does not necessarily negate heat transfer to the turbine surfaces. Film cooling protects the turbine blade surfaces by introducing a coolant flow at temperature, $T_{c}$, which is low relative to the freestream temperature, $T_{\infty}$. The temperature of the coolant film, $T_{f}$, is higher than the initial coolant temperature. Ideally, the coolant flow remains attached to the surface and $T_{f}$ is very close to $T_{c}$, creating the most effective barrier between the surface and the hot combustor exhaust. Typically, due to the injection orientation of the coolant flow, it mixes quickly with the freestream flow, resulting in $T_{f}$ somewhere between $T_{\infty}$ and $T_{c}$.

It is possible to calculate the heat flux if Equation 2 is rewritten using the coolant flow as a reference.

$$
q^{\prime \prime}=h_{f}\left(T_{f}-T_{S}\right)
$$

Where $h_{f}$ is the convective heat transfer coefficient of the cooling film. $T_{f}$ is not measured in this study. Equation 3 must be rewritten using $T_{\infty}$, as the reference temperature and $h_{f}$ is replaced with the effective heat transfer coefficient $h_{\text {eff. }}$ This results in the final form of the convective heat transfer equation used to calculate heat flux in this study.

$$
q^{\prime \prime}=h_{e f f}\left(T_{\infty}-T_{S}\right)
$$

\subsubsection{Blowing Ratio}

In this study, the film cooling is characterized by the mass flux ratio, referred to as the blowing ratio, $M$. The blowing ratio is an important parameter of film cooling 
flows since it has a noticeable effect on the effectiveness of the cooling scheme and on secondary reactions (see Section 2.9).

$$
M=\frac{\rho_{C} U_{C}}{\rho_{\infty} U_{\infty}}
$$

Based on the conservation of mass for an incompressible fluid for a constant area

flow,

$$
\frac{\dot{m}}{A}=\rho U
$$

Therefore equation 5 can be rewritten in the following form:

$$
M=\frac{\dot{m}_{C} A_{\infty}}{\dot{m}_{\infty} A_{C}}
$$

Where $\dot{m}_{C}$ is the total mass flow through the cooling holes, $A_{C}$ is the total area of the cooling holes, $\dot{m}_{\infty}$ is the mass flow of the reactor exhaust, and $A_{\infty}$ is the cross-sectional area of the test rig.

\subsection{THE ULTRA COMPACT COMBUSTOR}

The Ultra-Compact Combustor/Inter-Turbine Burner (UCC/ITB) is an advanced combustion system being developed at the Air Force Research Laboratories (AFRL). This design integrates compressor and turbine features. The combustion air is directed in the circumferential direction to reach higher residence times while reducing the length of the engine component. Figure 2.3 compares a conventional annular combustor with the UCC. 


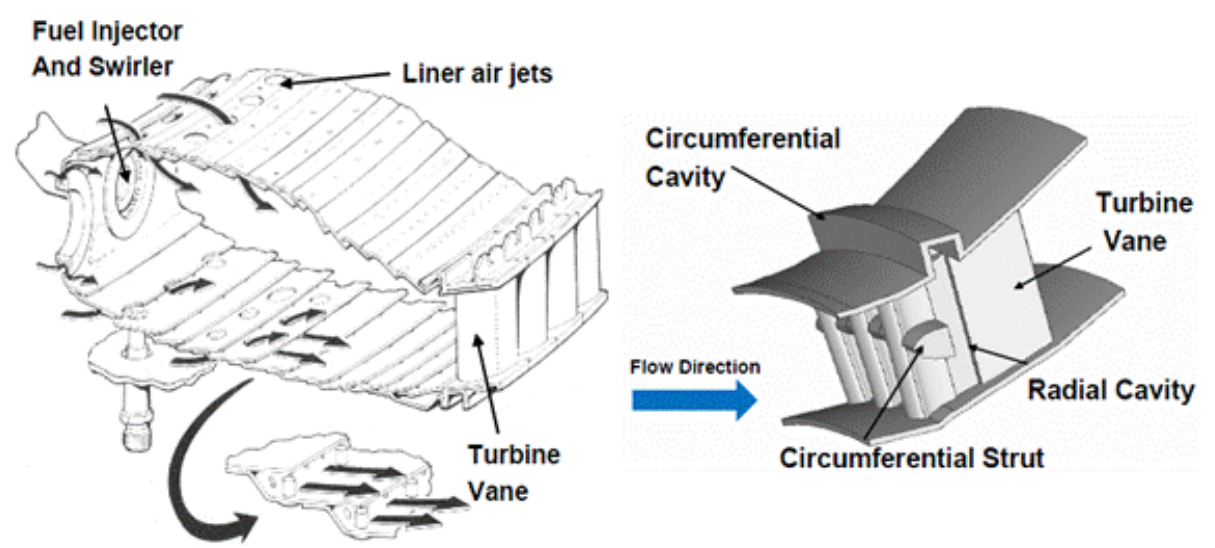

Figure 2.3 Annular combustor (left) and UCC (right) (7)

In the annular combustor, the air flows through in the axial direction. The residence time is a function of the flow speed and the combustor length. Thus, the combustor must be adequately long to allow for mixing, ignition, and complete combustion of the fuel and air.

The UCC has a circumferential cavity around the outer circumference of the extended turbine inlet vanes. The fuel is introduced into this cavity. Radial cavities on each vane are aligned with the outer cavity, and extend to an inner platform. This design burns rich in the circumferential cavity, allowing for the combustion residence time to take place in the circumferential direction. The intermediate combustion products flow into the vane cavities and combustion is completed there. (7)

The UCC shortens the length of the combustor and reduces the necessity of other engine components (i.e. compressor exit guide vanes). This design is found to be around $66 \%$ shorter than a conventional system, leading to a noticeable weight reduction. UCC systems are found to operate at $95-99 \%$ combustion efficiency over a range of operating conditions. (7) 
The use of UCC/ITB presents difficulty in blade cooling. The design fuel-to-air ratio is very high. The turbine blades are integrated into the combustor design, thus air is injected into a fuel-rich environment. The potential for unburned fuel to mix with the cooling air within the cooling film is large.

\subsection{AUTOIGNITION}

Auto-ignition is defined by Ref. (8) as the spontaneous combustion of a fuel and oxidizer mixture in the absence of any internal ignition source. An auto-ignition reaction occurs at a finite time after the fuel and oxidizer are combined, called the delay time. The delay time is a function of temperature, pressure, and fuel and oxidizer concentration.

Lefevbre et al. (8) showed that temperature has the strongest influence on the delay time of propane auto-ignition at equivalence ratios less than one. The effect of fuel concentration is comparatively weaker (8). Characteristics of ignition as a result of the coolant air injection into the vitiated flow may change dependent upon the temperature of the exhaust from the WSR. The WSR exhaust temperature changes with equivalence ratio. At higher equivalence ratio the temperature is lower, but there are more left over reactants present to cause combustion. Whereas at a lower equivalence ratio the temperature is higher, which is a favorable condition for reactions, but the amount of unburned fuel present is smaller. There is a tradeoff between these two factors as equivalence ratio is varied.

\subsection{HEAT TRANSFER CALCULATION}

A quantification of the local heat transfer coefficient and the local blade temperature is helpful in deciding on the necessary amount of film cooling flow and the 
efficacy of film cooling scheme. To determine the heat flux and the surface temperature, temperatures are measured using thermocouples at two depths within the flat plate. The orientation and setup of these thermocouples is discussed further in Section 3.2.4. Since the inner material temperatures are known, the heat flux for the system is found based on conductive heat transfer. In this study conduction can be related to convection, resulting in the quantification of the effective heat transfer coefficient.

Equation 8 provides the general formula for heat flux to the surface, $q_{s}$.

$$
q_{s}=q_{\text {conv }}+q_{\text {cond }}+q_{\text {rad }}
$$

The surface heat transfer can be related to the temperature of the wall using Newton's law of cooling.

$$
q_{s}=h\left(T_{f}-T_{s}\right)
$$

Inside the wall, the convective velocity is zero and the radiative transmissivity is negligible. Therefore, within a solid body, energy transport occurs through conduction only. The internal heat conduction can then be written as Equation 10.

$$
\left.q_{s}=-k \frac{\partial T}{\partial n}\right]_{s}
$$

Combining Eq. 9 and 10, Eq. 11 results, allowing for the use of material temperature measurements to find the heat transfer coefficient. Using direct intrusive measurement of the flow temperature to calculate $h_{\text {eff }}$ would disturb the flow patterns. (9) 


$$
\left.h\left(T_{f}-T_{s}\right)=-k \frac{\partial T}{\partial n}\right]_{s}
$$

Using Fourier's law of conduction (Eq. 10), the heat transfer between two thermocouples, assuming one-dimensional heat transfer, is calculated.

$$
q^{\prime \prime}{ }_{x}=-k \frac{d T}{d x}
$$

Where $q^{\prime \prime}{ }_{x}$ is the heat transfer per unit area, $k$ is the thermal conductivity of the material, $T$ is the temperature in the material, and $x$ is the distance of the thermocouples from the surface. In steady state conditions, which are assumed here, $q^{\prime \prime}{ }_{x}$ is constant, Eq. 12 can be rearranged. (9)

$$
\int q^{\prime \prime}{ }_{x} d x=-\int k d T
$$

The gauges are made of Hastelloy-X®. The thermal conductivity values vary greatly over the range of temperatures in this study. The values provided by the manufacturer are summarized in Table 2.1 for necessary temperatures (10). Plotting the thermal conductivity and temperature values provided in the table shows a nearly linear relationship (Fig. 2.4).

Table 2.1 Temperature and thermal conductivity for Hastelloy-X® (10)

\begin{tabular}{|c|c|}
\hline Temperature $(\mathbf{K})$ & $\mathbf{k}(\mathbf{W} / \mathbf{m}-\mathbf{K})$ \\
\hline 366.15 & 11 \\
\hline 533.15 & 14.1 \\
\hline 866.15 & 20.8 \\
\hline 977.15 & 22.9 \\
\hline
\end{tabular}




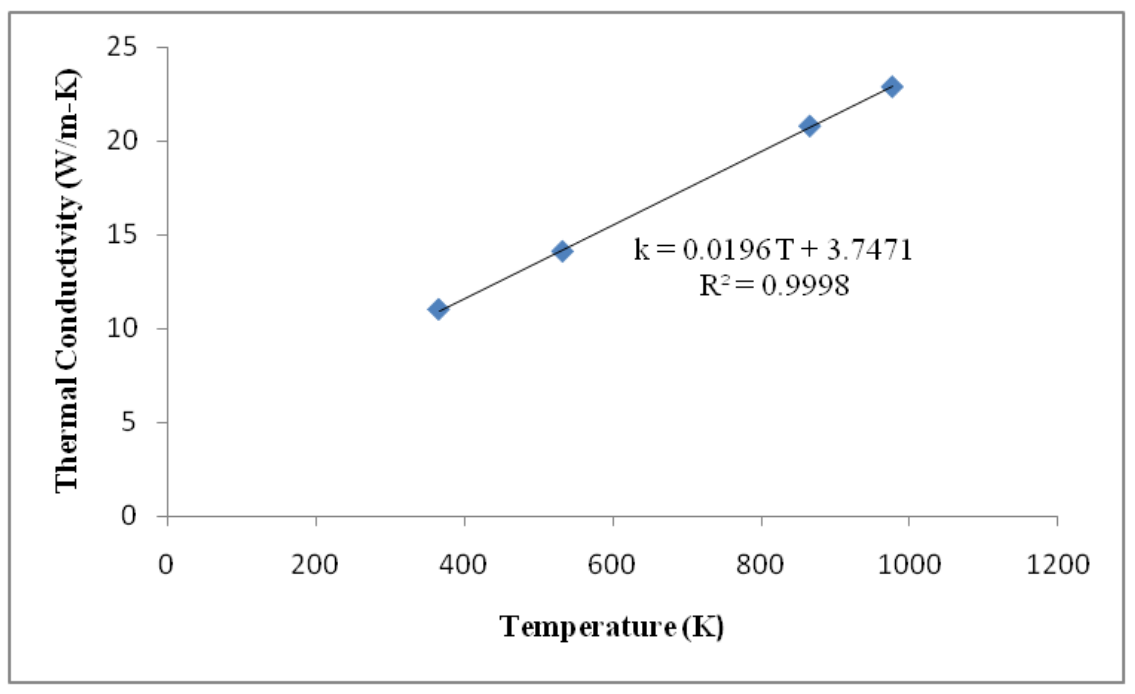

Figure 2.4 Least square line fit for thermal conductivity of Hastelloy-X®

Thus thermal conductivity can be found depending on temperature using the linear relationship $k(T)=a_{0}+a_{1} T$. This equation is substituted into Eq. 13 and integrated as follows.

$$
\begin{aligned}
& \int q^{\prime \prime}{ }_{x} d x=-\int\left(a_{0}+a_{1} T\right) d T \\
& q^{\prime \prime}{ }_{x}-C=-\left(a_{0} T+a_{1} \frac{T^{2}}{2}\right) \\
& \frac{a_{1}}{2} T^{2}+a_{0} T+q^{\prime \prime}{ }_{x} x-C=0
\end{aligned}
$$

Where $\mathrm{C}$ is the integration constant. $\mathrm{C}$ and $q^{\prime \prime} x$ are calculated using the two temperatures, $T_{1}$ and $T_{2}$, provided by the thermocouples.

$$
\frac{a_{1}}{2} T_{1}^{2}+a_{0} T_{1}+q^{\prime \prime}{ }_{x} x_{1}-C=0
$$




$$
\frac{a_{1}}{2} T_{2}^{2}+a_{0} T_{2}+q^{\prime \prime}{ }_{x} x_{2}-C=0
$$

Setting Eqs. 17 and 18 equal and solving for $q^{\prime \prime}{ }_{x}$ provides an equation for the heat flux.

$$
q^{\prime \prime}{ }_{x}=\frac{\frac{a_{1}}{2}\left(T_{1}^{2}-T_{2}^{2}\right)+a_{0}\left(T_{1}-T_{2}\right)}{\left(x_{2}-x_{1}\right)}
$$

Subbing Eq. 19 into Eq. 17 results in an equation for $C$.

$$
C=\frac{a_{1}}{2} T_{1}^{2}+a_{0} T_{1}+\left(\frac{\frac{a_{1}}{2}\left(T_{1}^{2}-T_{2}^{2}\right)+a_{0}\left(T_{1}-T_{2}\right)}{\left(x_{2}-x_{1}\right)}\right) x_{1}
$$

Once $q^{\prime \prime}{ }_{x}$ and $C$ have been found, $T_{S}$ can be calculated from Eq. 20 by setting $x=0$ and solving for $T$ using the quadratic equation.

\subsection{EQUIVALENCE RATIO CALCULATION}

The equivalence ratio, $\Phi$, is the ratio of the fuel-to-air ratio of a specific condition to the fuel-to-air ratio at stoichiometric conditions. In this study the equivalence ratio is used to set the fuel and air flow rates into the WSR. The fuel used in this study is propane $\left(\mathrm{C}_{3} \mathrm{H}_{8}\right)$. Propane was used to remain consistent with the related studies done previously (Section 2.9.4), and it is amenable to chemical kinetic modeling. Equation 21 provides the global combustion reaction of propane in air (11):

$$
\mathrm{C}_{3} \mathrm{H}_{8}+5\left(\mathrm{O}_{2}+3.76 \mathrm{~N}_{2}\right) \rightarrow 3 \mathrm{CO}_{2}+4 \mathrm{H}_{2} \mathrm{O}+18.8 \mathrm{~N}_{2}
$$


At stoichiometric conditions the fuel-to-air ratio is calculated from the moles of fuel and moles of oxidizer in the global reaction as shown below.

$$
\left(\frac{\dot{m}_{\text {fuel }}}{\dot{m}_{\text {air }}}\right)_{\text {stoich }}=\frac{1 \times M W_{C_{3} H_{8}}}{5 \times\left(4.76 \times M W_{\text {air }}\right)}=0.06395
$$

The equivalence ratio is calculated using Eq. 23

$$
\Phi=\frac{\left(\frac{\dot{m}_{f u e l}}{\dot{m}_{\text {air }}}\right)_{\text {condi }}}{\left(\frac{\dot{m}_{\text {fuel }}}{\dot{m}_{\text {air }}}\right)_{\text {stoich }}}
$$

So, $\Phi>1$ is fuel-rich, $\Phi<1$ is fuel lean, and $\Phi=1$ is stoichiometric.

The equivalence ratio is an important factor to the film cooling scheme effectiveness because it affects the species concentrations and the temperature of the initial fuel-air mixture flowing into the WSR.

\subsection{HIGH SPEED IMAGING AND CHEMILUMINESCENCE}

High speed monitoring devices allow for the capture of dynamic systems such as the combustion systems experienced in this study. Optical methods are extremely useful in combustion research because they are non-intrusive and can hold up to the harsh combustion environment. Chemiluminescence, or radiation emitted from excited molecules as they return to a lower energy state, is one such optical method, and is often used in combustion research because it is related to chemical kinetics of combustion processes. Measurement of chemiluminescence provides visualization of and quantitative information on combustion reactions which will aid in the characterization of 
reacting boundary layers created by the injection of cooling air into the exhaust flow. These measurements are made from a line-of-sight viewpoint.

Chemiluminescence is based on the theory that one photon of light is emitted for each molecule of excited species. The wavelength of the radiation is dependent upon the molecular species. Flame chemiluminescence is useful in combustion analysis due to the presence of excited state molecules in reactions. In the measurement of flame chemiluminescence, the concentrations of excited molecules are significantly above those concentrations found at the same temperature with no reaction. This suggests that excited molecules are not solely a product of thermal excitation, but can also occur as the products of reactions (12).

Excited radicals of $\mathrm{CH}\left(\mathrm{CH}^{*}\right)$ and $\mathrm{OH}\left(\mathrm{OH}^{*}\right)$, are present in flames and allow for chemiluminescent measurements of the reactions in this study since they both have peak chemiluminescence emission wavelengths at $431 \mathrm{~nm}$ and $308 \mathrm{~nm}$ respectively (13). A wavelength of $431 \mathrm{~nm}$ falls in the visible radiation spectrum, while $308 \mathrm{~nm}$ falls in the ultraviolet spectrum. Optics are readily available at both of these wavelengths.

The high temperature in flames causes decomposition of fuel molecules, resulting in incomplete combustion products. As these combustion products react with one another, exothermic reactions occur, leading to excited state molecules. In premixed combustion situations, the chemiluminescence emission can be correlated with the local equivalence ratio and rate of heat release (14).

\subsection{1. $\quad \mathrm{CH}^{*}$ Chemiluminescence}

There is strong temperature dependence on the reaction mechanisms involved in the production of $\mathrm{CH}^{*}$, thus this radical is a good indicator of flames. Identification of 
the production path for $\mathrm{CH}^{*}$ is difficult because there is no completely adequate way to measure all the radicals involved. Though it has been found that the dominant source of $\mathrm{CH}^{*}$ is from the following reaction:

$$
\mathrm{C}_{2} \mathrm{H}+\mathrm{O} \rightarrow \mathrm{CO}+\mathrm{CH}^{*}
$$

The breakdown of chemiluminescent species is important to the quantification of the radical molecule being investigated, such as $\mathrm{CH}^{*}$, because the emissions given off as it breaks down is what the filter and camera capture. The most common path for the removal of excess energy of $\mathrm{CH}^{*}$ is through a collision with another molecule, called quenching. In the case of $\mathrm{CH}^{*}$, the quenching process is extremely temperature dependent. Molecules move faster and interact more as the temperature increases (12). If the temperature changes enough in the test section, the amount of $\mathrm{CH}^{*}$ observed will also change. The occurrence of a reaction leads to high temperatures leading to increased amounts of $\mathrm{CH}^{*}$ quenching and increased emissions captured by the camera and filter.

\subsection{2. $\mathrm{OH}^{*}$ Chemiluminescence}

Formation of $\mathrm{OH}^{*}$ is more completely understood in comparison to the formation of $\mathrm{CH}^{*}$. The accepted production path of $\mathrm{OH}^{*}$ was initially proposed by Krishnamahari and Broida (12). The reaction is exothermic resulting in about $160 \mathrm{kcal} / \mathrm{mole}$.

$$
\mathrm{CH}+\mathrm{O}_{2} \rightarrow \mathrm{CO}+\mathrm{OH}^{*}
$$

This reaction has been studied various times since its proposal. Generally it has been found that this reaction effectively explains the observations made in other studies. 
Again, quenching is the most common path of the removal of excess energy for the $\mathrm{OH}^{*}$ radical. The rate of quenching, which causes the emission at a specific wavelength and is picked up by the camera and filter, for $\mathrm{OH}^{*}$ is presented for various quenching molecules in Ref. (13). In general the quenching of $\mathrm{OH}^{*}$ is highly temperature dependent, just as for $\mathrm{CH}^{*}(12)$.

\subsection{HEAT RELEASE RATE AND CHEMILUMINESCENCE}

The axial length of the UCC is significantly smaller than that of conventional combustors. The reduced volume results in increased heat release rates in the UCC as compared to a conventional combustor design. Figure 2.5 illustrates the increase in heat release rate in a UCC. The data shows that the UCC operates at higher heating rates compared to the primary zones in annular combustors. Heat release rate is an important factor for investigation, especially for integration of UCC systems.

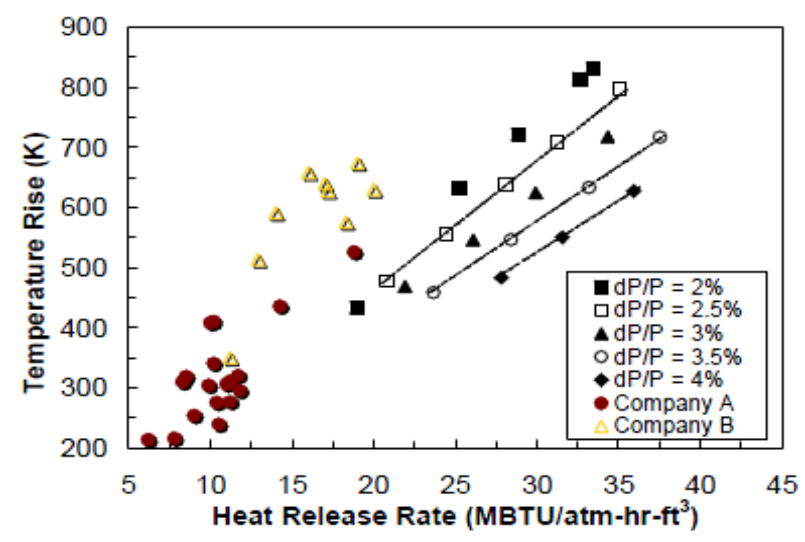

Figure 2.5 Heat release rate for the UCC compared to a conventional combustor (7)

The potential for and consequences of heat release in the turbine was discussed in Section 2.1.1. Quantifying the rate of heat release, or the heat released due to reactions per unit time and per unit volume (units of $\mathrm{J} / \mathrm{m}^{3}-\mathrm{s}$ ) (14), can help in understanding the 
efficacy of various film cooling schemes. One way to quantify heat release rate is through chemiluminescence intensity measurements.

Reference (14) discusses the ability of chemiluminescent intensity to indicate heat release rate. The chemiluminescent emissions from $\mathrm{OH}^{*}, \mathrm{CH}^{*}, \mathrm{C}_{2}{ }^{*}$, and $\mathrm{CO}_{2} *$ are measured in natural-gas-fueled, premixed, counterflow flames at equivalence ratios ranging from 0.7 to 1.3 . Chemiluminescence was captured using Cassegrain receiving optics coupled to a spectroscopic unit. It was found that chemiluminescent intensities from $\mathrm{OH}^{*}$ and $\mathrm{CH}^{*}$ are good indicators of heat release rate in combustion processes.

Knowing that chemiluminescence measurements of $\mathrm{CH}^{*}$ and $\mathrm{OH}^{*}$ can be used to quantify rate of heat release is helpful in this study. The chemiluminescent emission measurements taken are used to find heat release rate which can then be analyzed along with the heat flux calculations and flame spatial characteristics.

\subsection{LOCAL EQUIVALENCE RATIO AND CHEMILUMINESCENCE}

The equivalence ratio of the flow within the WSR is known because the air and fuel flow rates are set. After the main combustion in the WSR, the equivalence ratio within the test section is unknown. Measurement of chemiluminescence emissions allows for an investigation of the local equivalence ratio within the test section. Hardalupas and Orain (14) show that the ratio of $\mathrm{OH}^{*} / \mathrm{CH}^{*}$ is dependent upon equivalence ratio for premixed flames. It was found that the intensity ratio of $\mathrm{OH}^{*} / \mathrm{CH}^{*}$ decreases monotonically as equivalence ratio increases.

In Ref. (14) $\mathrm{OH}^{*}$ and $\mathrm{CH}^{*}$ emissions are measured as mentioned in the previous section (Section 2.6). The chemiluminescence intensity from individual radicals is dependent upon the equivalence ratio, fuel mass flow rate, temperature, pressure, and 
local flame strain rate. Thus the theory is that the ratio of intensities of emissions of different radicals might eliminate the dependence of other parameters, leaving only a dependence on equivalence ratio. It is found that there is an uncertainty of $5 \%$ for local equivalence ratios up to 1.1 and uncertainty of $20 \%$ for richer mixtures.

\subsection{PREVIOUS RESEARCH IN FILM COOLING}

\subsubsection{Non-Reacting Flows}

Many studies have been carried out investigating the effects of cooling air injection into a turbine environment. The freestream flow in these cases was fuel-rich thus the injection of cooling air did not lead to reactions. These studies provide information on the physical characteristics of the cooling jet and freestream flow fields and how they interact with one another.

The effect of blowing ratio, $M$, and coolant hole angle on $\alpha$ for cooling flow on a flat plate is examined in Ref. (15). At a low blowing ratio $(M=0.4)$ the coolant jet is fully attached to the surface. For a hole geometry typical to a gas turbine engine, the cooling effectiveness is high at the injection location, but the effectiveness decays quickly downstream. This is an effect of the relatively low coolant mass flux at a low blowing ratio. As the blowing rate increases $(M=0.6)$ the coolant mass flux also increases. At this blowing ratio there is a larger intensely cooled area and less effectiveness decay due to the higher thermal capacity of the coolant jet. The cooling effectiveness reaches its optimum at $M=1.0$ as the intensely cooled area moves further from the injection location. As the blowing ratio increases above 1.0, the peak cooling effectiveness decreases. In general, as blowing ratio increases, the location of peak 
effectiveness moves further downstream. Figure 2.6. shows the effectiveness distribution for typical hole geometry at blowing ratios.

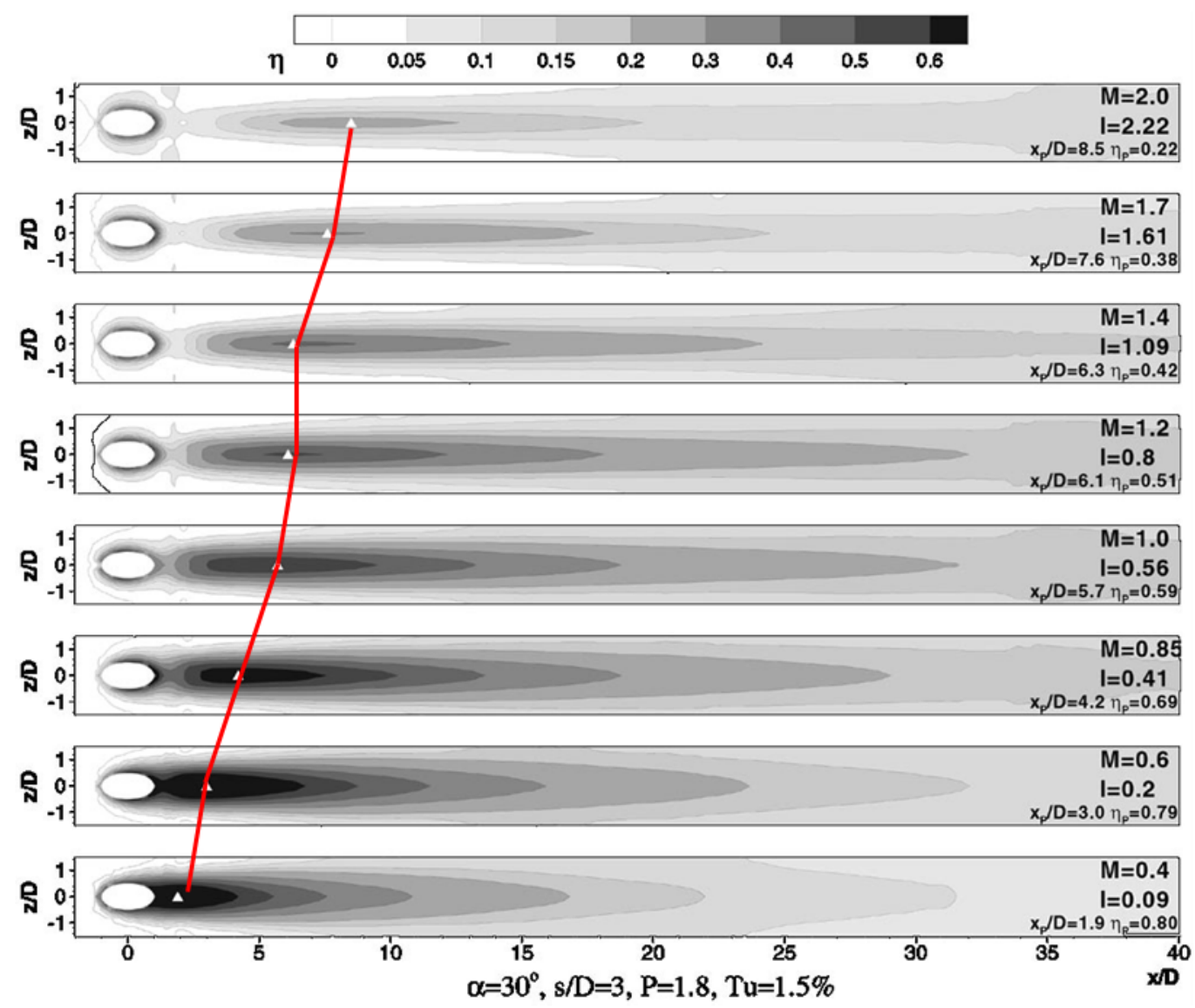

Figure 2.6 Cooling effectiveness field for a typical hole geometry (15)

Baldauf et al. (15) investigate the effect of various hole injection angles. At a steep injection angle the separation of the coolant jet takes place earlier than for a shallow injection angle. For steeper angles the peak effectiveness is lower and occurs closer to the injection location. At shallow injection angles, adjacent jets merge and leading to a larger spreading of coolant in the freestream flow. These trends are a result of the high surface normal injection at step angles which pushes the flow further from the surface. Figure 2.7 shows the effect of changing the injection angle on the effectiveness fields. 


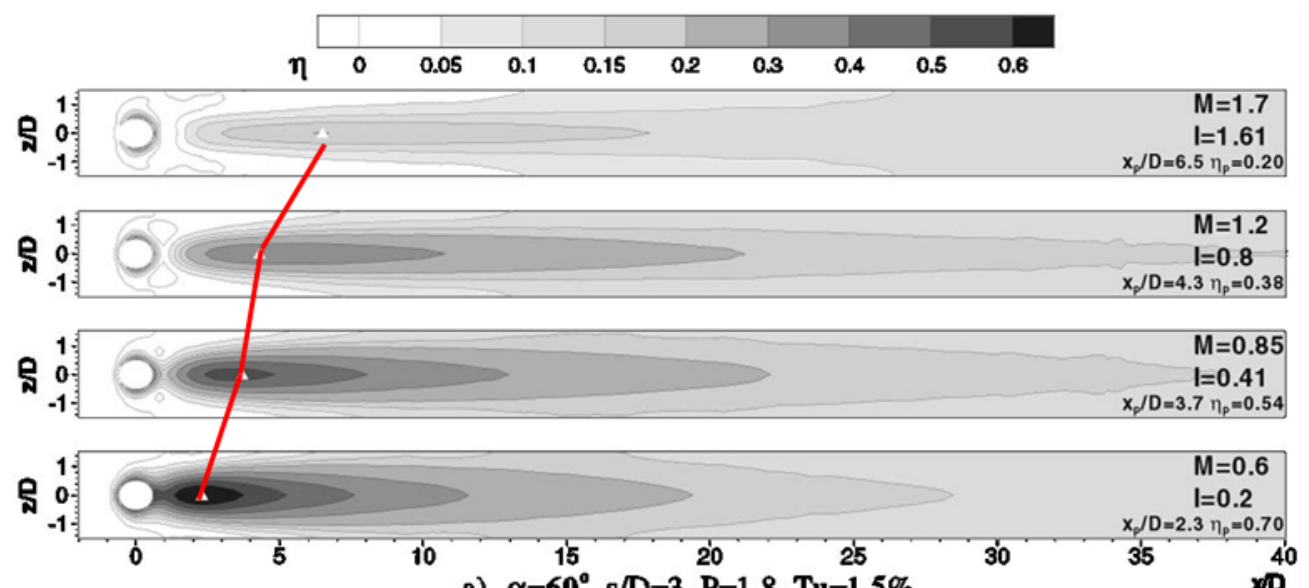

a) $\alpha=60^{\circ}, \mathrm{s} / \mathrm{D}=3, \mathrm{P}=1.8, \mathrm{Tu}=1.5 \%$
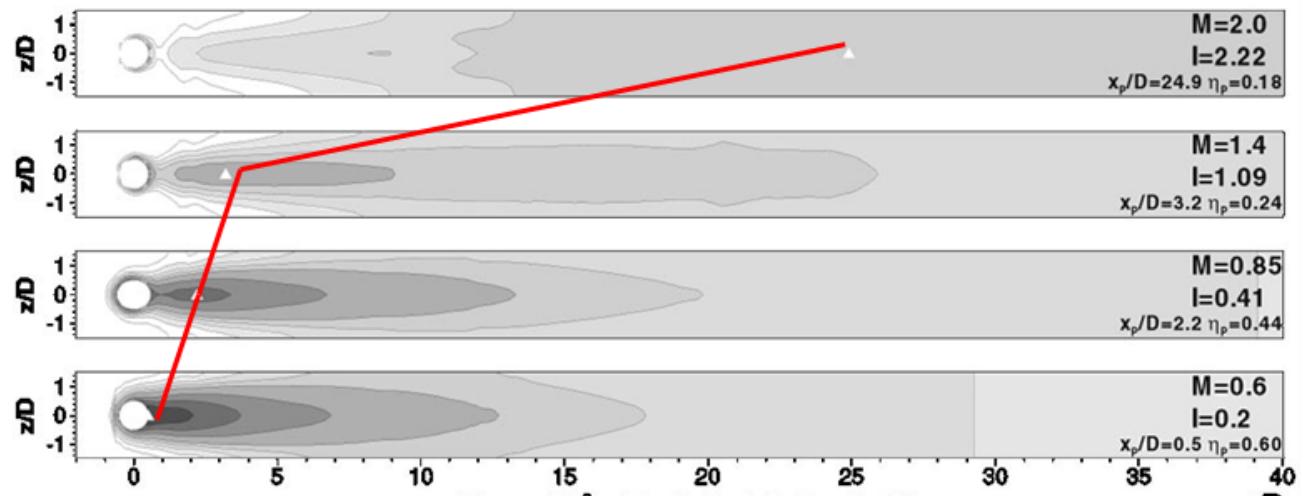

b) $\alpha=90^{\circ}, \mathrm{s} / \mathrm{D}=3, \mathrm{P}=1.8, \mathrm{Tu}=1.5 \%$

Figure 2.7 Effect of injection angle on cooling effectiveness fields (15)

In general it was found that intense interaction between jets prevents large coolant loss into the freestream flow. Interaction between jets is affected by changes in blowing ratio and injection angle.

The effect of blowing ratio and injection angle on $q$ has been investigated by Baldauf et.al. in Ref. (16). It was found that at lower blowing ratios the jet is closer to the surface resulting in lower heat transfer. At moderate blowing ratios, the coolant jet lifts off the surface. At high blowing ratios the jet is detached and penetrates the freestream flow. It was found that higher blowing ratios lead to higher vorticity as the jet mixes with the freestream flow. The high vorticity augments the heat transfer to the surface. 
Baldauf et al. (16) also saw that as the injection angle increases there is less downstream momentum in the coolant flow, leading to a shorter vortex region on the surface. As a result, heat transfer does not extend as far downstream for large injection angles. Though the heat transfer is higher directly downstream of the injection location due to the intense reaction between the coolant and the freestream flows.

This study (16) also shows that there are large interactions between adjacent jets. For smaller hole spacing, the jets interact more fully causing higher turbulence and more heat transfer to the surface. As the hole spacing increases interactions between adjacent jets remain, but they are not as intense. Larger hole spacing results in lower surface heat transfer.

\subsubsection{Reacting Flows}

The potential for secondary combustion within the turbine and its effects were studied by Lukachko et al. in Ref. (1). It was found that the potential for heat rise due to combustion is highly dependent upon the amount of chemical energy present in the flow. CO-equivalent concentration downstream of the combustor was used to define three different compositions. The dissociated species emissions of $\mathrm{CO}, \mathrm{OH}, \mathrm{H}_{2}, \mathrm{O}$, and $\mathrm{HC}$ as a result of reaction are summed into the CO-equivalent molar quantity by energy content. This value provides a measure of the total available energy to cause temperature rise. The potential for temperature rise is shown for each of the three compositions in Fig. 2.8 as a function of mixture temperature and pressure, where $\mathrm{H}^{*}$, the ratio of enthalpy change to the initial enthalpy $\left(\Delta H_{t} / H_{t}\right)$, is an alternative version of the temperature rise. 

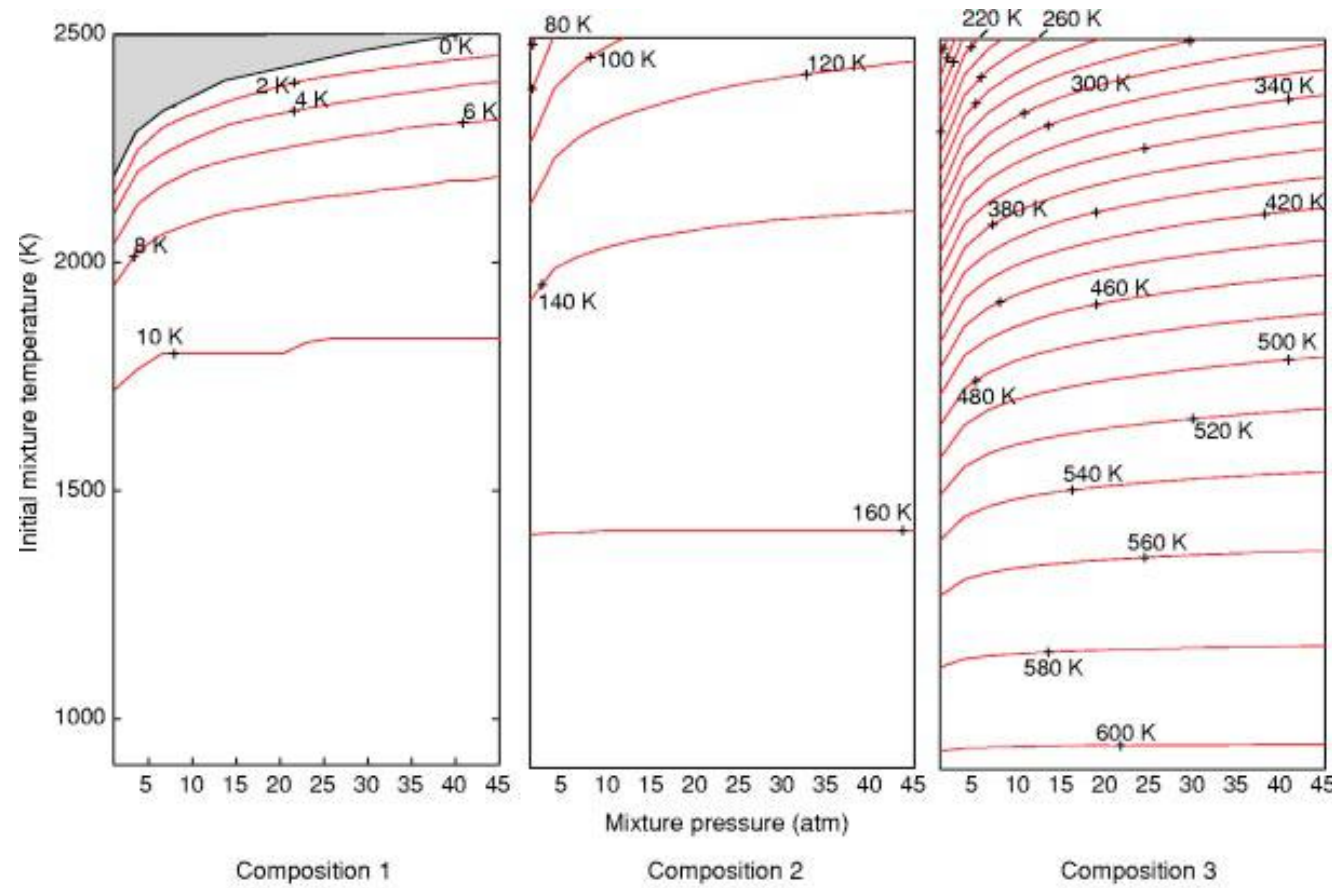

\begin{tabular}{ccr}
\hline Composition & CO-equivalent (ppmv) & \multicolumn{1}{c}{$\mathrm{H}^{*}$} \\
\hline 1 & $1400-12000$ & $0.05 \%-0.5 \%$ \\
2 & $21000-32000$ & $6 \%-11 \%$ \\
3 & $77000-81500$ & $18 \%-35 \%$ \\
\hline
\end{tabular}

Figure 2.8 Potential local temperature rise due to reaction in the turbine (1)

Here it is seen that the temperature rise can be significantly large at high levels of CO-equivalent which correspond to high fuel-to-air ratio conditions, as created in the experimentation in this study.

A secondary study was done in Ref. (3) (Kirk et al.) which completed a series of shock tube experiments at high temperature and pressure flows over a film-cooled flat plate at a series of fuel levels, blowing ratios, and Damköhler numbers. The flat plate contains two sets of angled film cooling holes that were supplied with different gases; one side with air and the other side with nitrogen. This study (3) investigated the increase in surface heat flux as a result of near wall reactions. In general it is shown that the impact of reactions on a film cooled surface is a function of the Damköhler number $D a$, heat release potential $H^{*}$, scaled heat flux $Q_{s}$, and blowing ratio $M$. 
Damköhler number is a nondimensional parameter that is defined as the ratio of characteristic flow time to characteristic chemical time. In this study (3) $D a$ is the amount of time required for the flow to travel a distance of 10 hole diameters divided by the time for the reaction to reach $95 \%$ completion.

$$
D a=\frac{\tau_{\text {flow }}}{\tau_{\text {chem }}}=\frac{10 D}{U_{\infty} \tau_{\text {chem } 95}}
$$

The study showed that the heat flux increases with increasing $D a$. Also, it was found that at high $\mathrm{CO}$-equivalent concentrations, up to $30 \%$ increase in heat flux can occur. At moderate CO-equivalent concentrations, up to $10 \%$ increase can occur. At low CO-equivalent concentrations, the difference in heat flux between reacting and nonreacting flows is minor. At already high engine temperatures even a small increase in heat flux is significant to the life of the turbine hardware. Figure 2.9 illustrates the difference between heat fluxes for reacting (air) and non-reacting (nitrogen) flows.

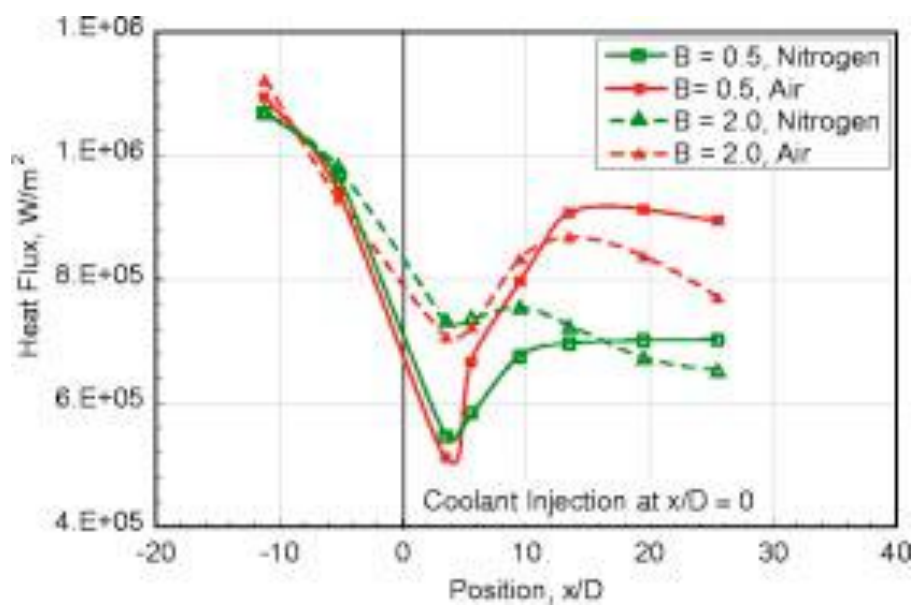

Figure 2.9 Heat flux at $M=0.6$ and $M=2.0$ for reacting and non-reacting cooling flow (3) 
Further, blowing ratio also has a significant effect on the heat flux. Figure 2.9 above and Fig. 2.10 below both illustrate the effect of blowing ratio. Figure 2.10 compares the temperature for reacting and non-reacting flows for $M=0.5$ (attached jet) and $M=2.0$ (lifted jet). It is seen that at $M=0.5$ the jet remains close to the surface (Cases 1a and 1b), while at $M=2$ the jet lifts off the surface (Cases $2 \mathrm{a}$ and $2 \mathrm{~b}$ ). There is a noticeable effect of reaction rate on the temperature and the heat flux. The heat flux for the lifted case has a lower minimum directly downstream of the injection location in comparison to the attached jet. This occurs because the attached jet remains close to the surface augmenting the local heat flux there. It is also noted that the heat flux is larger for the attached case and then decreases slowly, while the lifted jet decreases quickly post peak. Kirk et.al. (3) suggest that this is due to the time required for the heat to diffuse in the attached case, resulting in greater heat flux downstream. There is more mixing with the freestream in the lifted jet case, leading to lessened temperatures at the surface. 

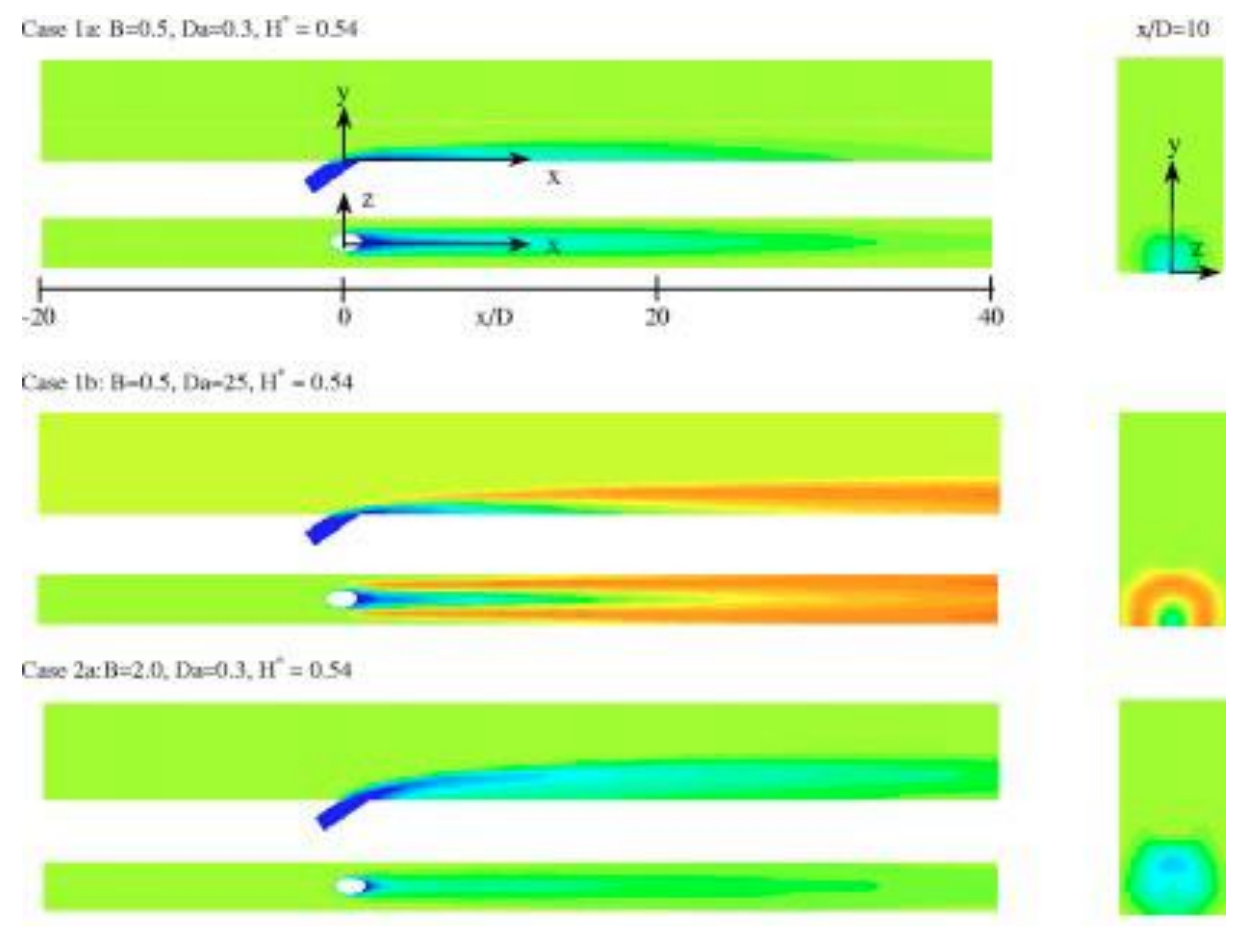

Case $2 b: B=20, D s=25, \mathrm{~B}^{*}=0.54$
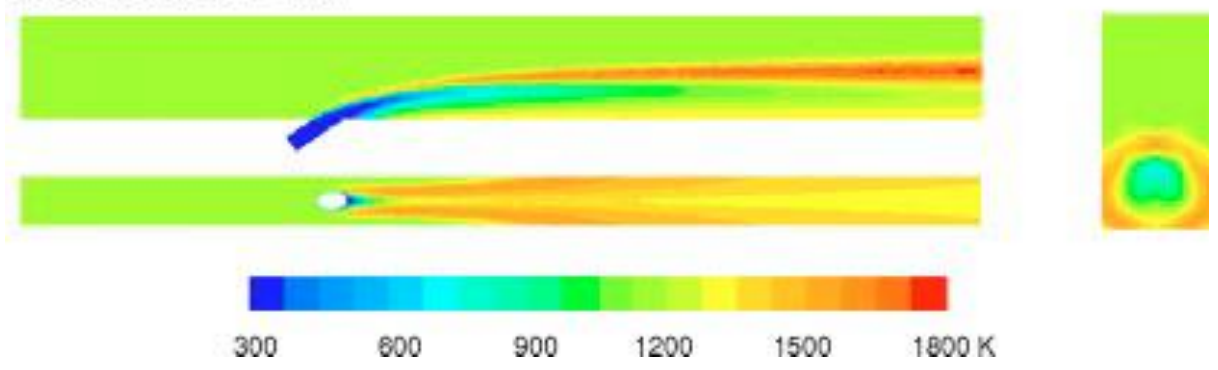

Figure 2.10 Numerical results of temperature profile of a reacting jet (3)

\subsubsection{Turbulence Effects}

In Ref. (17) Saumweber et al. investigate the effects of elevated freestream turbulence on film cooling through shaped holes. It was found that for cylindrical holes at low blowing ratios, the effectiveness of film cooling was reduced with increased turbulence. At high blowing ratios there is a slight increase in effectiveness with increased turbulence. This increase in effectiveness is due to the enhanced lateral spreading of coolant and a lower tendency to detach from the wall. 
Increasing turbulence for the shaped holes is detrimental to the film cooling effectiveness no matter what is the magnitude of the blowing ratio. This is an effect of the interaction between cooling flow jets. The coolant jets of the shaped holes interact with one another immediately downstream of the injection location forming a "closed cooling film." Thus the lateral spreading of cooling flow does not increase with turbulence as in the cylindrical holes. It was also observed that increased turbulence has a much more prominent effect on the shaped hole cooling flow than the cylindrical holes.

Figure 2.11 shows the difference in film cooling effectiveness for different blowing ratios, turbulence intensities, and hole geometries.

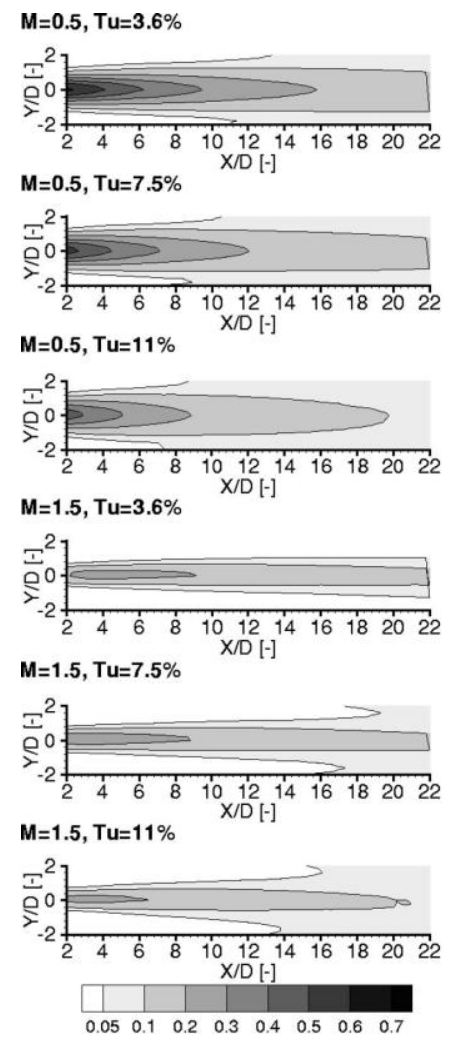

(a)

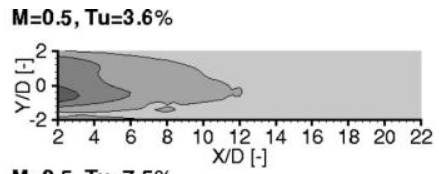

$\mathrm{M}=0.5, \mathrm{Tu}=7.5 \%$

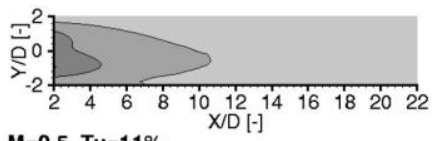

$M=0.5, T u=11 \%$

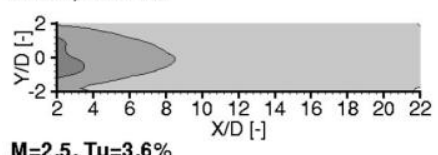

$\mathrm{M}=2.5, \mathrm{Tu}=3.6 \%$
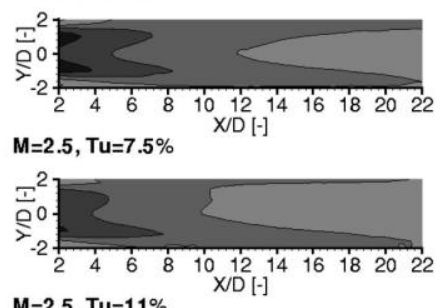

$\mathrm{M}=2.5, \mathrm{Tu}=11 \%$

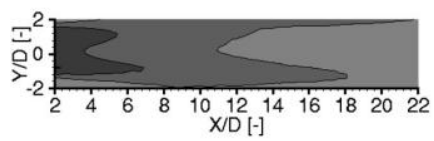

(b)

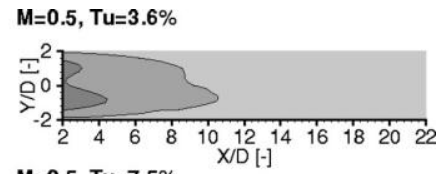

$\mathrm{M}=\mathbf{0 . 5}, \mathrm{Tu}=\mathbf{7 . 5} \%$

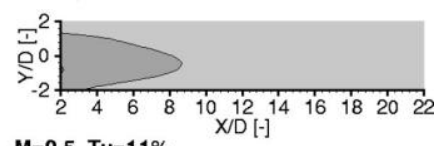

$\mathrm{M}=\mathbf{0 . 5}, \mathrm{Tu}=11 \%$

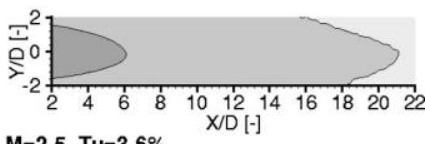

$\mathrm{M}=2.5, \mathrm{Tu}=3.6 \%$

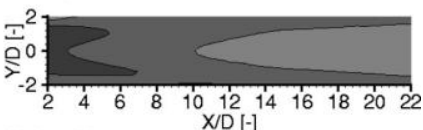

$M=2.5, T u=7.5 \%$
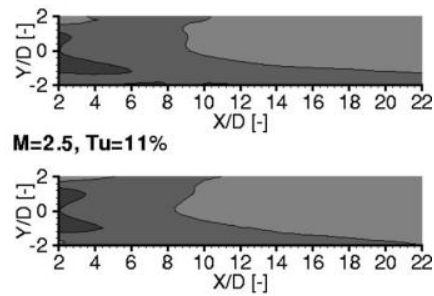

(c)

Figure 2.11 Local film cooling effectiveness for (a) cylindrical holes, (b) fan shaped holes, and (c) laidback fan shaped holes (17) 


\subsubsection{Related Work}

Previous studies involving the same experimental rig used in this study have been done and are related to the study presented in this thesis. Evans (18) measured the augmentation in heat flux as a result of reactions in the boundary layer due to the injection of cooling air flow. Temperatures, heat flux, and heat transfer coefficient were calculated at various equivalence ratios, cooling hole geometries, and blowing ratios. In general it was found that the reactions in the film cooling layer can lead to increased heat transfer to the surface. The magnitude of this increase depends on the hole geometry, the blowing ratio, and the equivalence ratio of the freestream flow. Examples of the changes in heat flux due to blowing ratio and hole geometry are provided in Figs. 2.12 and 2.13. It is observed that at an equivalence ratio of 1.5 , there is a noticeable difference between heat flux for reacting flow and heat flux for non-reacting flow. At an equivalence ratio of 0.6 there is almost no difference between heat fluxes for reacting and non-reacting flows.

Also note that in both images the heat flux with the non-reacting flow at 75 diameters downstream is higher than the heat flux with the non-reacting flow at 20 diameters downstream. This is because at 20 diameters downstream the cooling air has not fully mixed with the freestream flow and thus it is protecting the surface from heat flux. Further downstream the cooling flow has mixed more fully with the main flow. 


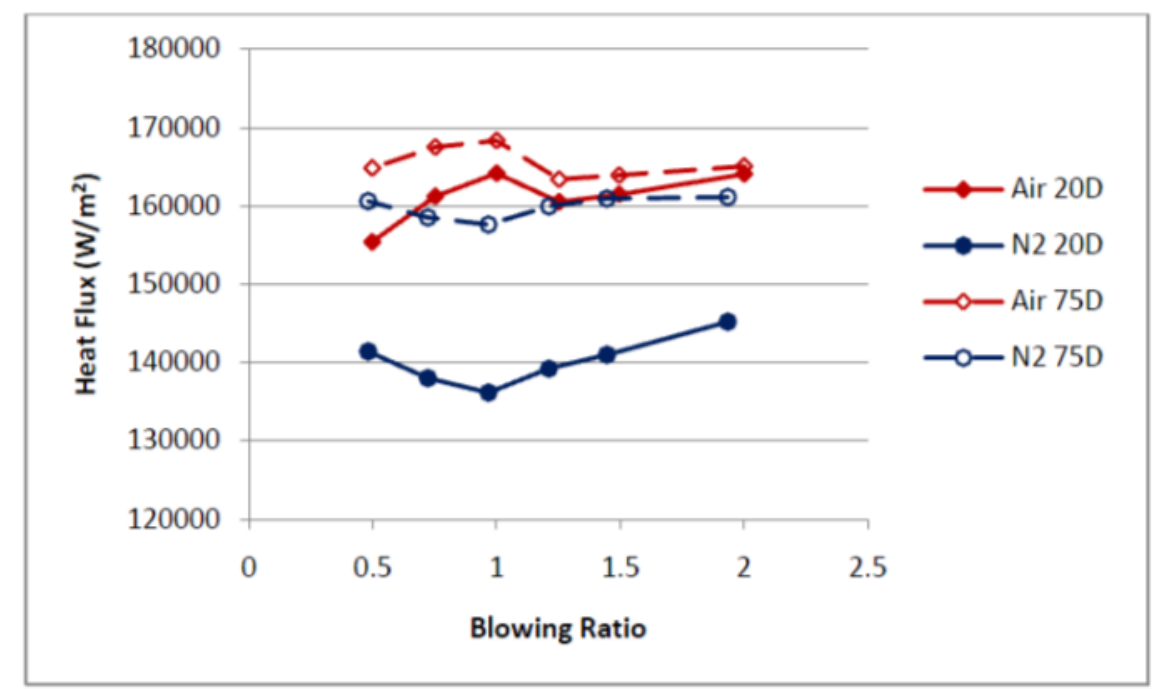

Figure 2.12 Comparison of heat flux between reacting (air) and non-reacting (nitrogen) cooling flows; fan shaped holes, $\Phi=1.5(18)$

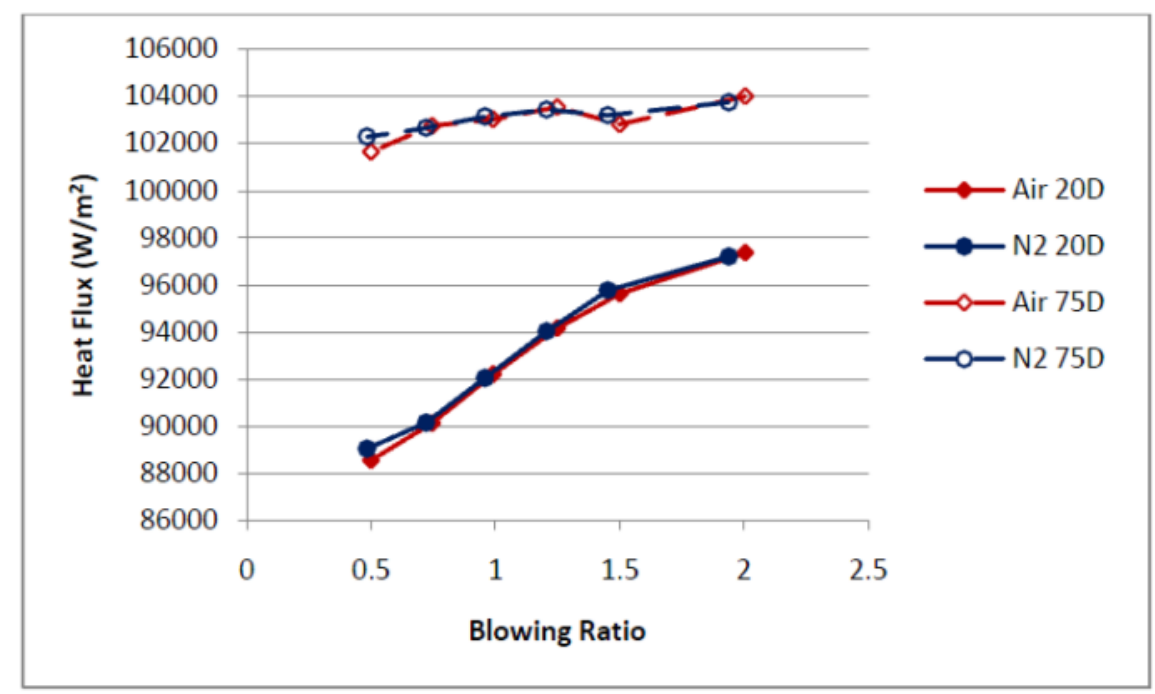

Figure 2.13 Comparison of heat flux between reacting (air) and non-reacting (nitrogen) cooling flows; normal holes, $\Phi=0.6(18)$

Bohan (19) investigated the use of film cooling schemes in a series in attempt to diminish or eliminate secondary reactions in film cooling jets in vitiated flow. It was found that geometry and blowing ratio both affect the heat flux, convective heat transfer coefficient, and surface temperature. Figure 2.14 presents an example of the change in 
heat flux experienced with two sets of cooling holes in series (upstream: offset normal, downstream: fan) due to changes in blowing ratio. In comparison to Fig. 2.15, which shows results with the slot in the upstream position, it is seen that different cooling hole geometries also have an effect on heat flux.

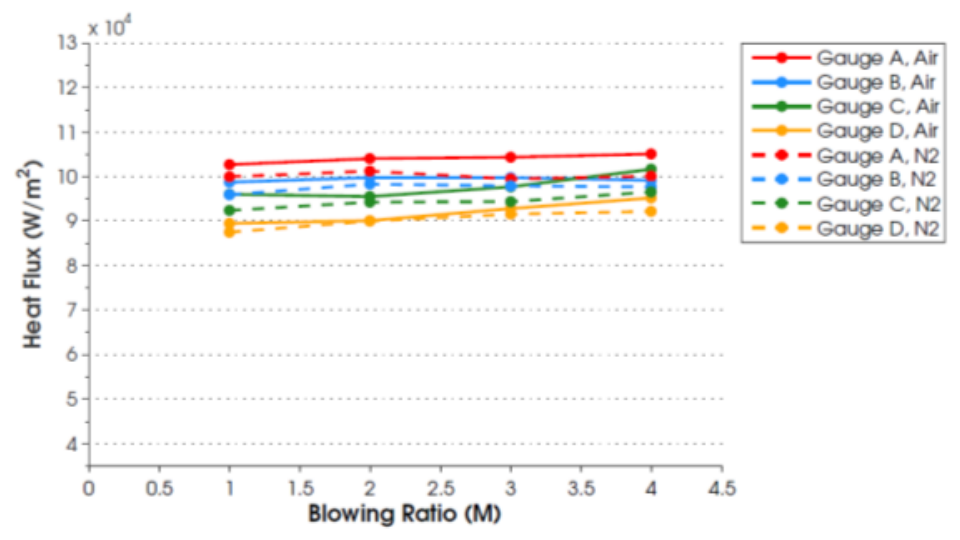

Figure 2.14 Heat flux, $\Phi=1.1$; upstream $=$ offset normal, coolant $=$ air, $M=$ variable; downstream $=$ fan, coolant $=$ air $/ \mathbf{N}_{2}, M=2(19)$

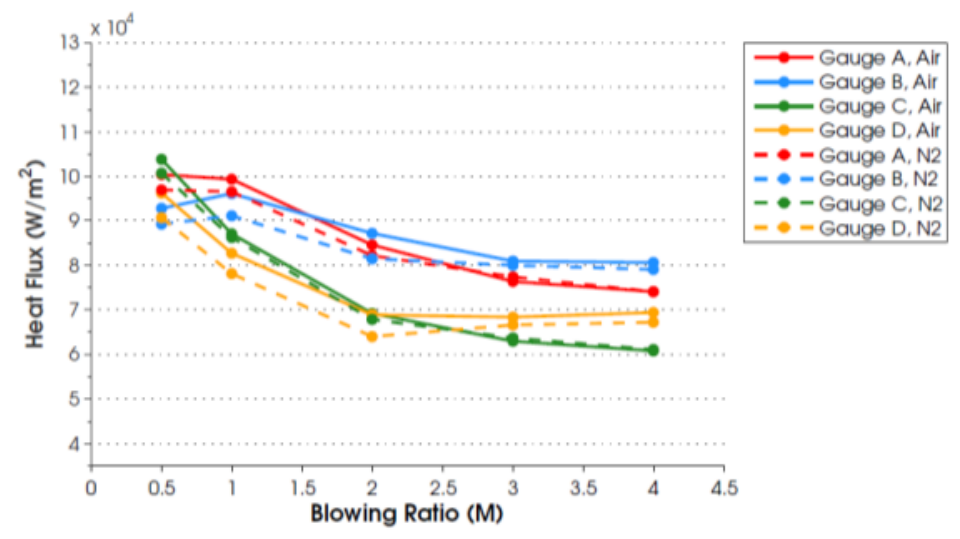

Figure 2.15 Heat flux, $\Phi=1.1$; upstream = slot, coolant = air, $M=$ variable;

$$
\text { downstream }=\text { fan, coolant }=\text { air/ } \mathbf{N}_{2}, M=2(19)
$$

An investigation of combustion fundamentals on film cooling flows was carried out by Blunck et al. (20). OH planar laser induced fluorescence (PLIF) and temperature measurements were taken. Spatially-resolved $\mathrm{OH}$ species and temperature measurements 
are compared at different blowing and equivalence ratios to investigate flame structure.

Flame interactions between neighboring holes and boundary layer conditions were also studied. It was observed that the separation between the flame and the wall is similar for blowing ratios 1 through 5 and increases for blowing ratio of 10, as illustrated in Fig.

2.16. Change in equivalence ratio has little effect on the flame location. In Fig. 2.17 it is seen that the equivalence ratio does not significantly change the flame.

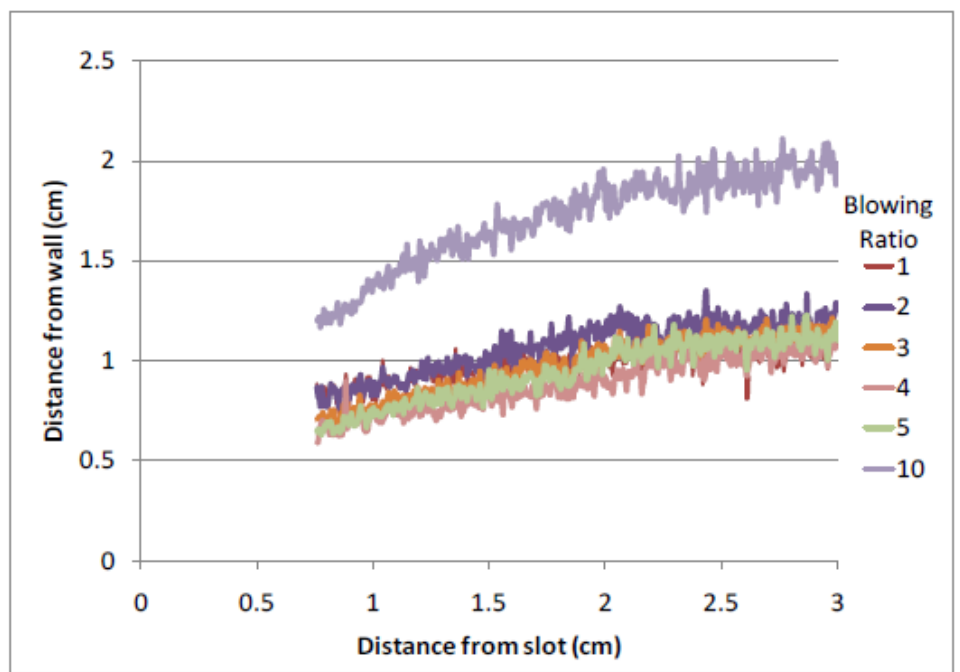

Figure 2.16 Distance between wall and location of peak $\mathrm{OH}$ concentration at axial locations 0.75 and $3 \mathrm{~cm}$ downstream of the injection location (20)

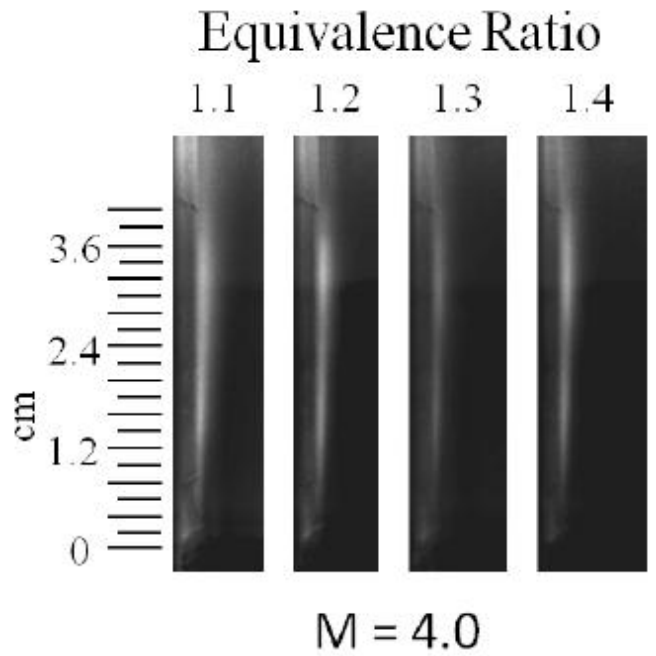

Figure 2.17 Average $\mathrm{OH}$ measurements at $\Phi=1.1,1.2,1.3$, and 1.4 at $\mathrm{M}=4$ (20) 
Complex geometries were also investigated in the film cooling test setup. The study examined if complex geometries are advantageous when reactions are present (21). These cooling schemes are holes that have more complex geometries in comparison to those used in actual engines.

Thornburg et al. (22) offers that hole geometry plays an important role in the cooling design effectiveness. A Reynolds-Averaged Navier-Stokes (RANS) approach was used to simulate film cooling flow from a surface into a crossflow. This approach models the combustion process and allows for the study of the physics of mixing between the cooling flow injected into the cross stream. Injection of nitrogen and air cooling flows were investigated for both fuel-lean and fuel-rich freestream flow.

Figure 2.18 shows the physical film cooling jet structure that forms when nitrogen is injected through different cooling holes. In this figure it is observed that flow through the normal cooling holes extends further from the surface, while flow from the fan shaped cooling holes (injected at $30^{\circ}$ ) stays much closer to the wall.

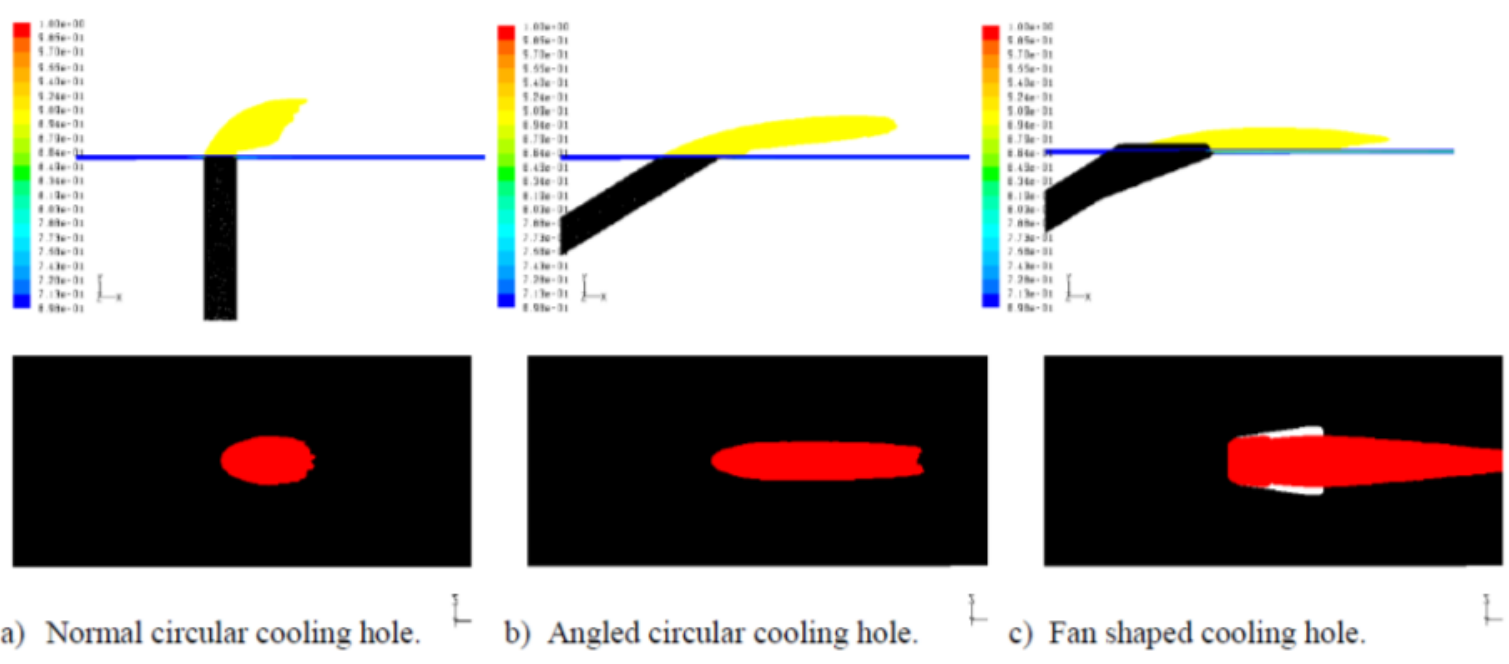

Figure 2.18 Film cooling jet structure for $\mathbf{N}_{2}$ injection (22) 
It was found that film cooling from the normal circular holes is not as effective as cooling from the angled and fan shaped holes. For fuel-rich freestream flow cases, Figs. 2.19 and 2.20 present the difference between nitrogen cooling flow and air cooling flow at a blowing ratio of 1 . For the fuel-rich conditions a hot area downstream of the cooling holes is created from the secondary combustion caused by the injection of air. Air injection at a high equivalence ratio could lead to negative cooling effectiveness in certain areas, especially for the fan shaped holes. Figure 2.19 shows that the injection of air also causes an increase in temperature at the wall noticeably for the fan shaped holes near to the cooling hole and further downstream. The film cooling effectiveness for injection of air into fuel-rich freestream flow is shown in Fig. 2.21. Here it is apparent that the film through the fan shaped holes effectively cools the wall to a greater length when compared to the other two geometries.

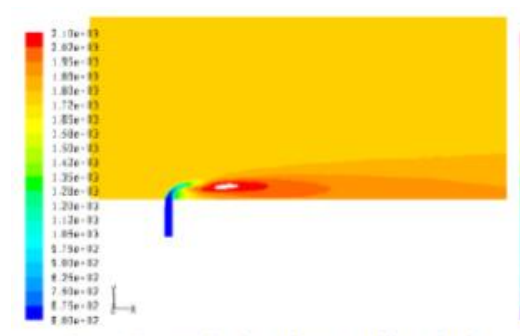

a) Normal circular cooling hole.

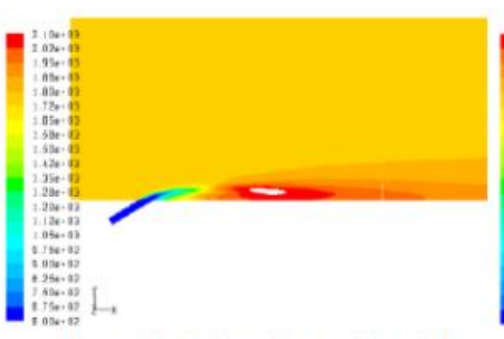

b) Angled circular cooling hole.

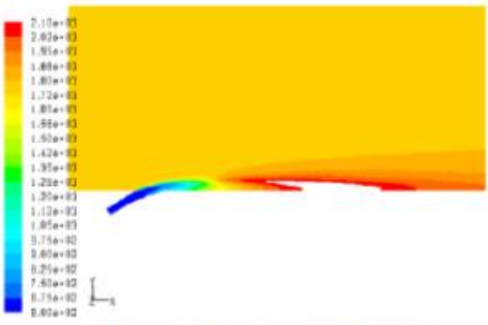

c) Fan shaped cooling hole.

Figure 2.19 Temperature contours for $\Phi=1.5, M=1$, air injection (22)

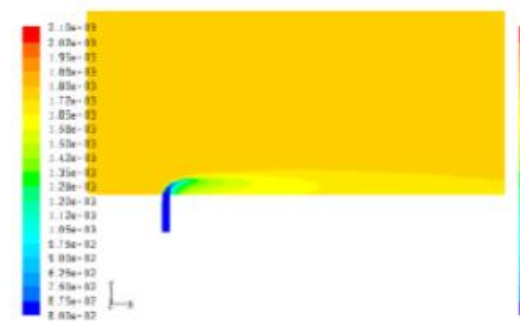

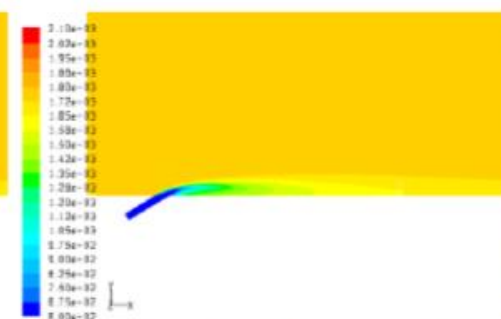

e) Angled circular cooling hole.

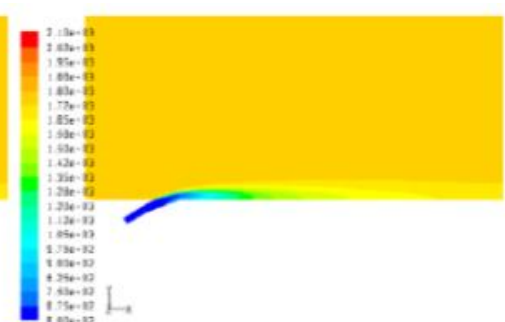

f) Fan shaped cooling hole.

Figure 2.20 Temperature contours for $\Phi=1.5, M=1, N_{2}$ injection (22) 


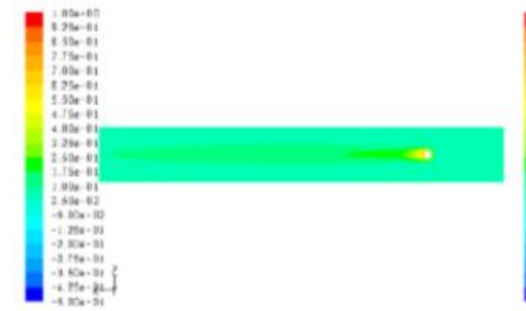

d) Normal circular cooling hole.

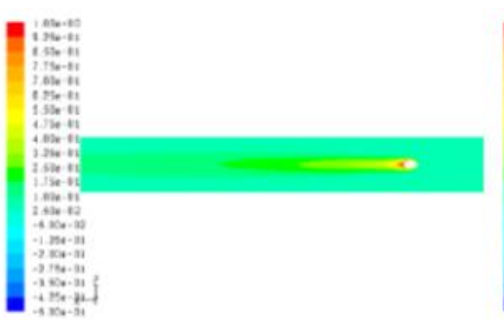

e) Angled circular cooling hole.

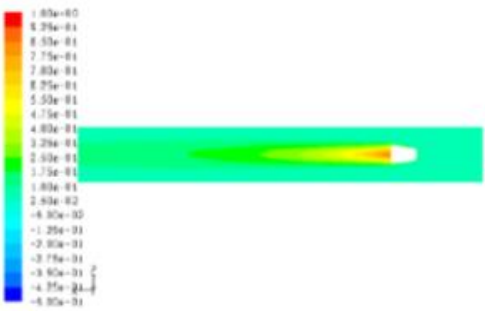

f) Fan shaped cooling hole.

Figure 2.21 Cooling effectiveness contours on the wall for $\Phi=1.5, M=1$, air

\section{injection (22)}

Lin et al. (23) use the same RANS model as discussed in the above paragraphs. This study further investigates the injection of air and nitrogen cooling flow through fan shaped holes into a cross-flow. Figure 2.22 presents temperature contours for air and nitrogen injection into fuel-rich cross-stream flow. Figure 2.23 shows temperature contours for air and nitrogen injection into fuel-rich freestream flow at a higher blowing ratio.

From these two figures it is seen that the secondary combustion which results from air injection leads to higher temperatures at the wall in comparison to nitrogen injection. Also, at a higher freestream equivalence ratio the temperature at the wall is higher. In general the proximity of the cooling flow from the fan shaped holes led to large areas of combustion on the surface. An increased blowing ratio raises the secondary combustion above the surface reducing the heat load to the surface. Figure 2.23 shows that at the higher blowing ratio $(M=2)$ extends further into the freestream flow. 

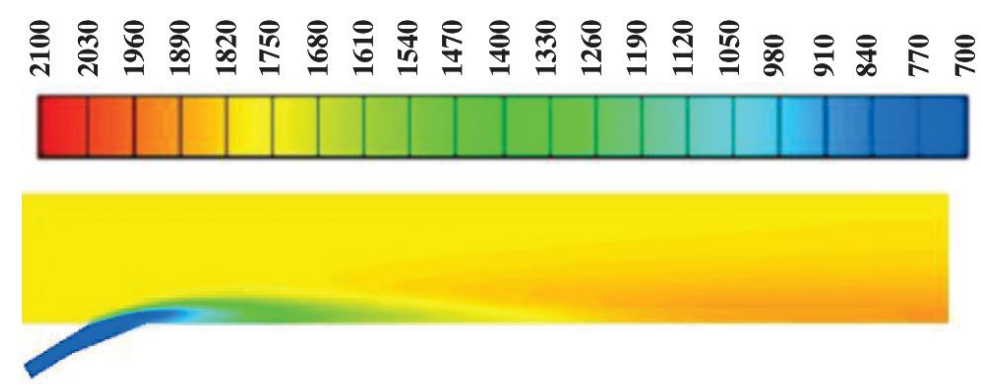

a) Air injection, $\Phi=1.1$

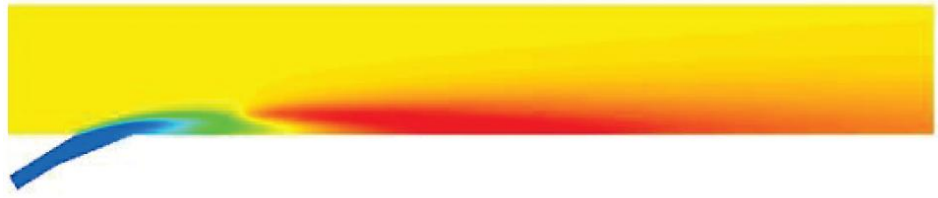

b) Air injection, $\Phi=1.5$

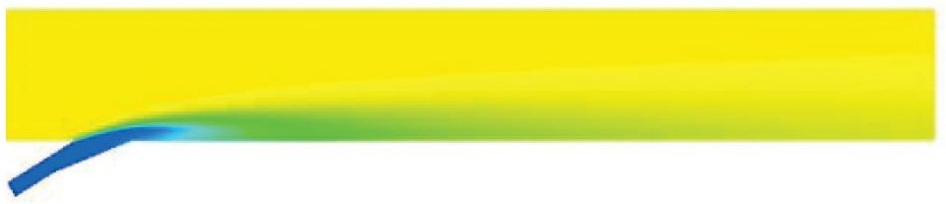

c) $\mathrm{N}_{\mathbf{2}}$ injection, $\Phi=1.1$

d) $\mathrm{N}_{2}$ injection, $\Phi=1.5$

Figure 2.22 Temperature contours for $\Phi>1, M=1$, fan shaped holes (23)

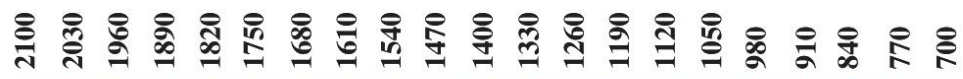
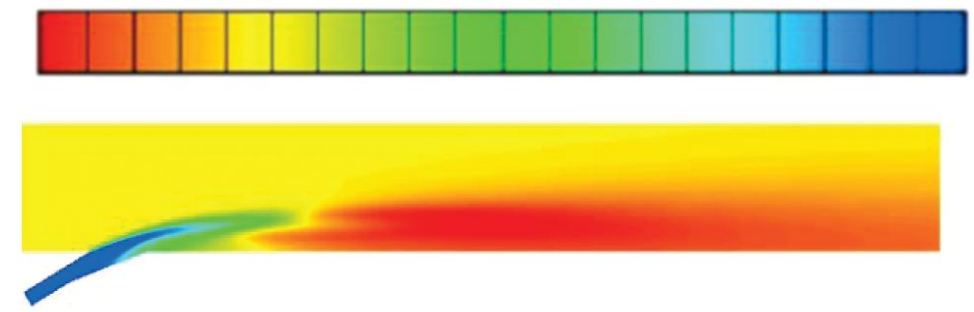

a) Air injection, $M=2.0$

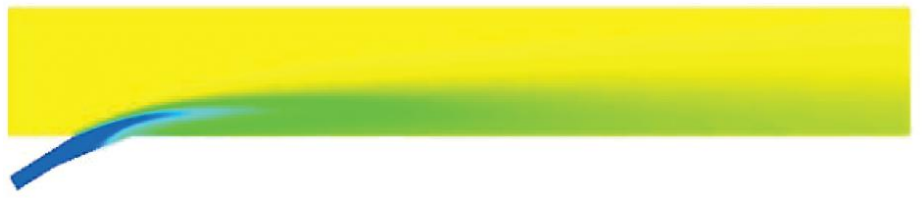

b) $\mathrm{N}_{2}$ injection, $M=\mathbf{2 . 0}$

Figure 2.23 Temperature contours for $\Phi=1.5, M=2$, fan shaped holes (23) 


\subsection{IMPORTANCE OF THIS STUDY}

Though much has been accomplished using the same rig set-up and cooling hole schemes (Section 2.9.4), chemiluminescence data and rate of heat release has never been related to heat flux. Chemiluminescent images provide us with two sets of data: rate of heat release of the flames and spatial characteristics of the flames. Relating the rate of heat release data from chemiluminescence measurements to the heat flux data from temperature measurements presents a way to compare the spatial characteristics of the reactions to the heat flux. In this study, we are able to relate heat flux data to flame spatial characteristics and flame heat release rates. This allows for the comparison of characteristics specific to the flames to heat flux experienced by the turbine hardware. From this experimentation and data it can be directly observed what reaction characteristics cause changes in the heat flux to the surface. Also, as a result of the high speed images, flame stability can be investigated and discussed. 


\section{EXPERIMENTAL SETUP AND PROCEDURE}

The experimental arrangement comprised of a film cooling test rig mounted on top of a well stirred reactor. Fuel-rich combustion products are generated in a WSR (24, 25), flow through a transition duct, and exit through the film cooling test section. A high speed camera with filters was used to capture images.

\subsection{WELL STIRRED REACTOR}

Turbine entry conditions are simulated at the test section inlet using the fuel-rich exhaust flow produced in a WSR as designed in Ref. (26) and modified in Refs. (24) and (25). A WSR provides a nearly uniform species and temperature distribution in the reactor and at the exit due to the high rate of mixing between the incoming fresh fuel/air mixture and the products in the reactor. It is assumed that this species and temperature uniformity extends into the test section.

The reactor is composed of an upper and lower toroidal section both made of a zirconia ceramic, an Inconel jet ring, and a metal housing. Premixed air and fuel travel through the fuel-air tubes into the jet ring. The jet ring has 48 fuel-air jets which inject the mixture into the reactor toroid at a high velocity resulting in a high rate of mixing. The two toroidal sections sandwich the jet ring and form a $250 \mathrm{ml}$ internal reactor volume. Inside the reactor the fuel-air mixture react and exits through a continuous circumferential exhaust port located in the center of the reactor, which is in contrast to the 
discrete exhaust holes used by Evans (18). The port leads to a common exhaust section directing the flow upward to the test section.

The lower half of the reactor has four ports which allow for the insertion of a thermocouple, igniter, pressure tap, and gas sampling probe into the reactor. A stepper motor controls the type-B thermocouple permitting it to be raised to a desired set position within the reactor or lowered out of the reactor. The igniter is mounted on a pneumatic actuator and is lowered out of the reactor after ignition occurs. The ceramic pressure tap and sampling probe remain stationary inside the reactor. These inserts are shown in Fig. 3.1.

The jet ring sits on top of the lower toroidal section. Four thermocouples are attached to the jet ring manifold at equally spaced locations. This allows for the monitoring of excessive ring temperatures, which can be due to inadequate cooling flow, insufficient fuel-air flow, extreme internal reactor temperatures, or a crack in the reactor allowing the leakage of gases into the reactor housing. The upper toroidal section mounts on top of the jet ring. The joining of the two sections creates the continuous exhaust ports mentioned previously (Fig 3.2). 


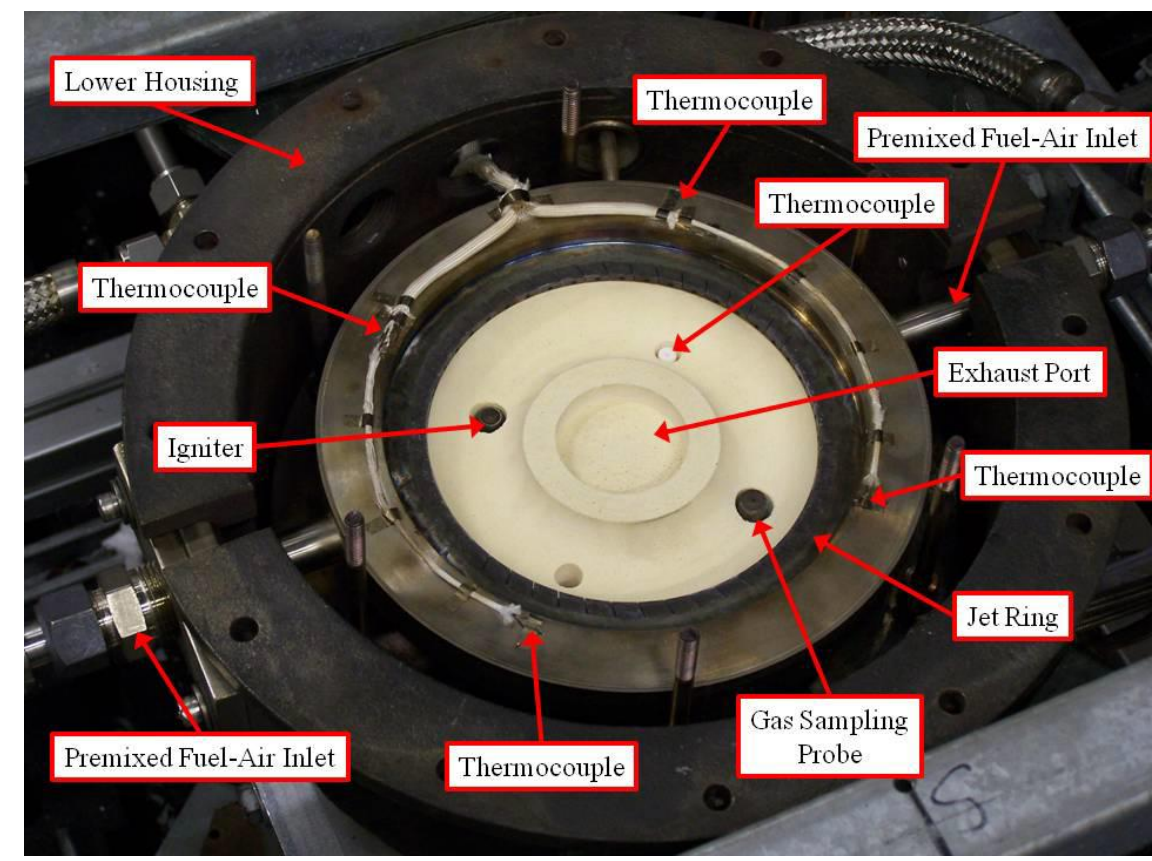

Figure 3.1 Lower half of the toroid with the jet ring in the WSR housing (19)

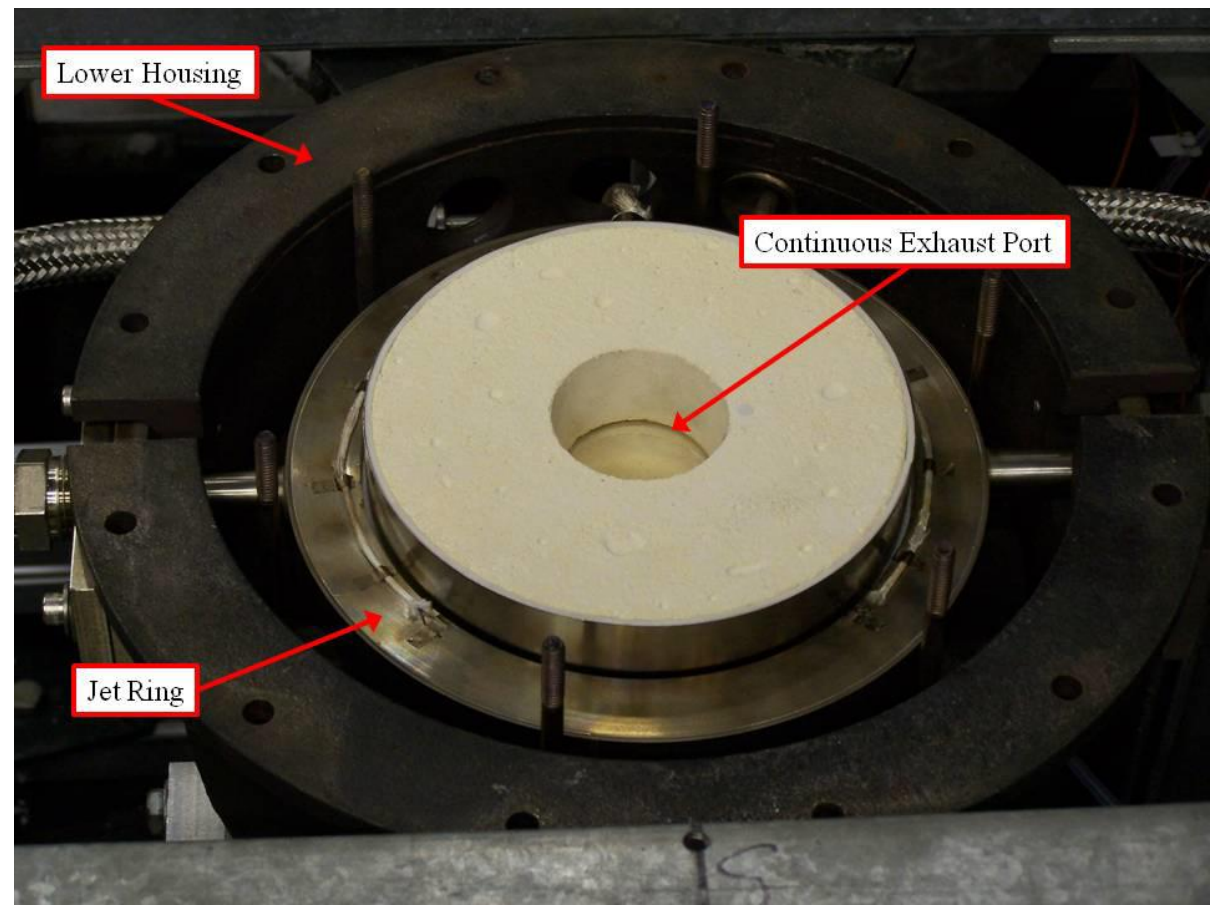

Figure 3.2 Complete toroidal set up with the jet ring in the WSR housing (19)

Two cooling rings surround the outside of the reactor, positioned above and below the jet ring. Nitrogen flows through the cooling rings and is ejected 
perpendicularly onto both the upper and lower surfaces of the jet ring manifold through a series of holes. A dual purpose is served, cooling the jet ring and filling the WSR housing with an inert gas. The WSR housing has an upper and lower portion which fit around the toroidal sections, the jet ring, and the cooling ring.

\subsection{TEST RIG}

The test rig was designed by Evans (18). It is comprised of a transition section, a test section, two cooling air assemblies, four heat transfer gauge assemblies, a window assembly, and an aft plate. Figure 3.3 shows the test rig with the various sections and assemblies labeled. The design process and geometry is described in detail in Ref. (18).

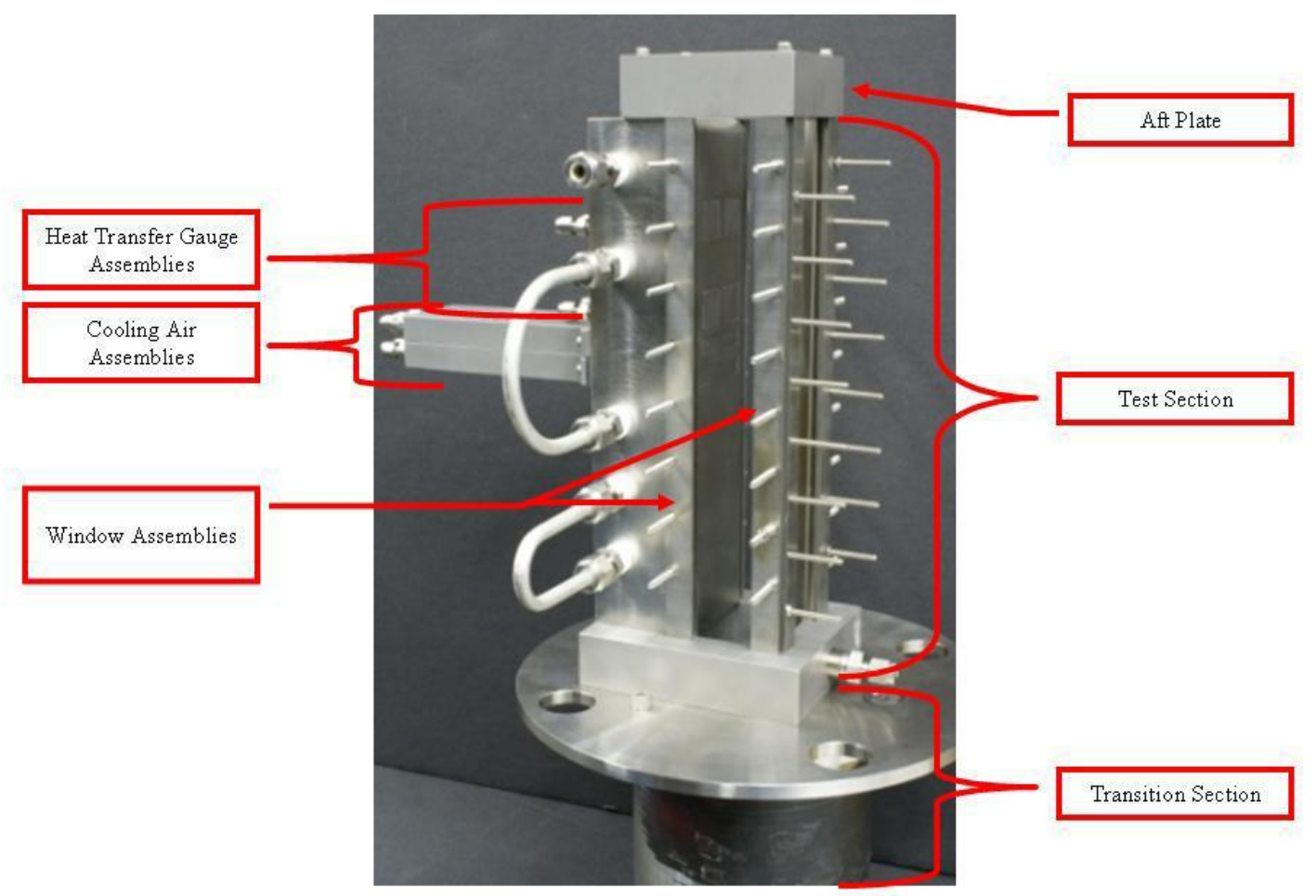

Figure 3.3 Test rig with sections identified (18) 


\subsubsection{Transition and Flow Straightening Section}

The transition section mounts on top of the WSR and is designed to smoothly transition the reactor flow from the circular exhaust to the test section geometry and eliminate separation of flow from the walls. Upstream of the transition section a flow straightening section is located to eliminated or reduce swirl in the exhaust flow. The flow straightener discs are located directly on top of the upper toroid and funnel the WSR exhaust flow directly into the transition section. Both the transition and flow straightening sections are fabricated from high-density zirconia-oxide which has a high melting point and is a good insulator.

The straightening and transition sections are held together with ceramic alignment rods and then inserted into a covering sleeve of low-density zirconia-oxide. The entire assembly is inserted into a stainless steel flange pipe and is then mounted on a plate which helps in supporting the test rig above the WSR. Figure 3.4 shows the transition section assembly. The flow straightening section is shown in Fig. 3.5

The mounting plate attaches to the WSR housing using spring supported rods, allowing for a large portion of the test rig weight to be carried by the WSR housing. The springs also accommodate any thermal expansion of the transition section. References (18) and (19) provide further images and details on the transition section design and mounting method. 


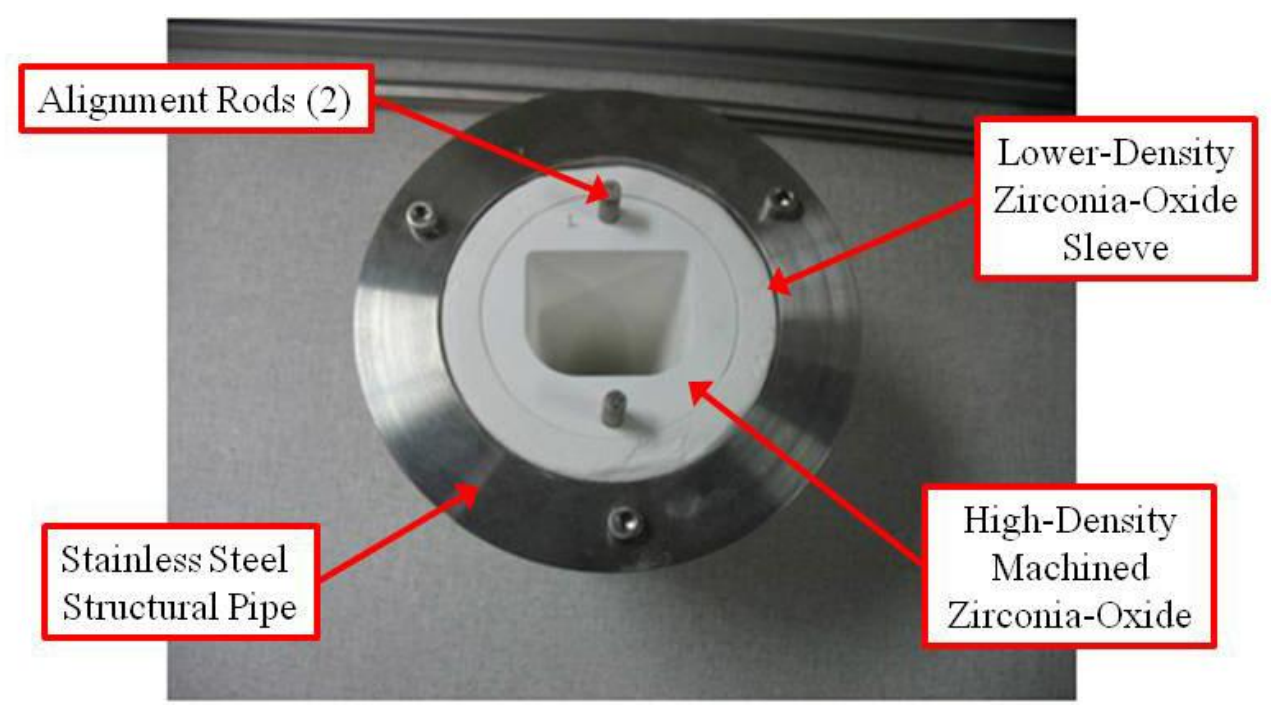

Figure 3.4 Transition section assembly (19)
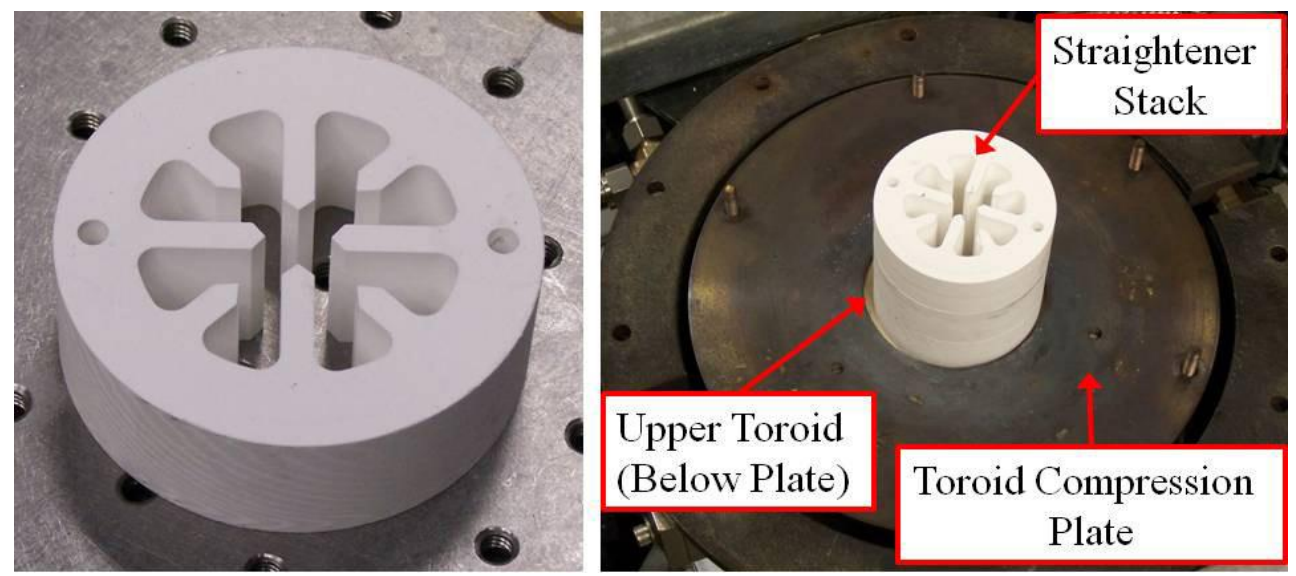

Figure 3.5 Single flow straightener disc (left) and flow straightener stack sitting on

the WSR exhaust port (right) (19)

\subsubsection{Test Section}

The test section is composed of an instrument block, a flat plate, a window assembly, and an aft plate, all made machined from Hastelloy-X. The instrument block provides access to the test section inlet flow for temperature and pressure measurement (Fig. 3.6). It also creates a forward facing step (Fig 3.7) at the inlet to the test section, tripping the incoming flow and ensuring a turbulent boundary layer at the cooling air inlet 
for all flow conditions. The forward facing step design reasoning is explained in detail in Ref. (18).

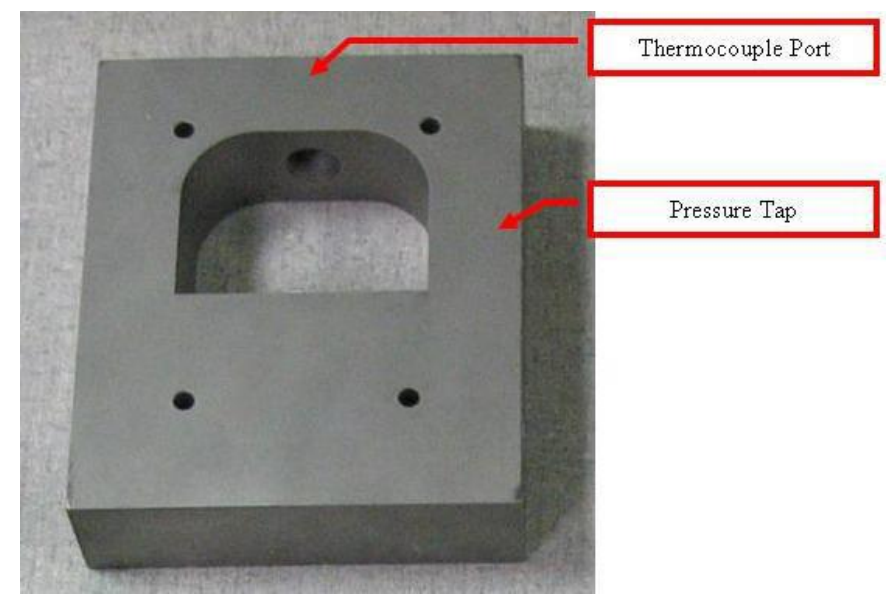

Figure 3.6 Instrument block (18)

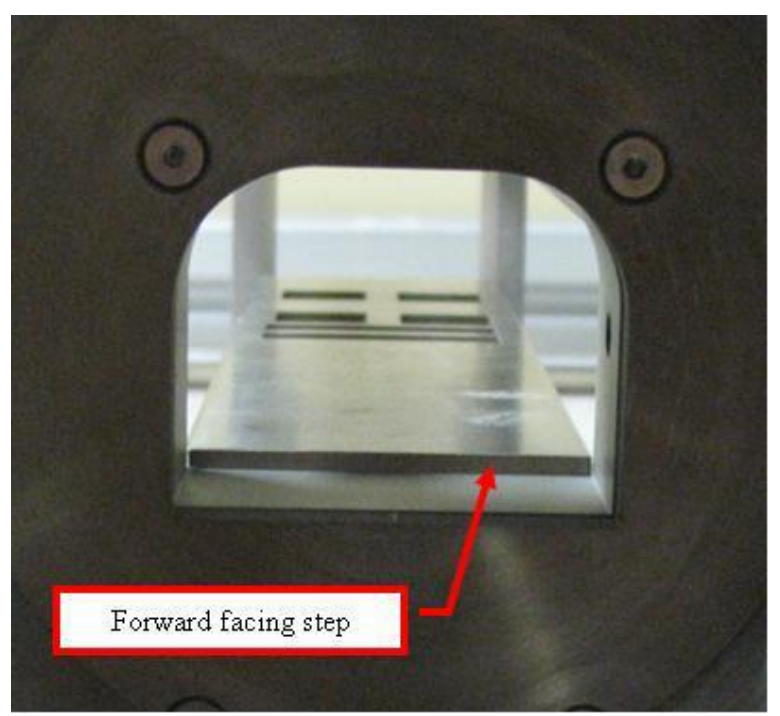

Figure 3.7 Forward facing step (18)

The flat plate design allows for the insertion of the cooling air assemblies and the heat transfer gauge assemblies into the test section. The assemblies are inserted into slots machined into the flat plate with surfaces flush to the surface of the flat plate. A schematic showing the design of the flat plate is provided in Fig. 3.8. 


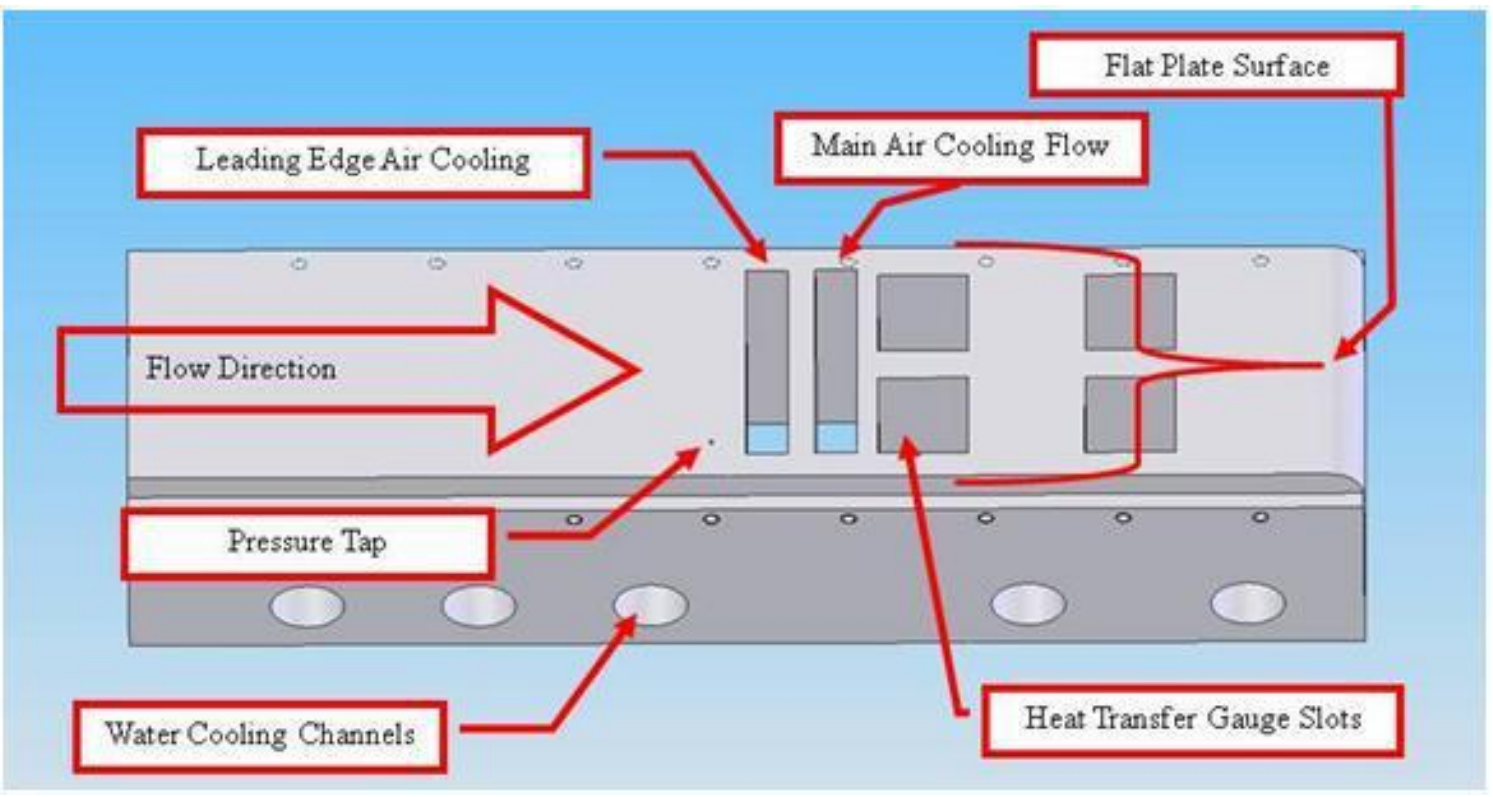

Figure 3.8 Flat plate design (18)

Due to temperature constraints of the flat plate material, cooling of the plate is necessary. Five water cooling channels, $6.4 \mathrm{~mm}$ in diameter, were machined into the flat plate. Water flows at a rate controlled by a rotometer with a needle valve through the channels in series. A type- $\mathrm{K}$ thermocouple is positioned at the water flow outlet to monitor the water temperature. The positioning of these channels and flow direction are shown in Fig 3.9. 


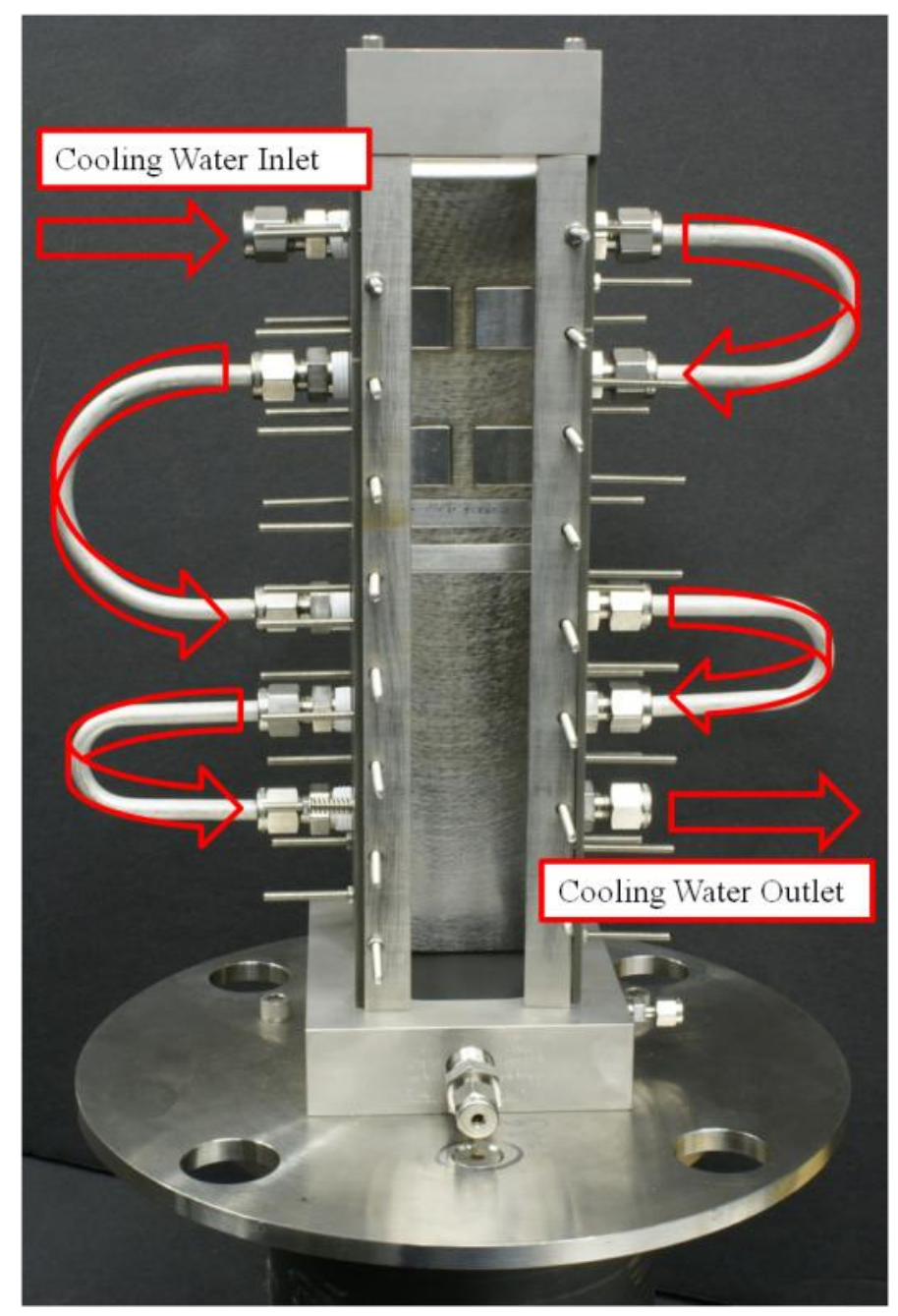

Figure 3.9 Cooling water flow direction

The viewing window assembly is comprised of window rails and window frames. The rails are held in position and attached to the aft plate instrument block by spring mounted screws. The springs take into account any thermal expansion of the rails that may occur. The window frame has hole cut into it through which the two cooling inserts can be viewed. The window frame is held against the flat plate using the rails with spring mounted nuts and threaded rods. A fused quartz window is held over the frame opening using four spring mounted nuts and threaded rods. The springs allow for thermal expansion while minimizing stress on the windows. The left and back sides of the test 
section have full length windows, held in place by rails and spring mounted nuts, allowing for tri-directional viewing of the test section.

The aft plate aids in anchoring of the window rails while shaping the exhaust flow. The cross-sectional area of the test section decreases slightly from the inlet area to the aft plate causing a small pressure drop at the exit. This pressure gradient stops fresh air from leaking into the test rig while pushing the exhaust upward, away from the test rig.

\subsubsection{Film Cooling Assemblies}

The cooling air assemblies are comprised of the plena and the cooling hole slot inserts (Fig. 3.10). Cooling air flows into the plenum, through the cooling hole insert, and into the test section. The plena are attached to the cooling hole inserts using screws and a high temperature sealant to ensure there are no leaks. Thermocouples are inserted into the plena at a location of $5.1 \mathrm{~mm}$ from the outside surface of the cooling hole inserts in order to measure the incoming temperature of the cooling air. To avoid contact with the wall, the thermocouples are placed inside a ceramic tube and held there by spotwelded shim stock. The cooling air assemblies are inserted into the flat plate and held in place by screws. 


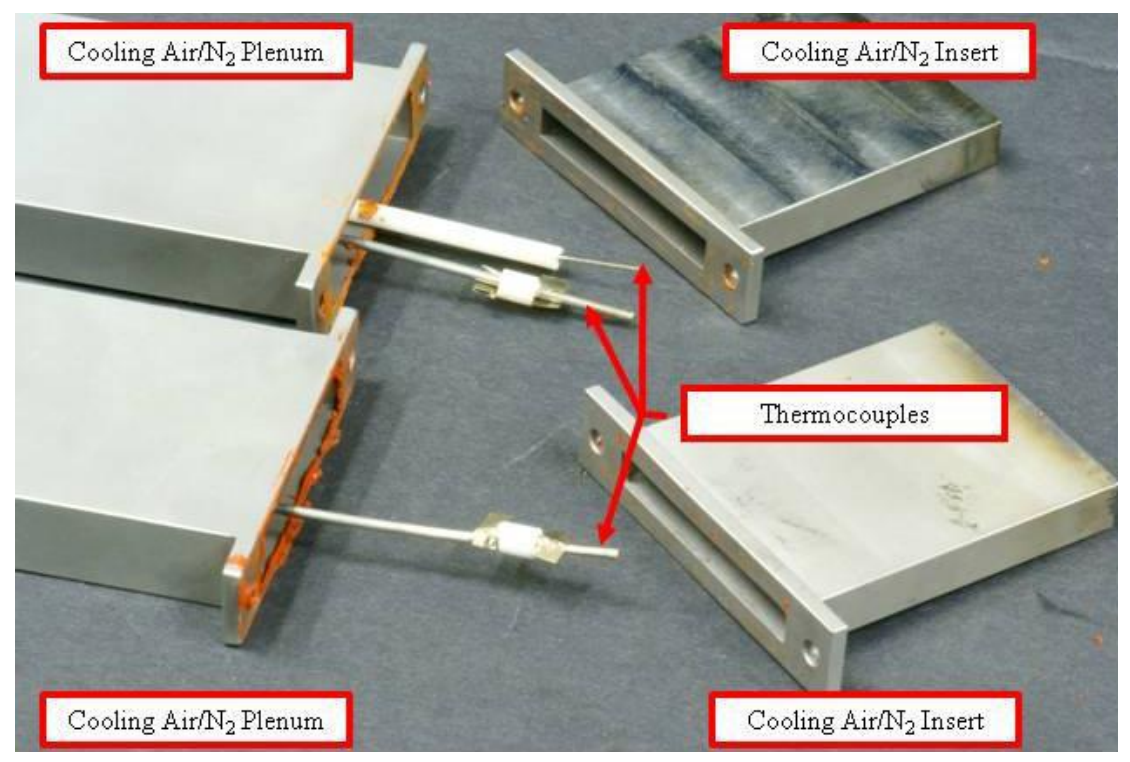

Figure 3.10 Cooling air assemblies with thermocouples inserted (18)

The various cooling hole geometries are machined into the cooling hole inserts.

Figure 3.11 shows the 3 different geometries which were used in this study, normal holes, fan shaped holes, and angled slot. The normal holes are a single row of $0.51 \mathrm{~mm}$ diameter holes, spaced $3.81 \mathrm{~mm}$ apart, and machined perpendicular through the $2.54 \mathrm{~mm}$ thick surface. The fan-shaped holes also have a $0.51 \mathrm{~mm}$ diameter, but are machined at an angle of $30^{\circ}$ to the $1.27 \mathrm{~mm}$ thick surface; at the surface the sides of the hole flare out $10^{\circ}$. The angled-slot is $0.51 \mathrm{~mm}$ by $3.81 \mathrm{~cm}$ cut at a $30^{\circ}$ angle through the $1.27 \mathrm{~mm}$ thick surface. The surfaces are different thicknesses to maintain a length-to-diameter ratio of 5 for each hole geometry. The total area of the normal holes is equal to the total area of the fan shaped holes and is about $0.003 \mathrm{~m}^{2}$. The total area of the slot is about $0.03 \mathrm{~m}^{2}$. 


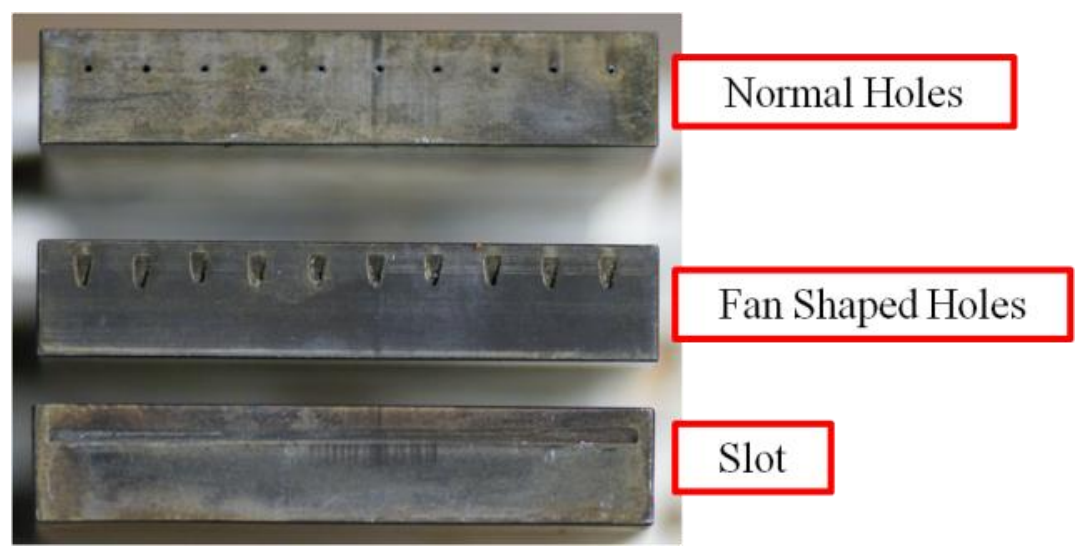

Figure 3.11 Cooling hole geometries used in this study

There are two insertion locations for the cooling hole assemblies; one upstream location and one downstream location. This allows for running experiments involving two cooling hole geometries simultaneously. A two cooling hole scheme was not investigated in this study.

\subsubsection{Heat Transfer Gauge Assemblies}

The heat transfer assemblies are composed of a heat transfer gauge block (Fig. 3.12) and mount. The gauge blocks are inserted into the flat plate and lay flush with the surface of the test section. The mount attaches the block to the outer side of the flat plate and allows for the insertion of two thermocouples. One thermocouple is inserted 11.7 $\mathrm{mm}$ into the block through a close fitting channel so it sits $3.8 \mathrm{~mm}$ from the block surface. The second thermocouple is inserted to a depth $19.1 \mathrm{~mm}$ from the block surface. The thermocouples are located at the center of the square block surface. 


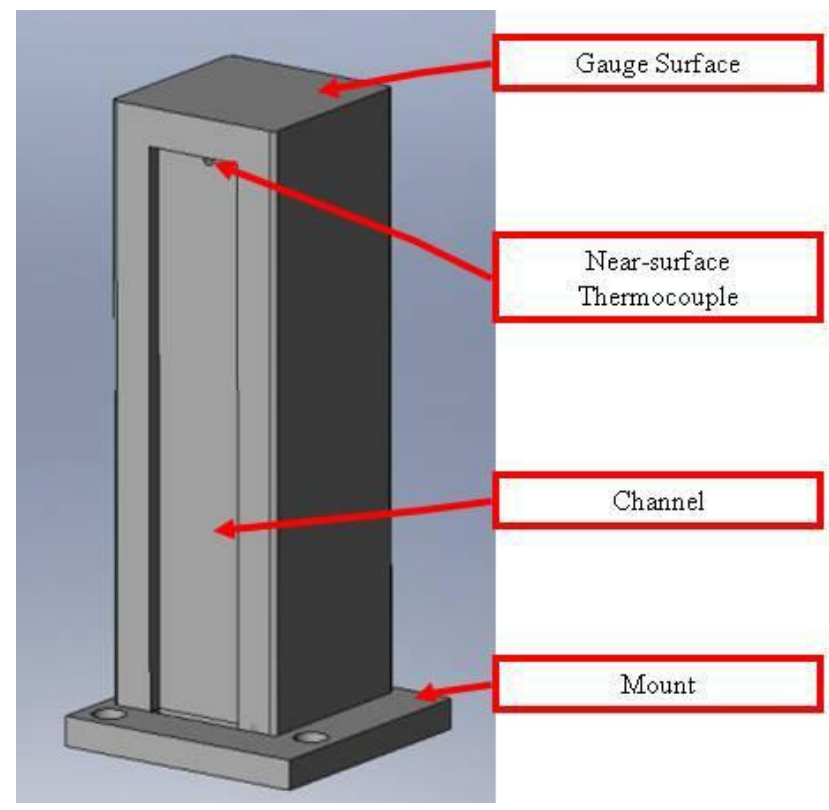

Figure 3.12 Heat transfer gauge block (18)

The four heat transfer gauge assemblies provide the capacity for calculating the heat transfer at four locations within the test section. Two upstream gauge assemblies are inserted into the flat plate at the same vertical location, so that the thermocouples are located $10.4 \mathrm{~mm}$ downstream of the cooling holes (gauges C and D). The downstream gauge assembly thermocouples are located $38.4 \mathrm{~mm}$ downstream of the cooling holes (gauges A and B). The locations of the gauges and cooling flow inserts are shown in Fig. 3.13. Assuming that there is negligible variation in the heat flux from left to right, the heat flux at the two upstream gauges should be equal and the heat flux at the two downstream gauges should be equal. The difference between gauges A and B and gauges $\mathrm{C}$ and $\mathrm{D}$ is quantified and discussed in Section 4.3. 


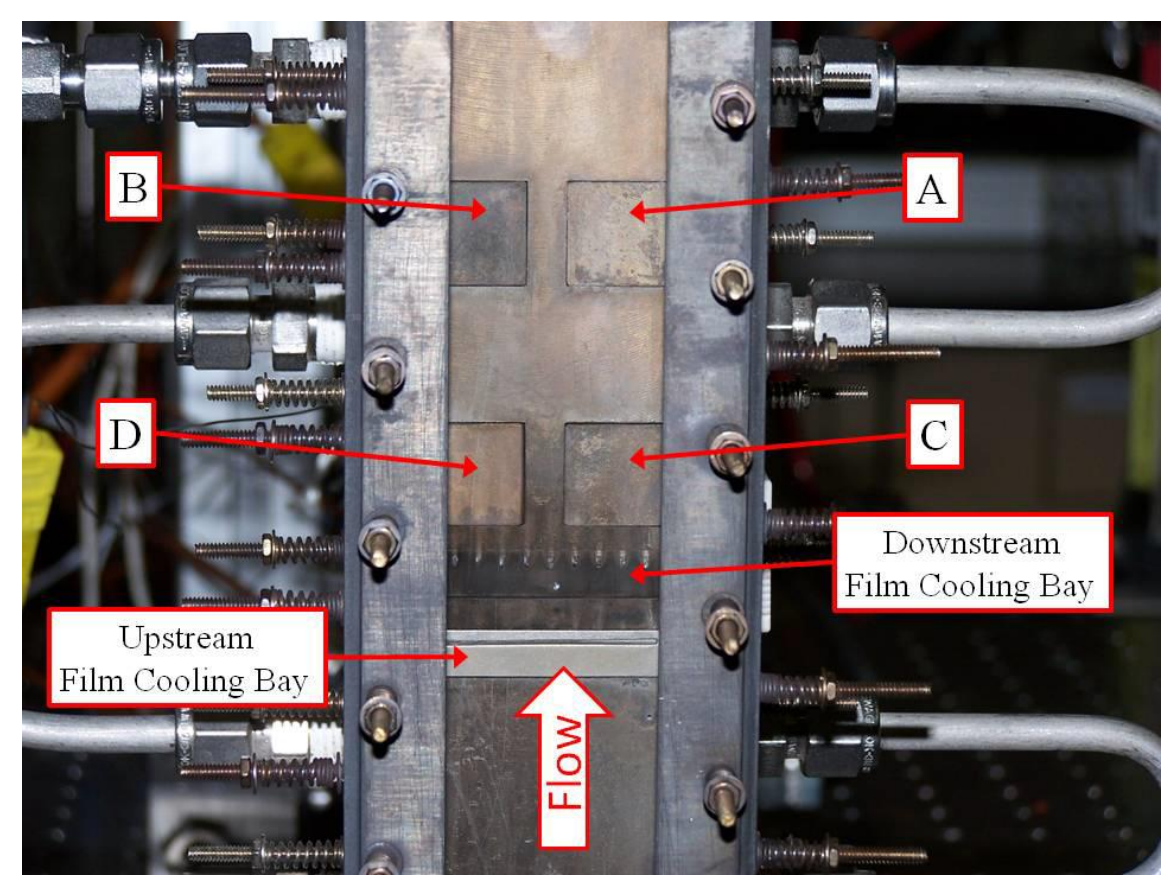

Figure 3.13 Heat transfer gauge labels and positions (19)

\subsection{CAMERA ASSEMBLY}

The camera assembly is comprised of an intensifier, a camera, a filter, and a mirror. To capture flame images and measure chemiluminescence of $\mathrm{CH}^{*}$ and $\mathrm{OH}^{*}$, a LaVision High Speed IRO camera is used. The camera is used with two filters to isolate radiation from the different radicals. An intensifier is used to enhance the brightness of the images allowing the images to be more easily viewed and analyzed. The camera is oriented parallel to the test section viewing plane and a mirror is placed at $45^{\circ}$ to the test section window and camera as shown in Fig. 3.14 as an overhead view. The view of the test section is reflected into the mirror and an image is captured by the camera. 


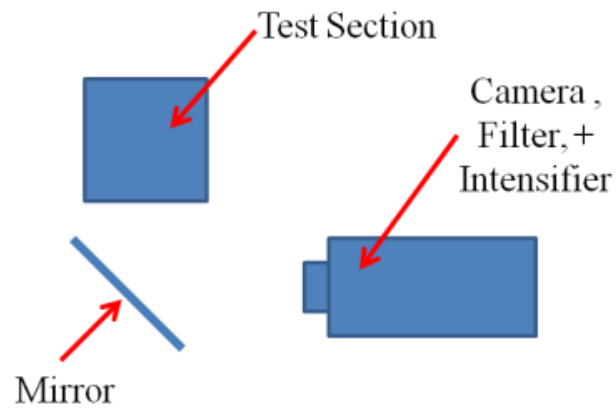

Figure 3.14 Camera assembly, mirror, and test section orientation

The images were captured at an angle, thus capturing some depth along the wall for the flame images. This was done in order to overcome space constraints in the lab and to provide some depth to the images. This angle is estimated at $30^{\circ}$. The depth captured along the test section wall allows for the viewing of two adjacent cooling jets in the case of the normal and fan shaped holes

\subsection{FUEL AND AIR CONTROL}

The WSR was supplied with propane, air, and nitrogen. The film cooling test section was supplied with air. Fuel and air are provided to the WSR for combustion. Nitrogen is supplied to the WSR housing for jet ring cooling and to flood the reactor housing through a metering valve.

The necessary air is supplied from the facility compressed air system. The combustion air passes through a thermal mass flow controller to an electric heater. The heated combustion air is joined with unheated combustion air, and are mixed together along with the fuel in the fuel-air mixer.

The upstream and downstream cooling flow plena are also supplied with air originating from the facility system. The downstream plenum cooling air is regulated using a mass flow controller and is heated using an electric heater before reaching the plenum. After flowing into the plenum air moves through the cooling holes and into the 
test section. The upstream cooling plenum can be supplied with both air and nitrogen. Air or nitrogen is chosen by the operator using the manual selector valve. In this study only air was used. The air flows through a mass flow controller, heater, the plenum, and into the test section through the cooling holes. Both air flows are controlled using the Brooks mass flow controller.

The propane is contained in $100 \mathrm{lb}(45.4 \mathrm{~kg})$ tanks located outside of the test cell. The tanks are heated by belt heaters to ensure that the propane boils adequately quickly to provide the desired fuel at these high flow rates. The gaseous propane flows from the tank, through the shutoff valve, and into the manifold, allowing for multiple tanks to provide fuel simultaneously. The fuel then passes through a regulator, through another shutoff valve at the test cell entrance, and to a thermal mass flow controller. The propane is mixed with combustion air upstream of the WSR. The uncertainty for the gaseous fuel flow measurement was previously measured to be $+/-1.5 \%$ (27).

The reactor fuel, air, and nitrogen flows are handled from the control panel. The measured signals (in $\mathrm{mA}$ ) from the mass flow controllers are processed by LabView and displayed on the screen. The only mass flow controller not connected to the data acquisition system is the film cooling air controller. As a result, the flow rates set for the film cooling are entered by hand into an Excel spreadsheet. Figure 3.15 shows the control panel, film cooling flow controller, and computers used in this study. 


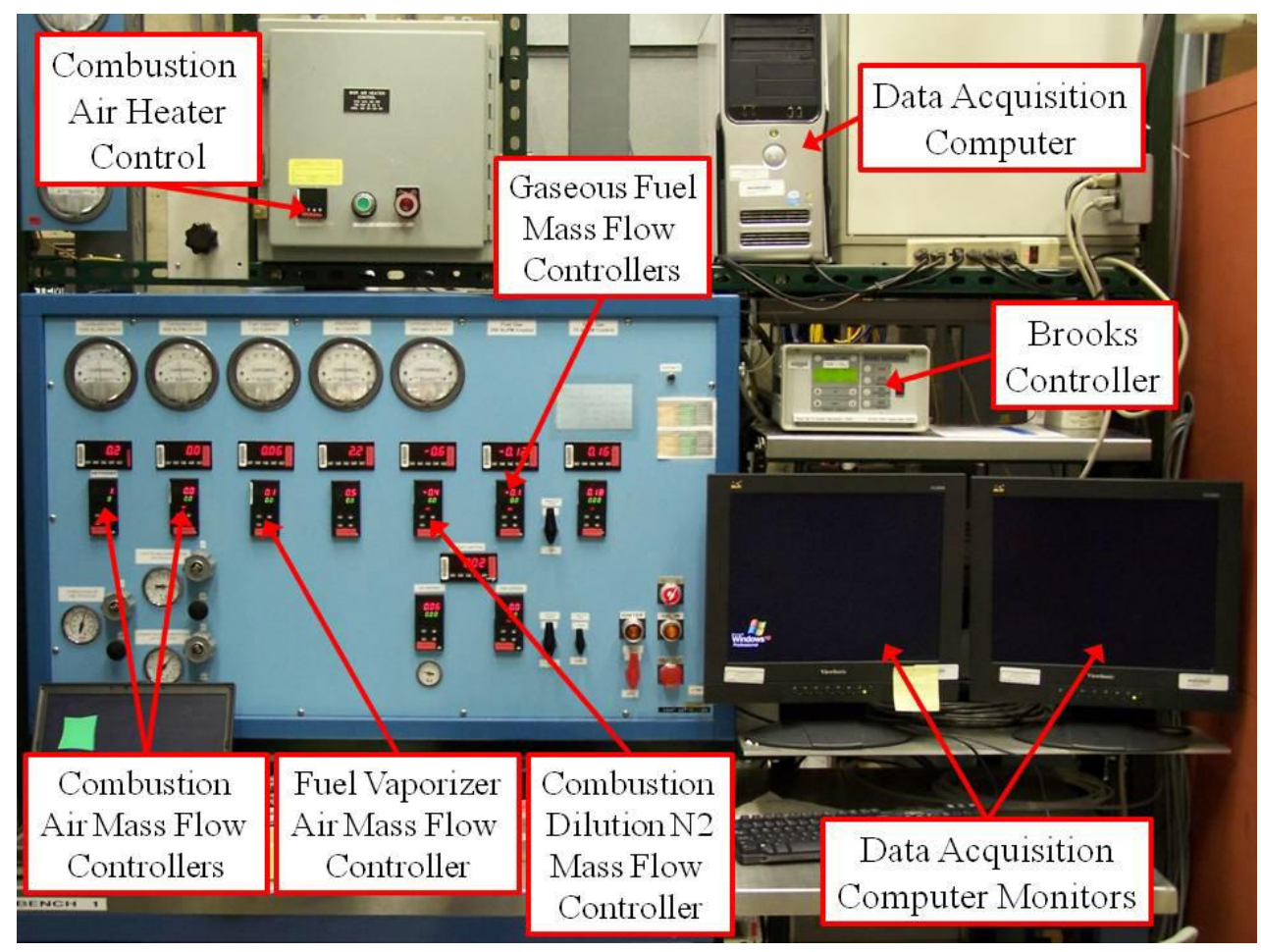

Figure 3.15 Flow controllers for air, nitrogen, and fuel supplied to the test rig and WSR (19)

\subsection{DATA ACQUISITION}

A National Instruments card/chassis is used to capture analog signals from thermocouples, mass flow controllers, and pressure transducers and converts them to digital values for analysis in LabView. A screen shot of LabView is provided in Fig. 3.16. Pressure measurements are taken at multiple locations in the rig. The locations of thermocouples and pressure transducers are presented in Ref. (18). The converted data from LabView is output into text files which can be opened in Excel for processing. 


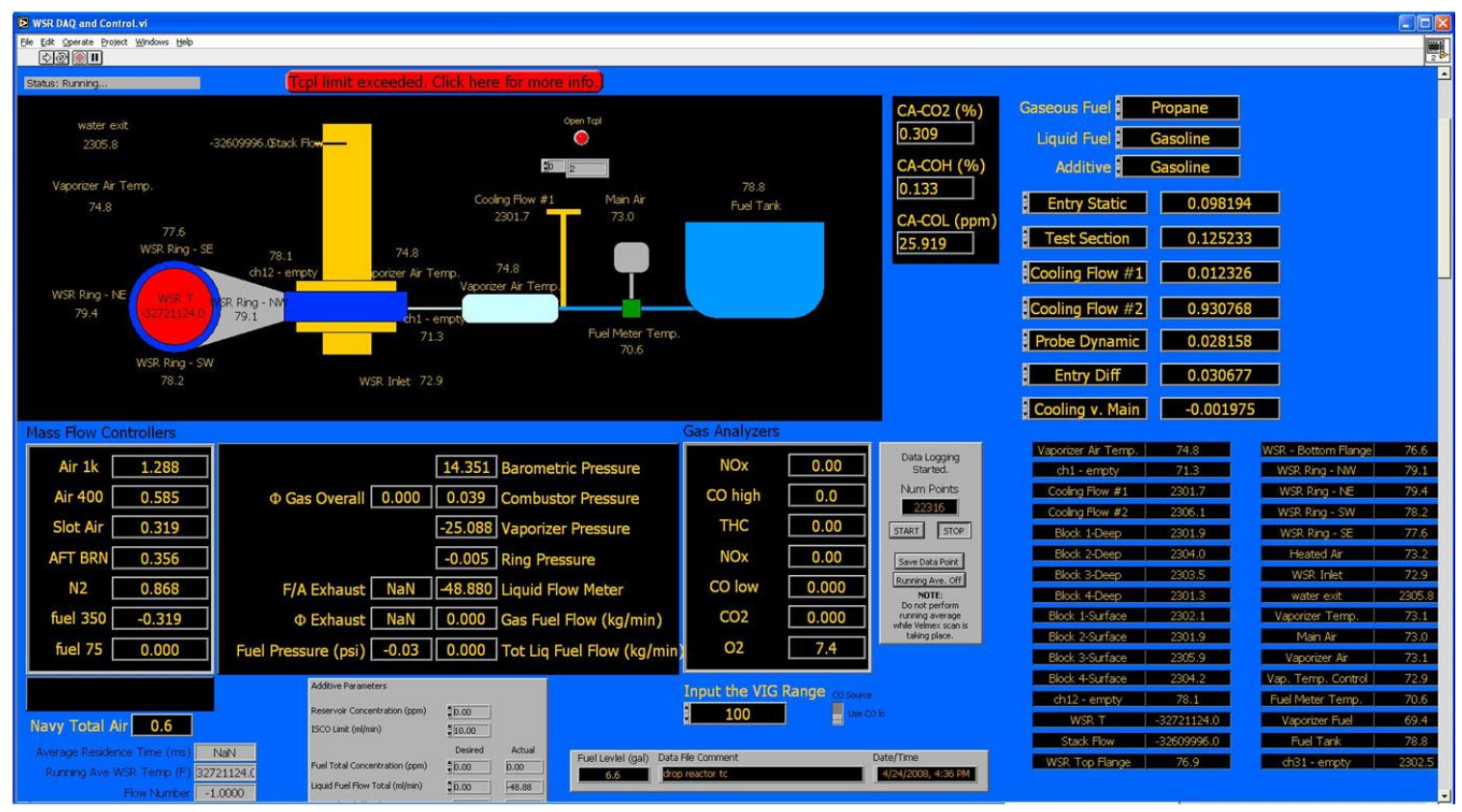

Figure 3.16 LabView screen shot (19)

\subsection{TEST PLAN AND PROCEDURE}

About one hour before light-off of the reactor, heated air flow is started through

the reactor. The heated air raises the temperature of the reactor to about $420 \mathrm{~K}$, making ignition occur easier and easing the shock on the ceramic components. Electric belt heaters on the propane tanks are turned on, allowing the propane to reach adequate pressure to provide the desired fuel flow. The test rig water supply is turned on several minutes before light-off. The data acquisition software is also started.

Once the reactor is ready for ignition, the air and fuel flow are increased to the desired flow rates while the igniter is simultaneously held on until ignition occurs. The reactor is lit at an equivalence ratio below stoichiometric around $\Phi=0.6$. After light-off the reactor is allowed to heat up reaching a steady state. The amount of fuel is set to achieve the desired equivalence ratio. Once the desired equivalence ratio is reached, the reactor is allowed to settle out to a constant temperature. After a steady state is reached 
at the desired equivalence ratio, the cooling air flow is started at the necessary flow rate based on the desired blowing ratio.

The air flow into the WSR was fixed at 425 SLPM (510 g/min) using a thermal flow controller. The fuel flow rate was varied to achieve desired fuel-rich equivalence ratios, $\Phi$, of 1.3, 1.4, and 1.5. Different blowing ratios, $M$, of the cooling air were investigated for each of the three equivalence ratios. Table 3.1 provides the test matrix for this study. Images were taken at these data points for both the $\mathrm{CH}^{*}$ filter and $\mathrm{OH}^{*}$ filter.

Table 3.1 Test Matrix

\begin{tabular}{|c|c|c|c|c|c|c|c|}
\hline Point & \multicolumn{2}{|c|}{ Normal Holes (N) } & \multicolumn{2}{c|}{ Fan Shaped Holes (F) } & \multicolumn{2}{c|}{ Slot (S) } & Figures \\
\hline & $\begin{array}{c}\text { Equivalence } \\
\text { Ratio }\end{array}$ & $\begin{array}{c}\text { Blowing } \\
\text { Ratio }\end{array}$ & $\begin{array}{c}\text { Equivalence } \\
\text { Ratio }\end{array}$ & $\begin{array}{c}\text { Blowing } \\
\text { Ratio }\end{array}$ & $\begin{array}{c}\text { Equivalence } \\
\text { Ratio }\end{array}$ & $\begin{array}{c}\text { Blowing } \\
\text { Ratio }\end{array}$ & \\
\hline $\mathbf{1}$ & 1.3 & 1 & 1.3 & 1 & 1.3 & 1 & 4.25 \\
\hline $\mathbf{2}$ & 1.3 & 2 & 1.3 & 2 & 1.3 & 2 & 4.27 \\
\hline $\mathbf{3}$ & 1.3 & 3 & 1.3 & 3 & 1.3 & 3 & 4.29 \\
\hline $\mathbf{4}$ & 1.3 & 4 & 1.3 & 4 & 1.3 & 4 & 4.31 \\
\hline $\mathbf{5}$ & 1.3 & 5 & 1.3 & 5 & 1.3 & 5 & 4.33 \\
\hline $\mathbf{6}$ & 1.3 & 7 & 1.3 & 7 & 1.3 & 7 & 4.35 \\
\hline $\mathbf{7}$ & 1.4 & 1 & 1.4 & 1 & 1.4 & 1 & 4.37 \\
\hline $\mathbf{8}$ & 1.4 & 4 & 1.4 & 4 & 1.4 & 4 & 4.39 \\
\hline $\mathbf{9}$ & 1.4 & 7 & 1.4 & 7 & 1.4 & 7 & 4.41 \\
\hline $\mathbf{1 0}$ & 1.5 & 1 & 1.5 & 1 & 1.5 & 1 & 4.43 \\
\hline $\mathbf{1 1}$ & 1.5 & 4 & 1.5 & 4 & 1.5 & 4 & 4.45 \\
\hline $\mathbf{1 2}$ & 1.5 & 7 & 1.5 & 7 & 1.5 & 7 & 4.47 \\
\hline
\end{tabular}

Previous studies carried out using the same test rig (see Section 2.9.4) used some similar test points. Evans (18) gathered data at both fuel-lean and fuel-rich equivalence ratios. The fuel-rich equivalence ratios, which will most closely compare to the points in this study, were 1.5, 1.6, and 1.7. The geometries studied included both the normal and fan shaped holes. The air was at a higher mass flow rate of either 850 SLPM (1020 $\mathrm{g} / \mathrm{min})$ or $600 \mathrm{SLPM}(720 \mathrm{~g} / \mathrm{min})$. A lower flow rate was decided upon for the study 
presented in this thesis to lower the thermal and aerodynamic stresses on the WSR and test rig.

Bohan (19) studied both single cooling schemes and cooling schemes in series, with both air and nitrogen as the cooling flow. Again, fuel-lean and fuel-rich data was gathered. The fuel-rich equivalence ratios were 1.1, 1.3, and 1.5, which compare more closely to the test conditions for the study in this paper. The air flow rate into the WSR was set to 425 SLPM (510 g/min) matching the air flow rate for the experiments presented in this thesis. The blowing ratios tested in by Bohan (19) were 0.5, 1, 2, 3, and 4. The blowing ratios in this thesis include some of the points considered previously and extend up to additional higher values $(M=5$ and $M=7)$.

The flow temperatures at the inlet to the test section $(12 \mathrm{~cm}$ upstream of air jet) range from $1660 \mathrm{~K}$ at an equivalence ratio of 1.5 to $1750 \mathrm{~K}$ at an equivalence ratio of 1.3 . The Reynolds number of the flow at the inlet to the test section was approximately 4000 assuming air properties and a diameter of $4.3 \mathrm{~cm}$. The average coolant air temperature is approximately $600 \mathrm{~K}$.

\subsection{IMAGE CAPTURE AND IMAGE PROCESSING SOFTWARE}

Images are captured by the camera and stored as a ".im7" file extension which can be read by DaVis software. The images are processed using DaVis camera software, a program offered by LaVision (28). This program is used for various applications including laser imaging of reactive and non-reactive flow fields and high speed imaging. DaVis has many functions available for image processing such as image subtraction, rotation, averaging, re-scaling, calibration, etc. 
One thousand images are captured at each test condition at a frequency of 1000 Hz. Background images were taken for each cooling scheme at each equivalence ratio with no cooling air flow. This allows for the subtraction of any background intensity present in the test section due to the vitiated freestream flow. The chemiluminescence intensity viewed in the images is due solely to the reaction resulting from the injection of film cooling air. An average of each set of 1000 images is taken and an average of the coordinating background image is subtracted.

A calibration image of a dot-plot of known measurements ( $2 \mathrm{~mm}$ dot spacing with $0.75 \mathrm{~mm}$ diameter dots) placed inside the test section is captured at the same camera settings and location as the experimental images. This allows for the geometric calibration of all images from a pixel scale to a millimeter scale.

For averaged images a color scheme is applied showing the chemiluminescence intensity of the flames. Each color equates to a numerical value of intensity applied by the software. Once images are averaged and oriented correctly, the pivmat (29) toolbox for MATLAB is used to export the raw DaVis images to MATLAB for further numerical processing and quantitative comparison. The exported files can be opened as images or as numerical arrays in MATLAB, allowing for plotting, comparison, and analysis of trends for $\mathrm{OH}$ and $\mathrm{CH}$ chemiluminescence, $\mathrm{OH} / \mathrm{CH}$ ratios, and physical flame characteristics. 


\section{EXPERIMENTAL RESULTS AND DISCUSSION}

\subsection{HIGH SPEED IMAGES AND STABILITY}

One thousand chemiluminescence images were taken with a high speed camera at each test point. Figure 4.1 provides 4 adjacent camera frames taken using the $\mathrm{OH}$ filter and high speed camera for the normal holes at a freestream equivalence ratio of 1.4 and a blowing ratio of 4 . From these images it appears that the flames are generally stable. There appears to be some fluctuation in the flame location and shape from frame to frame. High speed images the flames were viewed in quick succession and it was seen that the main flame region remains in the same position, with small fluctuation from frame to frame.

The stability of the flames can be quantified through calculation of the normalized standard deviation (standard deviation/average intensity value) between each of the 1000 images taken for each test point. This was accomplished using a MATLAB program. It

was found that in general the normalized standard deviation of the points within the flame region was generally small. Outside the flame region a lot of noise was experienced (because the signal to noise ratio of the non reacting region was low), but this region is not important to this study. For each geometry at each equivalence ratio at a blowing ratio of 1 , the steady flame region was small. Yet a steady flame region (i.e. small standard deviation between images) still exists for this low blowing ratio. At all other 
blowing ratio conditions the steady flame region was comparable in size to the area of the flame in the chemiluminescence images. Figure 4.2 (falsely colored MATLAB image) shows an example of a large region at which the standard deviation between photon count values of the 1000 images is under 0.2. Similar flame stability results were seen at other conditions for both $\mathrm{OH}^{*}$ and $\mathrm{CH}^{*}$ chemiluminescence images.

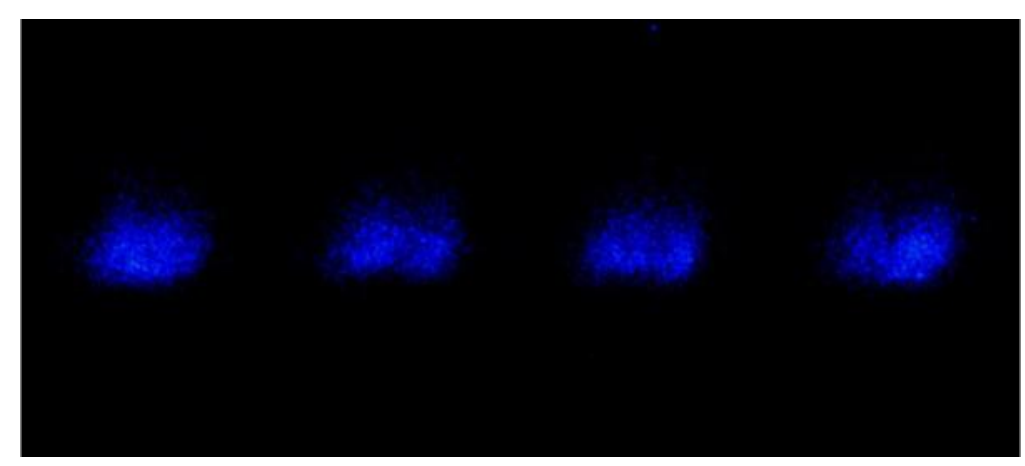

Figure 4.1 Four successive $O H$ chemiluminescence images, $\Phi=1.4, M=4$, normal holes

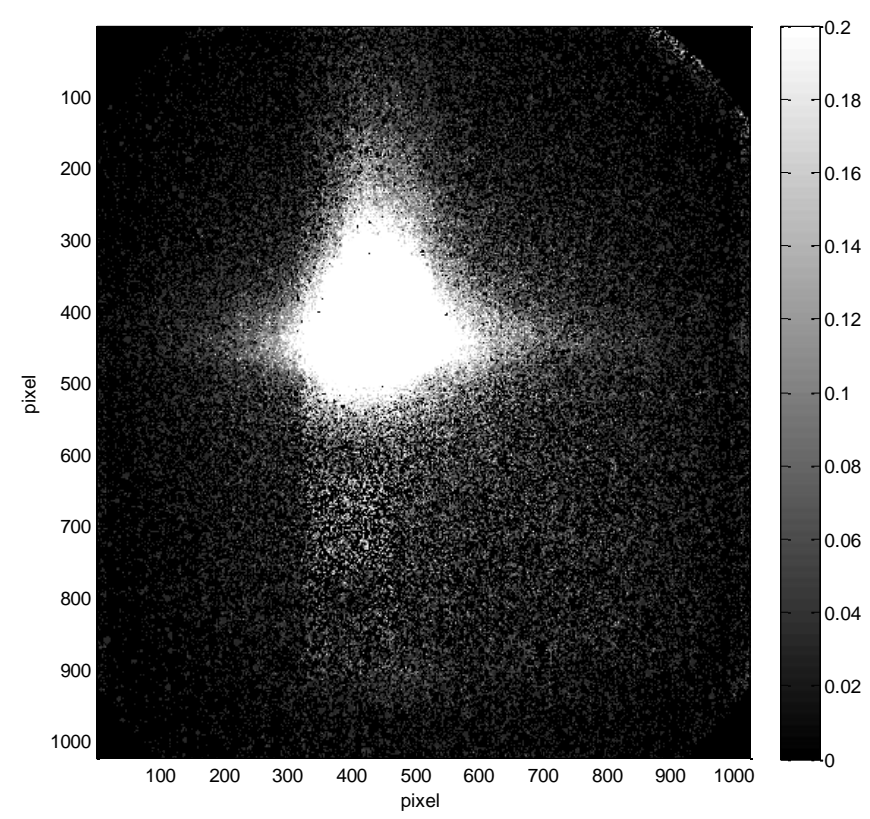

Figure 4.2 Flame normalized standard deviation for 1000 images, $\mathrm{OH} *, \Phi=1.4, \mathrm{M}$ $=4$, normal holes 


\subsection{CHEMILUMINESCENCE EMISSIONS - OH* AND CH*}

1000 high speed $\mathrm{CH}^{*}$ and $\mathrm{OH}^{*}$ chemiluminescence emission images were taken at each test point. Each set of 1000 images were combined and averaged resulting in a single image. These single averaged images are used to compare chemiluminescence emission trends for the test points. Figure 4.3 show an average image resulting from 1000 images. These averaged DaVis images were then exported to MATLAB as grayscale images for pixel intensity investigation. An example MATLAB image with the pixel intensity count scale is provided as Fig. 4.4.

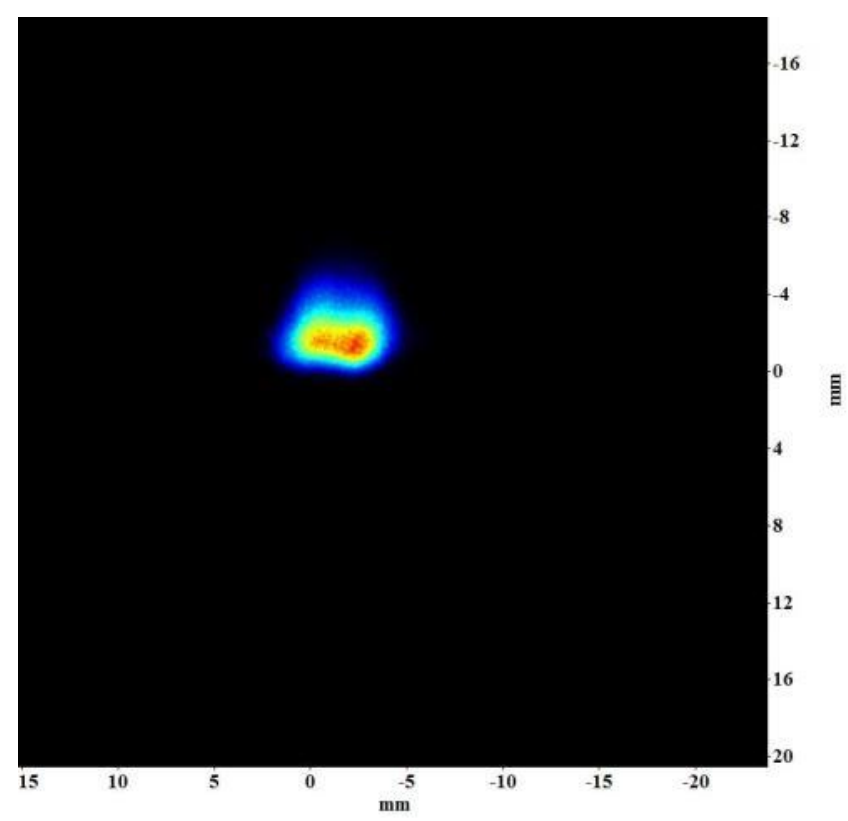

Figure 4.3 DaVis average chemiluminescence emissions image; $\mathrm{OH}^{*}, \Phi=1.4, \mathrm{M}=4$, normal holes 


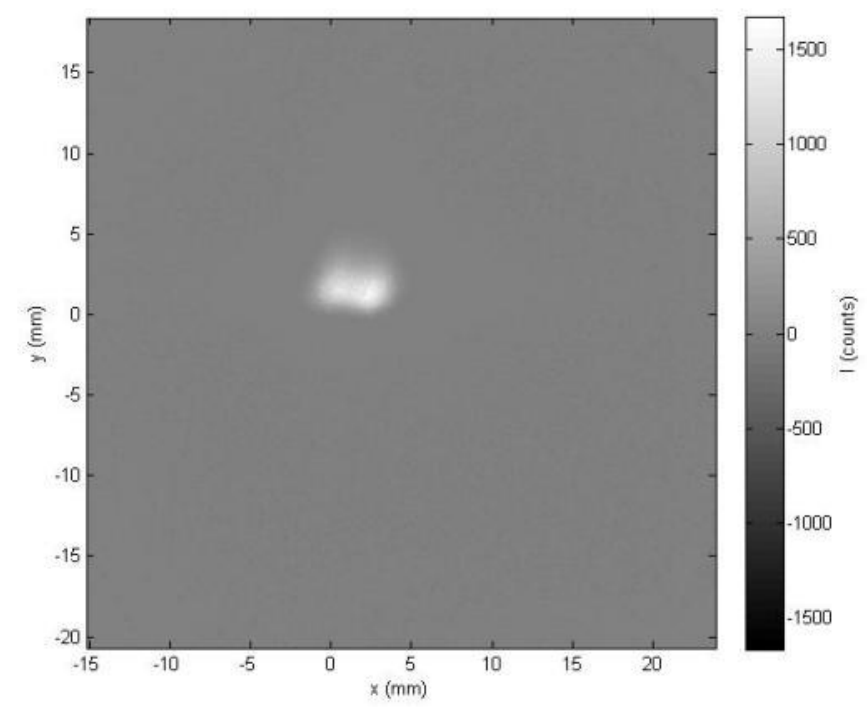

Figure 4.4 MATLAB chemiluminescence emissions image; $O H^{*}, \Phi=1.4, M=4$, normal holes

For the images presented in this study, the origin along the ordinate axis represents the vertical coolant flow injection location and the origin along the abscissa axis is located at the center of the injection surface. Plots are created from the photon counts of the chemiluminescence images. The maximum chemiluminescent value at each axial row across the image and the average (averaged across the width of the flame image) chemiluminescent values at each axial row of pixels on the flame image are plotted. For these plots, the abscissa is the height above (positive) or below (negative) the injection location, and the ordinate axis is the chemiluminescent photon count value. In the following sections, trends are investigated for the different blowing ratios and the three geometries (normal, fan, and slot). 


\subsection{1. $\mathrm{OH}^{*}$ versus $\mathrm{CH}^{*}$}

Chemiluminescence images were captured using two different filters, one for $\mathrm{CH}^{*}$ and one for $\mathrm{OH}^{*}$. Both $\mathrm{CH}^{*}$ and $\mathrm{OH}^{*}$ are radicals present in combustion and are thus good flame indicators, as discussed previously in Section 2.6. The trends of $\mathrm{OH}^{*}$ versus $\mathrm{CH}^{*}$ were compare and found to be the same. $\mathrm{OH}^{*}$ has higher photon count values so the images are easier to view. This is due to the intensifier which picks up the wavelength of the $\mathrm{OH}^{*}$ emissions more effectively than that of the $\mathrm{CH}^{*}$ emissions. The $\mathrm{OH}^{*}$ images and plots are presented in the following sections as trends are discussed and analyzed. The $\mathrm{CH}^{*}$ average photon count plots are presented in Appendix B. Figures 4.5 and 4.6 show the flame images and average photon count plots respectively at the same equivalence ratio, blowing ratio, and geometry for $\mathrm{OH}^{*}$ and $\mathrm{CH}^{*}$ filters, illustrating the difference in brightness.
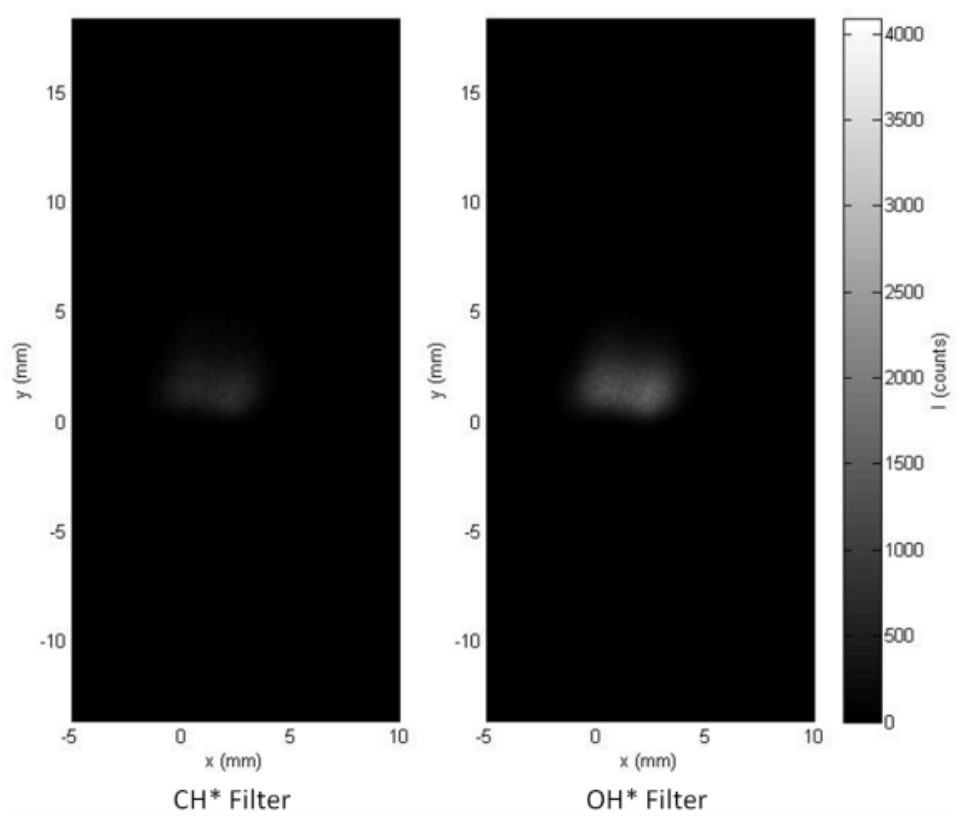

Figure 4.5 $\mathrm{OH}^{*}$ versus $\mathrm{CH}^{*}$ chemiluminescence images at $\Phi=1.4, \mathrm{M}=4$, normal holes 


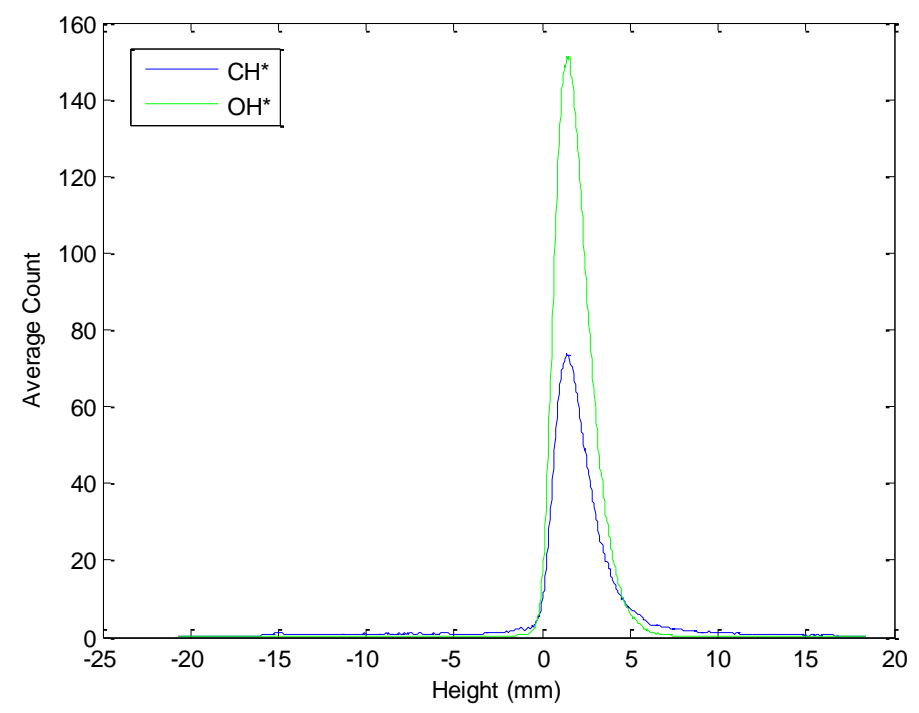

Figure 4.6 CH* versus $\mathrm{OH}^{*}$ chemiluminescence average photon count plots, $\Phi=$

\section{4, $M=4$, normal holes}

\subsubsection{Blowing Ratio Comparison}

Images and plots are presented for the $\mathrm{OH}^{*}$ filter comparing blowing ratio trends for each geometry and equivalence ratio. Table 4.1 provides an overview of the results presented in this section, where "N" denotes normal holes, "F" denotes fan shaped holes, and "S" denotes slot. The trends for chemiluminescence intensity and origination point of the flame are presented based on blowing ratios 1 through 7.

Table 4.1 Summary of blowing ratio comparison results for chemiluminescence data

\begin{tabular}{|c|c|c|c|}
\hline Ge ome try & $\begin{array}{c}\text { Equivalence } \\
\text { Ratio }\end{array}$ & Chemilumine scence & Flame Origination \\
\hline $\mathrm{N}$ & 1.3 & $1>2>3>4>5>7$ & $7,5,4,3,2,1$ \\
\hline $\mathrm{N}$ & 1.4 & $1>4>7$ & $7,4,1$ \\
\hline $\mathrm{N}$ & 1.5 & $1>4>7$ & $7,4,1$ \\
\hline $\mathrm{F}$ & 1.3 & $1>2>3>4>5>7$ & $1,2,3,4,5,7$ \\
\hline $\mathrm{F}$ & 1.4 & $1>4>7$ & $1,4,7$ \\
\hline $\mathrm{F}$ & 1.5 & $1>4>7$ & $1,4,7$ \\
\hline $\mathrm{S}$ & 1.3 & $1>2>3>4>5>7$ & $1,2,3,4,7,5$ \\
\hline $\mathrm{S}$ & 1.4 & $1>4>7$ & $1,7,4$ \\
\hline $\mathrm{S}$ & 1.5 & $1>4>7$ & $1,7,4$ \\
\hline
\end{tabular}




\subsubsection{Normal Holes}

Figures $4.7,4.8$, and 4.9 provide the averaged chemiluminescence images from MATLAB. These figures aid in the investigation of chemiluminescence emission intensity and flame location and shape. It was found that as blowing ratio increases the length and width of the flame increases. Note from Fig. 4.7 the length of the flame increases from less than $5 \mathrm{~mm}$ at $M=1$ to around $10 \mathrm{~mm}$ at $M=7$; the flame width also increases with blowing ratio from less than $5 \mathrm{~mm}$ at $M=1$ to just over $5 \mathrm{~mm}$ at $M=7$. It is understandable then that the size of the reaction increases as the amount of oxidizer present grows.

The average chemiluminescence emission also increases with blowing ratio, as shown in Figs. 4.10, 4.11, and 4.12. Note that the brightness of the flame increases as the blowing ratio does. The brightest spot in each flame appears to occur just downstream of the injection location at the center of the reaction region. The chemiluminescence emission then tapers off downstream in the flame. Because chemiluminescence can be equated to rate of heat release, we see that the rate of heat release increases with increasing blowing ratio. The highest heat release occurs where the emission intensity is largest, just downstream of the injection location.

This effect is most likely due to the fact that an increase in blowing ratio equates to an increase in coolant mass flow rate. This increase in mass flow rate is an increase in oxidizer available for reaction with the unburned fuel in the vitiated flow. At equivalence ratios of $1.3,1.4$, and 1.5 , the amount of fuel present in the freestream flow is such that introducing more oxidizer leads to a higher rate of heat release from the reaction. 
It was observed that at a blowing ratio of 1 the flame image is faint, regardless of the equivalence ratio. It appears that the amount of oxidizer in the flow is not adequate in comparison to the amount of fuel to cause a large reaction at these low coolant flow rates. This effect could also be a function of the amount of mixing that occurs. At low blowing ratios the coolant flow may not mix as thoroughly with the freestream flow resulting in smaller flame volumes.

In the flame images it is also seen that there appear to be two separate flames, which grow together as the blowing ratio increases at each equivalence ratio. These two flames are a function of the discrete cooling holes. At lower blowing ratios the coolant flow exits the holes with adequately low mass flow that each discrete jet exiting each hole does not mix with the other jets as completely. As the blowing ratio increases, the mixing between each jet increases.

In the chemiluminescence photon count plots (Figs. 4.10, 4.11, and 4.12) we see that a peak average intensity is experienced just downstream of the injection location. The shapes of the emissions curves are the same regardless of blowing ratio; they peak at the injection location and then decrease as distance downstream increases.

No matter the blowing ratio, the peak average intensity appears to be in the same location for each flame. Though the value increases, the location does not change significantly. It seems that the majority of the reaction takes place very close to the injection location. The coolant air reacts with the vitiated flow almost immediately after it is injected. The largest rate of heat release takes place at this peak emission location. The normal holes inject flow normal to the freestream flow. It is plausible that the air injected through the normal holes immediately comes in contact with the vitiated flow 
because it originally has a nonexistent tangential velocity component. Rather all the flow initially travels normal to the freestream causing the air to almost immediately meet with the fuel in the freestream flow and react. The blowing ratio has little effect on the location of the flame because of the extreme angle at which the flow is injected. 

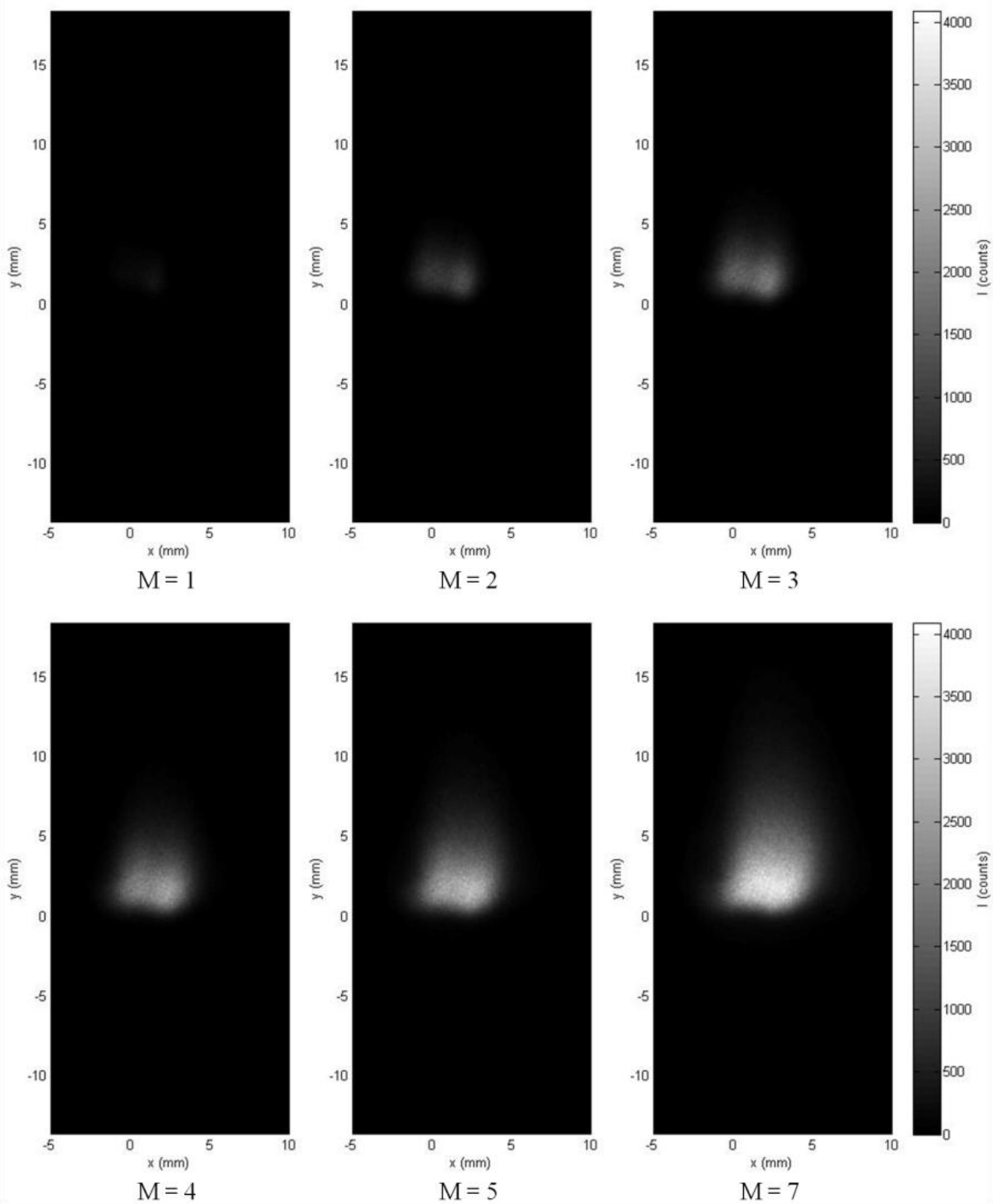

Figure 4.7 $\mathrm{OH}^{*}$ chemiluminescence images at blowing ratios, $\Phi=1.3$, normal holes 

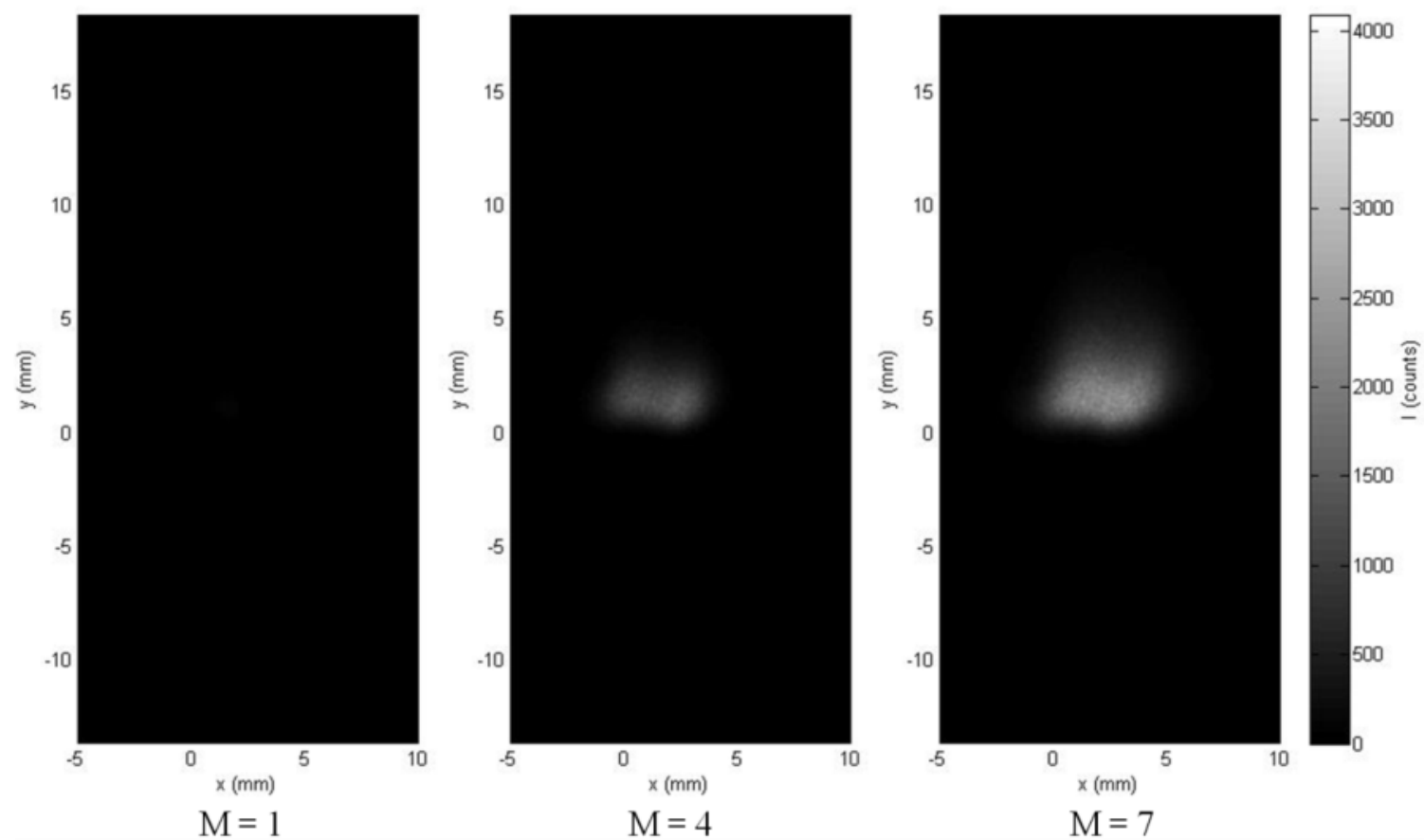

Figure 4.8 OH* chemiluminescence images at blowing ratios, $\Phi=1.4$, normal holes
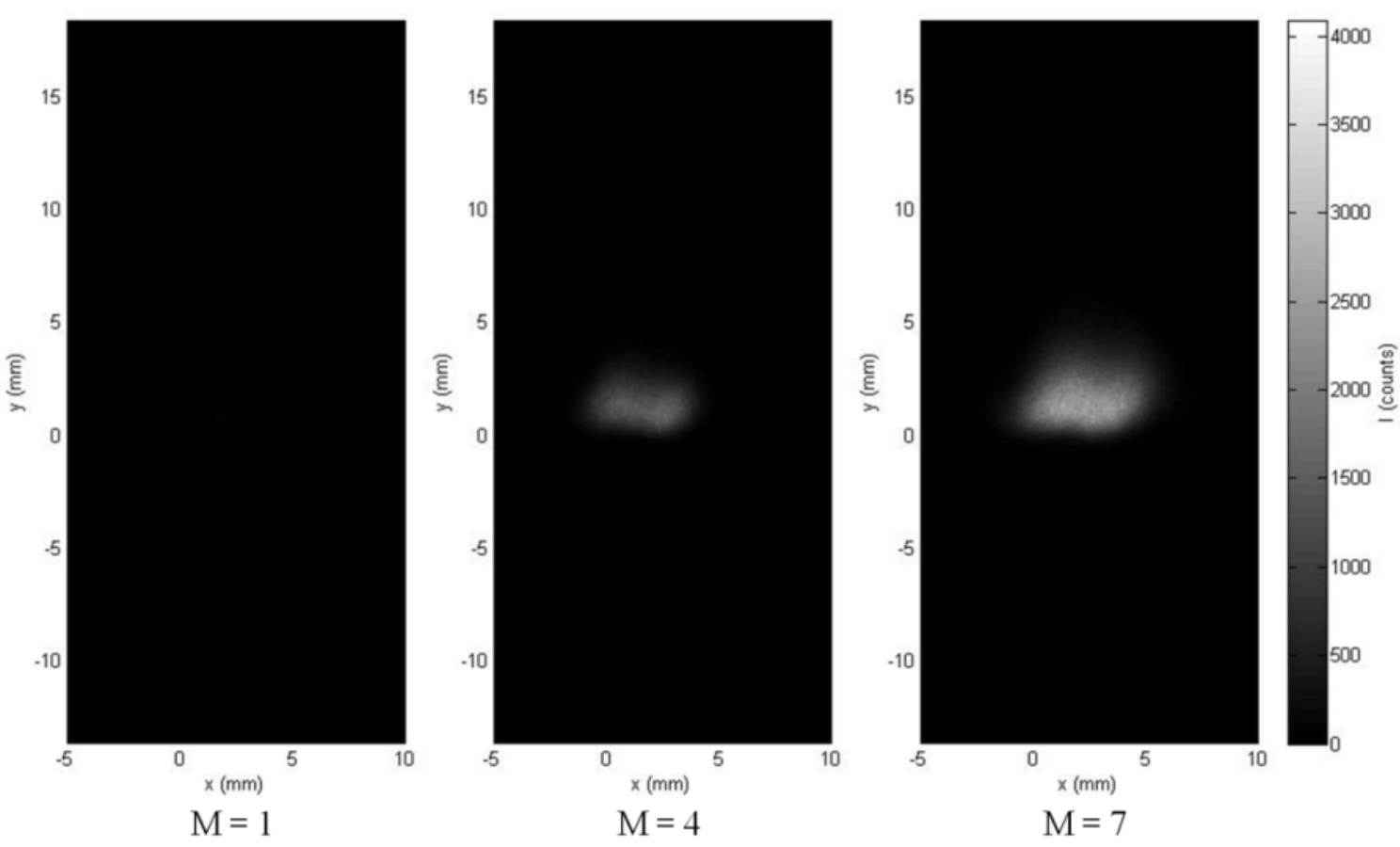

Figure 4.9 $\mathrm{OH}^{*}$ chemiluminescence images at blowing ratio, $\Phi=1.5$, normal holes 


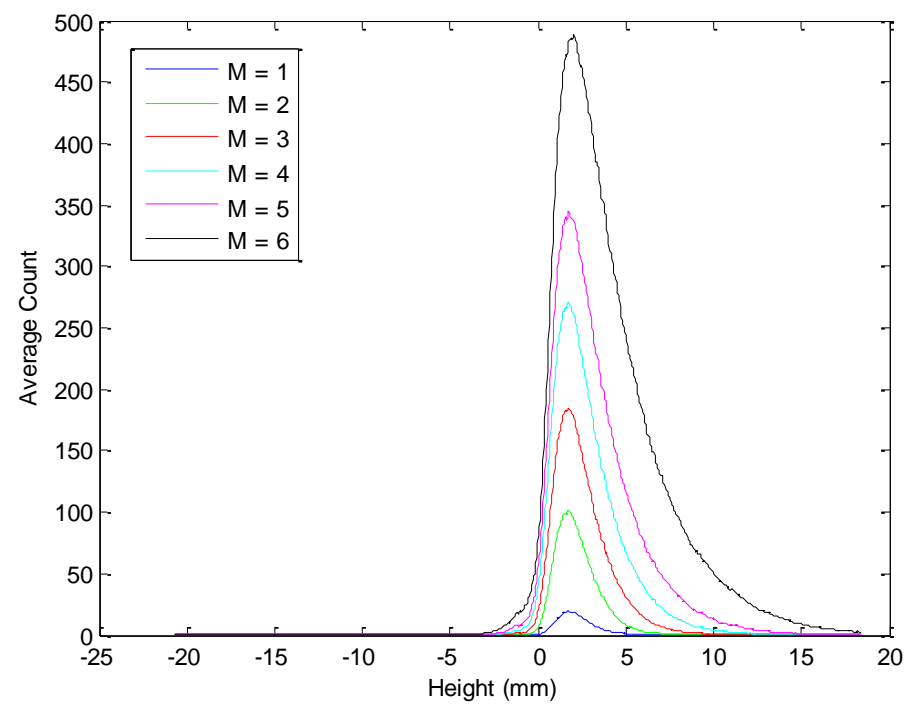

Figure 4.10 $\mathrm{OH}^{*}$ average photon count at blowing ratios, $\Phi=1.3$, normal holes

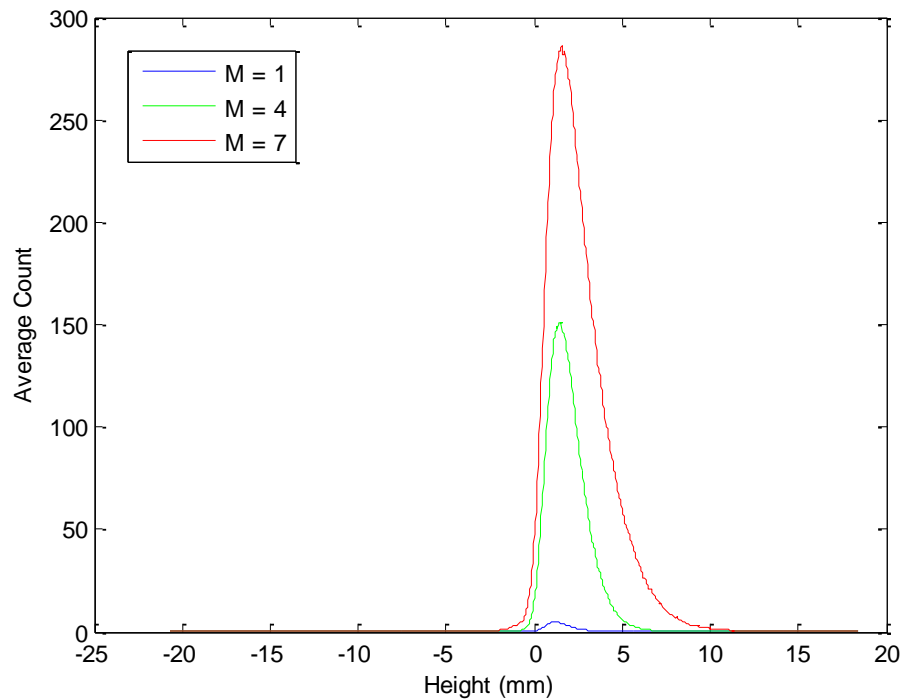

Figure 4.11 OH* average photon count at blowing ratios, $\Phi=1.4$, normal holes 


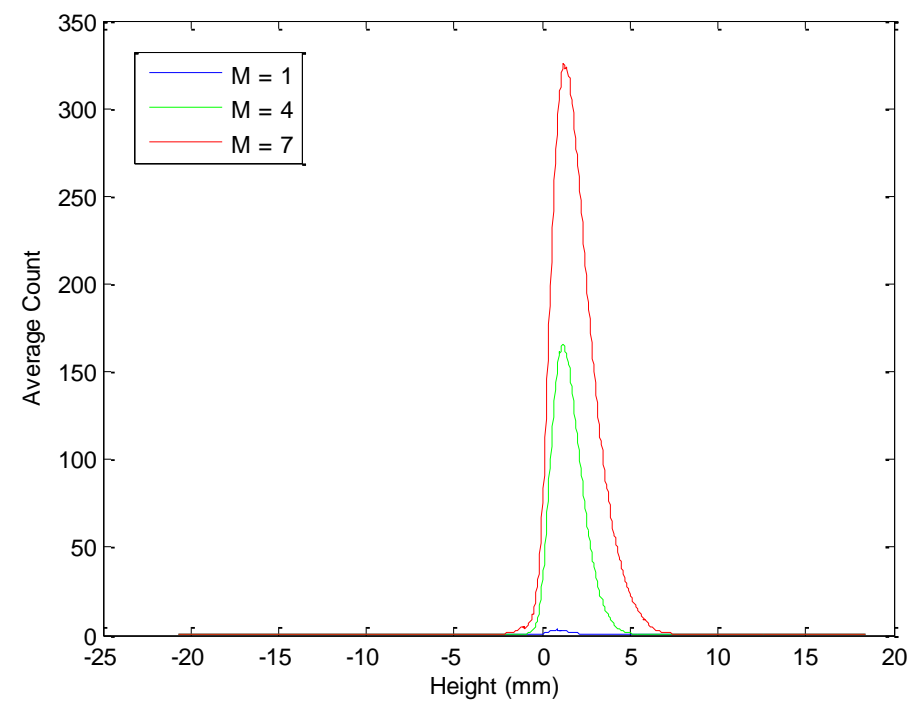

Figure 4.12 $\mathrm{OH}^{*}$ average photon count at blowing ratios, $\Phi=1.5$, normal holes

\subsubsection{Fan Shaped Holes}

Figures 4.13 through 4.18 provide flame images resulting from cooling air injection through fan shaped holes and the accompanying width averaged chemiluminescence emissions plots. The chemiluminescence images (Figs. 4.13, 4.14, and 4.15) show that the flame size and intensity increases with the blowing ratio. The images show that the size of the flame grows from less than $5 \mathrm{~mm}$ in length at a blowing ratio of 1 to greater than $10 \mathrm{~mm}$ in length at a blowing ratio of 7 . The reaction area also increases in width as blowing ratio increases.

As with the normal holes, it appears that there are two small separate flames in these images. Each of the flames originates from a single cooling hole. Again the separate flames join together more as the blowing ratio increases. This is most likely a function of the higher cooling mass flow rate at higher blowing ratios. There are slight differences between the discrete flames here and the ones resulting from normal hole cooling flow injection. The discrete flames in these fan shaped hole images are more 
separate than those from the normal holes. A plausible explanation for this may be the vertical velocity component that occurs in the cooling flow injected from the fan shaped holes. The cooling flow from the fan shaped holes does not mix as quickly with the freestream flow. This slower mixing results in less turbulence and thus less mixing of adjacent cooling jets.

As blowing ratio increases, the intensity of the chemiluminescent emissions increases, as seen in Figs. 4.16, 4.17, and 4.18. This is a result of the amount of air that is present at each different blowing ratio. An increase in blowing ratio means an increase in cooling air which allows for larger reactions to take place.

The plots also show that the peak average intensity moves slightly downstream with each increase in blowing ratio. A reasonable explanation for this is the downstream vertical velocity component present in the cooling flow exiting from these holes. As discussed previously, the fan shaped holes are angled so that the cooling flow exiting them has both vertical and horizontal velocity components, in comparison to the normal holes which inject the flow in a solely horizontal direction. Thus with a higher blowing ratio there is a larger amount of flow moving in the vertical direction causing the peak intensity to travel downstream. In the case of the normal holes the flow is injected with no vertical velocity component, thus the flow becomes entrained in the freestream flow more quickly and reacts at the same vertical location (almost immediately after being injected), no matter the blowing ratio. 

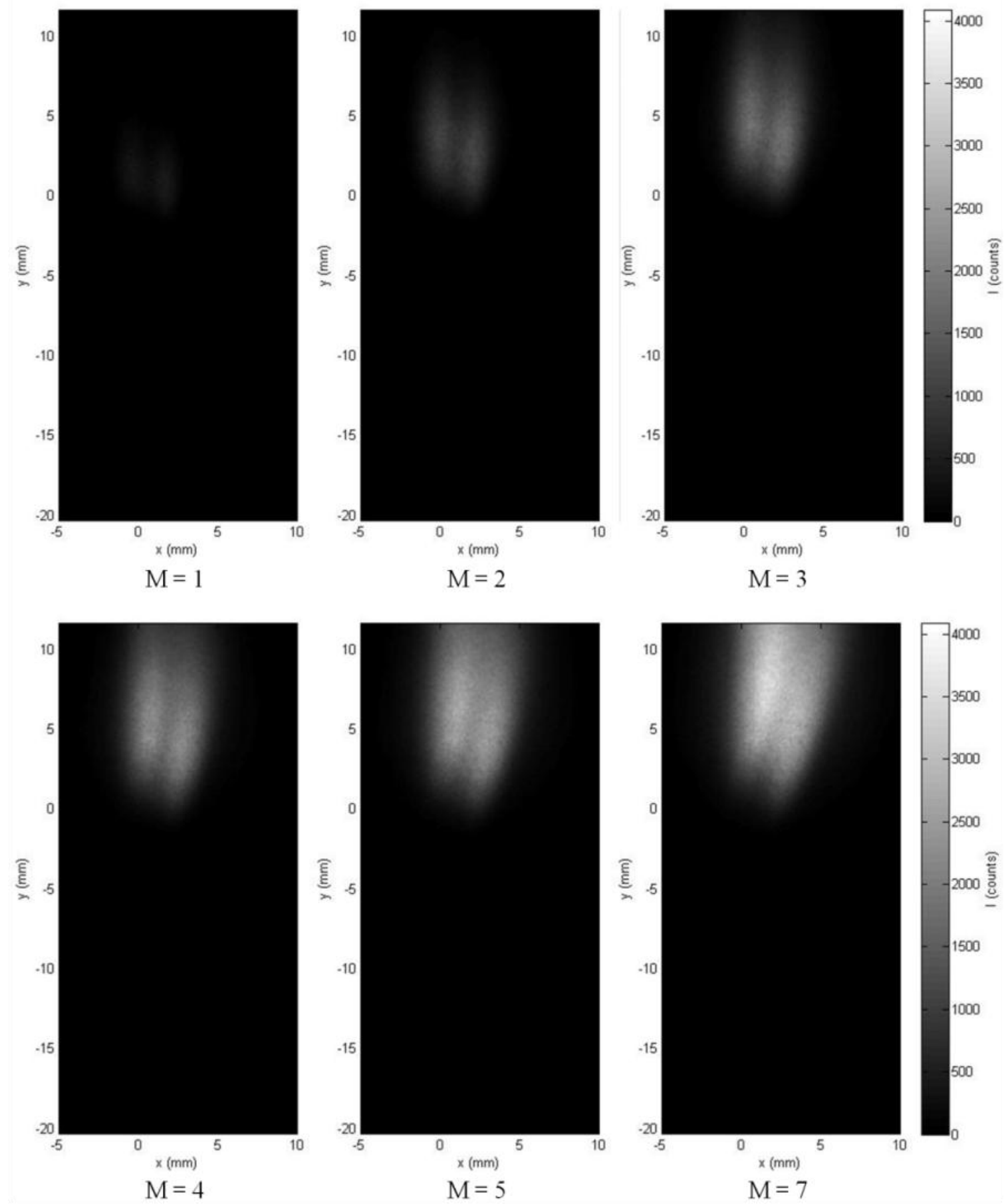

Figure 4.13 $\mathrm{OH}^{*}$ chemiluminescence images at blowing ratios, $\Phi=1.3$, fan shaped holes 

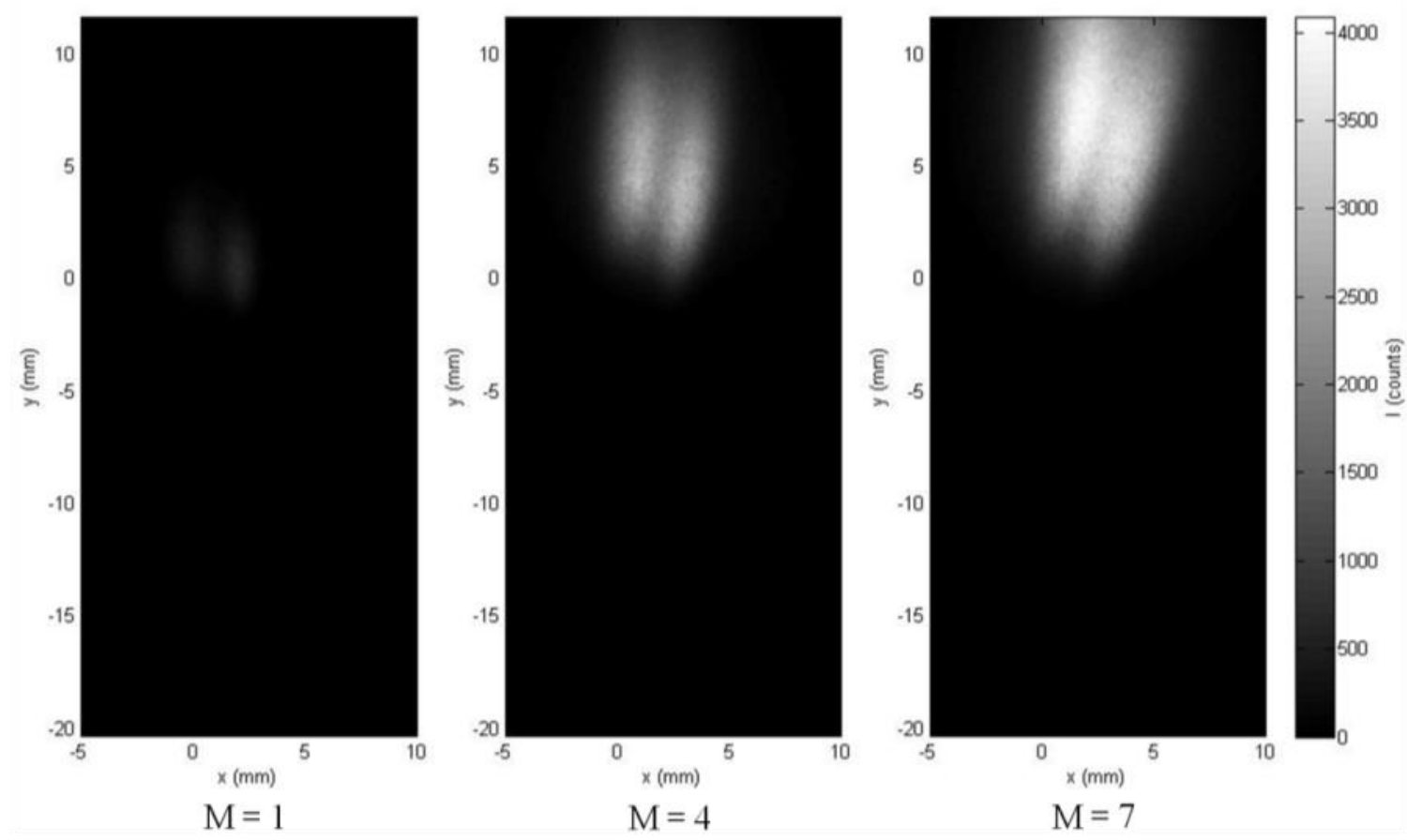

Figure 4.14 OH* chemiluminescence images at blowing ratios, $\Phi=1.4$, fan shaped holes
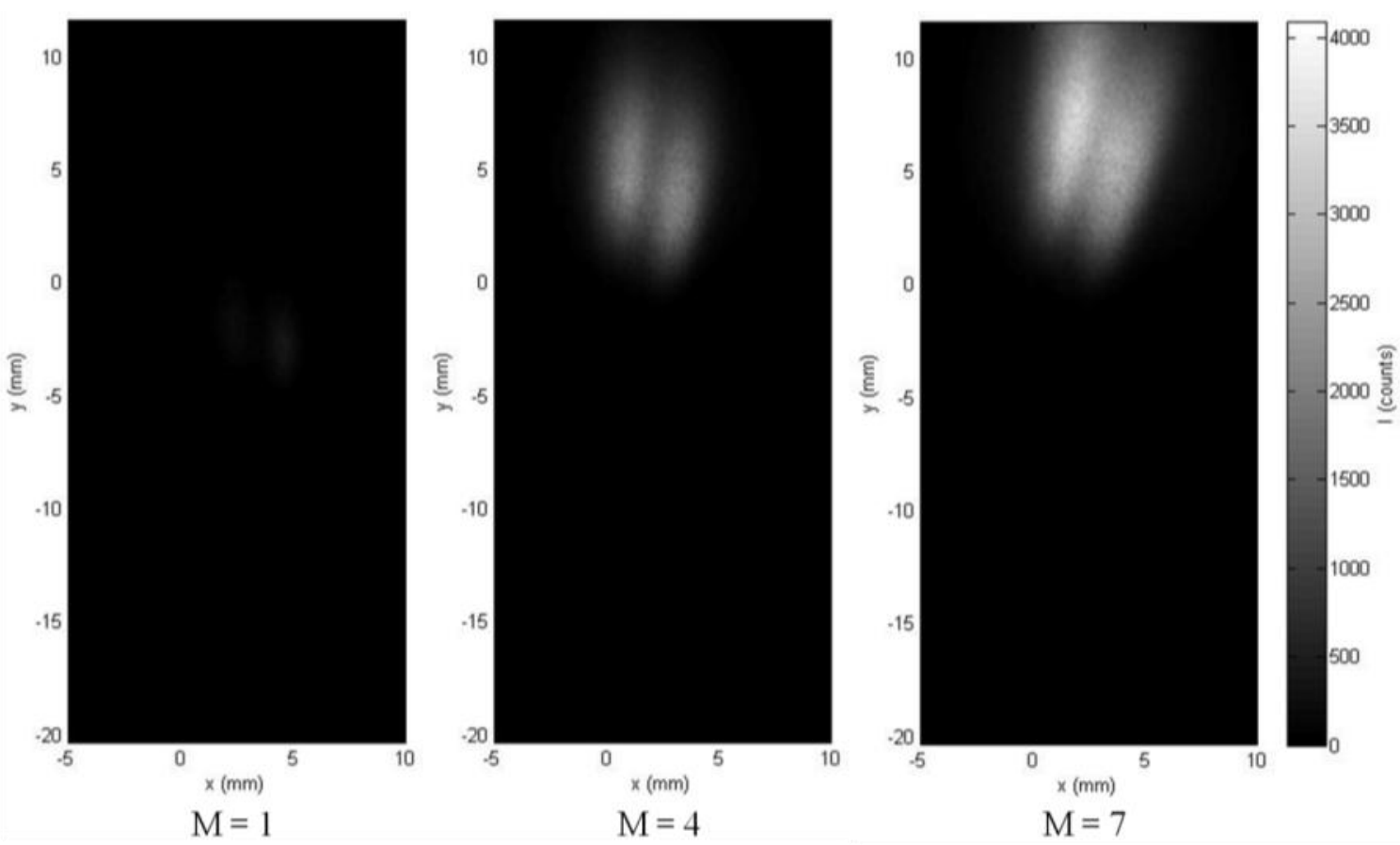

Figure 4.15 $\mathrm{OH}^{*}$ chemiluminescence images at blowing ratios, $\Phi=1.5$, fan shaped holes 


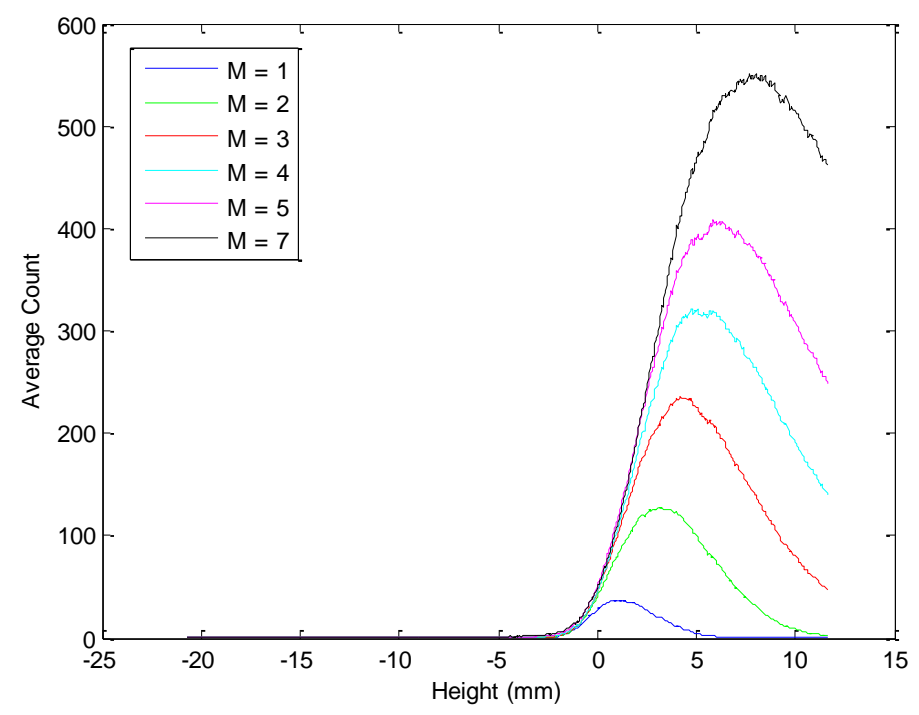

Figure 4.16 $\mathrm{OH}^{*}$ average photon count at blowing ratios, $\Phi=1.3$, fan shaped holes

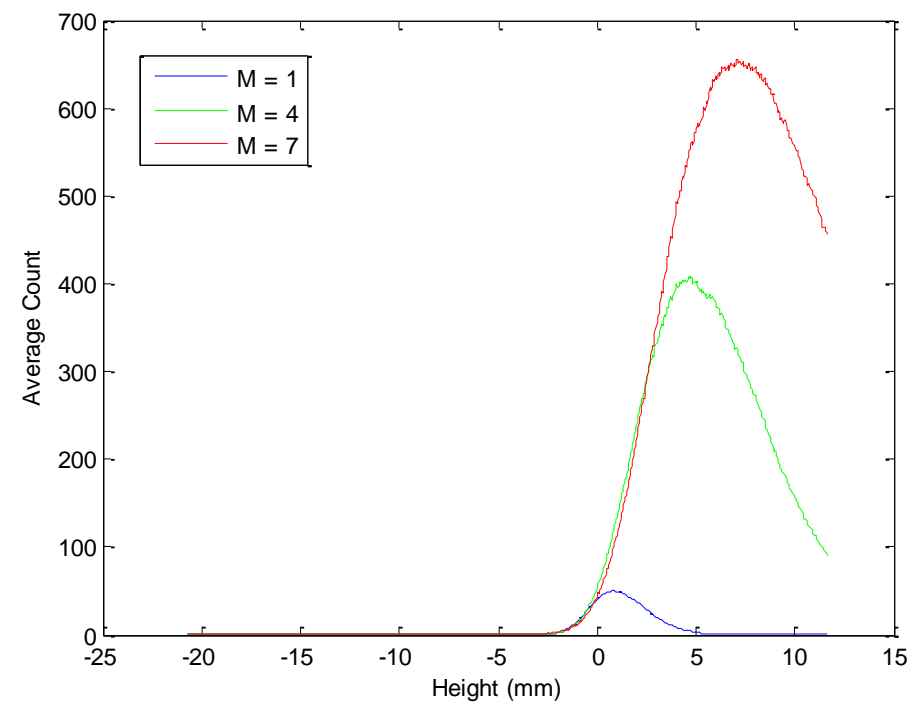

Figure 4.17 $\mathrm{OH}^{*}$ average photon count at blowing ratios, $\Phi=1.4$, fan shaped holes 


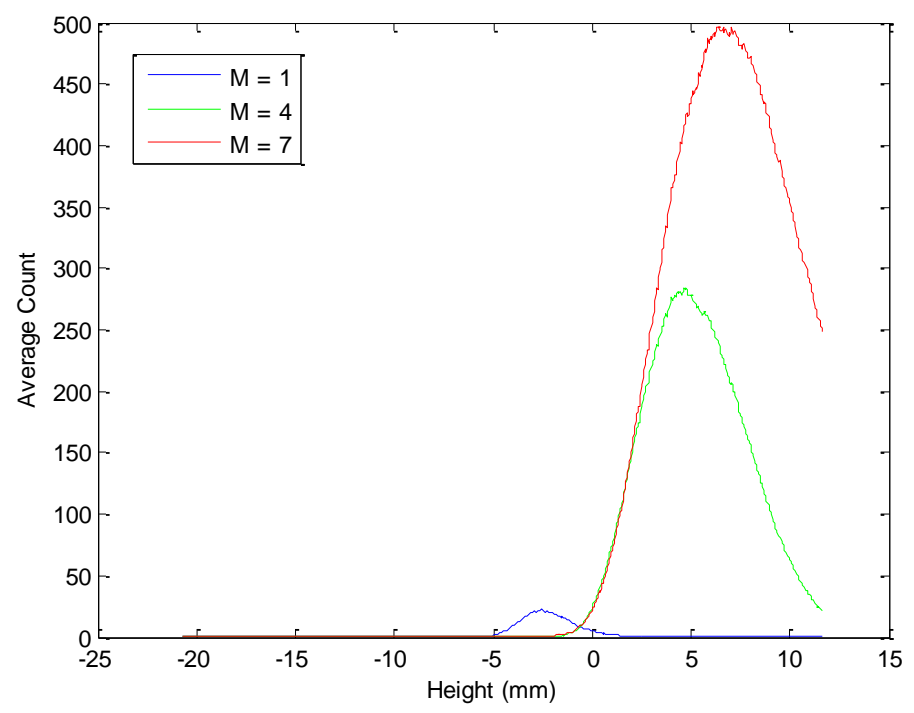

Figure 4.18 $\mathrm{OH}^{*}$ average photon count at blowing ratios, $\Phi=1.5$, fan shaped holes

\subsubsection{Slot}

The slot geometry is significantly different that the normal hole and fan shaped hole geometries. This geometry has a much larger total exit area for the cooling flow. At the same blowing ratio, the slot injects more air into the test section than the normal and fan shaped holes. General trends remain the same though. The chemiluminescence flame images are shown in Figs. 4.19, 4.20, and 4.21, and the photon count plots are shown in Figs. 4.22, 4.23, and 4.24.

An increase in blowing ratio coincides with an increase in the flame chemiluminescent emissions. As previously discussed, increasing the blowing ratio leads to larger amounts of air available to oxidize the unburned fuel present in the freestream flow, leading to larger reactions. Also, the increased mass flow helps with more thorough mixing between the cooling flow and the freestream flow leading to more complete reactions between the two. 
The flames increase in length with blowing ratio, as can be seen in Figs. 4.19, 4.20, and 4.21. This is a result of the increased cooling air mass flow with each increase in blowing ratio. The vertical velocity component of the cooling flow is larger with each successive blowing ratio. This also adds to the overall length of the flame.

The origin point of the flame moves only slightly (if at all) downstream for each increase in blowing ratio. This compares more closely to the trend noticed in the normal flame images and plots presented above in Section 4.2.2.2. Because the slot is angled, there is a vertical velocity component to the cooling flow. This vertical component has an effect on the flame location because there is significantly more flow entering the test section through the slot. Thus the flow in the horizontal direction is still adequate to cause a high rate of mixing between it and the freestream and provides a large amount of oxidizer to the unburned fuel for reaction but the flow in the vertical direction is adequate to cause movement downstream.

There are some noteworthy points to be made about the emission plots. In figure 4.19 (equivalence ratio of 1.3) it is shown that the chemiluminescence emission intensity increases at larger and larger intervals as the blowing ratio increases. The change between emissions from $M=1$ to $M=2$ is noticeably different than the change between emission levels from $M=3$ to $M=4$. The blowing ratio has an increasingly large effect on the chemiluminescence emissions. A likely reason for this is the large amount of mass flow that coincides with each blowing ratio for this cooling hole geometry. Each increase in blowing ratio means an increase in mass flow, which has a larger effect in this case because of the large amount of mass flow that is injected. 

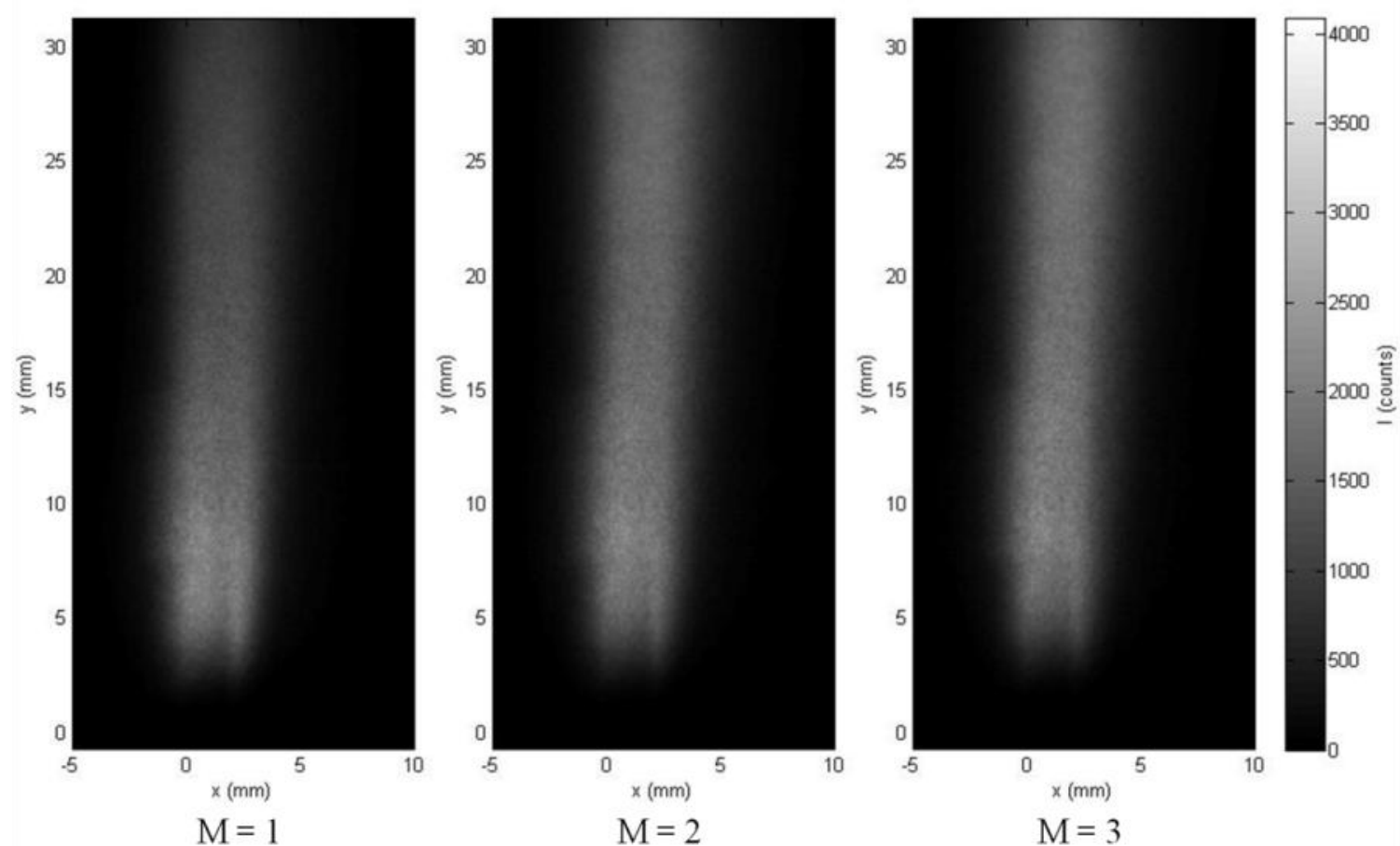

$M=1$
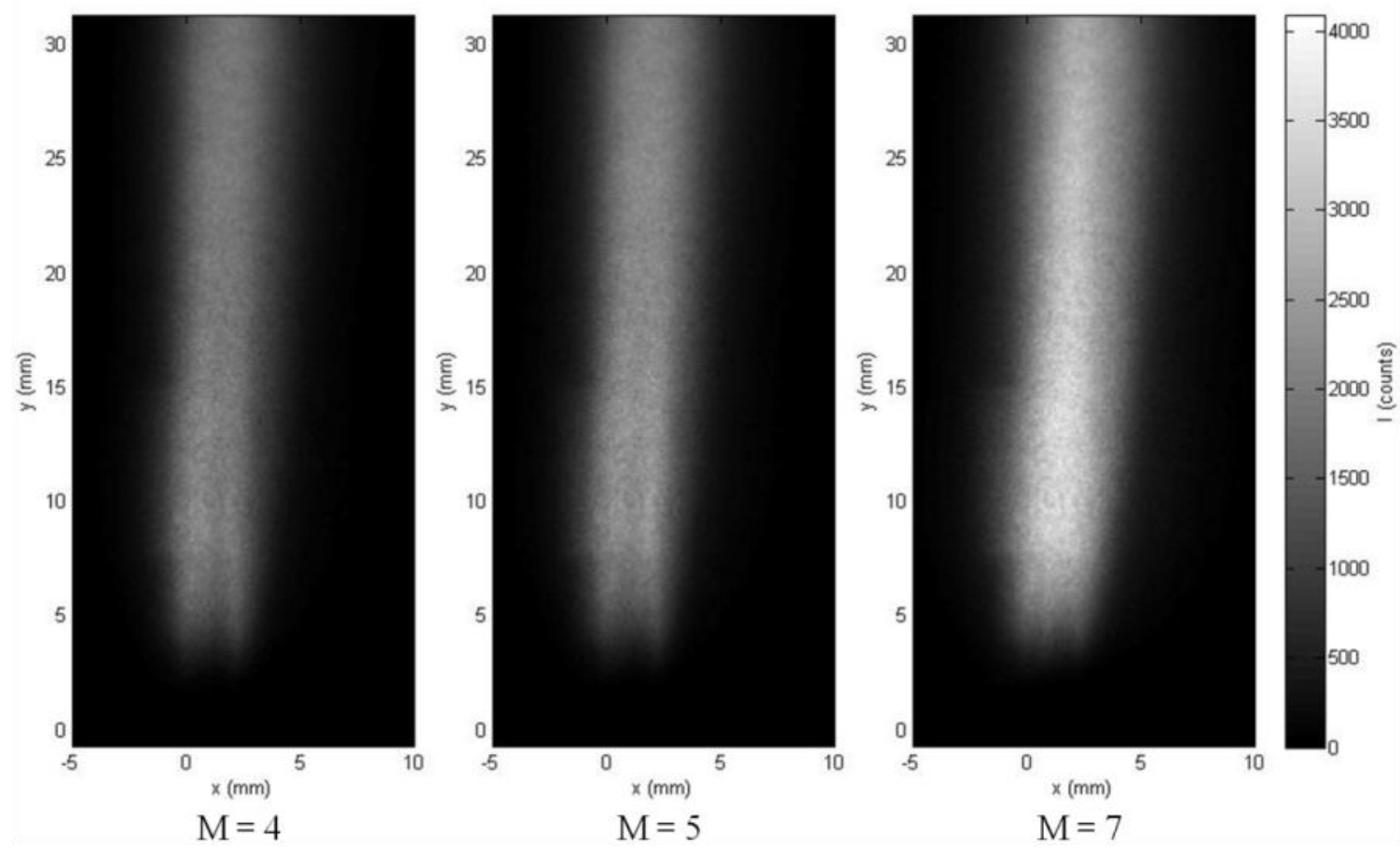

Figure 4.19 OH* chemiluminescence images at blowing ratios, $\Phi=1.3$, slot 

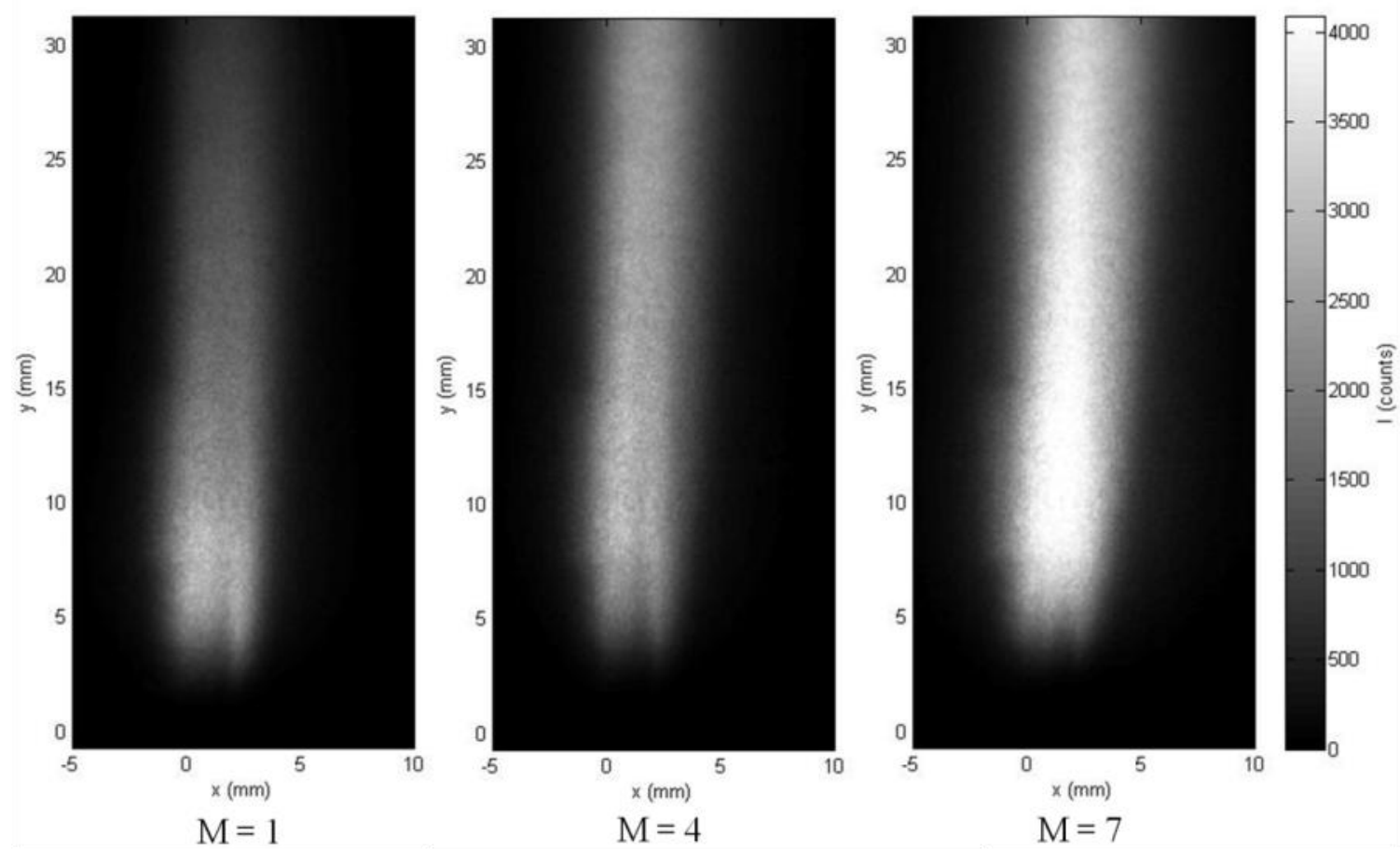

Figure 4.20 OH* chemiluminescence images at blowing ratios, $\Phi=1.4$, slot
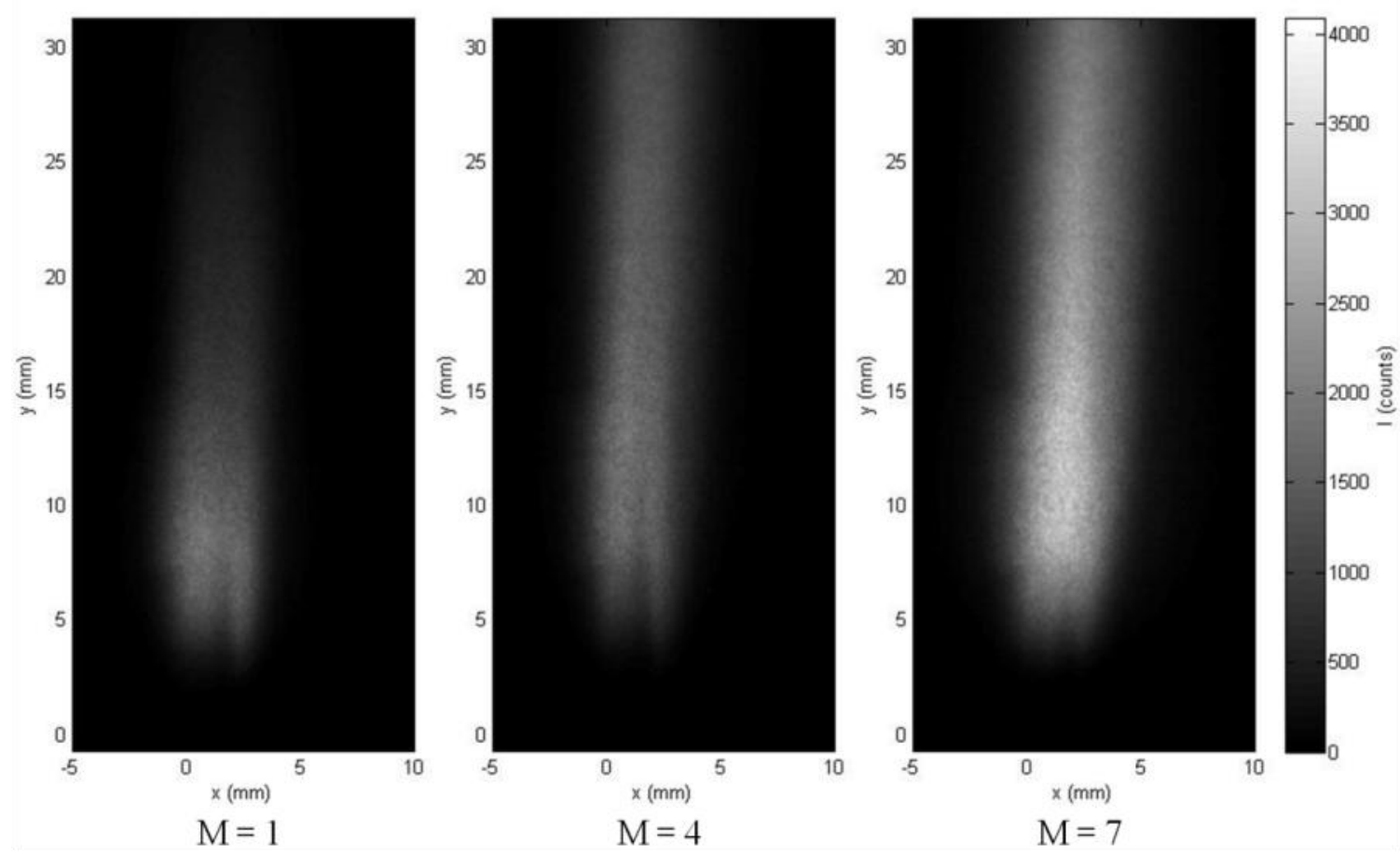

Figure 4.21 $\mathrm{OH}^{*}$ chemiluminescence images at blowing ratios, $\Phi=1.5$, slot 


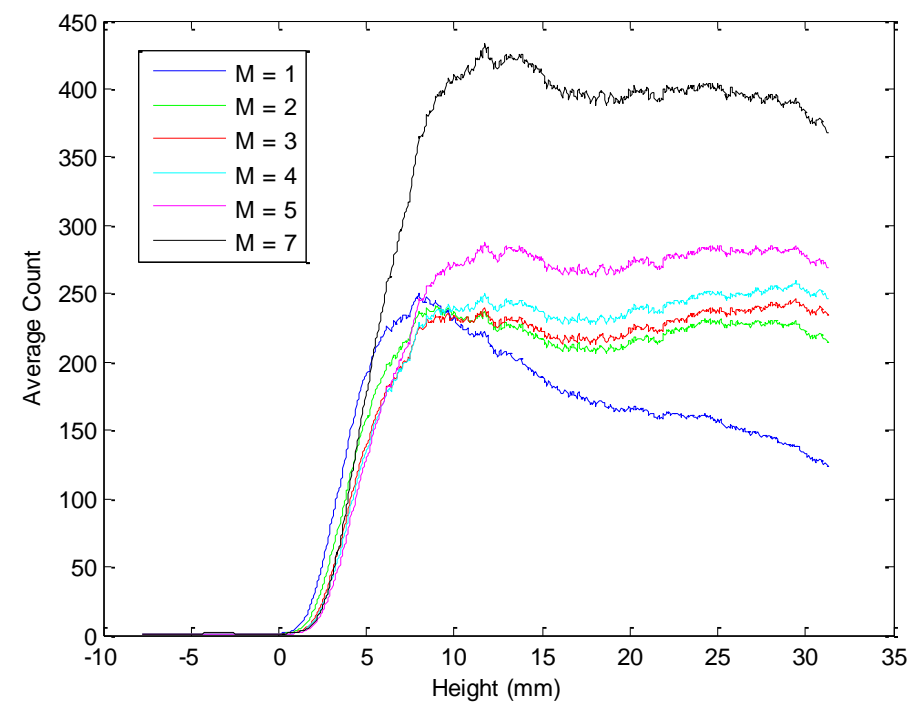

Figure 4.22 $\mathrm{OH}^{*}$ average photon count at blowing ratios, $\Phi=1.3$, slot

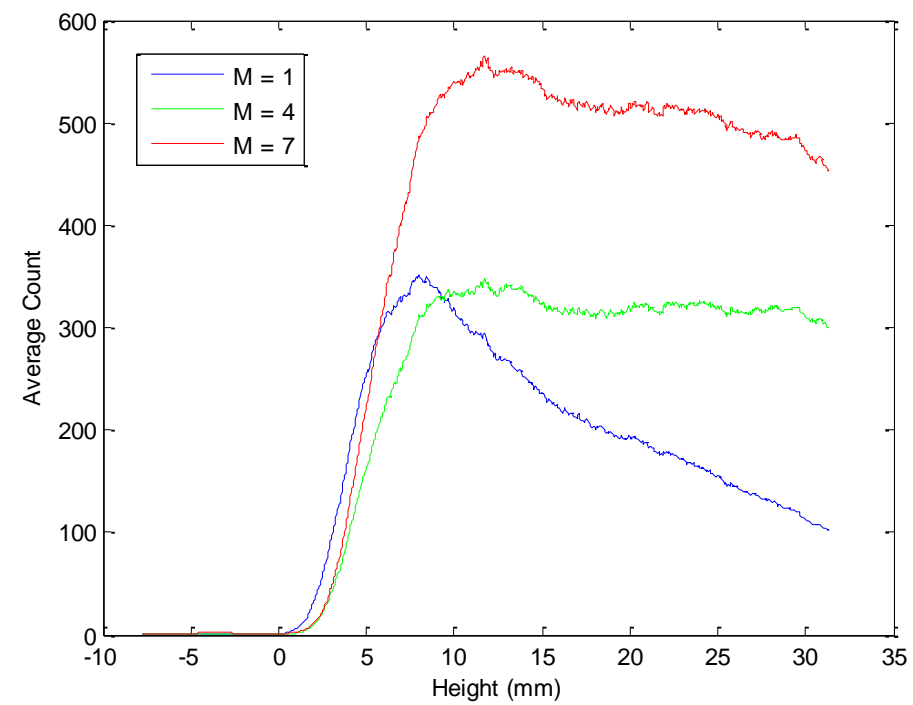

Figure 4.23 $\mathrm{OH}^{*}$ average photon count at blowing ratios, $\Phi=1.4$, slot 


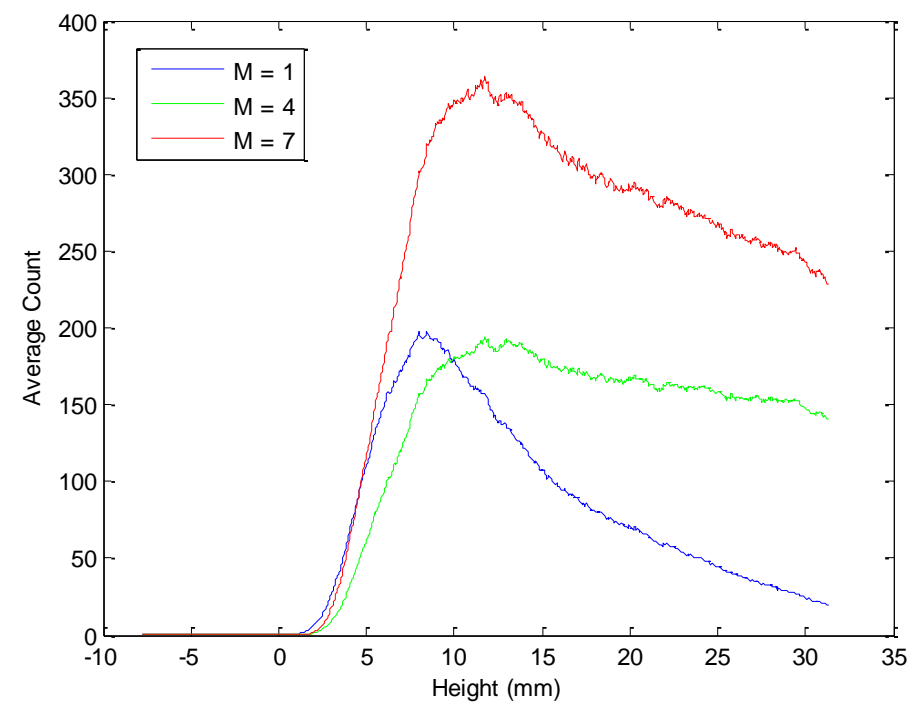

Figure 4.24 $\mathrm{OH}^{*}$ average photon count at blowing ratios, $\Phi=1.5$, slot

\subsubsection{Geometry Comparison}

Images and plots are presented for the $\mathrm{OH}^{*}$ filter comparing each of the three

cooling insert geometries at each blowing ratio and equivalence ratio. Table 4.2 presents the results for chemiluminescence compared based on geometry. The results are discussed further in this section.

Table 4.2 Summary of geometry comparison results for chemiluminescence data

\begin{tabular}{|c|c|c|c|}
\hline $\begin{array}{c}\text { Equivalence } \\
\text { Ratio }\end{array}$ & $\begin{array}{c}\text { Blowing } \\
\text { Ratio }\end{array}$ & Che milumine scence & $\begin{array}{c}\text { Flame } \\
\text { Origination }\end{array}$ \\
\hline 1.3 & 1 & $\mathrm{~S}>>$ F $>$ N & F, N, S \\
\hline 1.3 & 2 & $\mathrm{~S}>>$ F $>$ N & N, F, S \\
\hline 1.3 & 3 & $\mathrm{~S}=\mathrm{F}>\mathrm{N}$ & $\mathrm{N}, \mathrm{F}, \mathrm{S}$ \\
\hline 1.3 & 4 & $\mathrm{~F}>\mathrm{N}>\mathrm{S}$ & $\mathrm{N}, \mathrm{F}, \mathrm{S}$ \\
\hline 1.3 & 5 & $\mathrm{~F}>\mathrm{N}>\mathrm{S}$ & $\mathrm{N}, \mathrm{F}, \mathrm{S}$ \\
\hline 1.3 & 7 & $\mathrm{~F}>\mathrm{N}>\mathrm{S}$ & $\mathrm{N}, \mathrm{F}, \mathrm{S}$ \\
\hline 1.4 & 1 & $\mathrm{~S}>>$ F $>\mathrm{N}$ & $\mathrm{F}, \mathrm{N}, \mathrm{S}$ \\
\hline 1.4 & 4 & $\mathrm{~F}>\mathrm{S}>\mathrm{N}$ & $\mathrm{N}, \mathrm{F}, \mathrm{S}$ \\
\hline 1.4 & 7 & $\mathrm{~F}>\mathrm{S}>\mathrm{N}$ & $\mathrm{N}, \mathrm{F}, \mathrm{S}$ \\
\hline 1.5 & 1 & $\mathrm{~S}>>$ F $>\mathrm{N}$ & $\mathrm{F}, \mathrm{N}, \mathrm{S}$ \\
\hline 1.5 & 4 & $\mathrm{~F}>\mathrm{S}>\mathrm{N}$ & $\mathrm{N}, \mathrm{F}, \mathrm{S}$ \\
\hline 1.5 & 7 & $\mathrm{~F}>\mathrm{S}>\mathrm{N}$ & $\mathrm{N}, \mathrm{F}, \mathrm{S}$ \\
\hline
\end{tabular}




\subsubsection{Equivalence Ratio of 1.3}

The images show that the flames originating from the slot are much longer than those of the fan shaped and normal geometries. There are two main reasons the flames originating from the slot flow are longer. First, there is much more flow exiting the slot at the same blowing ratio. Second, the slot has a vertical velocity component because it is oriented at an angle. The fan shaped holes also provide the flow with a vertical velocity component making the flames longer downstream than the flames from the normal hole geometry. The flow from the fan shaped geometry is still significantly less than the slot flow and much more comparable to the normal hole flow thus making only a slight difference in the length of the flames in comparison to the flames from the normal holes. The widths of flames for each geometry are much more comparable in size.

It is also observed that the flames from the normal and fan shaped holes are much less visible than the flame from the slot. This is a function of the amount of oxidizer that is injected for the slot in comparison to the normal and fan shaped holes at the same blowing ratio. As the blowing ratio increases, all flames become more visible as a result of the larger amount of cooling flow allowing for more intense reactions.

At the initial blowing ratio of 1 , it can be seen that the flames from the normal hole cooling flow and the fan shaped cooling flow occurs almost immediately at the injection location, though the fan shaped hole flames are typically slightly further downstream of the injection location than the normal hole flames. The normal holes inject flow orthogonal to the freestream flow. This causes immediate mixing between the cooling flow and the freestream flow which results in a reaction close to the injection location. The fan shaped flow is injected at a $30^{\circ}$ angle resulting in a downstream 
(vertical) velocity component. The vertical velocity component causes the flame to occur slightly further downstream of the injection location.

It is also noted that as the blowing ratio increases the flames from the fan shaped holes move further downstream. A reasonable explanation for this is again the presence of the vertical velocity component, which grows with each increase in blowing ratio. This causes the cooling air to move further downstream before it reacts with the fuel in the freestream flow as their vertical component increases.

The flames from the slot cooling flow occur further downstream of the injection location in comparison to the other two geometries. Not only does the slot inject the flow at an angle providing it with a downstream component, more flow is injected at the same blowing ratio. The large overall mass flow equates to a larger vertical component causing the flame to travel slightly further downstream before it mixes and reacts with the freestream flow.

At all blowing ratios lower than $M=4$, the slot chemiluminescence is greater than that of the fan shaped holes and the normal holes. Because of the larger amount of cooling air injected into the vitiated flow, the slot flow produces larger areas of reaction. At $\mathrm{M}=4$, the fan and normal peak chemiluminescence exceed the slot peak chemiluminescence. The heat release rate of the fan and normal holes at a blowing ratio of 4 onward is higher at its peak than the slot heat release rate. This effect may be a result of the large amount of cooling flow injected through the slot at the same blowing ratio. At a blowing ratio of 4 the amount of cooling flow through the slot overcomes the amount fuel present in the vitiated flow. There is such a large amount of cooling air that some of it is allowed to do just that, cool the test section area, and initially quench any 
reactions occurring before igniting downstream. This causes lower chemiluminescence emissions and a lower rate of heat release to the surrounding area.

These trends can be seen on both the flame images (Figs. 4.25, 4.26, 4.27, 4.28, 4.29, and 4.30), and the photon count plots (Figs. 4.31, 4.32, 4.33, 4.34, 4.35, and 4.36). The plots make it apparent that the flames from the slot geometry occur the entire length of the test section, while the flames from the normal and fan shaped geometries taper off down to zero emissions after their peak.

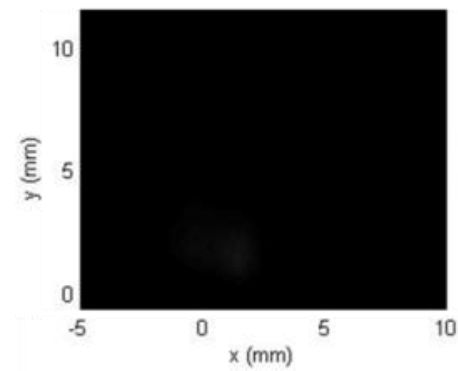

Normal Holes

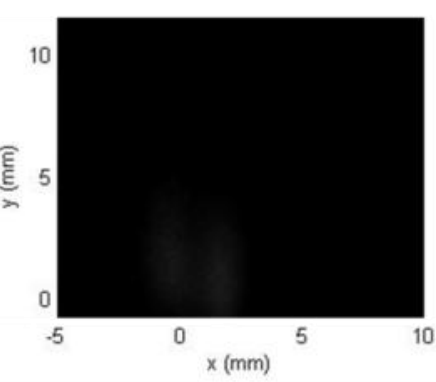

Fan Shaped Holes

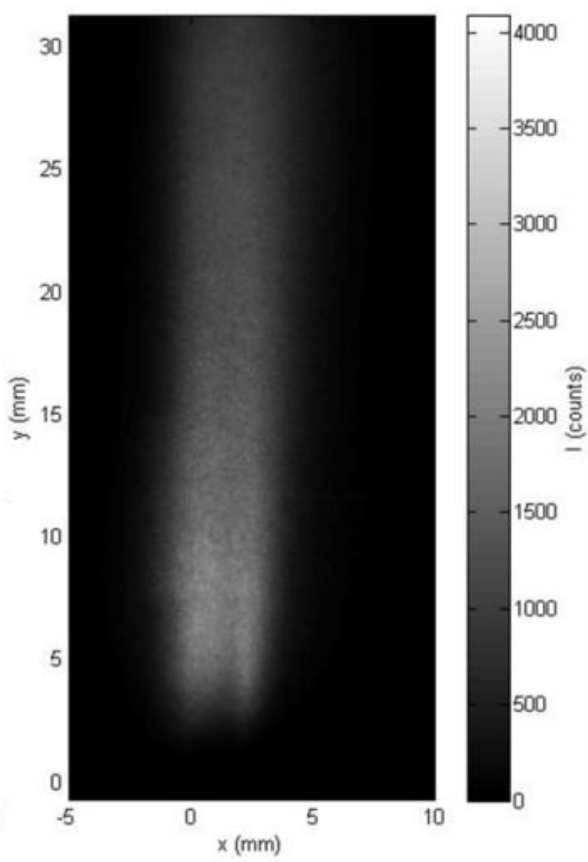

Slot

Figure 4.25 $\mathrm{OH}^{*}$ chemiluminescence images for three geometries, $\Phi=1.3, \mathrm{M}=1$ 


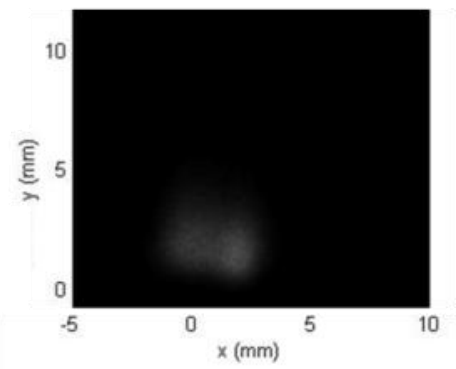

Normal Holes

Figure 4.26 $\mathrm{OH}^{*}$ chemiluminescence images for three geometries, $\Phi=1.3, \mathrm{M}=2$

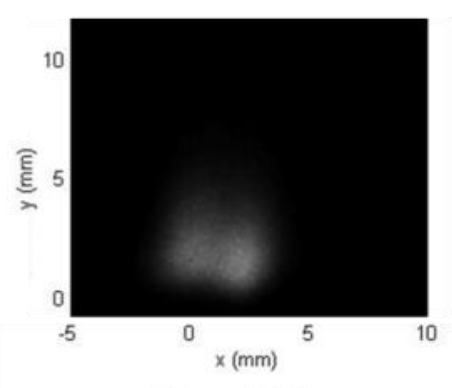

Normal Holes

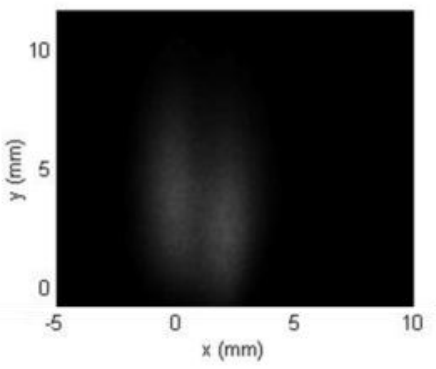

Fan Shaped Holes
Slot
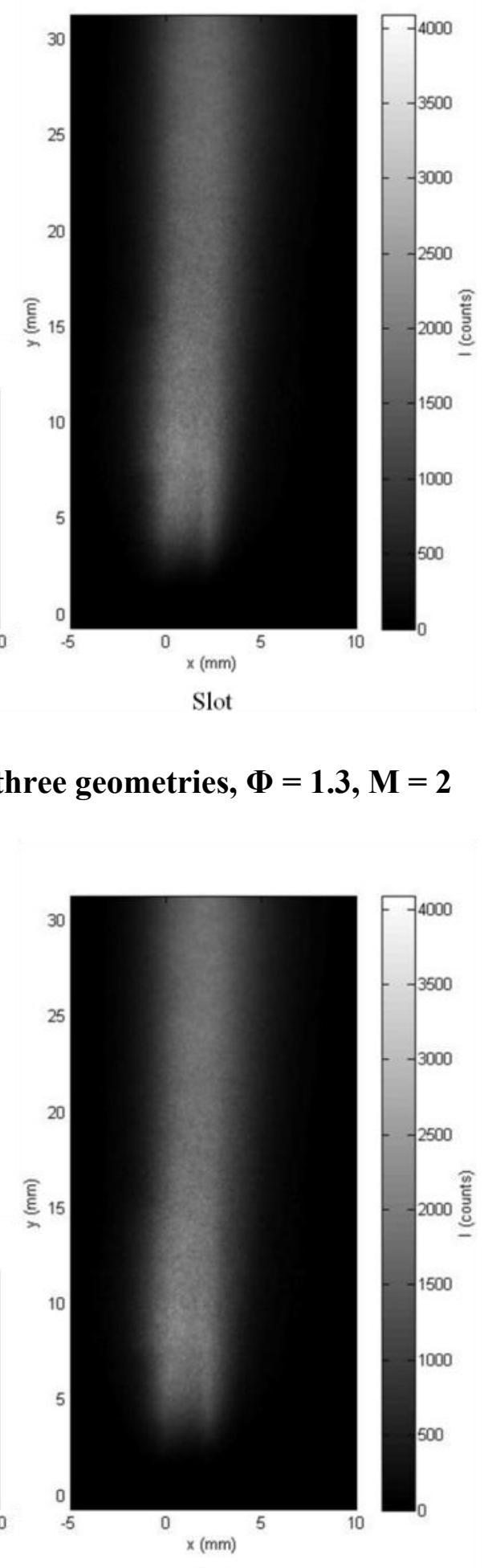

Fan Shaped Holes

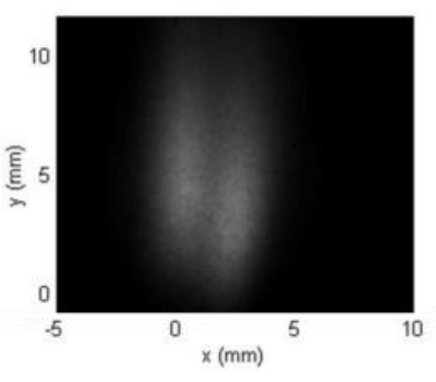

Figure 4.27 $\mathrm{OH}^{*}$ chemiluminescence images for three geometries, $\Phi=1.3, \mathrm{M}=3$ 


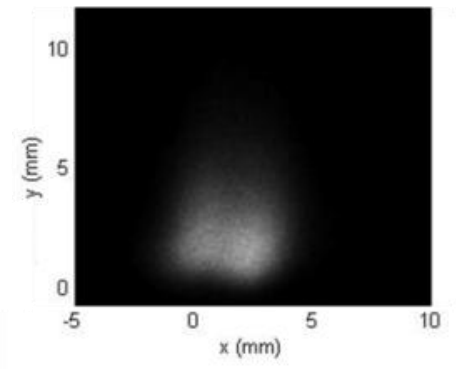

Normal Holes

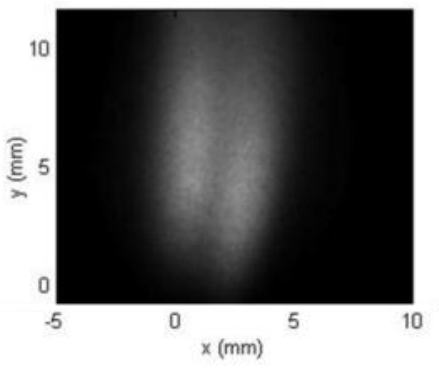

Fan Shaped Holes

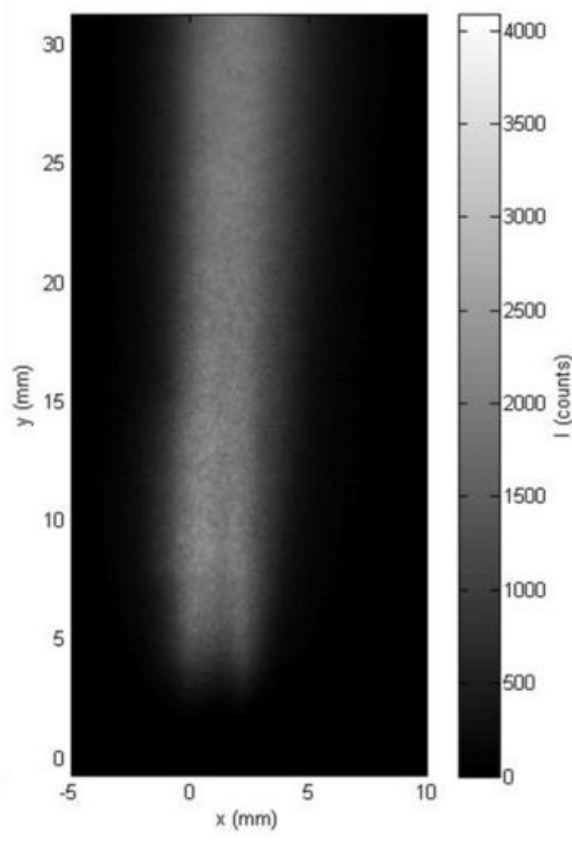

Slot

Figure 4.28 $\mathrm{OH}^{*}$ chemiluminescence images for three geometries, $\Phi=1.3, \mathrm{M}=4$

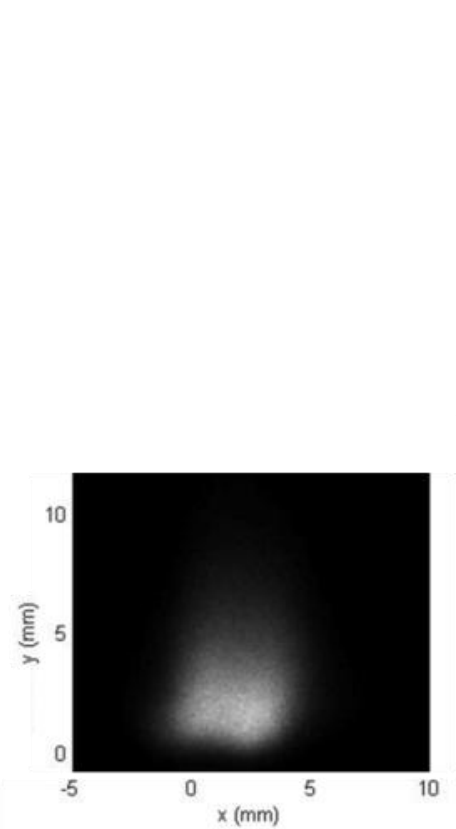

Normal Holes

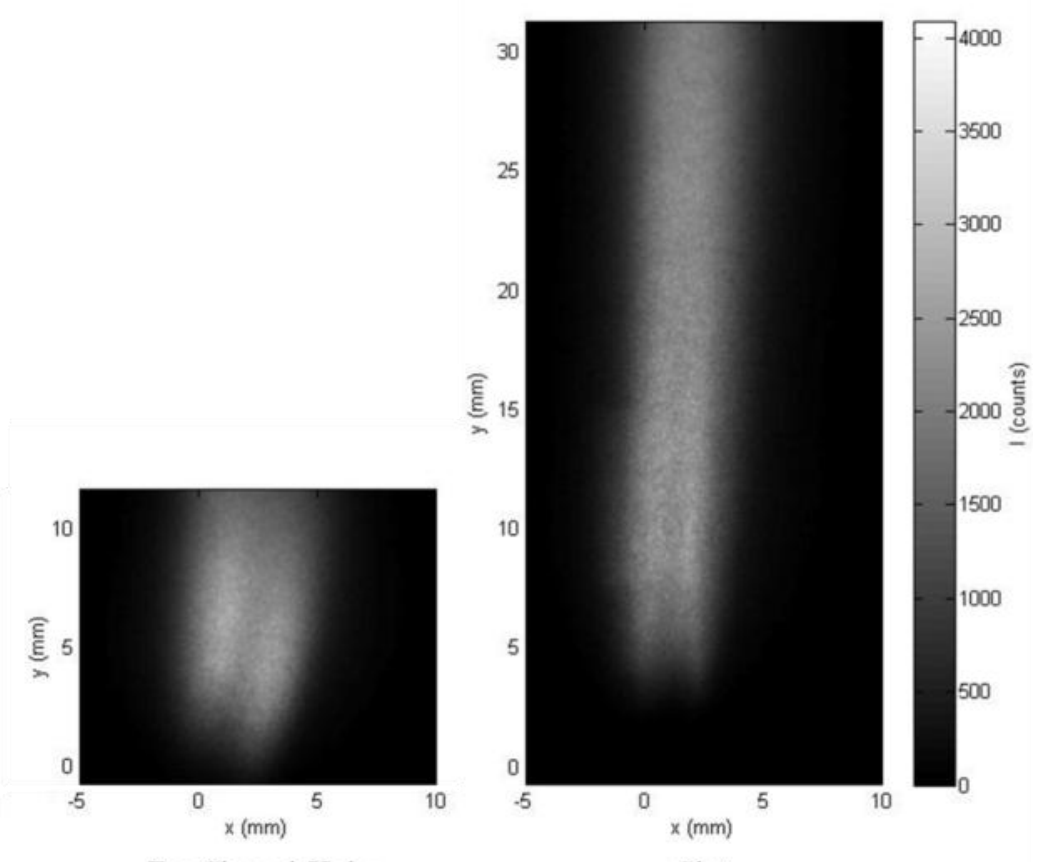

Fan Shaped Holes
Slot

Figure 4.29 $\mathrm{OH}^{*}$ chemiluminescence images for three geometries, $\Phi=1.3, \mathrm{M}=5$ 


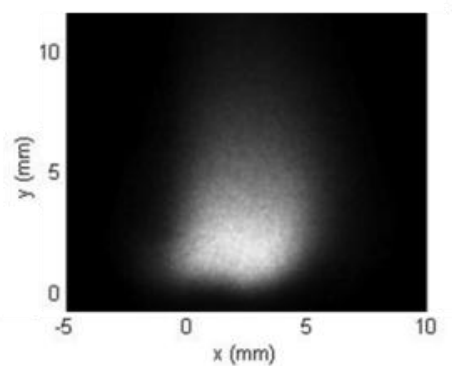

Normal Holes

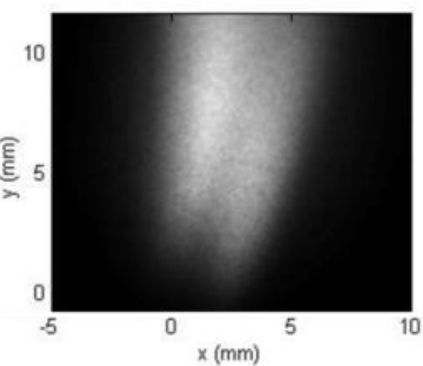

Fan Shaped Holes

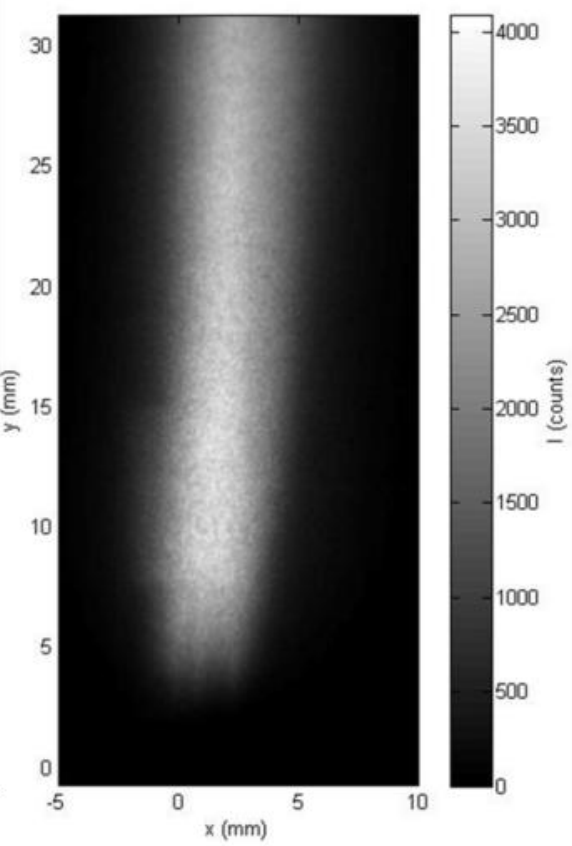

Slot

Figure 4.30 $\mathrm{OH}^{*}$ chemiluminescence images for three geometries, $\Phi=1.3, \mathrm{M}=7$

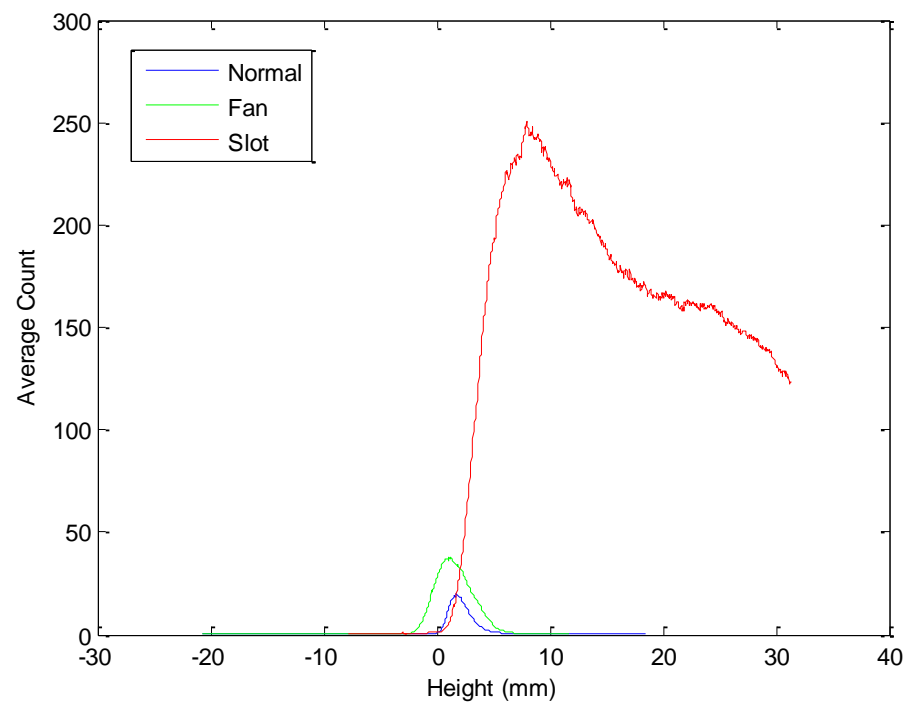

Figure 4.31 $\mathrm{OH}^{*}$ average photon count for three geometries, $\Phi=1.3, \mathrm{M}=1$ 


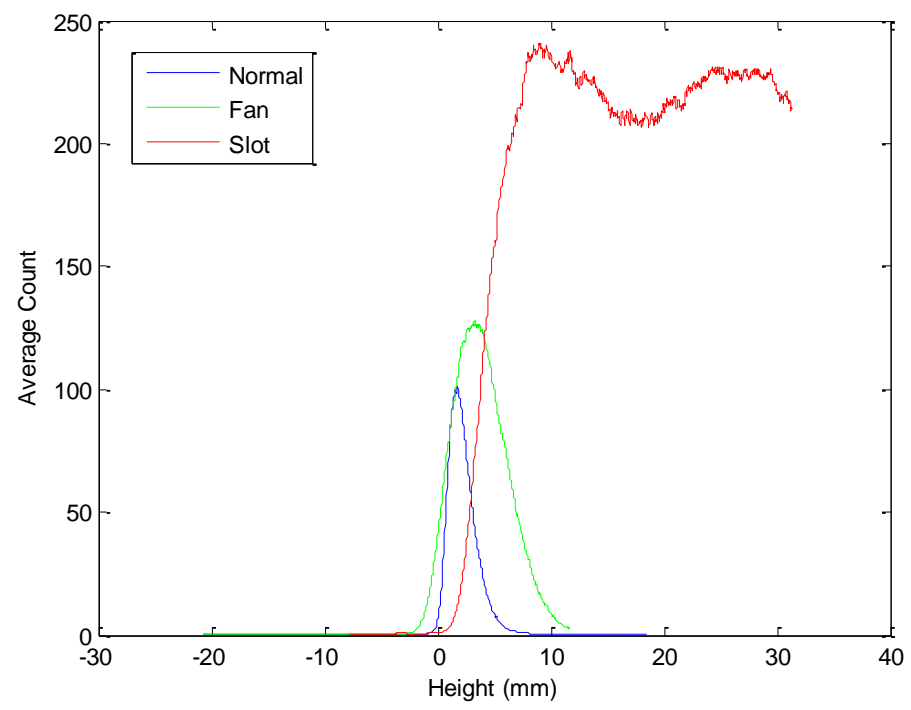

Figure 4.32 $\mathrm{OH}^{*}$ average photon count for three geometries, $\Phi=1.3, \mathrm{M}=2$

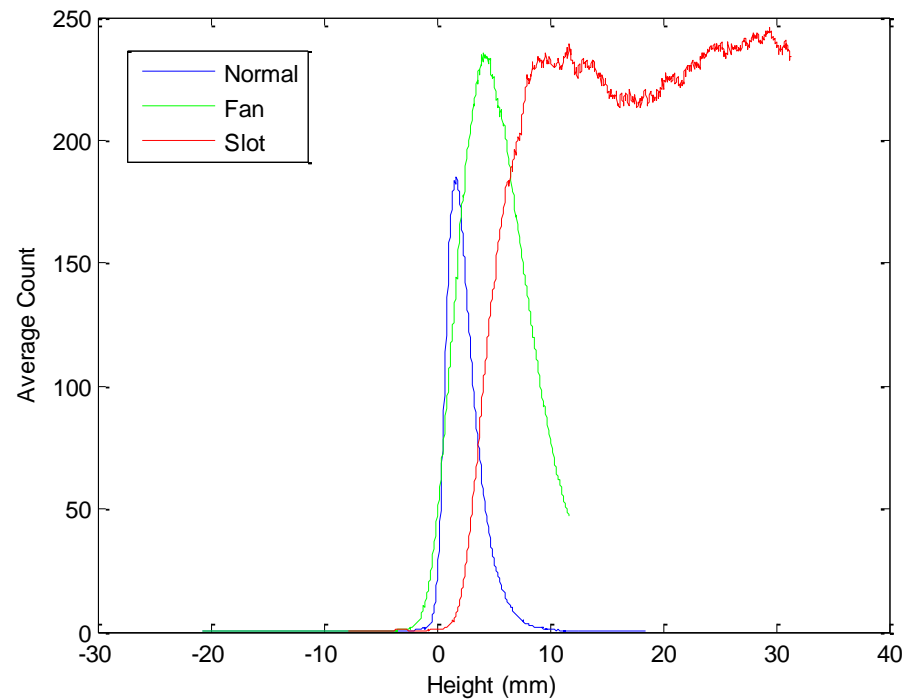

Figure 4.33 $\mathrm{OH}^{*}$ average photon count for three geometries, $\Phi=1.3, M=3$ 


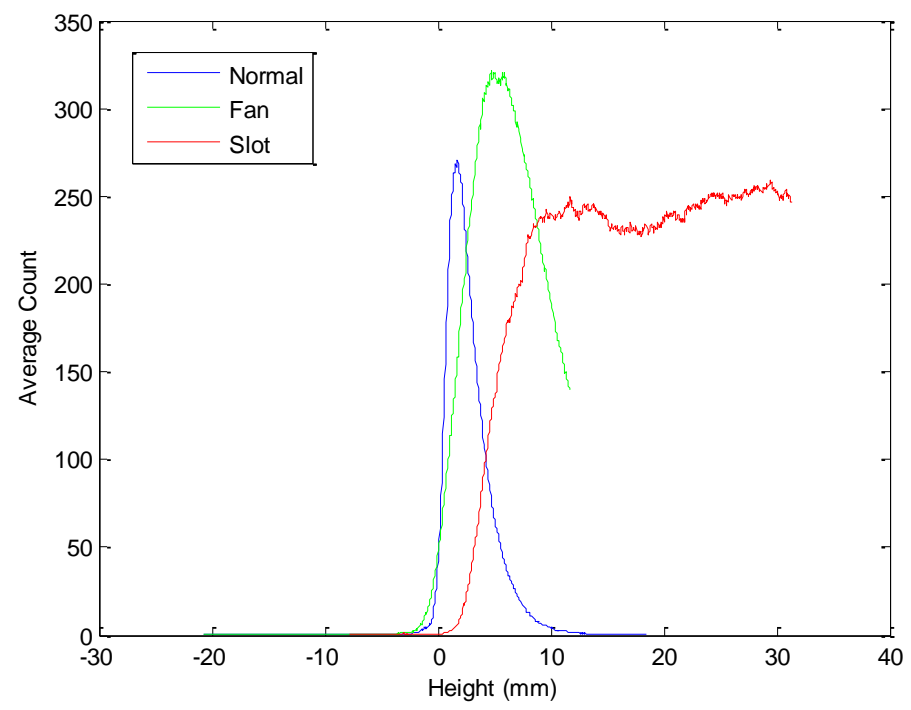

Figure 4.34 $\mathrm{OH}^{*}$ average photon count for three geometries, $\Phi=1.3, \mathrm{M}=4$

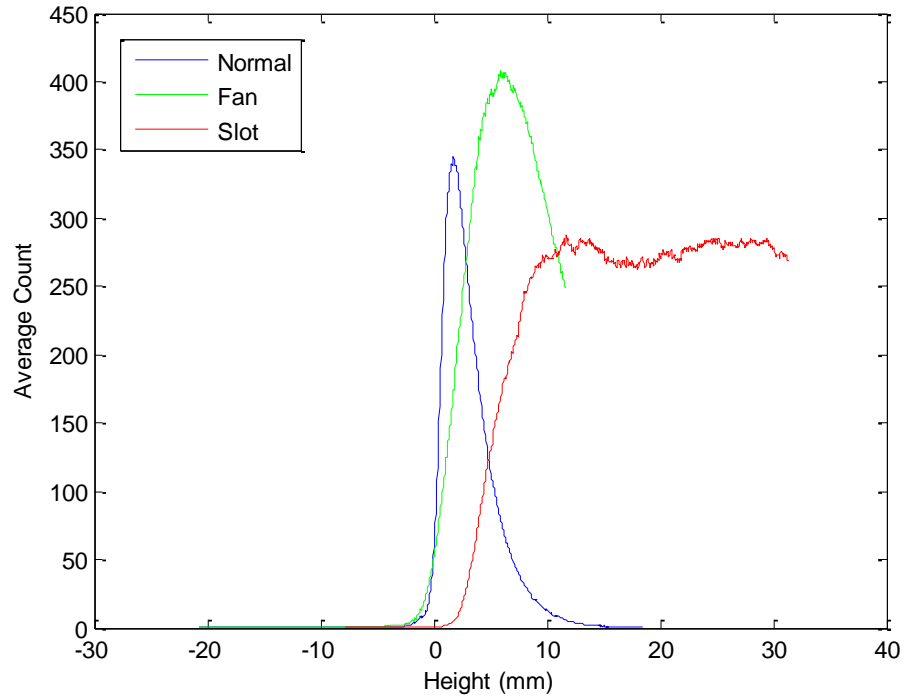

Figure 4.35 $\mathrm{OH}^{*}$ average photon count for three geometries, $\Phi=1.3, \mathrm{M}=5$ 


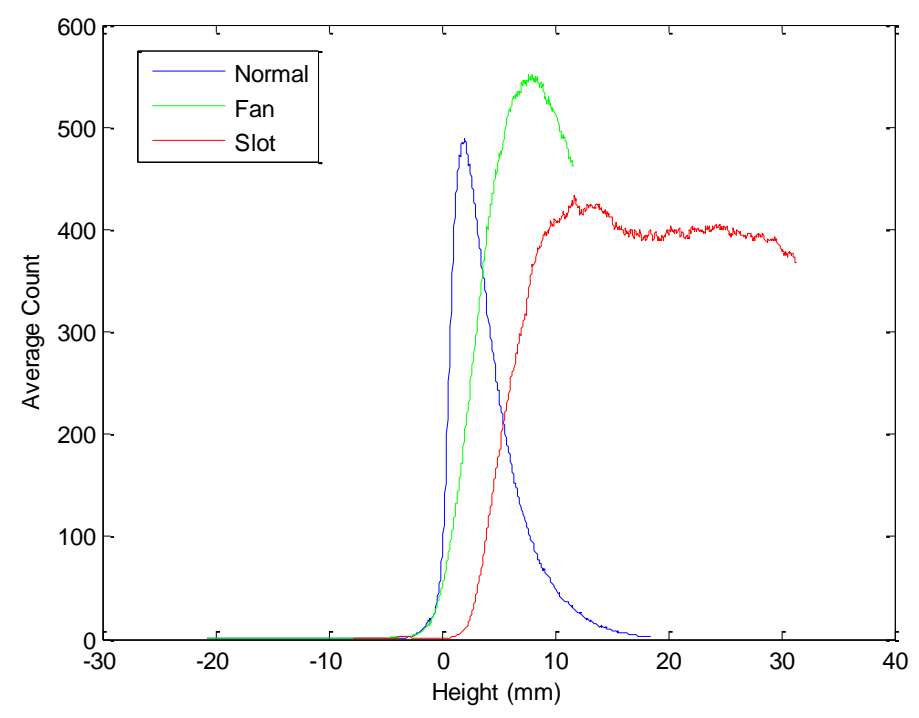

Figure 4.36 $\mathrm{OH}^{*}$ average photon count for three geometries, $\Phi=1.3, \mathrm{M}=7$

\subsubsection{Equivalence Ratio of 1.4}

Many of the same trends are viewed here as were seen at an equivalence ratio of

1.3. Thus trends are mentioned, but reasoning for these trends is often omitted since it is presented in the previous section. In this section trends specific to an equivalence ratio of 1.4 are discussed further.

As seen for the flames at an equivalence ratio of 1.3, the flames from the slot flow are noticeably larger than those from the normal and fan shaped hole flow (Figs. 4.37, 4.38, and 4.39). Also, the flame origination location for the slot occurs further downstream of its injection location than the maximum measurements for the normal and fan shaped holes. The flames from the fan shaped holes start only slightly further downstream from the injection location than the flames from the normal holes. The explanation for these two trends is the same as presented in the previous section; the amount and orientation of the cooling flow results in the varying flame origination locations and flame sizes and shapes. 
A difference in trends noticed at this blowing ratio is further illustrated by the width averaged chemiluminescence plots (Figs. 4.40, 4.41, and 4.42). The chemiluminescence emissions from the flame anchored to the slot are larger than the emissions from the flow through fan shaped and the normal holes at $M=1$. At $M=4$ and $M=7$, the fan shaped chemiluminescence slightly exceeds or is close to that of the slot. This is similar to what is observed at an equivalence ratio of 1.3 , but the peak normal hole chemiluminescence remains lower than the slot at each blowing ratio. A plausible explanation for this is the amount of flow at the same blowing ratio for each of the geometries.

In the case of the slot, the mass flow is higher at each blowing ratio providing more oxidizer for the fuel to react with, resulting in a larger photon count value. At a high blowing ratio there is excess cooling air and reaction is delayed until further downstream, at which point further mixing between the cooling air and the freestream flow has occurred. At a high blowing ratio, the air flow for the fan shaped holes is still adequately small that the flow is not causing the reaction to lessen. In the case of the normal holes, the amount of cooling flow is just as small as in the fan shaped holes, but the angle at which it is injected into the test section also plays a role. The small amount of cooling air through the normal holes is injected perpendicular to the freestream flow and thus disperses quickly into the main flow. Reaction between the fuel in the freestream flow and the small amount of cooling flow is not permitted to occur due to this immediate dispersion of the oxidizer before it can react significantly with the unburned fuel. 


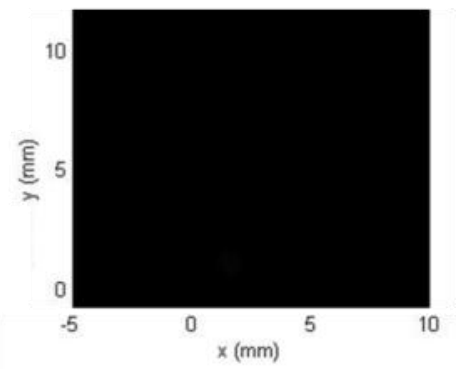

Normal Holes

Figure 4.37 $\mathrm{OH}^{*}$ chemiluminescence images for three geometries, $\Phi=1.4, \mathrm{M}=1$

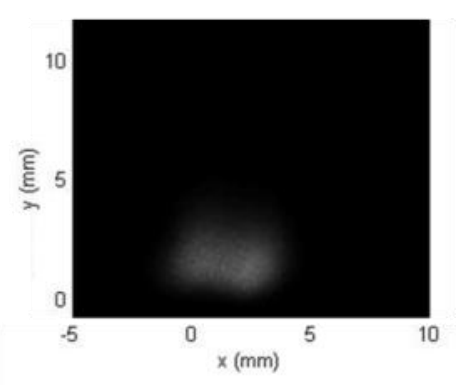

Normal Holes

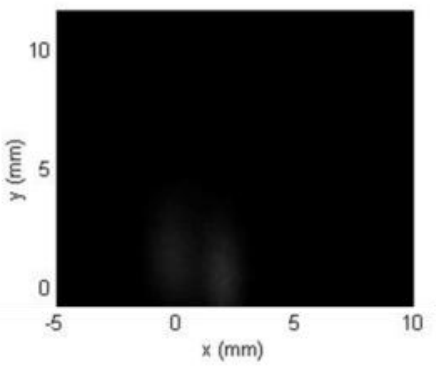

Fan Shaped Holes
Slot
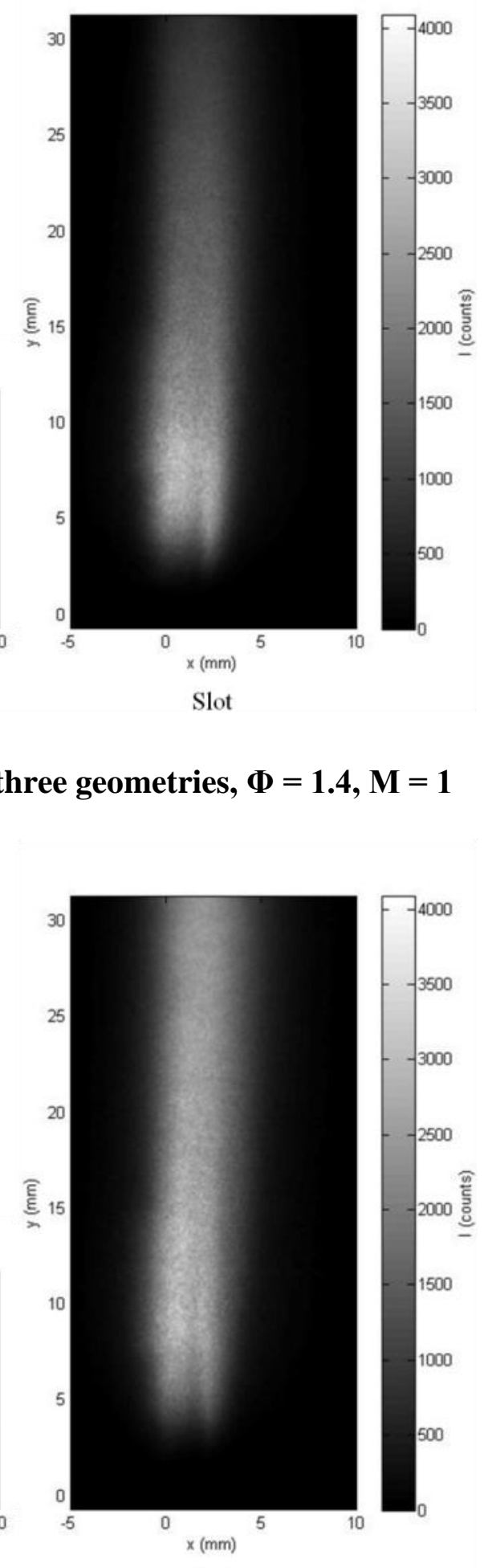

Fan Shaped Holes

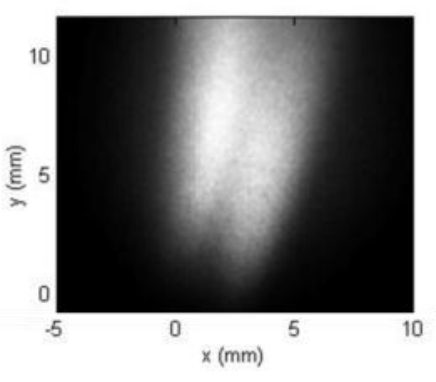

Figure 4.38 $\mathrm{OH}^{*}$ chemiluminescence images for three geometries, $\Phi=1.4, \mathrm{M}=4$ 


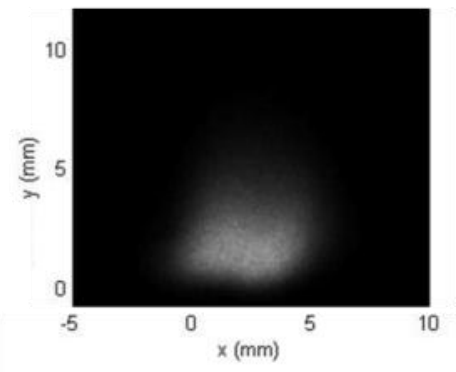

Normal Holes

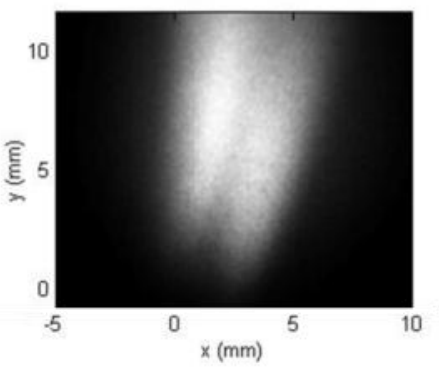

Fan Shaped Holes

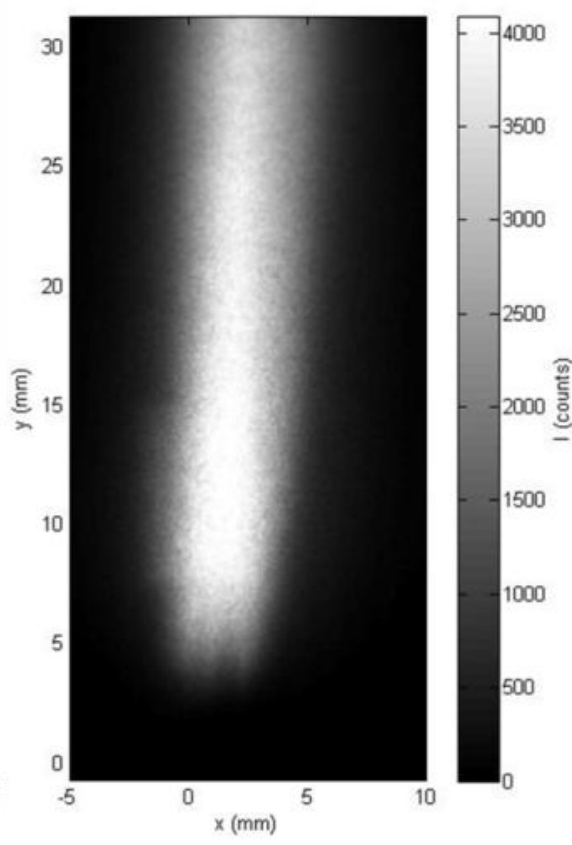

Slot

Figure 4.39 $\mathrm{OH}^{*}$ chemiluminescence images for three geometries, $\Phi=1.4, \mathrm{M}=7$

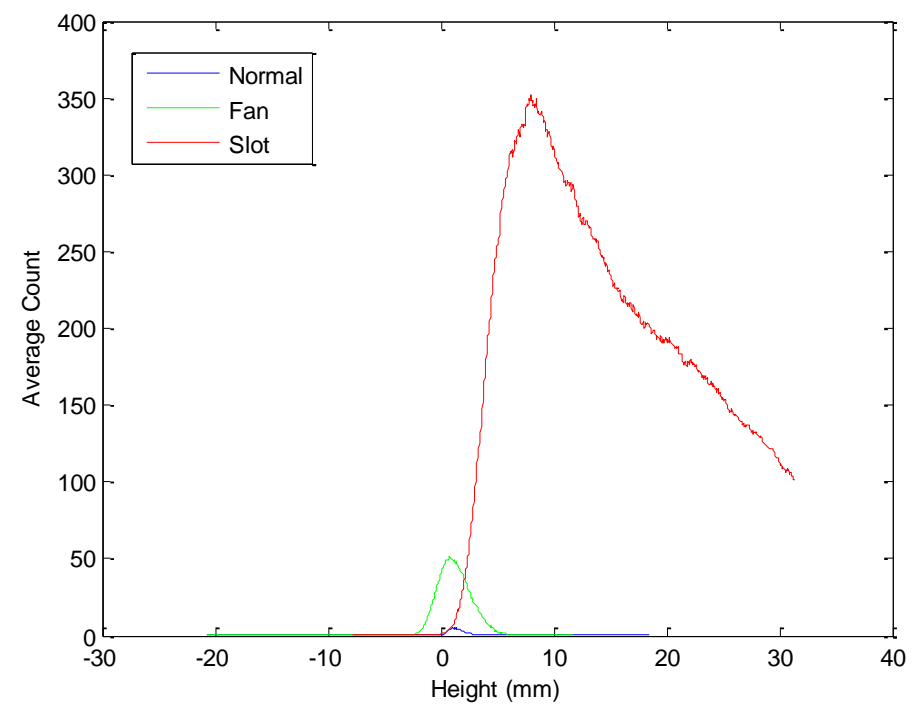

Figure 4.40 $\mathrm{OH}^{*}$ average photon count for three geometries, $\Phi=1.4, \mathrm{M}=1$ 


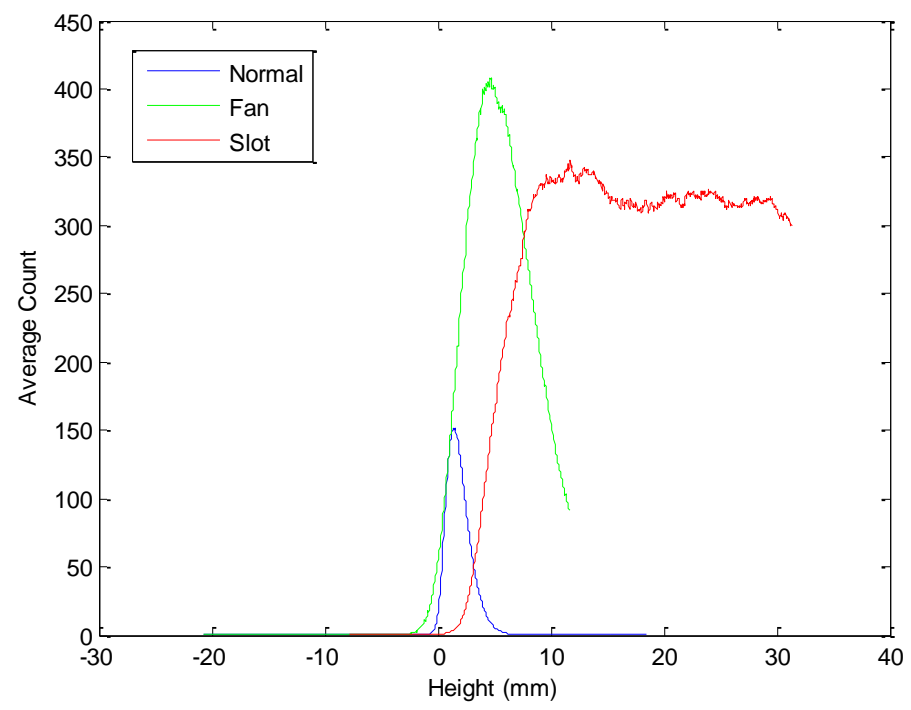

Figure 4.41 $\mathrm{OH}^{*}$ average photon count for three geometries, $\Phi=1.4, \mathrm{M}=4$

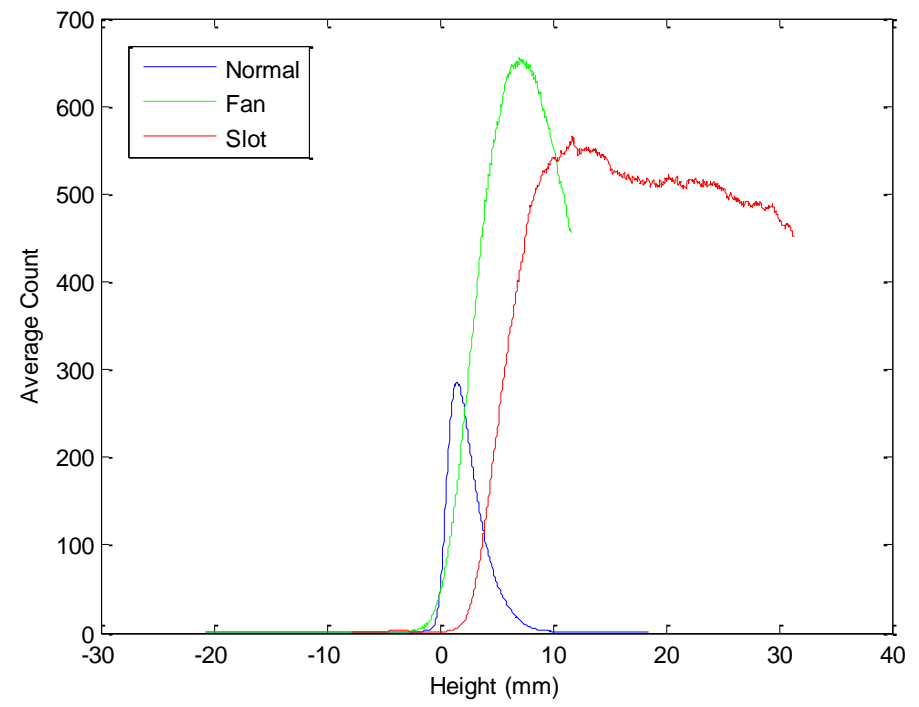

Figure 4.42 $\mathrm{OH}^{*}$ average photon count for three geometries, $\Phi=1.4, M=7$

\subsubsection{Equivalence Ratio of 1.5}

The trends seen here are similar to those experienced at equivalence ratios of 1.3 and 1.4. The flames (Figs. 4.43, 4.44, and 4.45) have similar shapes and the trends based on the shapes of the flames do not change at this larger equivalence ratio. The flames from the slot flow are noticeably larger than those from the normal and fan shaped hole 
flow, and the flame locations trend in the same fashion as present previously. Again, the reasoning for this is based on the amount and orientation of the cooling flow.

Figures $4.46,4.47$, and 4.48 show the average photon counts at an equivalence ratio of 1.5 for blowing ratios of 1,4 , and 7 . At a blowing ratio of 1 (Fig. 4.46) the slot has the highest chemiluminescence, followed by the fan, and then the normal holes. At a blowing ratio of 4 (Fig. 4.47) the fan shaped hole chemiluminescence is larger than the slot. The normal hole chemiluminescence maximum remains below those of the slot and fan shaped holes at each blowing ratio.

The observed trends at this equivalence ratio are the same as those seen at an equivalence ratio of 1.4. This suggests that the higher equivalence ratios of 1.4 and 1.5 have a noticeable effect on the characteristics of the flow and flames. In the case of equivalence ratio of 1.3 , there is enough difference in the amount of fuel within the freestream flow in comparison to $\Phi=1.4$ and 1.5 to change the observed trends and characteristics. 


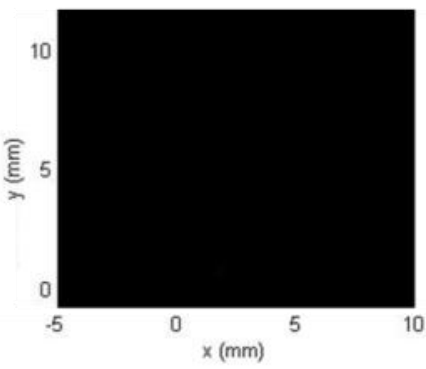

Normal Holes

Figure 4.43 $\mathrm{OH}^{*}$ chemiluminescence images for three geometries, $\Phi=1.5, M=1$

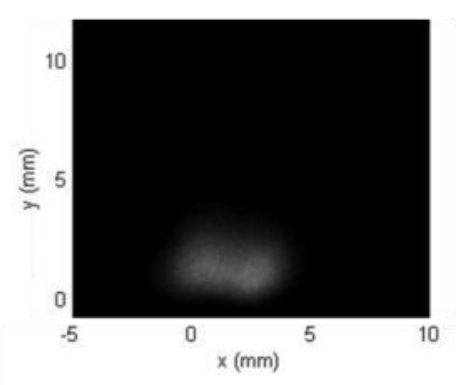

Normal Holes

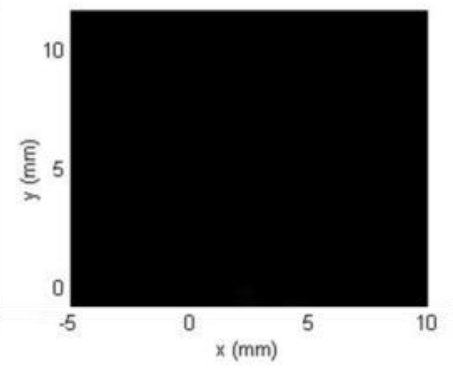

Fan Shaped Holes
Slot
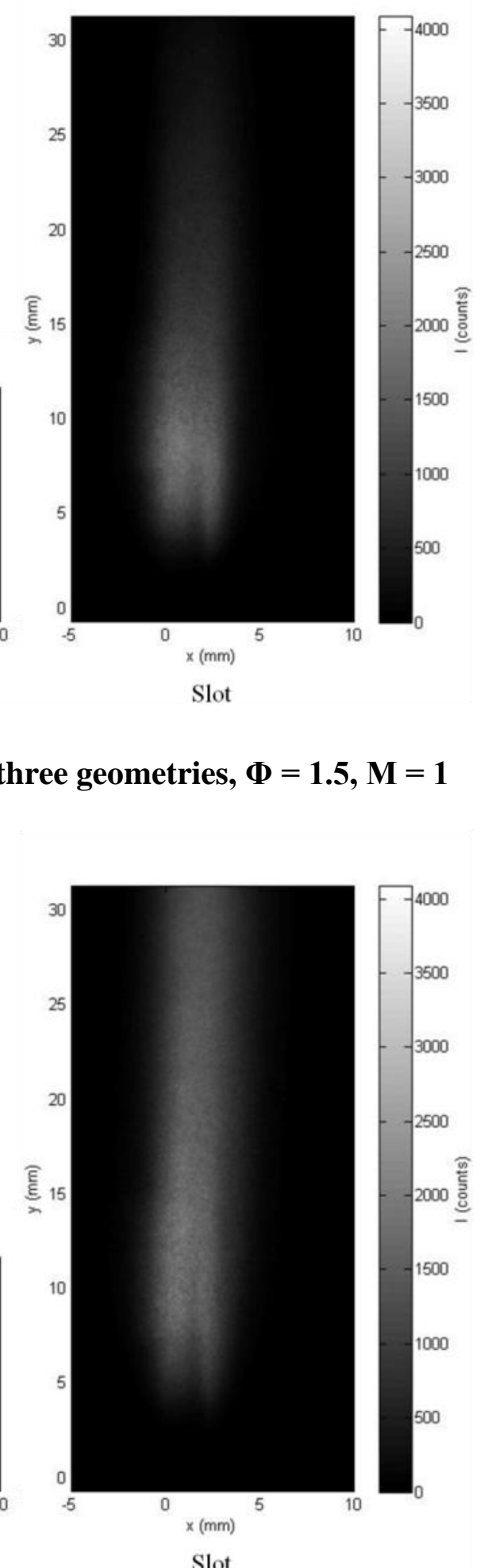

Fan Shaped Holes
Slot

Figure 4.44 $\mathrm{OH}^{*}$ chemiluminescence images for three geometries, $\Phi=1.5, \mathrm{M}=4$ 


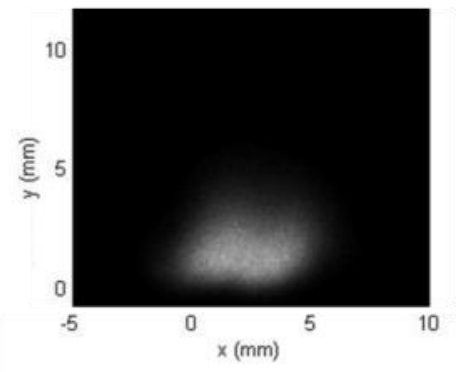

Normal Holes

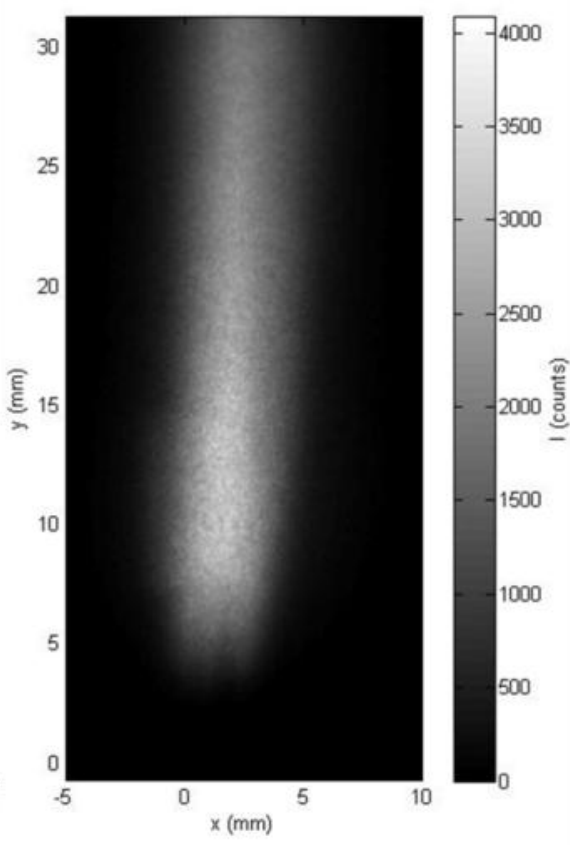

Slot

Figure 4.45 $\mathrm{OH}^{*}$ chemiluminescence images for three geometries, $\Phi=1.5, M=7$

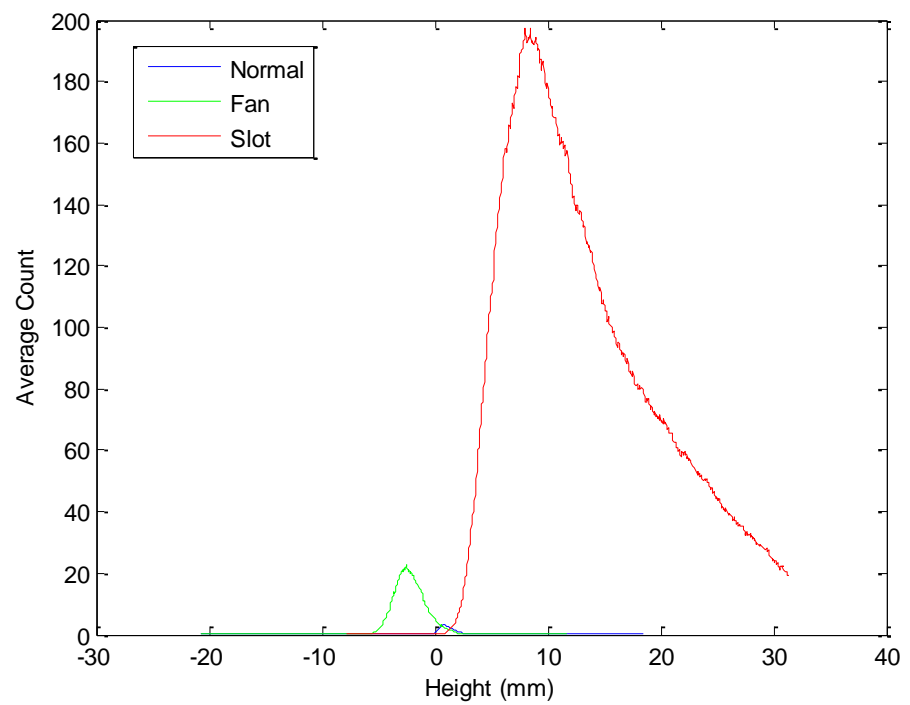

Figure 4.46 $\mathrm{OH}^{*}$ average photon count for three geometries, $\Phi=1.5, M=1$ 


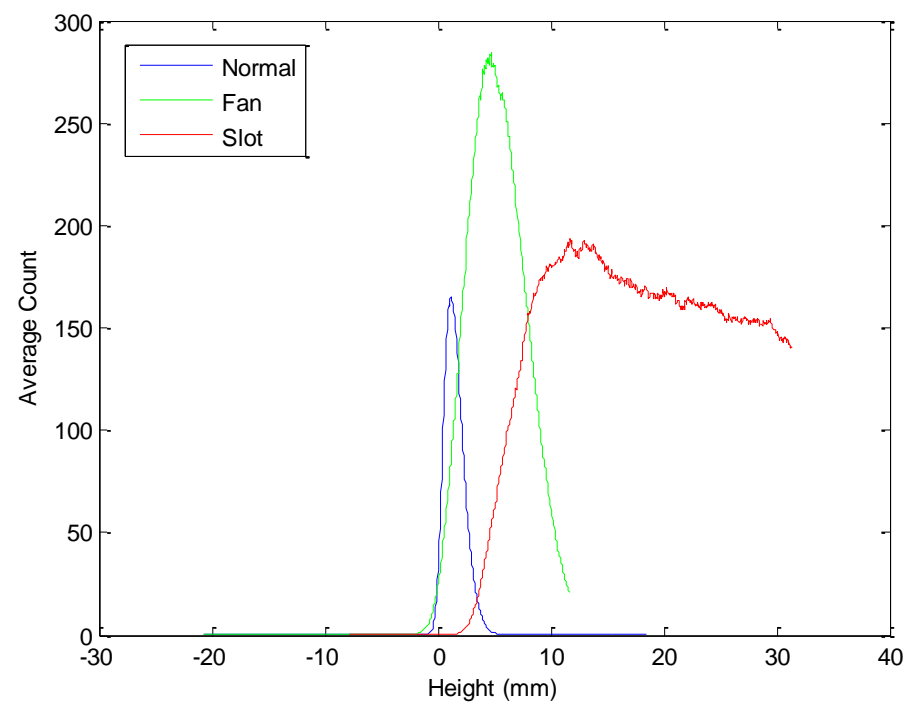

Figure 4.47 $\mathrm{OH}^{*}$ average photon count for three geometries, $\Phi=1.5, \mathrm{M}=4$

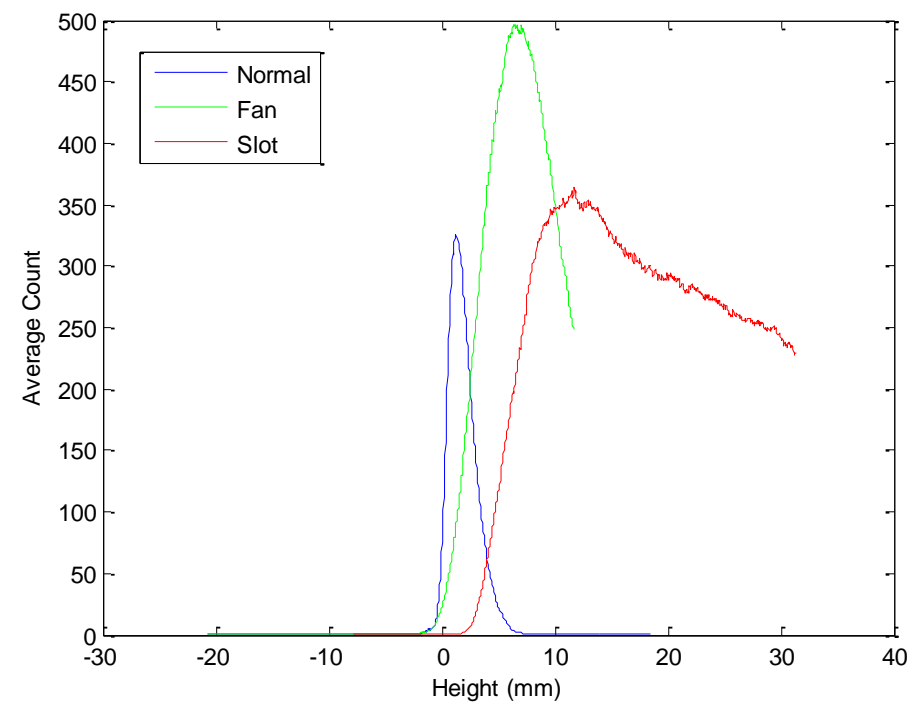

Figure 4.48 $\mathrm{OH}^{*}$ average photon count for three geometries, $\Phi=1.5, \mathrm{M}=7$

\subsubsection{Equivalence Ratio Comparison}

Plots are presented for the $\mathrm{OH}^{*}$ filter comparing blowing ratios of 1,4 , and 7 at each equivalence ratio for each geometry. The accompanying equivalence ratio comparison flame images are offered in Appendix A (since the flames at each of these 
conditions have been viewed in previous sections). Table 4.3 provides the results for chemiluminescence data based on equivalence ratio, as discussed further in this section.

Table 4.3 Summary of equivalence ratio comparison results for chemiluminescence data

\begin{tabular}{|c|c|c|c|}
\hline $\begin{array}{c}\text { Blowing } \\
\text { Ratio }\end{array}$ & Geometry & Chemilumine scence & $\begin{array}{c}\text { Flame } \\
\text { Origination }\end{array}$ \\
\hline 1 & $\mathrm{~N}$ & $1.3>1.4>1.5$ & $1.5,1.4,1.3$ \\
\hline 1 & $\mathrm{~F}$ & $1.4>1.3>1.5$ & $1.5,1.4,1.3$ \\
\hline 1 & $\mathrm{~S}$ & $1.4>1.3>1.5$ & $1.4,1.3,1.5$ \\
\hline 4 & $\mathrm{~N}$ & $1.3>1.5>1.4$ & $1.5,1.4,1.3$ \\
\hline 4 & $\mathrm{~F}$ & $1.4>1.3>1.5$ & $1.4,1.3,1.5$ \\
\hline 4 & $\mathrm{~S}$ & $1.4>1.3>1.5$ & $1.4,1.3,1.5$ \\
\hline 7 & $\mathrm{~N}$ & $1.3>1.5>1.4$ & $1.5,1.4,1.3$ \\
\hline 7 & $\mathrm{~F}$ & $1.4>1.3>1.5$ & $1.4,1.3,1.5$ \\
\hline 7 & $\mathrm{~S}$ & $1.4>1.3>1.5$ & $1.4,1.3,1.5$ \\
\hline
\end{tabular}

\subsubsection{Blowing Ratio of 1}

With the normal hole geometry the observable flame chemiluminescence in the images is faint regardless of the equivalence ratio, making it difficult to investigate trends using these images. The plots present a much better method by which to observe normal hole trends at low blowing ratio. The small amount of air that is injected into the test section at a blowing ratio of 1 is part of the reason for the faint flames.

It is observed that the fan shaped and slot geometries have noticeably larger emission intensities at a blowing ratio of 1 . In the case of the slot, the reason for this is as discussed previously; due to the larger exit area, there is a larger amount of air injected at the same blowing ratio. The large amount of air flow injected causes greater reaction between the cooling air and the fuel in the freestream flow. The reason for the slight difference in intensity between the normal holes and the fan shaped holes is likely due to the angle with which the flow is injected. The fan shaped flow is injected with a 
tangential velocity component while the normal flow is injected orthogonal to the freestream. The normal hole cooling flow is quickly dispersed into the main flow causing mixing of the cooling air before it reacts significantly with the unburned fuel. The flow through the fan shaped holes does not disperse as quickly as a result of the tangential velocity component allowing the reaction to occur in the boundary layer.

For the normal holes the average count plot (Fig. 4.49) shows that with an increase in equivalence ratio comes a decrease in the flame intensity. A reasonable explanation for this may be the increase in the freestream flow. At the lowest equivalence ratio and blowing ratio, the fuel to air ratio is adequate for reactions to take place, and there is less flow in the freestream to overwhelm the cooling flow. As the equivalence ratio increases the freestream flow is larger and it is able to more easily mix with the cooling flow causing dispersion of the cooling flow throughout the test section. This leads to a less concentrated and intense reaction region within the boundary layer. For the fan shaped holes and the slot, the chemiluminescence emissions are highest at an equivalence ratio of 1.4 , and lowest at an equivalence ratio of 1.5 , as shown in Figs. 4.50 and 4.51. The peak intensity at an equivalence ratio is arguably due to the ratio of fuel to oxidizer after the injection of the cooling air. At an equivalence ratio of 1.5 , the larger amount of freestream flow overcomes the injection of the cooling air, which thus has a lesser effect on the reaction. There seems to be a peak reaction between cooling air flow and vitiated flow around an equivalence ratio of 1.4. 


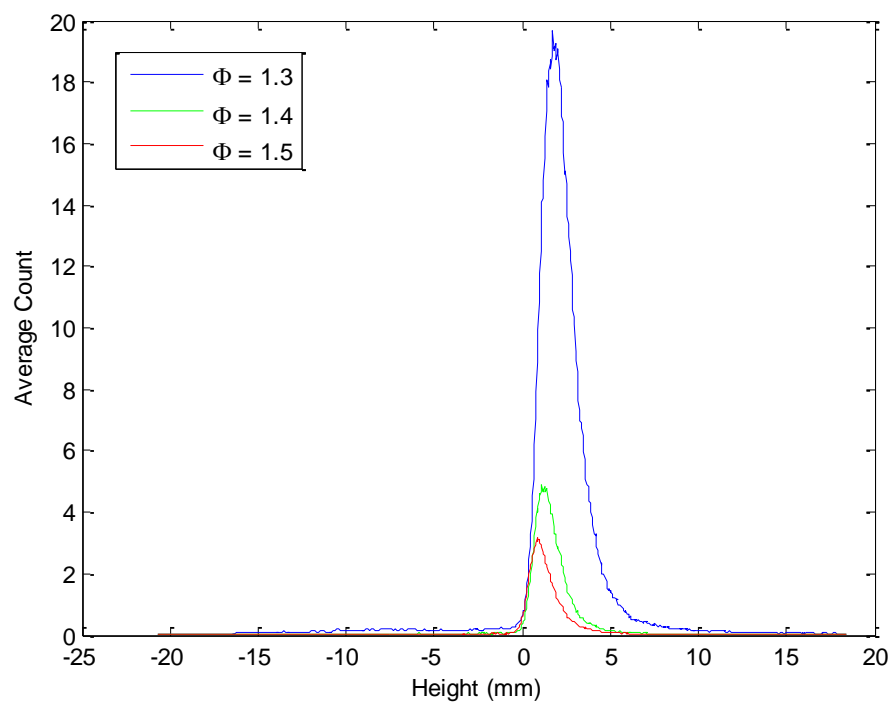

Figure 4.49 $\mathrm{OH}^{*}$ average photon count at equivalence ratios, $\mathrm{M}=1$, normal holes

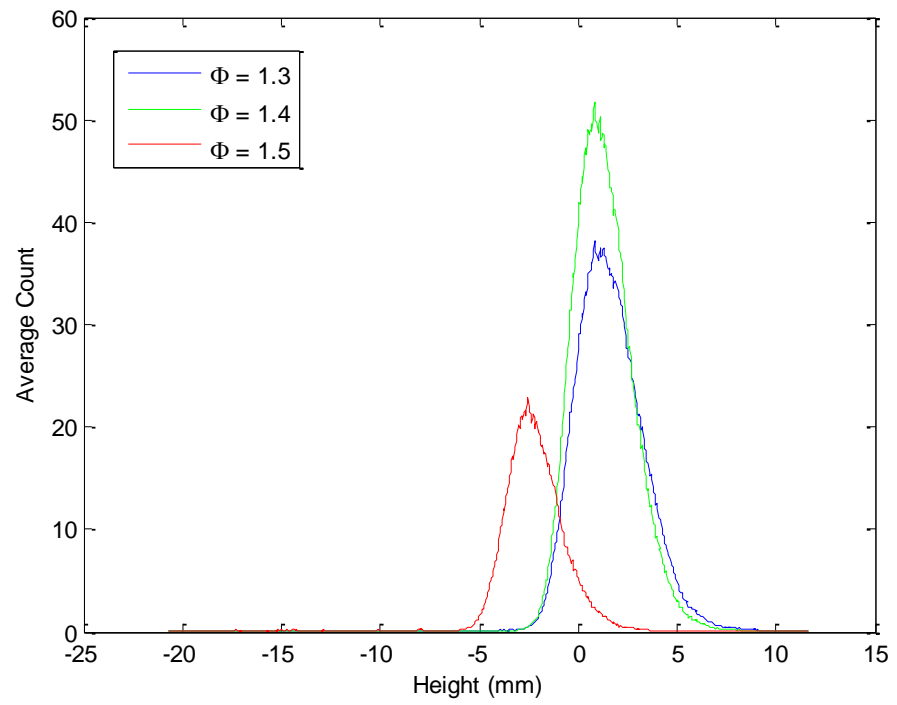

Figure 4.50 $\mathrm{OH}^{*}$ average photon count at equivalence ratios, $M=1$, fan shaped holes 


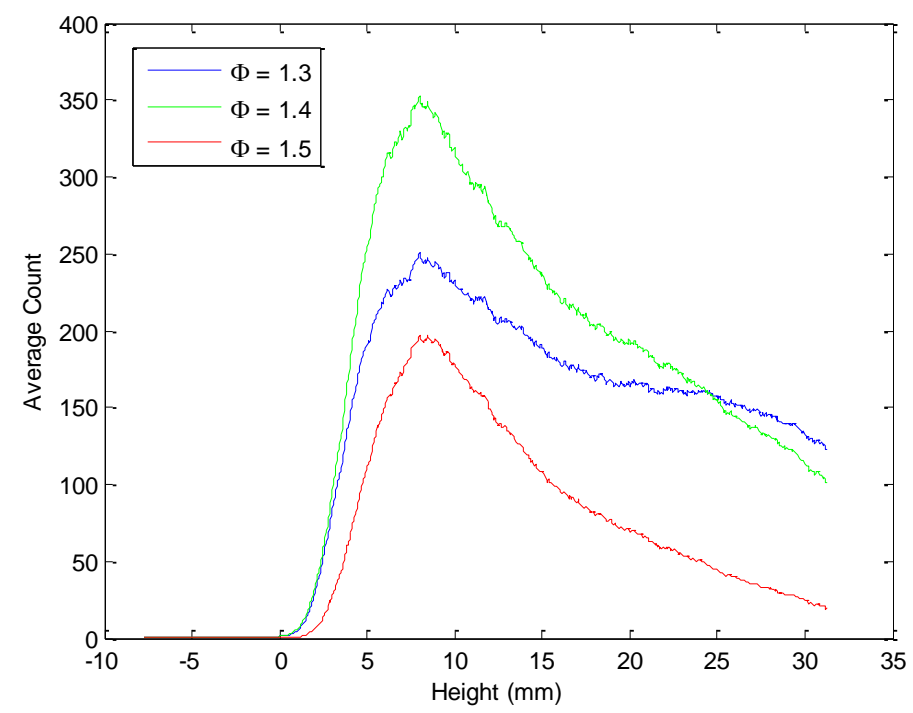

Figure 4.51 $\mathrm{OH}^{*}$ average photon count at equivalence ratios, $M=1$, slot

\subsubsection{Blowing Ratio of 4}

At a blowing ratio of 4 all the flames are more visible at each equivalence ratio (see flame images in Appendix A, Figs. A.4 through A.6). For the normal holes the size of the flame decreases with an increase in equivalence ratio. The plot (Fig. 5.52) shows that the peak average intensity is largest at an equivalence ratio of 1.3. The peak intensity values are similar at equivalence ratios of 1.4 and 1.5. It is probable that this effect is a function of the amount of freestream flow in comparison to the amount of cooling flow. As discussed in previous sections, the flame origination location does not change for the normal holes. Regardless of the equivalence ratio, the flame begins in the same location.

Just as in the normal flames, the flames from cooling flow through the fan shaped holes appear to decrease in size with equivalence ratio. The peak average chemiluminescence emissions do not decrease with equivalence ratio. The maximum occurs at an equivalence ratio of 1.4. This is an effect of the fuel to air ratio created at an equivalence ratio of 1.4 and a blowing ratio of 4 , coupled with the injection angle of the 
flow. Though the same amount of flow exits the fan shaped holes as does the normal holes at the same blowing ratio, the difference in injection angle causes the observed differences in trends. The location of the flame origination does not change much with equivalence ratio. The most intense flame (at $\Phi=1.4$ ) starts the earliest, while the least intense flame (at $\Phi=1.5$ ) starts the latest. The chemiluminescence intensity of the reaction and the flame location appear to be a function of the ratio of fuel to air once the cooling flow is injected into the test section; the more conducive that ratio is to reaction, the sooner the reaction originates.

Figure 4.54 illustrates the change in the flame from the slot geometry with equivalence ratio. The chemiluminescence emissions appear to peak at an equivalence ratio of 1.4. The change in size of the flame between the equivalence ratios of 1.3 and 1.4 is not very large. The flame at an equivalence ratio of 1.5 is noticeably narrower and shorter than the other two reaction regions. Somewhere after an equivalence ratio of 1.4, the chemiluminescence emissions and thus the heat release rate begins to decrease. It is observed at a low point for this study at an equivalence ratio of 1.5 .

The changes in chemiluminescence emissions due to the boundary layer reactions likely have to do with the change in fuel-to-cooling air ratio as the equivalence ratio of the freestream flow changes. As seen with the fan shaped hole flames, the optimum ratio for reaction is around an equivalence ratio of 1.4. Because this trend is seen for both the fan shaped holes and slot, it is probable that it is not only an effect of the fuel-to-air ratio, but also an effect of the injection angle of the cooling flow; the fan and slot flow are injected at the same angle into the test section. 


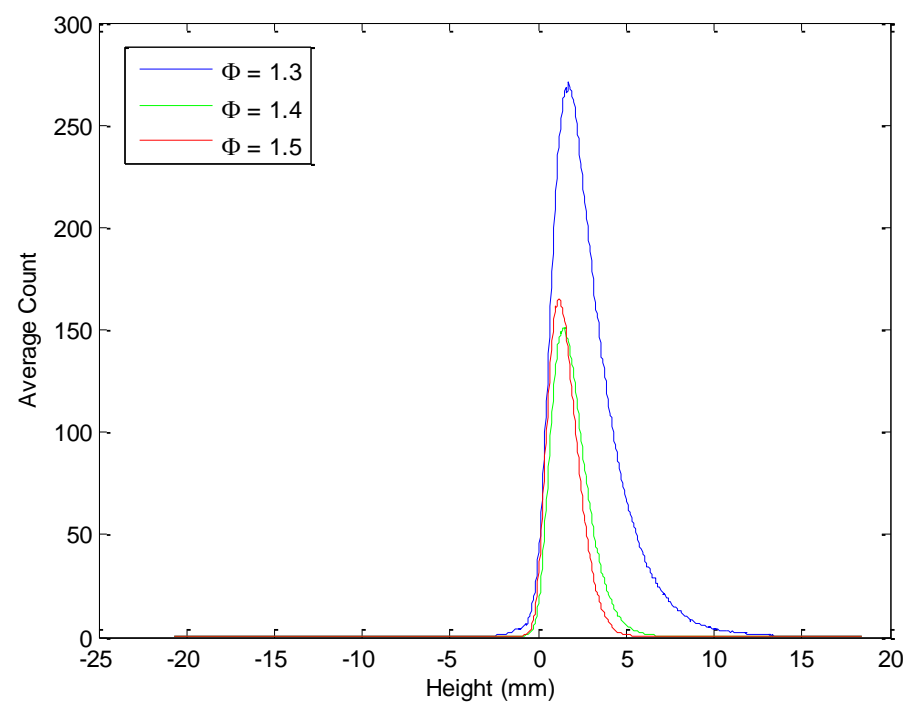

Figure 4.52 $\mathrm{OH}^{*}$ average photon count at equivalence ratios, $M=4$, normal holes

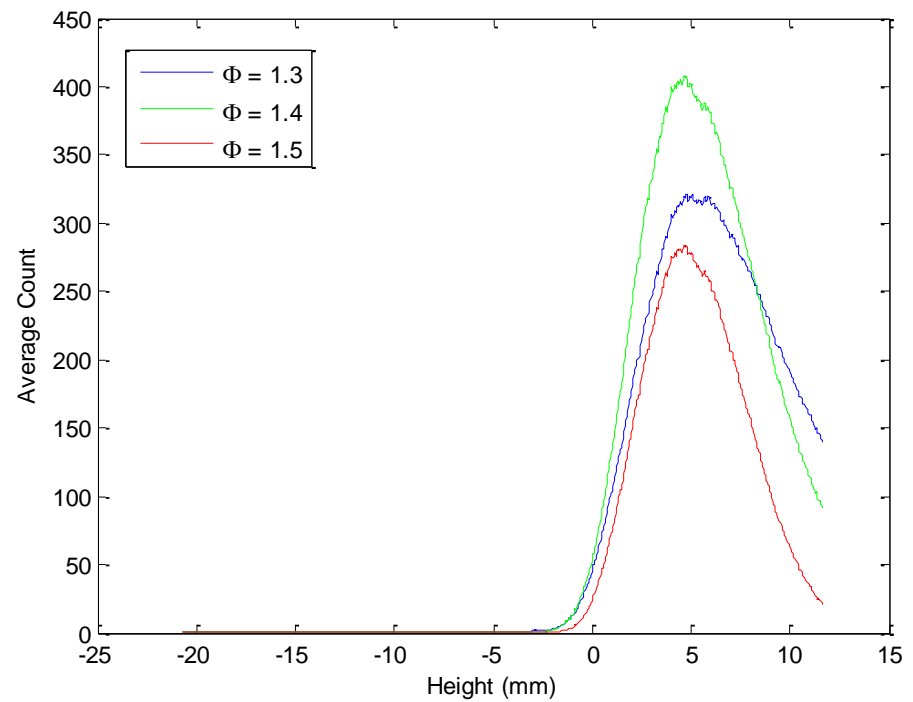

Figure 4.53 $\mathrm{OH}^{*}$ average photon count at equivalence ratios, $M=4$, fan shaped

holes 


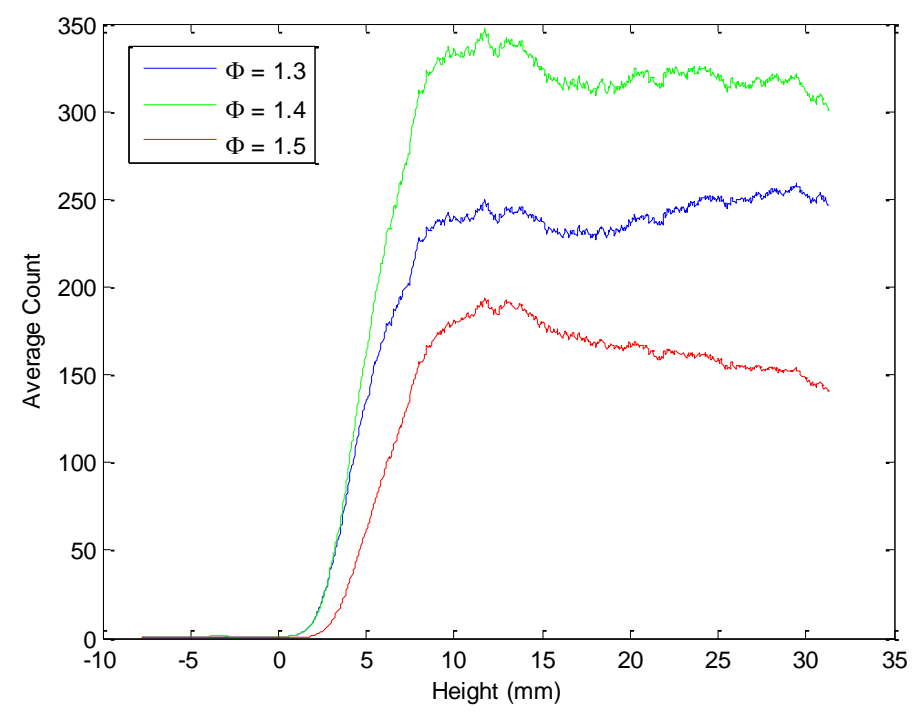

Figure $4.54 \mathrm{OH}^{*}$ average photon count at equivalence ratios, $M=4$, slot

\subsubsection{Blowing Ratio of 7}

This section presents the chemiluminescence $\mathrm{OH}^{*}$ emission plots at a blowing ratio of 7 (the images are contained in Appendix A). For the normal holes, the size of the reaction region decreases as the equivalence ratio increases (Fig. 5.55). There is a noticeably larger decrease in flame size between equivalence ratios of 1.3 and 1.4 than between equivalence ratios of 1.4 and 1.5. The peak average amount of emissions appears to be the largest at an equivalence ratio of 1.3. Then the emissions decrease at $\Phi$ $=1.4$ and begin to increase again up to $\Phi=1.5$.

It is probable that both the change in flame size and the change in chemiluminescence emissions intensity are based on the fuel-to-cooling air ratio and on the amount of freestream flow present. The emissions decrease with increasing equivalence ratio suggests that the fuel-to-cooling air ratio is not conducive to reactions. As the freestream flow increases with the increase in equivalence ratio it has an effect on the dispersion of the cooling flow from the boundary layer to the rest of the test section; 
an increase in the freestream flow causes higher dispersion and thus a smaller and less intense main reaction region. In the case of the normal holes, the change in freestream flow has more effect on the size of the reaction due to the fact that the cooing air is injected orthogonal to the main flow and is thus immediately mixed with the main flow.

The trends for the fan shaped holes are seen in Fig. 4.56 and the trends for the slot are seen in Fig. 4.57. The same trends for the flame size and chemiluminescence emissions occur here as did for the fan shaped holes and the slot at a blowing ratio of 4 . Again it is expected that the changes are a function of the fuel-to-cooling air ratio and the injection angle of the cooling flow.

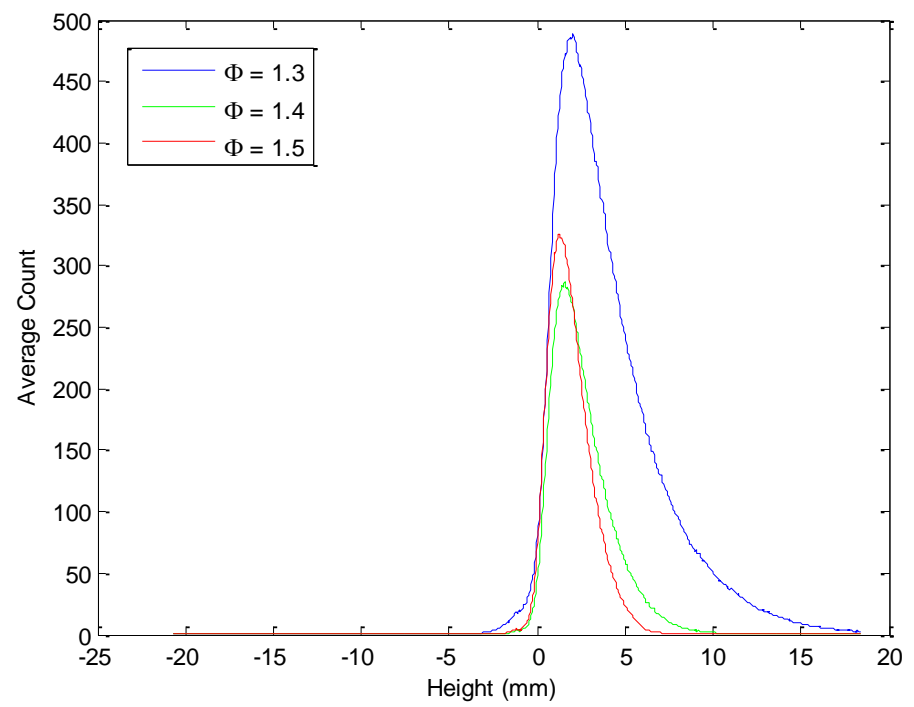

Figure 4.55 $\mathrm{OH}^{*}$ average photon count at blowing ratios, $\mathrm{M}=7$, normal holes 


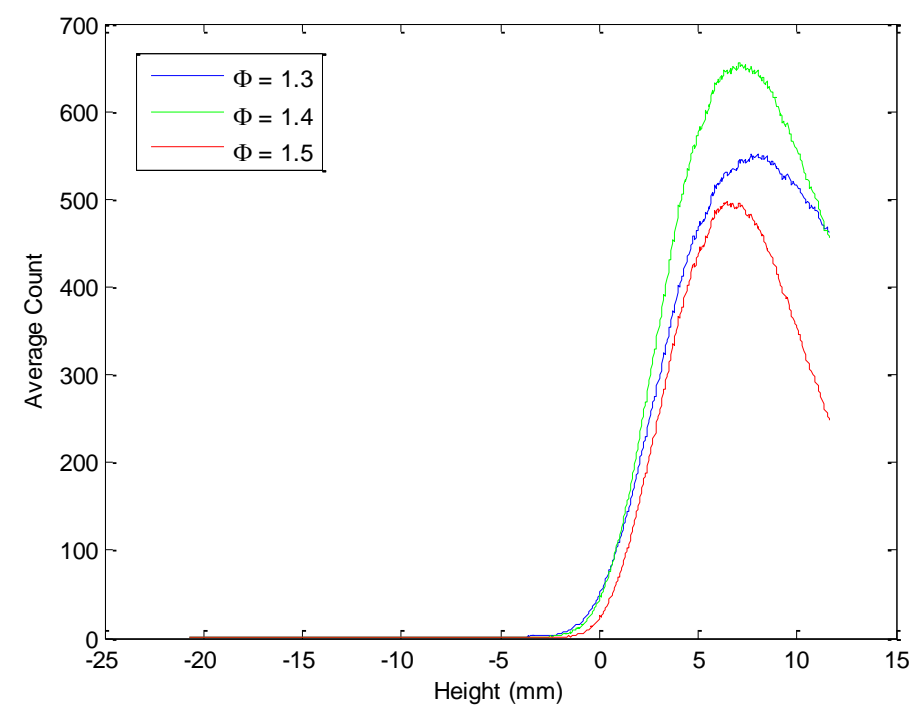

Figure 4.56 $\mathrm{OH}^{*}$ average photon count at equivalence ratios, $\mathrm{M}=7$, fan shaped holes

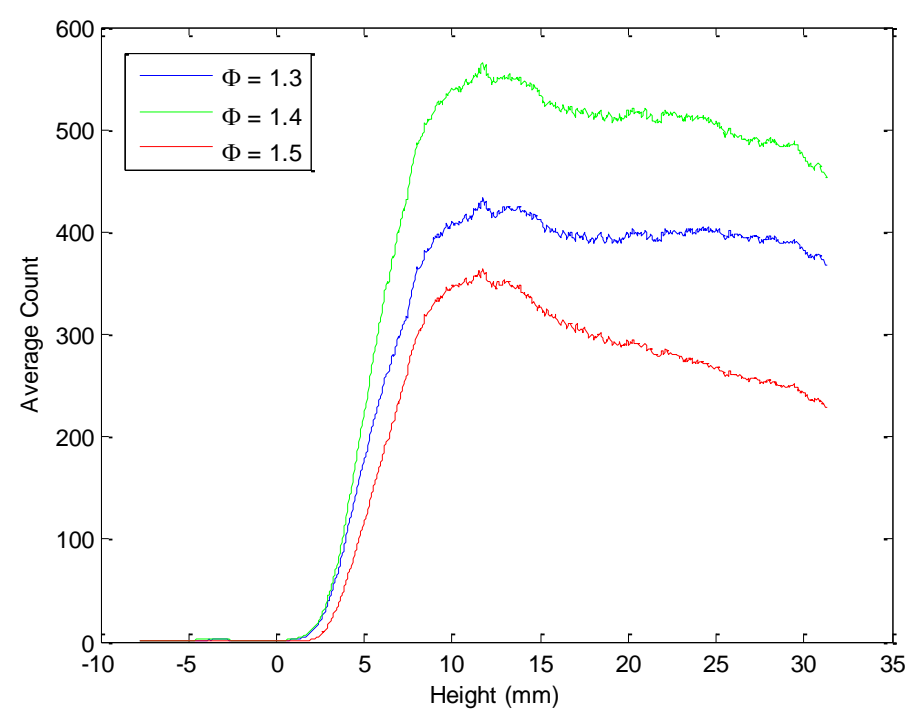

Figure $4.57 \mathrm{OH}^{*}$ average photon count at equivalence ratios, $M=7$, slot

\subsection{HEAT FLUX MEASUREMENTS}

The heat fluxes were calculated using the measured temperatures from the thermocouples located in the heat flux gauges. The heat flux gauges closer to the cooling film are located $10.4 \mathrm{~mm}$ downstream of the cooling holes, referred to as Station 1 from 
this point onward. The heat fluxes presented at this vertical location are an average of two (front and back) heat flux gauges. The heat flux gauges located $38.4 \mathrm{~mm}$ downstream of the cooling holes are referred to as Station 2. The het flux presented in this section as $38.4 \mathrm{~mm}$ downstream is an average of the measurements from the two far heat flux gauges.

There is some difference between the heat flux data from the two gauges at each height. For the normal holes the heat flux data from Station 1 varies $10 \%$ on average; the heat flux data from Station 2 varies $12 \%$ on average. For the fan shaped holes heat flux data from Station 1 varies $6 \%$ on average; the heat flux data from Station 2 varies $10 \%$ on average. For the slot the heat flux data from Station 1 varies $18 \%$ on average; the heat flux data from Station 2 varies $12 \%$ on average.

\subsubsection{Equivalence Ratio and Blowing Ratio Comparison}

Presented in the following sections are comparisons of the heat flux data based on equivalence ratio and blowing ratio. Tables 4.4 and 4.5 summarize the findings discussed in these sections.

Table 4.4 Summary of equivalence ratio comparison results for heat flux data

\begin{tabular}{|c|c|c|}
\hline Geometry & Location & Heat Flux \\
\hline N & 1 & $1.3>1.4>1.5$ \\
\hline N & 2 & $1.3>1.4>1.5$ \\
\hline F & 1 & $1.3>1.4>1.5$ \\
\hline F & 2 & $1.3>1.4>1.5$ \\
\hline S & 1 & $1.5>1.4>1.3$ \\
\hline S & 2 & $1.5>1.4>1.3$ \\
\hline
\end{tabular}


Table 4.5 Summary of blowing ratio comparison results for heat flux data

\begin{tabular}{|c|c|c|c|}
\hline Geometry & Location & \begin{tabular}{|c|} 
Equivalence \\
Ratio
\end{tabular} & Heat Flux \\
\hline $\mathrm{N}$ & 1 & 1.3 & $\begin{array}{c}7>4>3>2>1 \\
\text { drops at } 5 \\
\end{array}$ \\
\hline $\mathrm{N}$ & 2 & 1.3 & $\begin{array}{c}7>4>3>2>1 \\
\text { drops at } 5\end{array}$ \\
\hline $\mathrm{N}$ & 1 & 1.4 & $7>4>1$ \\
\hline $\mathrm{N}$ & 2 & 1.4 & $7>4>1$ \\
\hline $\mathrm{N}$ & 1 & 1.5 & $7>4>1$ \\
\hline $\mathrm{N}$ & 2 & 1.5 & $7>4>1$ \\
\hline $\mathrm{F}$ & 1 & 1.3 & $\begin{array}{c}7>5>4>3>1 \\
\text { drops at } 2\end{array}$ \\
\hline $\mathrm{F}$ & 2 & 1.3 & $\begin{array}{c}7>5>4>3>1 \\
\text { drops at } 2\end{array}$ \\
\hline $\mathrm{F}$ & 1 & 1.4 & $7>4>1$ \\
\hline $\mathrm{F}$ & 2 & 1.4 & $7>4>1$ \\
\hline $\mathrm{F}$ & 1 & 1.5 & $7>4>1$ \\
\hline $\mathrm{F}$ & 2 & 1.5 & $7>4>1$ \\
\hline$S$ & 1 & 1.3 & $\begin{array}{c}1>2>3>4>5 \\
\text { jumps at } 7\end{array}$ \\
\hline $\mathrm{S}$ & 2 & 1.3 & $\begin{array}{c}>2>3>4>5 \\
\text { jumps at } 7\end{array}$ \\
\hline $\mathrm{S}$ & 1 & 1.4 & $1>4=7$ \\
\hline$S$ & 2 & 1.4 & $1>4=7$ \\
\hline $\mathrm{S}$ & 1 & 1.5 & $1>4=7$ \\
\hline $\mathrm{S}$ & 2 & 1.5 & $1>4=7$ \\
\hline
\end{tabular}

\subsubsection{Normal Holes}

Figures 4.58 and 4.59 show the temperature gauge trends for the normal holes. In both plots it is seen that the heat flux varies with both equivalence ratio and blowing ratio. There is an overall increase in heat flux as the blowing ratio increases, though at both gauge locations there is a dip in heat flux at a blowing ratio of 5 . This small drop in heat flux suggests that there is an optimum blowing ratio around 5 for achieving minimum heat flux to the surface. It is also possible that this data point is anomalous and is possibly a result of a broken ceramic piece from the WSR moving through the test 
section. As the equivalence ratio increases the heat flux to the surface decreases at both gauge locations.

The Station 1 gauge, which is closer in proximity to the cooling flow injection location and thus closer to the peak reaction zone (resulting in larger temperature differences), has a larger range of heat flux values than the Station 2 gauge. The further downstream gauge is further from the peak reaction where the temperature has settled more and it is closer to the freestream temperature regardless of the equivalence ratio. The heat flux at this downstream location is based less on the reaction, blowing ratio, and equivalence ratio, and more on the temperature of the freestream flow.

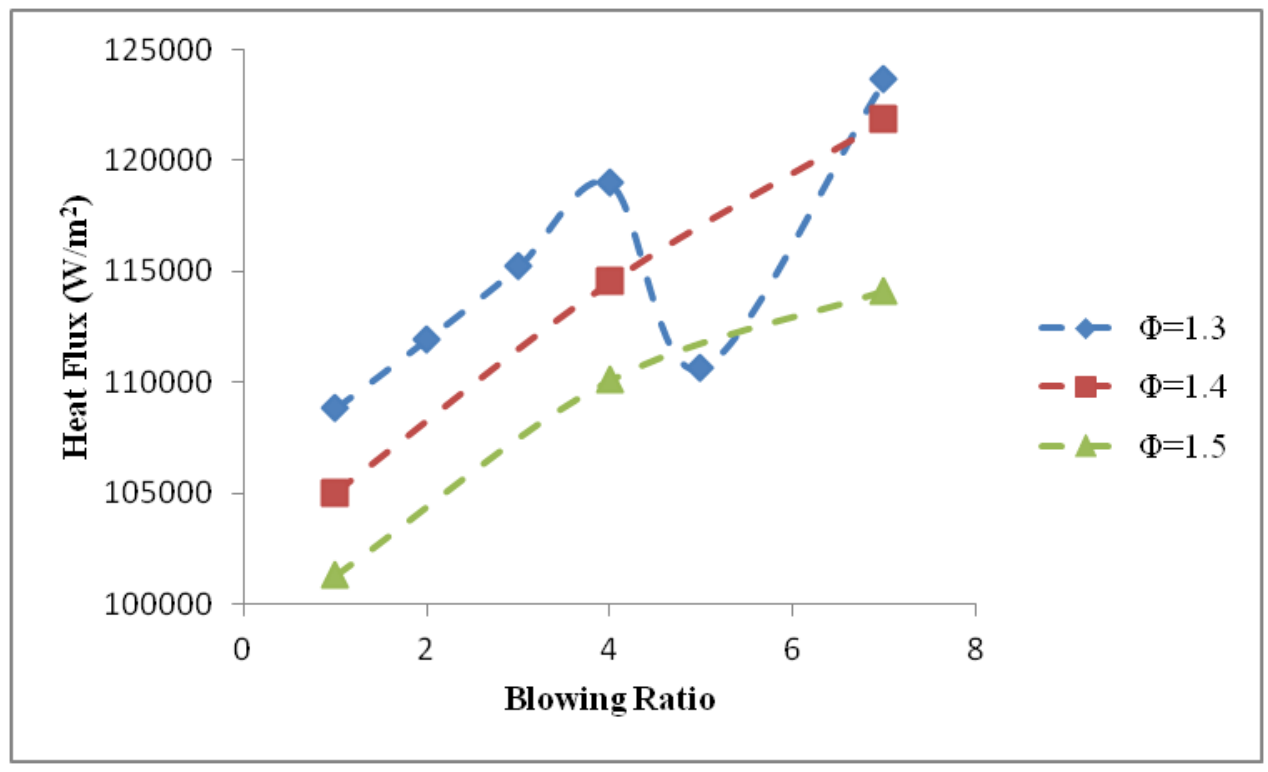

Figure 4.58 Station 1 average heat flux at blowing ratios for three equivalence ratios, normal holes 


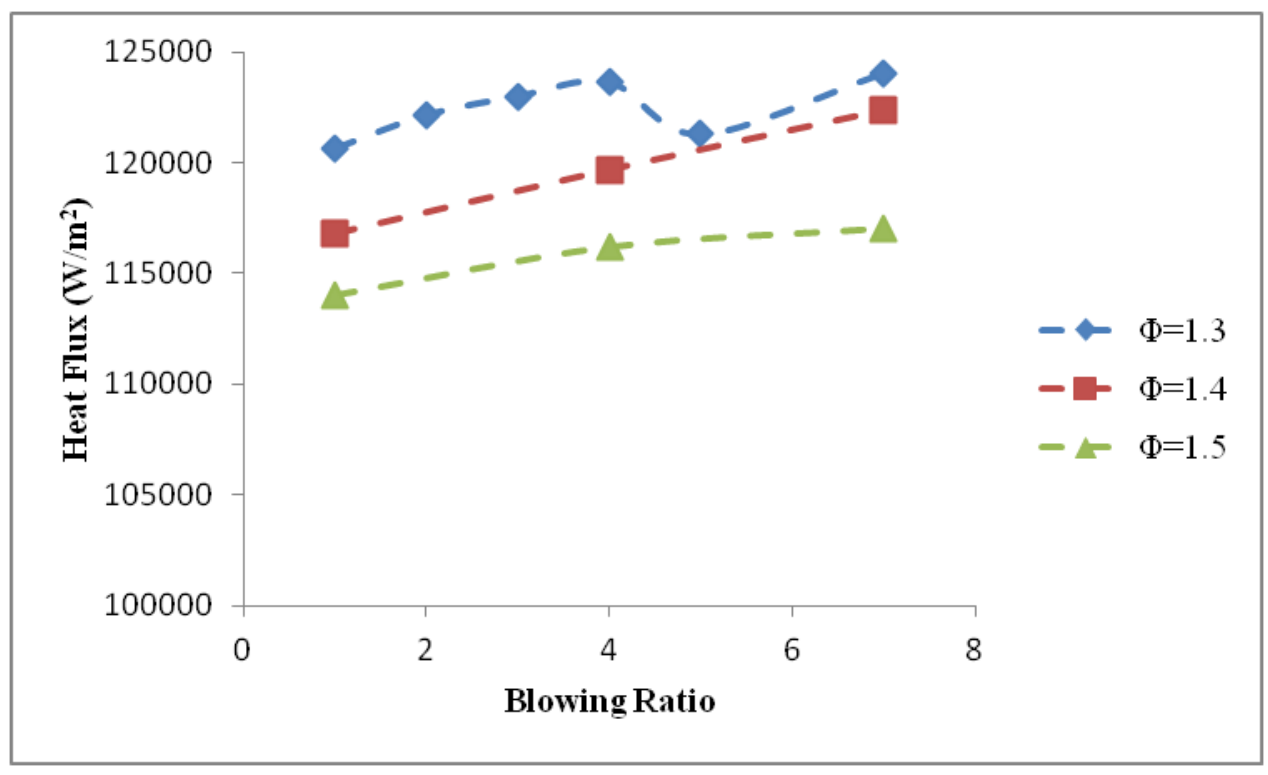

Figure 4.59 Station 2 average heat flux at blowing ratios for three equivalence ratios, normal holes

\subsubsection{2. $\quad$ Fan Shaped Holes}

Figures 4.60 and 4.61 show the average heat flux at the upstream and downstream locations for the fan shaped holes. Again, the change in heat flux at the near gauge location as a result of changes in equivalence ratio is higher than that of the far gauge location.

At both gauge locations there is an upward trend in heat flux to the surface as the blowing ratio increases. As more oxidizer is present for the fuel, the heat transfer to the surface increases. The increase in cooling flow does not appear to have a positive effect on stopping heat transfer to the surface.

In the case of this geometry, the heat flux does not appear to drop at a blowing ratio of 5; instead a slight dip in heat flux occurs at a blowing ratio of 2. It appears that an optimum heat flux value is achieved between blowing ratios of 1 and 3 , where the 
oxidizer to fuel ratio is such that there is minimal heat flux to the surface. It is also observed that as equivalence ratio increases, the heat flux decreases.

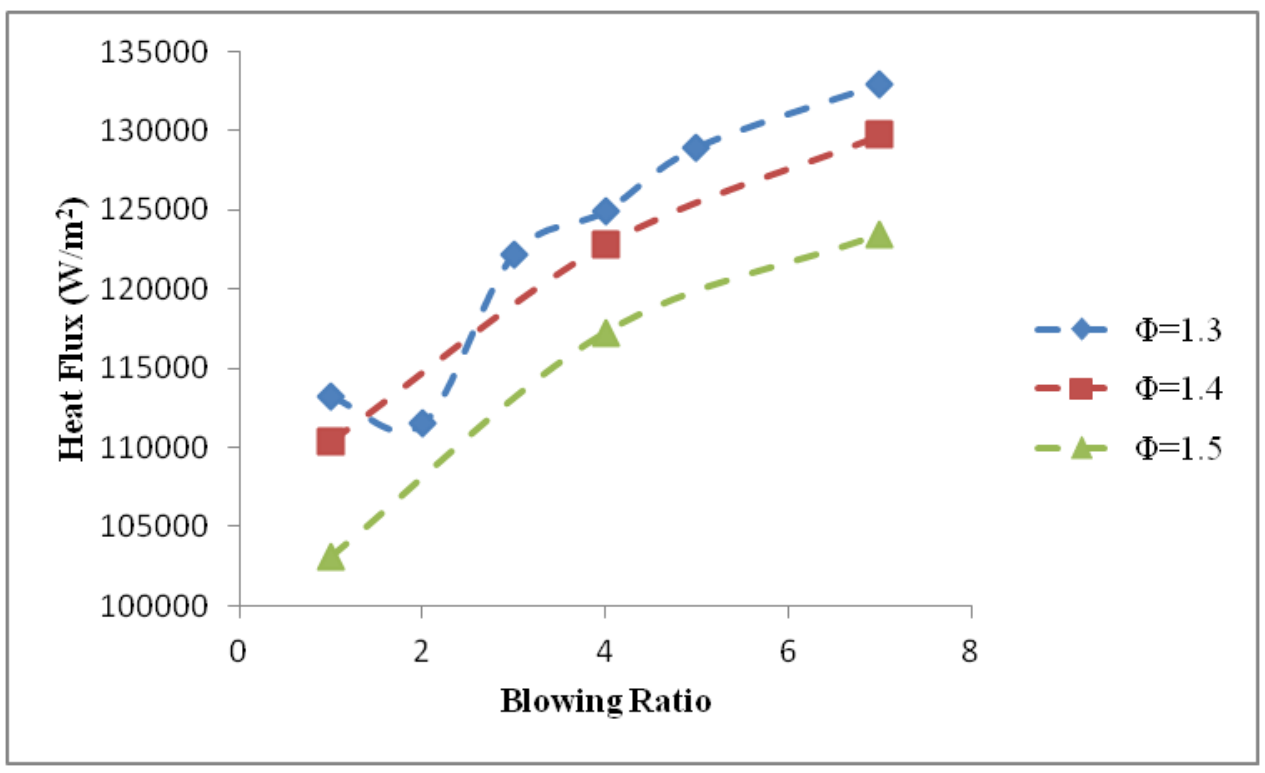

Figure 4.60 Station 1 average heat flux at blowing ratios for three equivalence ratios, fan shaped holes

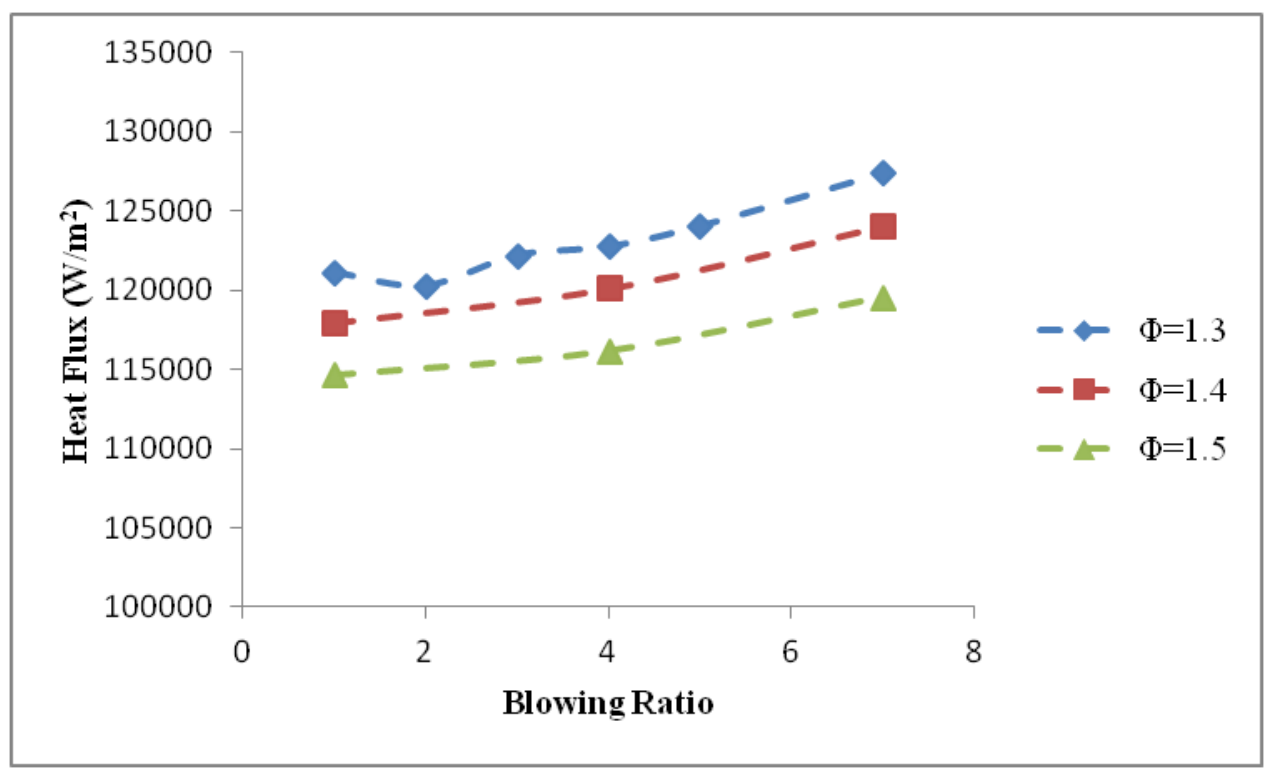

Figure 4.61 Station 2 average heat flux at blowing ratios for three equivalence ratios, fan shaped holes 


\subsubsection{Slot}

Figures 4.62 and 4.63 show the heat flux trends for the slot. At both gauge locations it is observed that the heat flux does not change noticeably with equivalence ratio. The large amount of coolant flow that is injected with the use of the slot geometry leads to a fairly constant temperature difference regardless of the equivalence ratio.

There is a decrease in heat flux to the surface as the blowing ratio increases. The increasingly large amounts of air injected into the test section leads to lower heat transfer to the surface. The cooling air may be providing a barrier between the reaction and the wall keeping heat generated by combustion from being absorbed by the surface. Rather the heat is absorbed into the boundary layer flow. The volume of air injected through the slot has a large effect on the heat flux to the surface.

It is also noted that the heat flux starts to increase again at a blowing ratio of 7 at both gauge locations. This suggests that the cooling flow is not protecting the wall from the high temperatures of the flame.

At Station 1 the heat flux reaches lower measurements for the slot in comparison to Station 2. This may be due to the large amount of air that is injected into the main flow. At Station 1 (closest to the injection location) the large velocity of the cooling air decreases the amount of heat transferred to the surface directly after injection. At Station 2 the reaction can occur closer to the surface leading to increased heat transfer to the surface. 


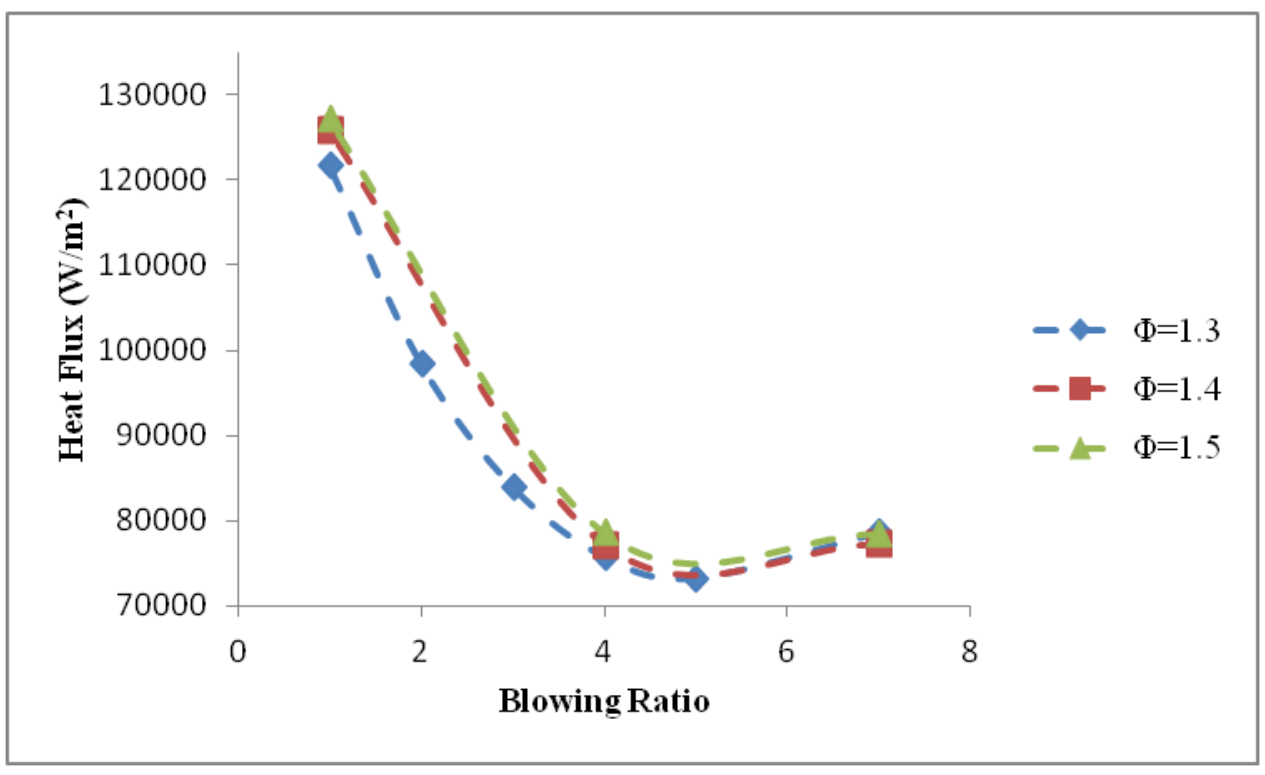

Figure 4.62 Station 1 average heat flux at blowing ratios for three equivalence ratios, slot

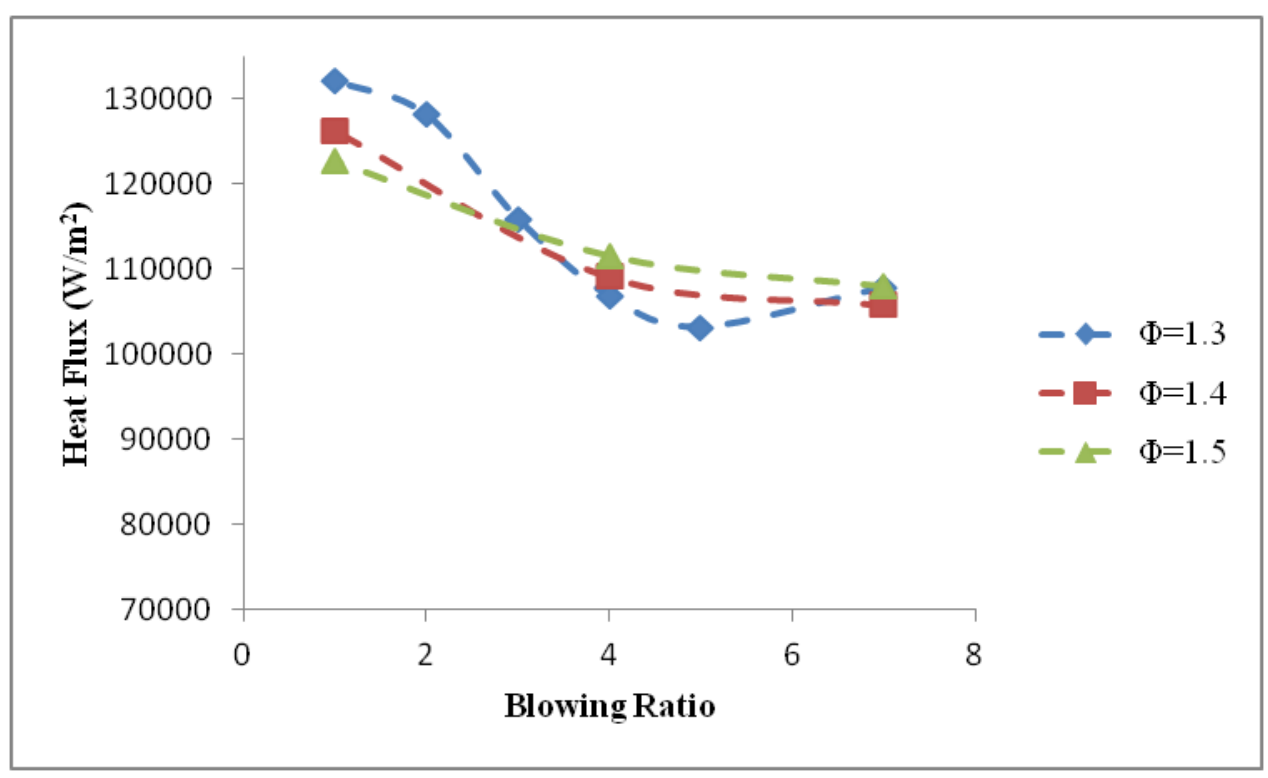

Figure 4.63 Station 2 average heat flux at blowing ratios for three equivalence

ratios, slot

\subsubsection{Geometry Comparison}

Figures 4.64 and 4.65 compare the heat flux to the surface for the three geometries at an equivalence ratio of 1.3 at each gauge location. The trends were found 
to be the same at each equivalence ratio. Plots for equivalence ratio of 1.4 are shown in Figs. 4.66 and 4.67, and plots for equivalence ratio of 1.5 are shown in Figs. 4.68 and 4.69. The difference in heat flux between geometries at Station 2 is smaller than the difference in heat flux at Station 1. Table 4.6 summarizes the findings dicussed in this section.

Table 4.6 Summary of geometry comparison results for heat flux data

\begin{tabular}{|c|c|c|}
\hline $\begin{array}{c}\text { Equivale nce } \\
\text { Ratio }\end{array}$ & Location & Heat Flux \\
\hline 1.3 & 1 & $\begin{array}{c}\text { F }>~ N>S \\
\text { S }>\text { at } M=1\end{array}$ \\
\hline 1.3 & 2 & $\mathrm{~F}=\mathrm{N}>\mathrm{S}$ \\
\hline 1.4 & 1 & $\begin{array}{c}\mathrm{F}>\mathrm{N}>\mathrm{S} \\
\mathrm{S}>\text { at } \mathrm{M}=1\end{array}$ \\
\hline 1.4 & 2 & $\mathrm{~F}=\mathrm{N}>\mathrm{S}$ \\
\hline 1.5 & 1 & $\begin{array}{c}\mathrm{F}>\mathrm{N}>\mathrm{S} \\
\mathrm{S}>\text { at } \mathrm{M}=1\end{array}$ \\
\hline 1.5 & 2 & $\mathrm{~F}=\mathrm{N}>\mathrm{S}$ \\
\hline
\end{tabular}

The fan shaped holes and normal holes trend vary similarly, increasing with blowing ratio for both gauge locations. The change in heat flux for the slot is more noticeable and trends downward with increasing blowing ratio at both gauge locations. The heat flux to the surface is less for the slot. This may be a result of the increased mass flow of cooling air injected into the vitiated flow. Though the flame that is created by this injection is large, there is enough flow present to create a barrier. Also there may be enough cooling flow present to push the flame out and far away from the wall.

The normal hole and fan shaped hole geometries are shown to have little difference in the heat flux values at Station 1 as a result of changes in equivalence ratio. It is possible that this trend is experienced because of the reaction that takes place immediately downstream of the cooling holes. In general the reaction occurs within close 
proximity of Station 1, causing a similar heat flux to the surface no matter the equivalence ratio and blowing ratio. At Station 2 the reaction may or may not occur there depending on equivalence ratio and blowing ratio. In short, the reactions for the normal and fan shaped holes do not extend far downstream from the injection location, thus the temperatures vary more far downstream in comparison to the slot.

For the slot, the heat flux does not change drastically at each equivalence ratio at the same blowing ratio at either gauge location. This is due to the large size of the reaction created by the cooling air injection. The slot flame extends the entire distance of the viewing window, thus covering the upstream and downstream gauge locations. Since the reaction is occurring at both the gauge locations for every equivalence ratio, the heat flux to the surface does not change significantly based on equivalence ratio. The temperature of the flame, which is present in every case, leads to a similar heat transfer to the surface no matter the equivalence ratio.

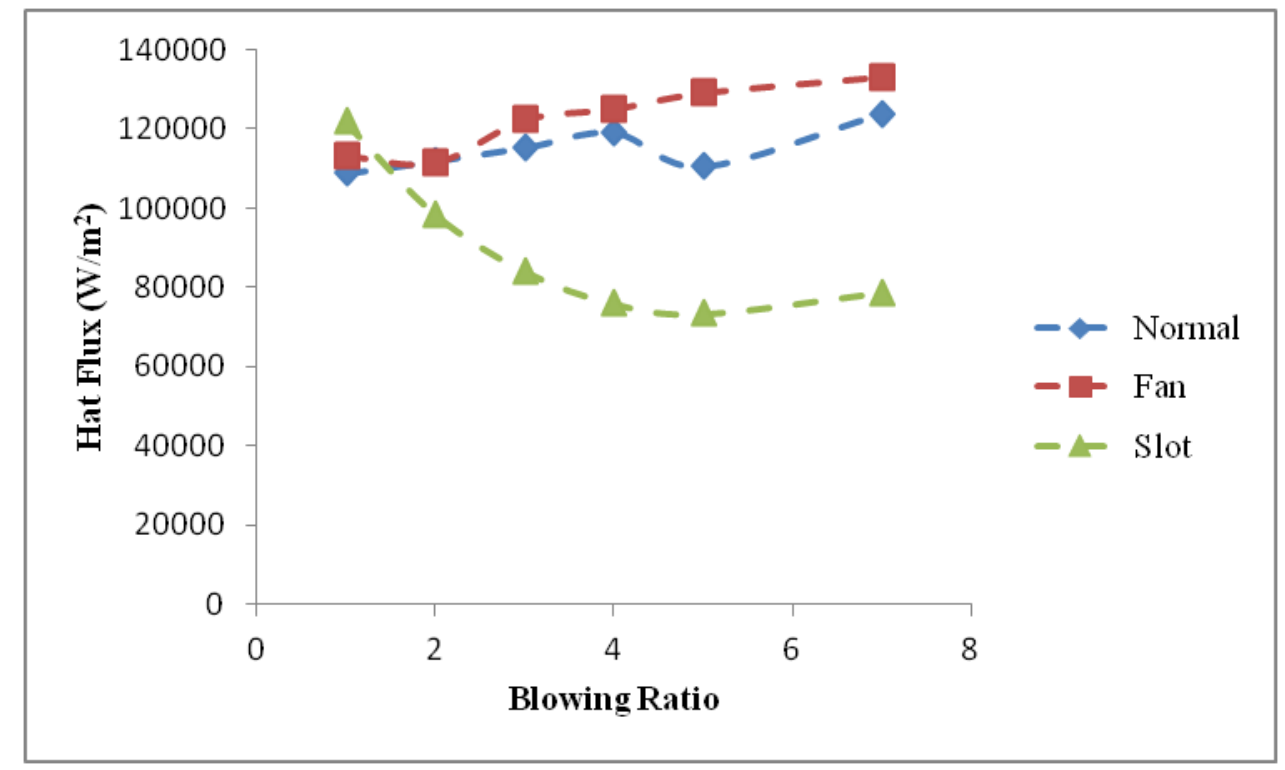

Figure 4.64 Station 1 average heat flux at blowing ratios for three geometries at $\Phi=$ 


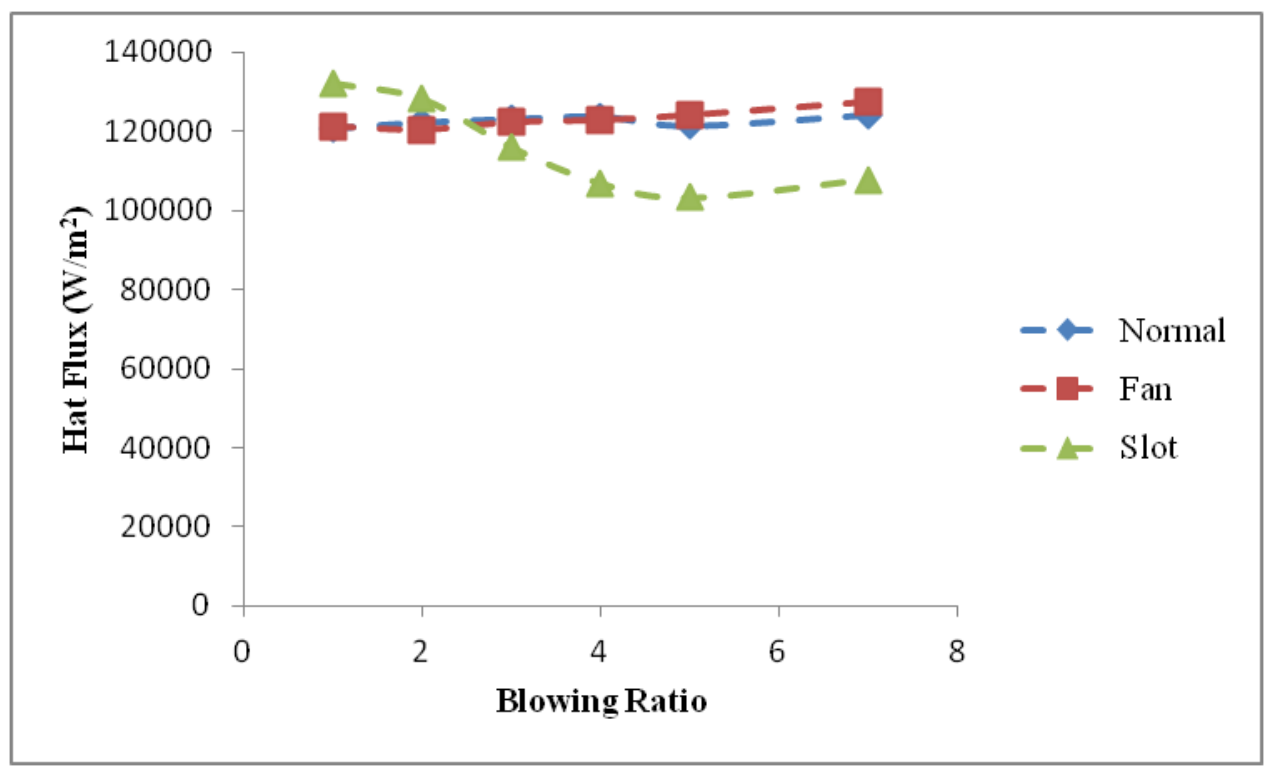

Figure 4.65 Station 2 average heat flux at blowing ratios for three geometries at $\Phi=$ 1.3

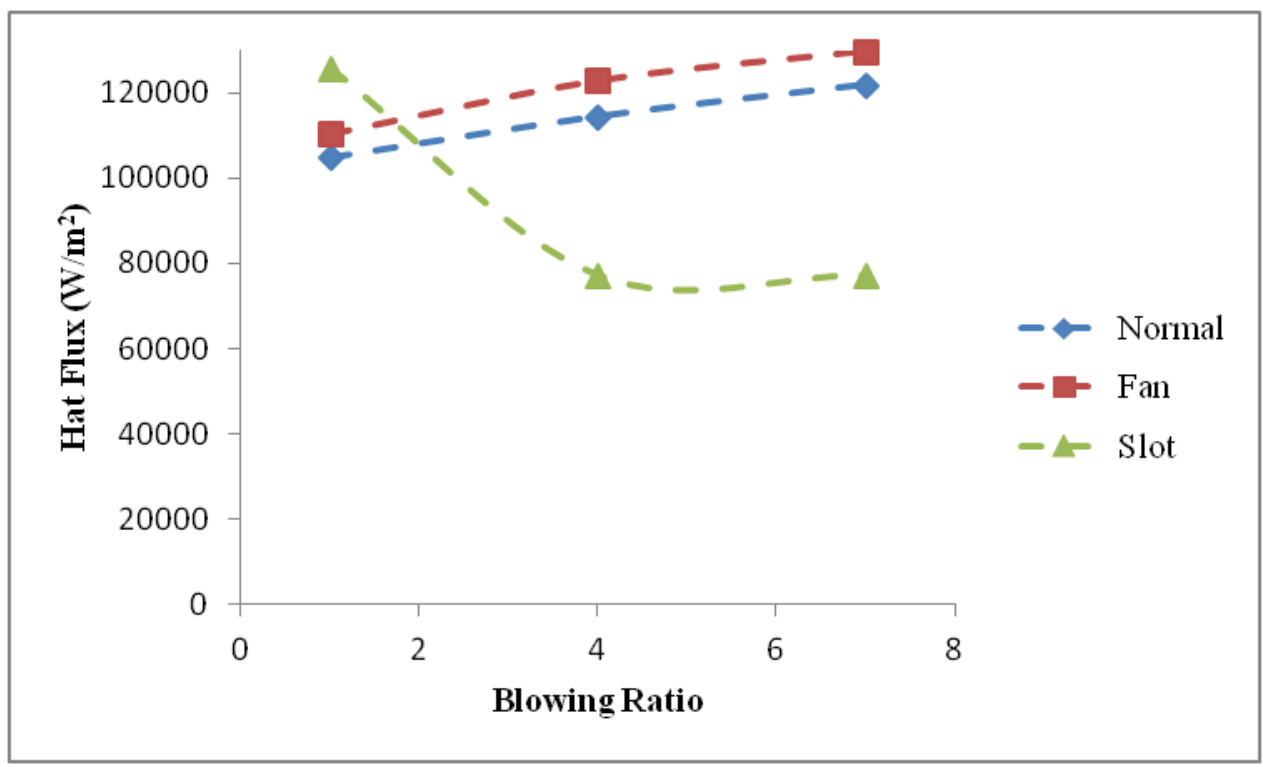

Figure 4.66 Station 1 average heat flux at blowing ratios for three geometries at $\Phi=$ 1.4 


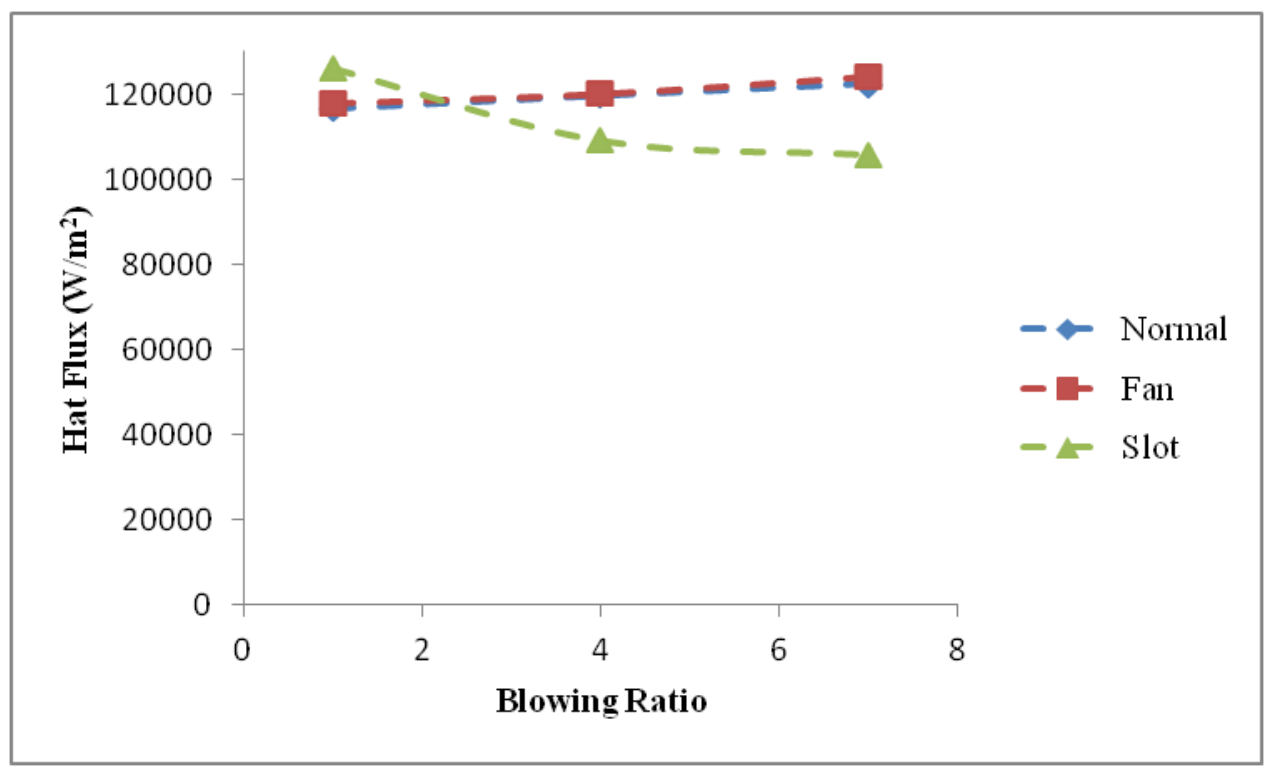

Figure 4.67 Station 2 average heat flux at blowing ratios for three geometries at $\Phi=$ 1.4

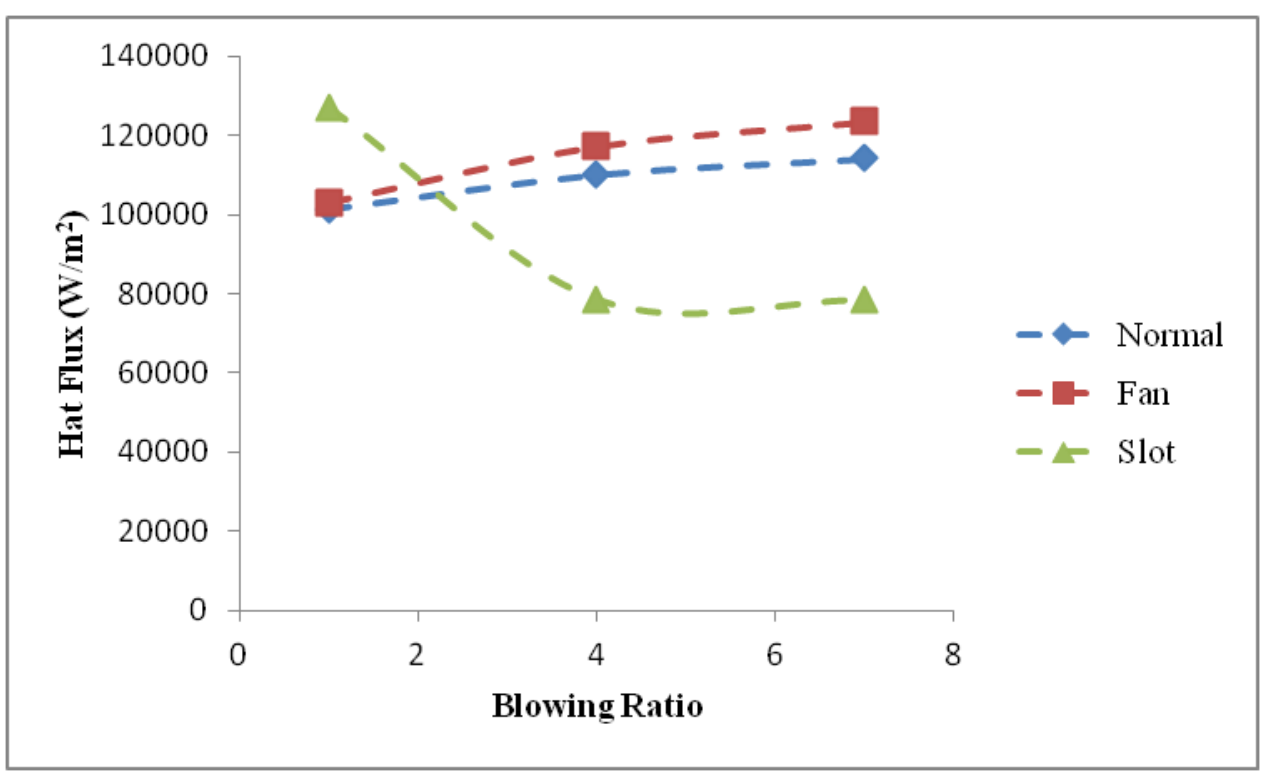

Figure 4.68 Station 1 average heat flux at blowing ratios for three geometries at $\Phi=$ 1.5 


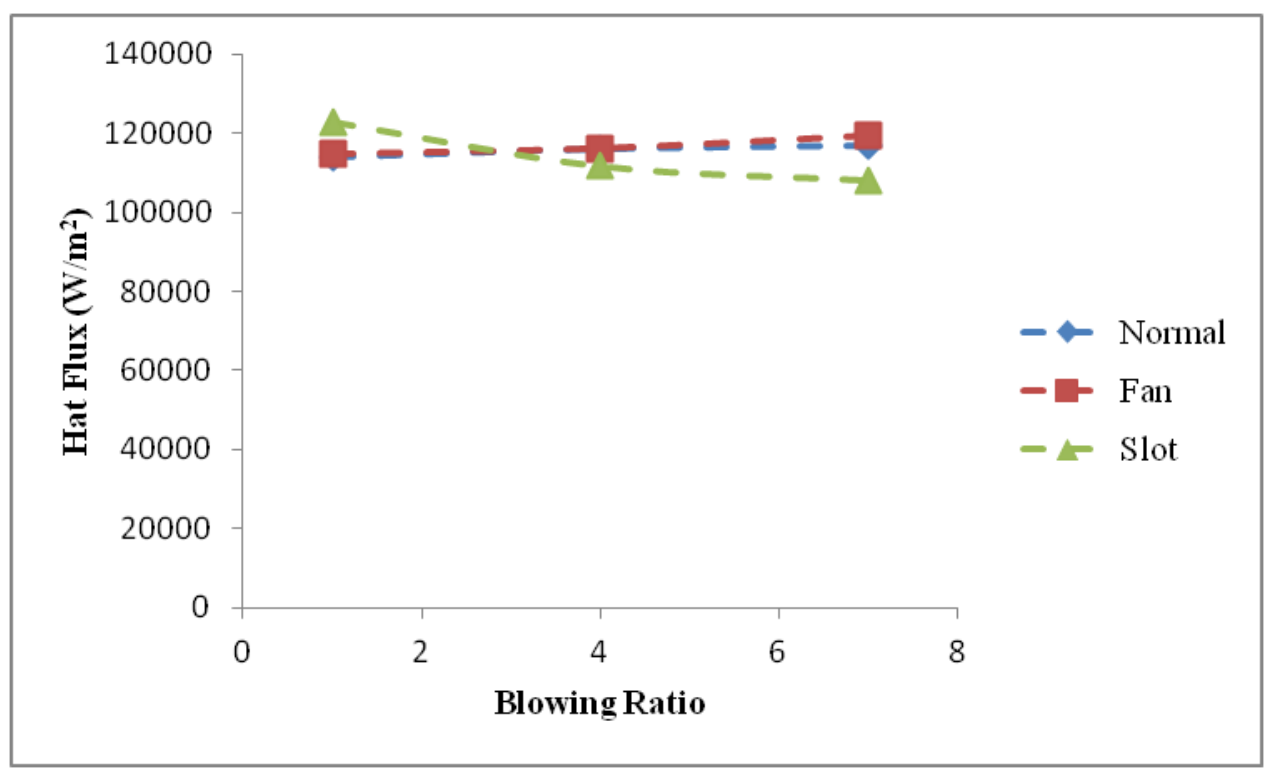

Figure 4.69 Station 2 average heat flux at blowing ratios for three geometries at $\Phi=$ 1.5

\subsubsection{Heat Flux Gauge Location Discussion}

The maximum heat flux may occur upstream of Station 1. The vertical gauge locations used here were set by previous studies $(18,19,21)$. It is not certain that Station 1 is measuring the max heat flux, but this location is still closest in proximity to the reaction region and thus the data it provides is useful in drawing conclusions between the flame spatial characteristics, flame rate of heat release, and heat flux to the surface.

Heat flux data from the previous studies using $\mathrm{N}_{2}$ as the cooling flow through fan shaped holes is presented in Fig. 4.70, where Gauges C and D are at Station 1 and Gauges $\mathrm{A}$ and $\mathrm{B}$ are at Station 2. The heat flux for cooling air through the fan shaped holes at the same conditions is presented in Figs. 4.71 and 4.72. Comparison of these data plots show that the heat flux data presented in this thesis using air as a cooling flow is larger than the heat flux for a non-reacting flow. Thus it is known that the gauges are located in an 
effective spot to measure heat flux as a result of reactions, regardless of whether the maximum heat flux is being measured.

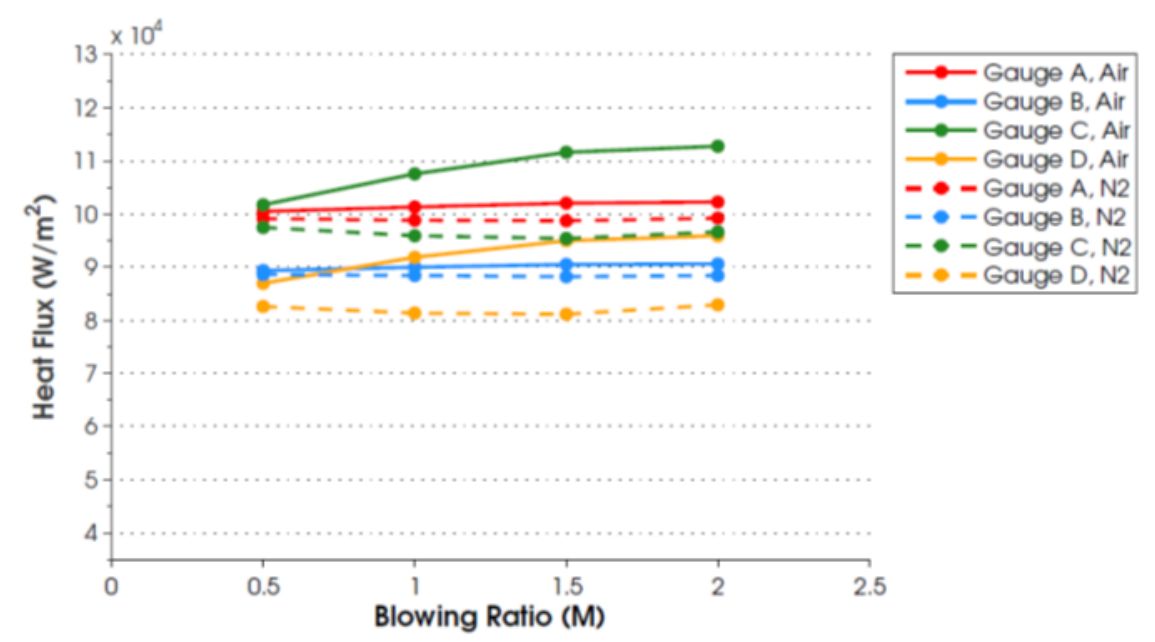

Figure 4.70 Heat flux at varying blowing ratios for reacting and non-reacting flow, $\Phi=1.3$, fan shaped holes (19)

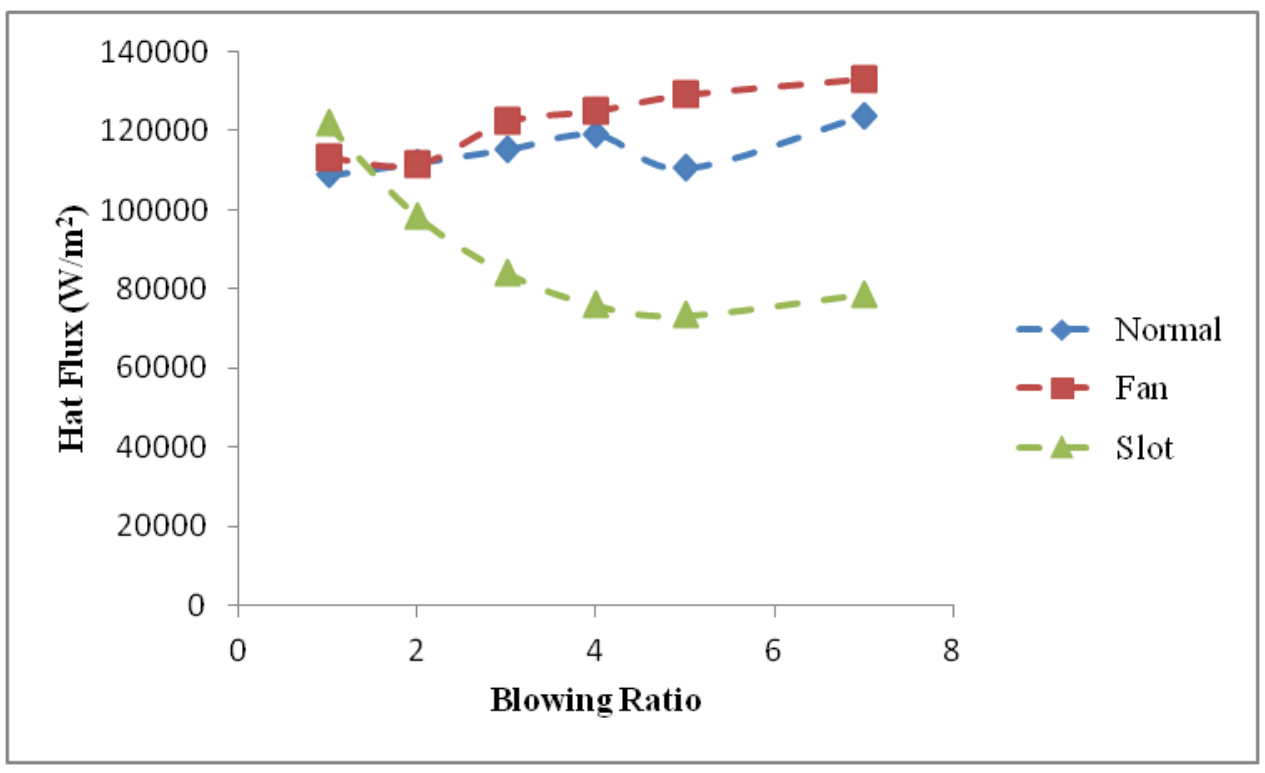

Figure 4.71 Station 1 average heat flux at blowing ratios for three geometries at $\Phi=$ 1.3 


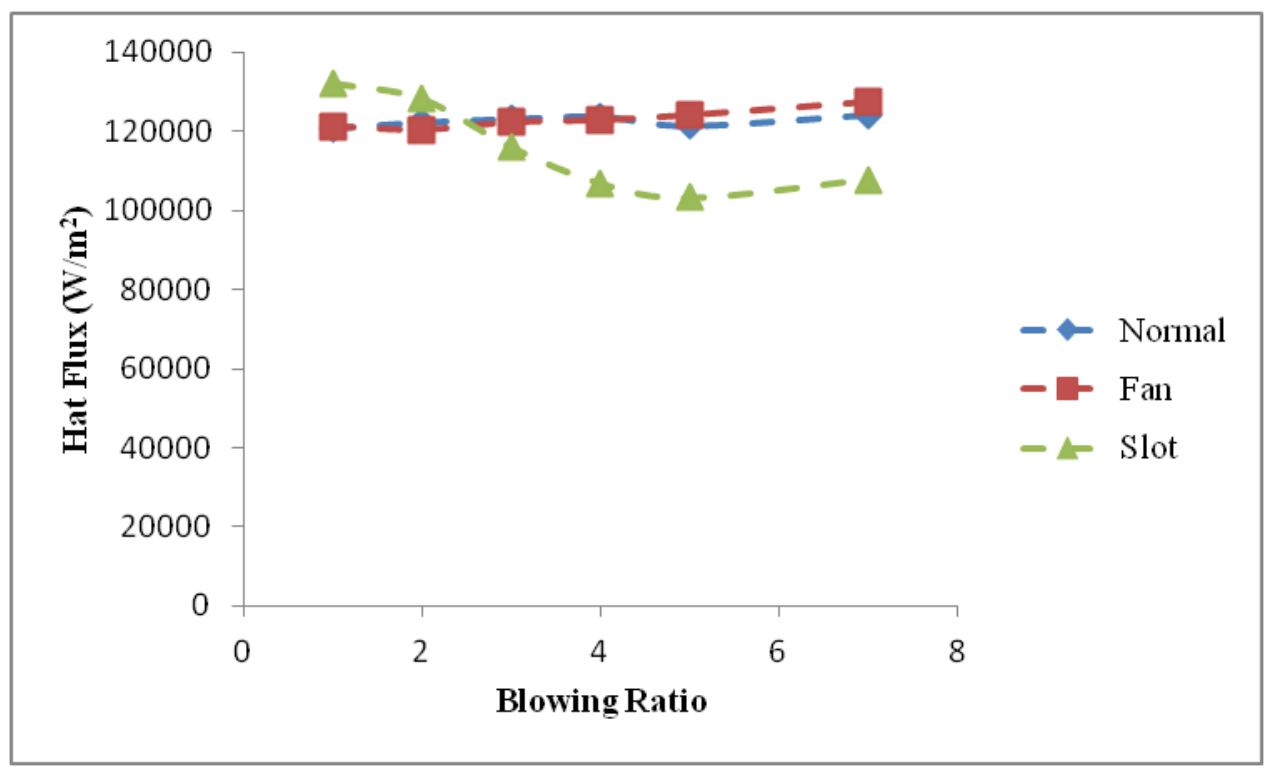

Figure 4.72 Station 2 average heat flux at blowing ratios for three geometries at $\Phi=$

\section{3}

\subsection{ANALYSIS OF HEAT FLUX AND RATE OF HEAT RELEASE}

As discussed in Section 2.7, chemiluminescence emissions from flames are proportional to the rate of heat release of that flame. Thus the chemiluminescence intensity plots and chemiluminescence flame images are an indication of heat release. This section presents an investigation of how heat release rate, heat flux, and flame size compare to one another. The rate of heat release, heat flux, and reaction region are discussed in conjunction with each other.

This thesis is built around the comparison of flame shapes and rate of heat release to heat flux measurements. The Station 1 (near-field) heat flux gauge measurements are used and discussed along with the peak average chemiluminescence emission values. The peak emission values occur closest to the Station 1 gauge and thus comparison between this gauge and the peak average values makes the most sense. 


\subsubsection{Equivalence Ratio of 1.3}

At a blowing ratio of 1 , the heat flux is largest for the slot, followed by the fan shaped holes, and then the normal holes. At a blowing ratio of 4 the heat flux for the flames from the fan is largest, followed by the normal, and then the slot. For a blowing ratio of 7 , the heat flux for the fan is greater than the normal, which is greater than the slot.

In each case the rate of heat release behaves in the same fashion as the heat flux at each blowing ratio. In other words, an increase or decrease in the chemiluminescence intensity, which equates to an increase or decrease in rate of heat release respectively, coincides with an increase or decrease in heat flux. This suggests that at this equivalence ratio the heat released by the reaction is directly responsible for the heat flux to the wall. It is plausible that all the cooling flow is consumed by the reaction and thus there is not enough flow to form a protective barrier between the reaction and the wall.

It is important to compare the heat flux trends with the size and shape of the flame as well. For each of the geometries, the reaction region increases in size with the blowing ratio. For the normal and fan shaped hole geometries, the heat flux from their respective flames increase along with the size of the flame. The opposite is true for the flames originating from the slot cooling flow. In the case of the slot, the large amount of cooling air is adequate to react and also create a protective barrier between the reaction and the wall. Thus the heat flux to the surface is lessened as the amount of cooling flow increases. 
The amount of cooling flow from the normal holes and fan shaped holes is not enough to provide a protective barrier regardless of the blowing ratio. As the size of the reaction region increases the heat transfer to the surface also increases.

\subsubsection{Equivalence Ratio of 1.4}

For a blowing ratio of 1 the heat flux from the slot flames is larger than those of the fan shaped holes, which is larger than those of the normal holes. This heat flux trend matches the pattern of the rate of heat release. This is likely an effect of the low blowing ratio, which coincides with a small amount of cooling flow. The flame with the largest rate of heat release causes a large amount of heat transfer to the surface because there is not enough cooling flow to protect the surface from the hot flame and freestream.

At blowing ratios of 4 and 7 the heat flux for the fan shaped holes is the largest followed by the heat flux for the normal holes, followed by the heat flux for the slot. In both cases the rate of heat release does not follow this trend. Rather the rate of heat release for the fan shaped holes is greater than the slot is greater than the normal holes.

The fan has the highest rate of heat release and the largest heat flux to the surface. It is plausible that the orientation of the fan shaped holes holds the flame close to the surface and does not provide enough flow so that there is some left over to act as a barrier, resulting in high heat transfer to the surface. The slot holds the flame close to the surface while having a fairly high rate of heat release, but enough cooling air appears to be provided that it can create a barrier between the heat release of the flame and the wall, creating a low heat flux to the wall surface. The normal holes provide the smallest rate of heat release, but the heat flux to the surface is still larger than the slot. A reasonable explanation for this is because there is not enough flow provided through the normal 
holes to allow for the protective cooling flow barrier between the surface and the freestream.

Again the heat flux to the surface is compared to the size of the flames. At this equivalence ratio, the size of the flames from the normal holes and from the fan shaped holes increase along with blowing ratio, just as the heat flux to the surface does. It is conceivable that the amount of cooling flow provided through these two geometries is not enough to provide the desired protective barrier over the wall, regardless of the blowing ratio. Thus, as the reaction region increases in size, the heat transfer to the surface increases.

At this equivalence ratio, the size of the slot flame is largest at a blowing ratio of 7. The flame is the smallest at a blowing ratio of 4 . The heat flux does not follow this trend, rather it decreases with blowing ratio. It would seem then that the high blowing ratio of 7 , though it causes a large flame, also provides adequate cooling flow to create a protective layer over the wall preventing large heat flux.

\subsubsection{Equivalence Ratio of $\mathbf{1 . 5}$}

At $M=1$ the heat flux of the flames from the slot is the largest, followed by that of the fan shaped holes, followed by that of the normal holes. The rate of heat release follows this pattern. As seen for the other two equivalence ratios at a blowing ratio of 1 , the amount of cooling flow has little effect on stopping heat transfer to the surface. The flames with the highest rate of heat release result in the highest heat transfer to the surface because of the lack of a protective barrier of cooling flow.

For blowing ratios of 4 and 7 the heat flux follows the same trend; the heat flux from the fan shaped holes exceeds that of the normal holes which exceeds that of the slot. 
The rate of heat release trends are also the same at these two blowing ratios; the fan shaped holes exceeds that of the slot which exceeds that of the normal holes.

The flames originating from the fan shaped holes result in the greatest rate of heat release and the greatest heat transfer to the surface. This is a function of the amount of cooling air and the orientation of that cooling air. The flame is held close to the surface because it is injected into the flow with a vertical velocity component. There is not enough cooling air to protect the surface from the close reaction. Not only is the rate of heat release from the flames originating from the normal holes smaller than that of the flames originating from the fan shaped holes, but the normal hole flames are also further from the surface. Thus their heat release does not cause as much heat transfer to the surface. The rate of heat release of the slot is small at this equivalence ratio which coincides with low heat flux.

For the normal holes and the fan shaped holes, the size of the flame increases along with the blowing ratio. Again this coincides with the heat flux trends, suggesting that the size of the flame has an effect on the heat flux to the surface. The larger flames cause higher heat flux and the smaller flames cause lower heat flux.

For the slot, the smallest flame occurs at a blowing ratio of 4 , and the largest flame occurs at a blowing ratio of 7 . The heat flux does not follow this trend, rather it decreases with blowing ratio. It would seem then that the high blowing ratio of 7 , though it causes a large flame, also provides adequate cooling flow to create a protective layer over the wall preventing large heat flux. While the blowing ratio of 1 causes a large flame but not enough cooling flow to protect the surface from this flame. 


\section{CONCLUSION}

\subsection{PROBLEM SUMMARY}

In this thesis an experimental study was carried out to investigate the heat transfer and rate of heat release as a result of reactions due to the injection of film cooling air into the exhaust of fuel rich combustion. Three different cooling hole schemes were investigated (normal holes, fan shaped holes, and slot), along with three WSR equivalence ratios $(1.3,1.4$, and 1.5), and three blowing ratios $(1,4$, and 7$)$. Chemiluminescence data for $\mathrm{OH}$ and $\mathrm{CH}$ radicals was gathered using a high speed camera and filters, which correlates to rate of heat release data and local equivalence ratio data. Temperatures in the test section are also gathered in order to calculate the heat transfer to the surface. The results of this study add to the information being gathered in order to most effectively implement film cooling into advanced combustion systems, such as the UCC.

\subsection{CONCLUSIONS}

- $\quad \mathrm{OH}$ and $\mathrm{CH}$ chemiluminescence are both good flame indicators.

- $\mathrm{OH}$ chemiluminescence is stronger than $\mathrm{CH}$ chemiluminescence.

- It was found that flame size does not always correlate with measured heat

flux; generally the heat flux for the normal holes and fan shaped holes increases with the size of the reaction region. The cooling flow through the slot results in 
large, intense reaction regions, but the heat flux to the surface is lower comparatively. The slot cooling flow is effective at slowing heat transfer to the wall when there are reactions in the boundary layer.

- The rate of heat release does not always trend with the heat flux. In some cases barriers between the wall and the reaction are created by the cooling flow. The existence of these barriers leads to lower heat flux regardless of the rate of heat release from the reaction by keeping the hot reaction region and the hot freestream flow away from the surface.

- For low blowing ratios and/or equivalence ratios, the heat flux does trend with the rate of heat release. No matter the equivalence ratio, at a blowing ratio of 1 the amount of cooling flow is not adequate to lessen the heat flux to the surface. This is also true for all blowing ratios at an equivalence ratio of 1.3. The trends of heat flux and rate of heat release coincide at this equivalence ratio. At these conditions it is concluded that the amount of cooling air has little effect on lessening the heat transfer to the surface, and that the rate of heat release has a larger effect on the heat flux.

- At equivalences ratios of 1.4 and 1.5 the rate of heat release does not trend with the heat flux. At these equivalence ratios it is concluded that the heat flux to the surface is a function of the injection angle of the cooling flow, presence of a cooling flow barrier, and reaction region size, not just the heat release rate. 
- The heat transfer to the surface from a flame originating from the slot cooling flow decreases with an increase in the amount of cooling flow; this geometry flow results in lowest heat flux to the surface. It is concluded that at high blowing ratios, the slot is thus a possible solution for negating heat transfer to the surface. This geometry is the most effective at blocking heat transfer to the surface from the reaction. Also though, it is noted that this geometry requires the largest amount of cooling flow. The overall minimum heat flux to the surface occurs with the slot geometry at an equivalence ratio of 1.3 and blowing ratio of 5.

\subsection{FUTURE WORK}

A possibly anomalous point was seen in the heat flux data at a blowing ratio of 5 and equivalence ratio of 1.3 for the normal holes. It would help to return to this data point and gather heat flux data again in order to see if the same results are achieved. Also, filling in the range of blowing ratios at the higher equivalence ratios (1.4 and 1.5) would be helpful in seeing if this is the case at each equivalence ratio, or if the point is actually an anomaly.

Also, carrying out an investigation of $\mathrm{OH} / \mathrm{CH}$ ratio of the reaction region may be beneficial in offering information on the local equivalence ratio of that area. This has been done for premixed flames, but an examination of $\mathrm{OH} / \mathrm{CH}$ ratio and how this connects to local equivalence ratio for diffusion flames could be beneficial.

The work done in this study could be furthered by completing the same test points for more complicated hole geometries. Related studies discussed in Section 2.9.4 investigated geometries other than the normal holes, fan shaped holes, and the slot. 
Gathering the chemiluminescence data for these other hole geometries would offer further data to compare to previous studies.

Two cooling hole geometries in series were also investigated in past work. Gathering chemiluminescence data for cooling holes in series would provide heat release and flame equivalence ratio data to compare to the already gathered heat flux data. Flame images can also be gathered for multiple cooling flows. This would offer opportunity for the investigation of the physical flow and flame characteristics.

An aspect of reactive flows that was not investigated in this study is emissions data. Gathering such data would provide further information on emissions. A possible method of achieving this information is through further laser diagnostics. Emissions data without film cooling can be compared to data with film cooling. This would allow for seeing what emissions are a result of the film cooling, and how film cooling changes the emissions an gas turbine engine would lead to. 


\section{BIBLIOGRAPHY}

1. Lukachko, S., Kirk, D., Waitz, I., "Gas Turbine Engine Durability Impacts of High Fuel-Air Ratio Combustors - Part I: Potential for Secondary Combustion of Partially Reacted Fuel," Journal of Engineering for Gas Turbines and Power, Vol. 125, pp. 742-750, 2003.

2. Godin, T., Harvey, S., Stouffs, P., "Theoretical Analysis of Environmental and Energetic Performance of Very high Temperature Turbo-jet Engines," International Journal of Thermal Sciences, Vol. 38, pp. 442-451, 1999.

3. Kirk, D., Guenette, G., Lukachko, S., Waitz, I., "Gas Turbine Engine Durability Imparcts of High Fuel-Air Ratio Combustors - Part II: Near-Wall Reaction Effects on Film Cooled Heat Transfer," Journal of Engineering for Gas Turbines and Power, Vol. 125, pp. 751-759, 2003.

4. Anderson, W.S., Evans, D.S., Justinger, G.R., Polanka, M.D., Stouffer, S.D., Zelina, J., "Effects of a Reacting Cross-Stream on Turbine Film Cooling," Journal of Engineering for Gas Turbines and Power, Vol. 132, 2010.

5. Mattingly, J.D., Elements of Gas Turbine Propulsio, McGraw-Hill, Inc, New York, 1996.

6. Ballal, D.R., Zelina, J., "Progress in Aero Engine Technology (1939-2003)," AIAA 2003-4412, 39th Joint Propulsion Conference, Huntsville, AL, 2003. 
7. Zelina, J., Sturgess, G.J., Shouse, D.T., "The Behavior of an Ultra-Compact Combustor (UCC) Based on Centrifugally-Enhanced Turbulent Burning Rates," AIAA 2004-3541, 40th Joint Propulsion Conference, Fort Lauderdale, FL, 2004.

8. Lefevbre, A., Freeman, W., Cowell, L., "Spontaneous Ignition Delay Characteristics of Hydrocarbon Fuel/Air Mixtures," NASA Contractor Report 175064, 1986.

9. Scott, C.J., "Transient Experimental Techniques for Surface Heat Flux Rates," Measurements in Heat Transfer. 2nd Ed., pp. 375-396, Hemisphere Publishing Corporation, 1976.

10. H-3009a, Material Data Sheet, "Hastelloy (r) X alloy," Haynes International Inc., Kokomo, IN, 1997.

11. Turns, S.R., An Introduction to Combustion. 2nd Ed., McGraw Hill, Inc., New York, 1996.

12. Haber, L.C.,. "An Investigation into the Origin, Measurement, and Application of Chemiluminescent Light Emissions from Premixed Flames," Master's Thesis, Virginia Polytechnic Institute and State University, Blacksburg, VA, 2000.

13. Gaydon, A.G., The Spectroscopy of Flames, John Wiley \& Sons Inc., New York, 1957.

14. Hardalupas, Y., Orain, M., "Local Measurements of the Time-Dependent Heat Release Rate and Equivalence Ratio Using Chemiluminescent Emission from a Flame," Combustion and Flame, Vol. 139, pp. 188-207, 2004.

15. Baldauf, S., Schulz, A., Wittig, S., "High-Resolution Measurements of Local Heat Transfer Coefficients from Discrete Hole Film Cooling," Journal of Turbomachinery, Vol. 123, pp. 749-757, 2001. 
16. Baldauf, S., Schulz, A., Wittig, S., "High-Resolution Measurements of Local Effectiveness from Discrete Hole Film Cooling," Journal of Turbomachinery, Vol. 123, pp. 758-765, 2001.

17. Saumweber, C., Schulz, A., Wittig, S., "Free-Stream Turbulence Effects on Film Cooling with Shaped Holes," Journal of Turbomachinery, Vol. 125, pp. 65-73, ASME, January 2003.

18. Evans, D.S., "The Impact of Heat Release in Turbine Film Cooling," Master's Thesis, Air Force Institute of Technology, Wright Patterson Air Force Base, 2008.

19. Bohan, B.T., "Analysis of Flow Migration in an Ultra Compact Combustor," Master's Thesis, Air Force Institute of Technology, Wright Patterson Air Force Base, 2011.

20. Blunck, D., Gord, J.R., Kostka, S., Lynch, A., Polanka, M., Roy, S., Stouffer, S., "Flame Structure of Vitiated Fuel Rich Inverse Diffusion Flames in a CrossFlow," 7th U.S. National Combustion Meeting, Paper T05, 2011.

21. Dellallo, M., Master's Thesis, In Preparation, Air Force Institute of Technology. Wright Patterson Air Force Base, 2012.

22. Thornburg, H., Sekar, B., Zelina, J., Anderson, W., Polanka, M.D., Lin, C.X., Holder, R.J., Briones, A.M., Stouffer, S.D., "Design Studies of Turbine Blade Film Cooling with Unburned Fuel in Cross Stream Flow," AIAA 2009-510, 47th AIAA Aerospace Sciences Meeting, Orlando, FL, 2009.

23. Lin, C., Holder, R.J., Sekar, B., Zelina, J., Polanka, M.D., Thornburg, H.J., Briones, A.M., "Heat Release in Turbine Cooling II: Numerical Details of Secondary Combustion Surrounding Shaped Holes," Journal of Propulsion and Power, Vol. 27, pp. 269-281, March-April 2011. 
24. Zelina, J., "Combustion Studies in a Well Stirred Reactor," PhD Thesis, University of Dayton. Dayton, OH, 1995.

25. Stouffer, S.D., Struebich, R.C., Frayne, C.W., Zelina, J., "Combustion Particulates Mitigation Using a Well Stirred Reactor," AIAA 2002-3723, 2002.

26. Nenniger, J.E., Kridiotis, A., Chomiak, J., Longwell, J.P., Sarofim, A.F., "Characterization of a Toroidal Well Stirred Reactor," The Combustion Institute, 20th International Symposium on Combustion. pp. 473-479, 1984.

27. Stouffer, S.D., Pawlik, R., Justinger, G., Heyne, J., Zelina, J., Ballal, D., "Combustion Performance and Emissions Characteristics for a Well-Stirred Reactor for Low Volatility Hydrocarbon Fuels," AIAA 2007-5663, 43rd Joint Propulsion Conference, Cincinnati, OH, 2007.

28. DaVis 7.2 Software Manual, LaVision GmbH, Gottigem, Germany, 2009.

29. Moisy, F., "Pivmat - a post-processing and data analysis toolbox for MATLAB," Online, version 2.01, 2011.

30. Ohyama, Y., Ohsuga, M., Kuroiwa, H., "Study on Mixture Formation and Ignition Process in Spark Ignition Engine Using Optical Combustion Sensor," SAE Paper No. 901712, 1990.

31. Liu, S., Fotache, C.G., Chao, B., Hautman, D.J., Ochs, S.S., "Boundary Layer Modeling of Reactive Flows over a Porour Surface with Angled Injection," Combustion and Flame, Vol. 154, pp. 378-386, 2008.

32. Sidwell, C.V., "On the Impact of Variability and Assembly on Turbine Blade Cooling Flow and Oxidation Life," PhD Thesis, Massachusetts Institute of Technology, Cambridge, MA, 2004. 
33. Law, C.K., Combustion Physics, Cambridge University Press, New York, 2006.

34. Stouffer, S.D., Ballal, D.R., Zelina, J., Shouse, D.T., Hancock, R.D., Mongia, H.C., "Development and Combustion Performance of a High-Pressure WSR and TAPS Combustor," AIAA 2005-1416, 43rd AIAA Aerospace Sciences Meeting, Reno, NV, 2005. 
A. APPENDIX A - OH* EQUIVALENCE RATIO COMPARISON IMAGES
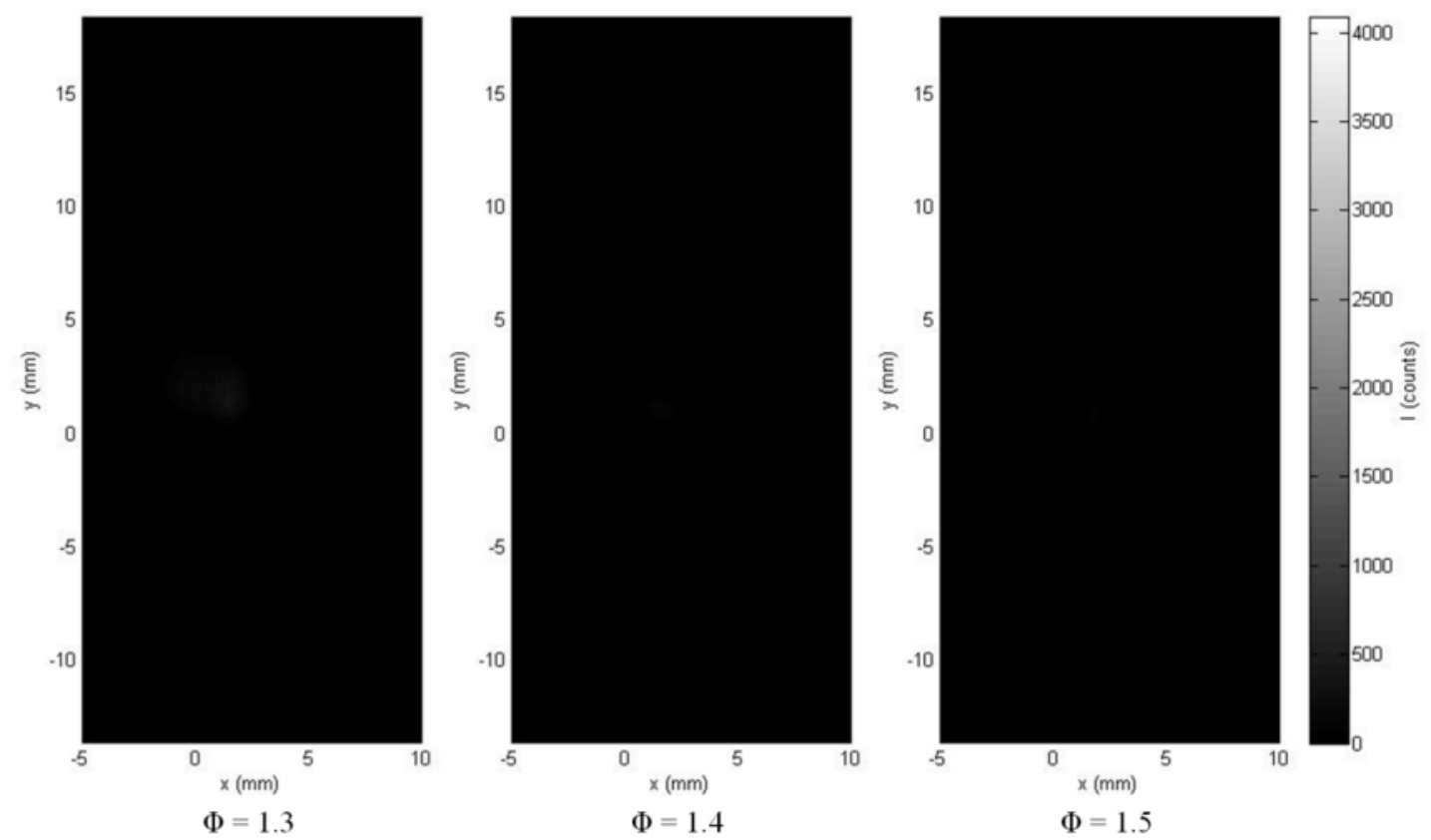

Figure A.1 $\mathrm{OH}^{*}$ chemiluminescence images at equivalence ratios, $M=1$, normal holes 

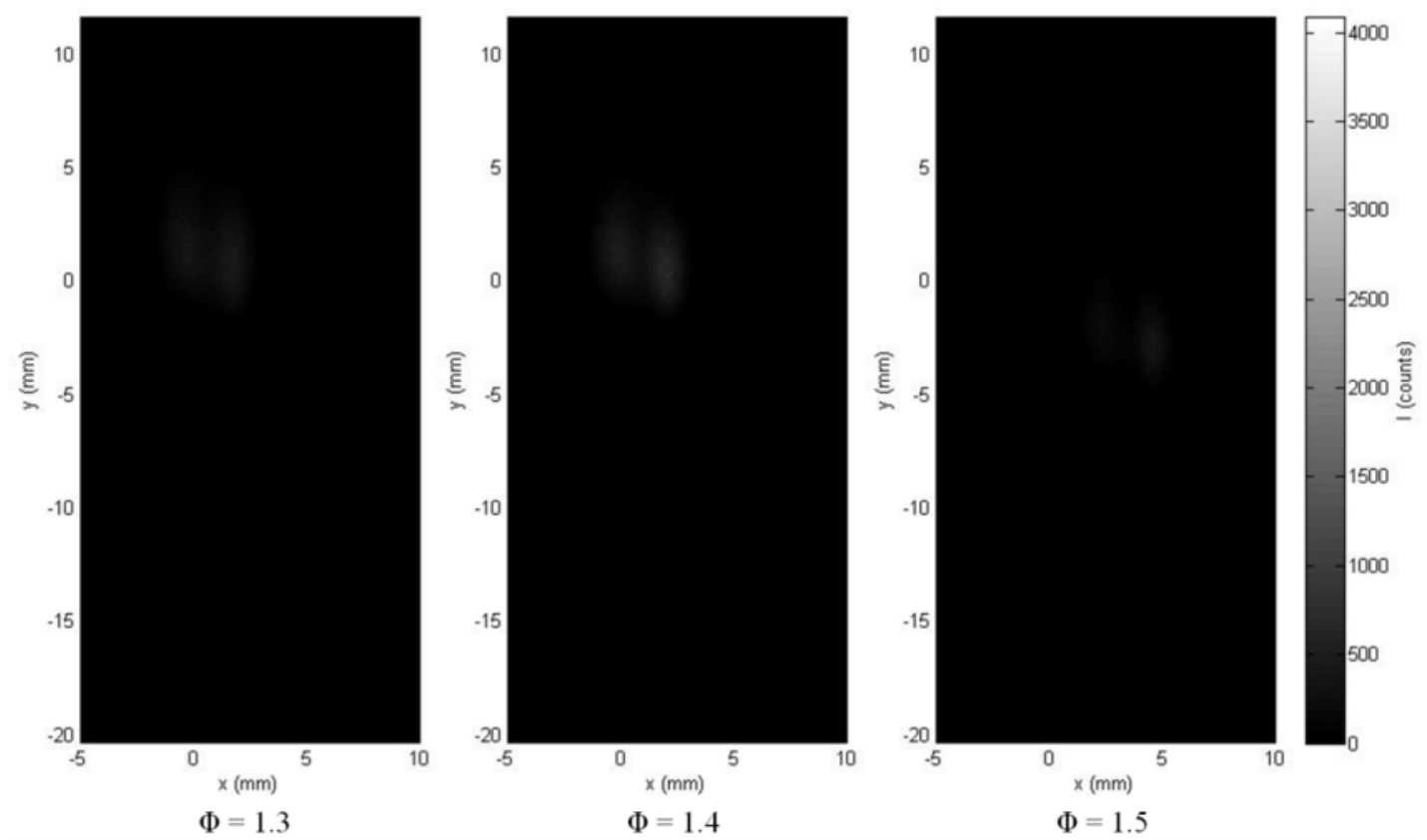

Figure A.2 $\mathrm{OH}^{*}$ chemiluminescence images at equivalence ratios, $\mathrm{M}=1$, fan shaped holes
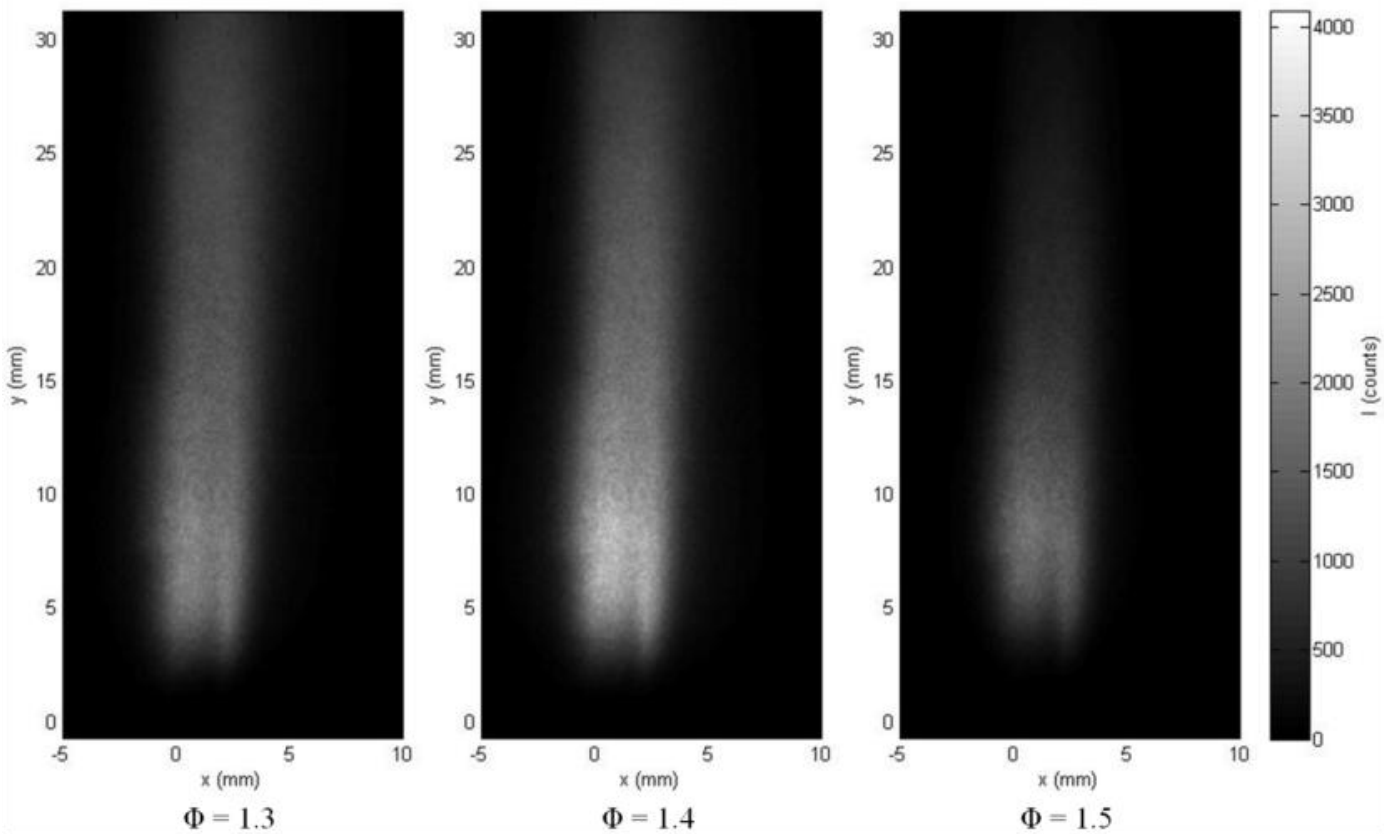

Figure A.3 $\mathrm{OH}^{*}$ chemiluminescence images at equivalence ratios, $M=1$, slot 

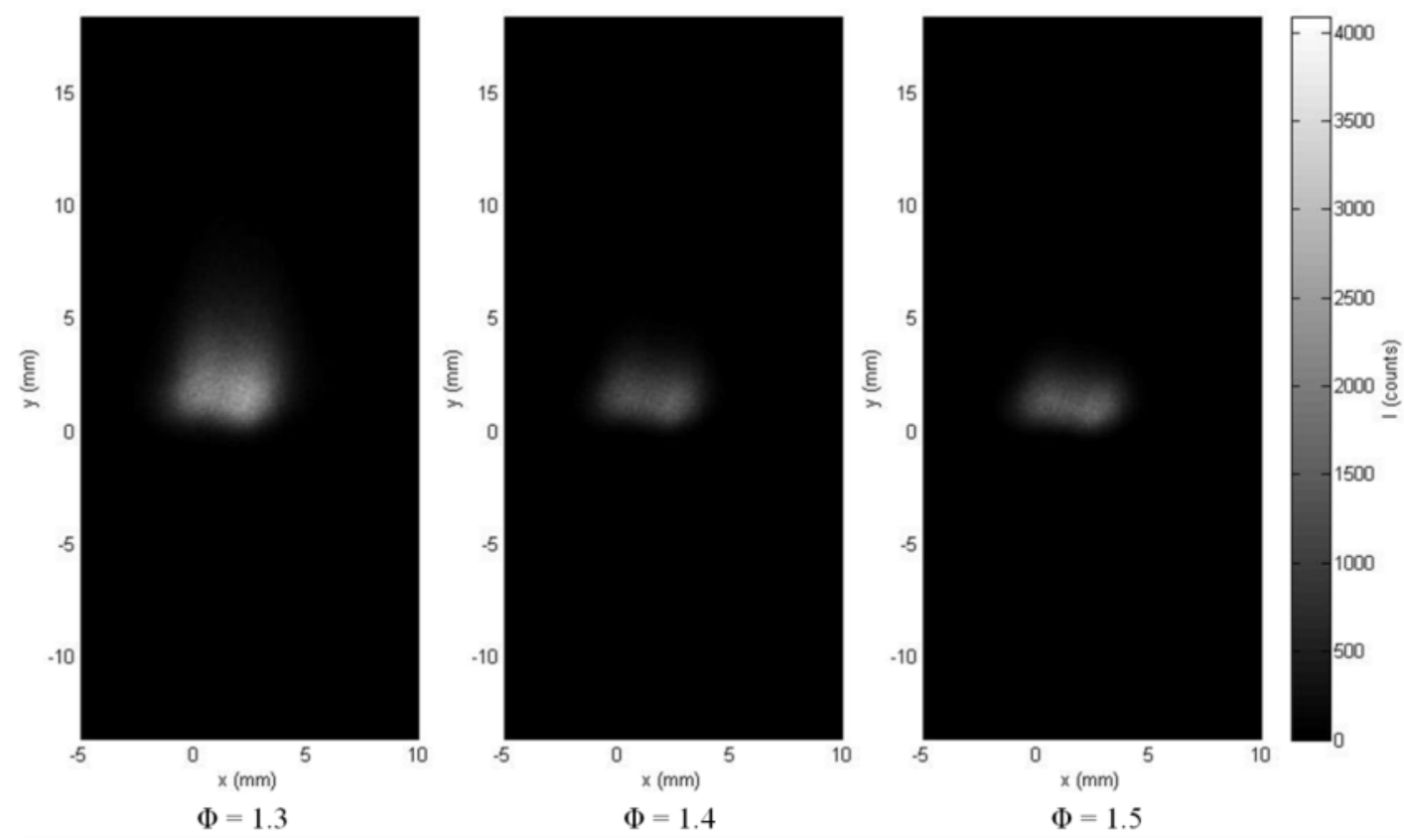

Figure A.4 $\mathrm{OH}^{*}$ chemiluminescence images at equivalence ratios, $M=4$, normal holes
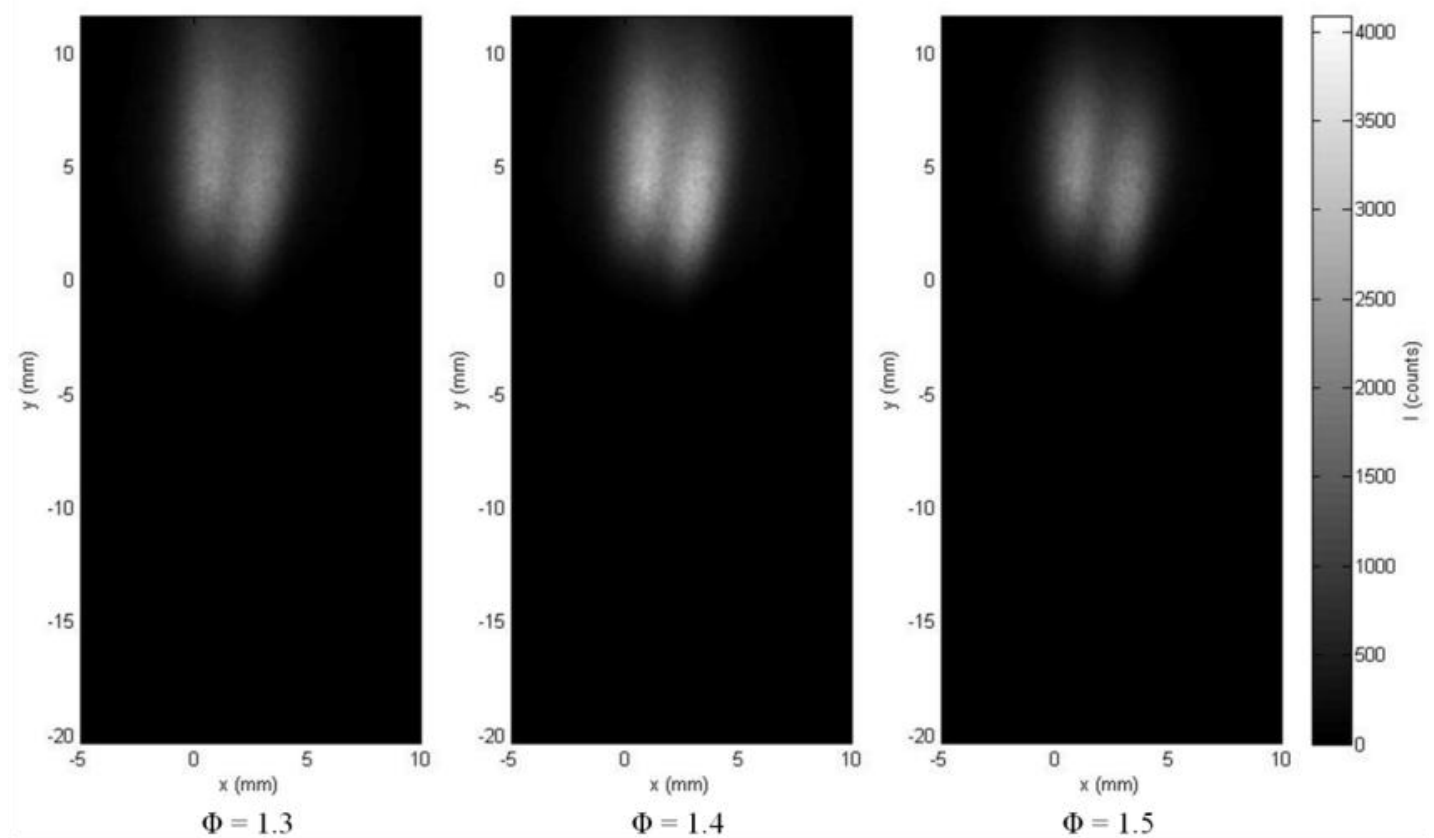

Figure A.5 $\mathrm{OH}^{*}$ chemiluminescence images at equivalence ratios, $M=4$, fan shaped holes 

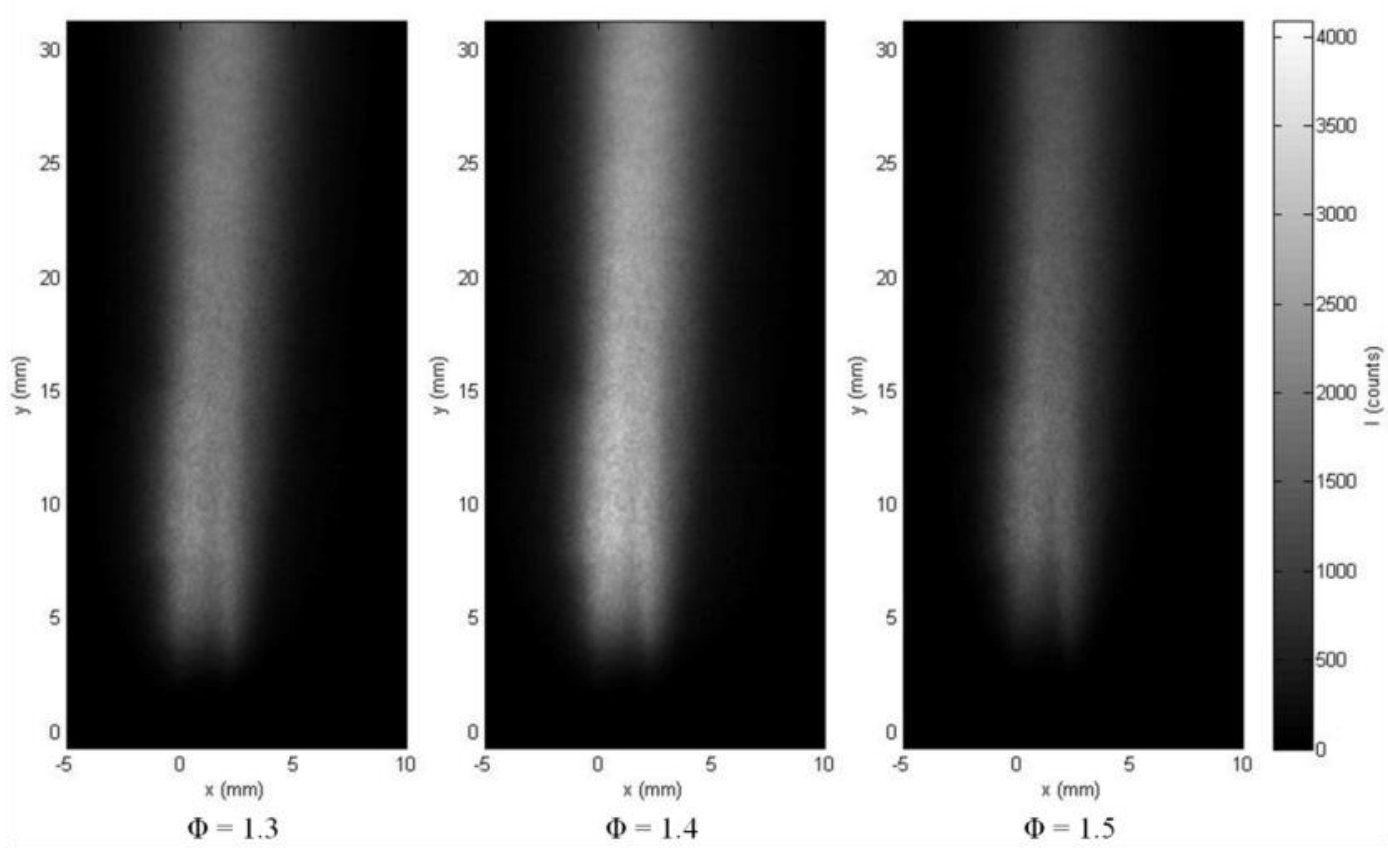

Figure A.6 OH* chemiluminescence images at equivalence ratios, $M=4$, slot
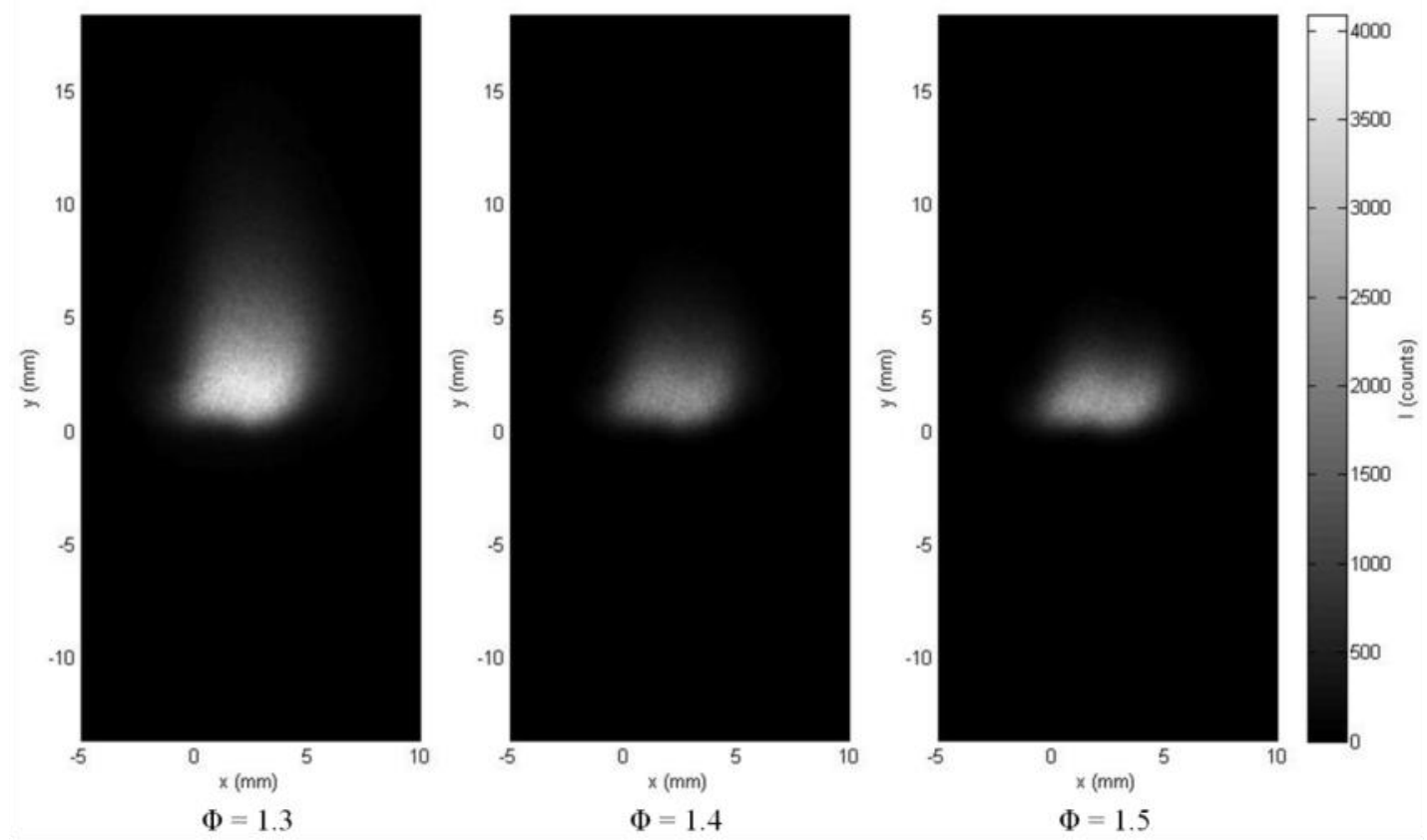

Figure A.7 $\mathrm{OH}^{*}$ chemiluminescence images at equivalence ratios, $M=7$, normal holes 

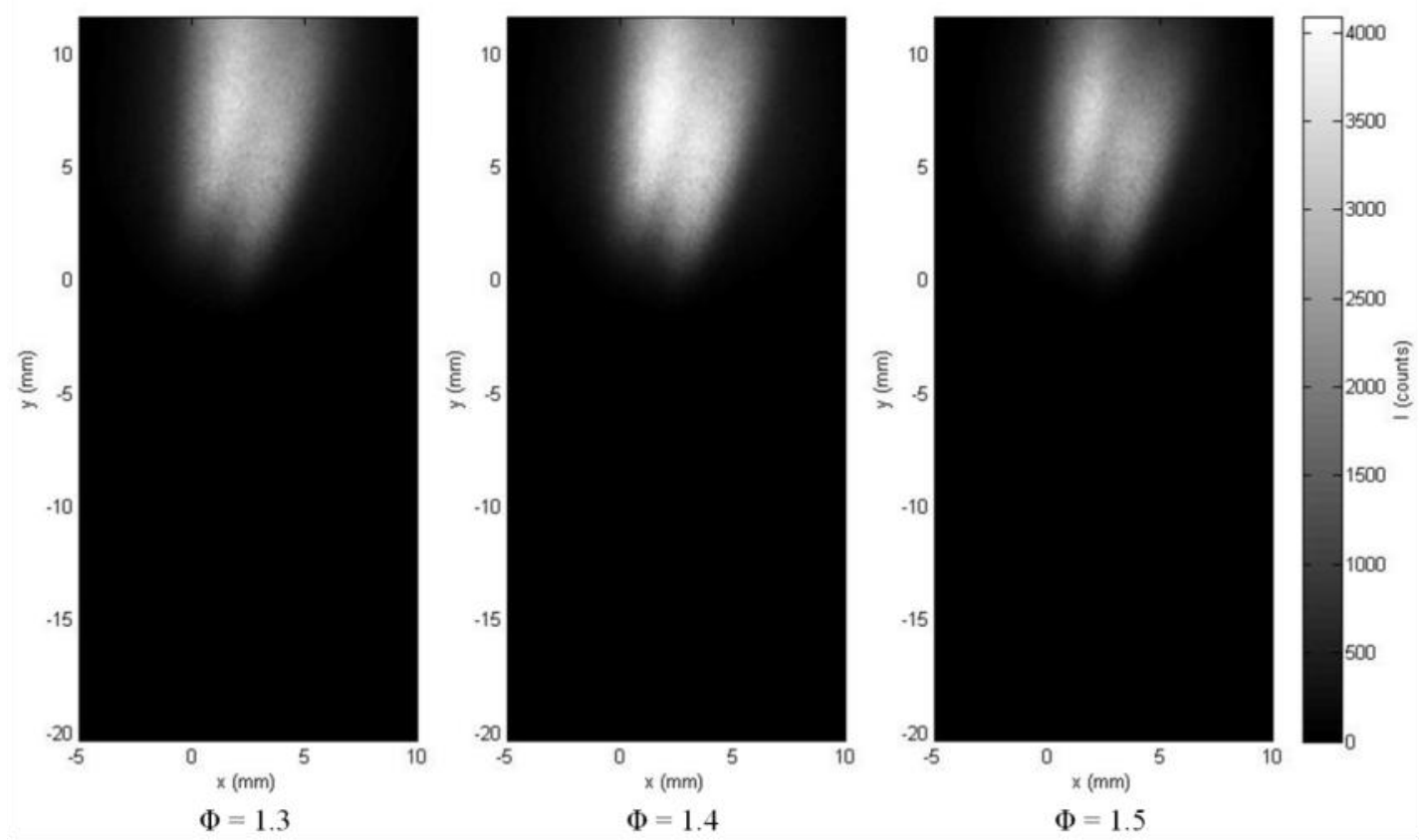

Figure A.8 OH* chemiluminescence images at equivalence ratios, $M=7$, fan shaped holes
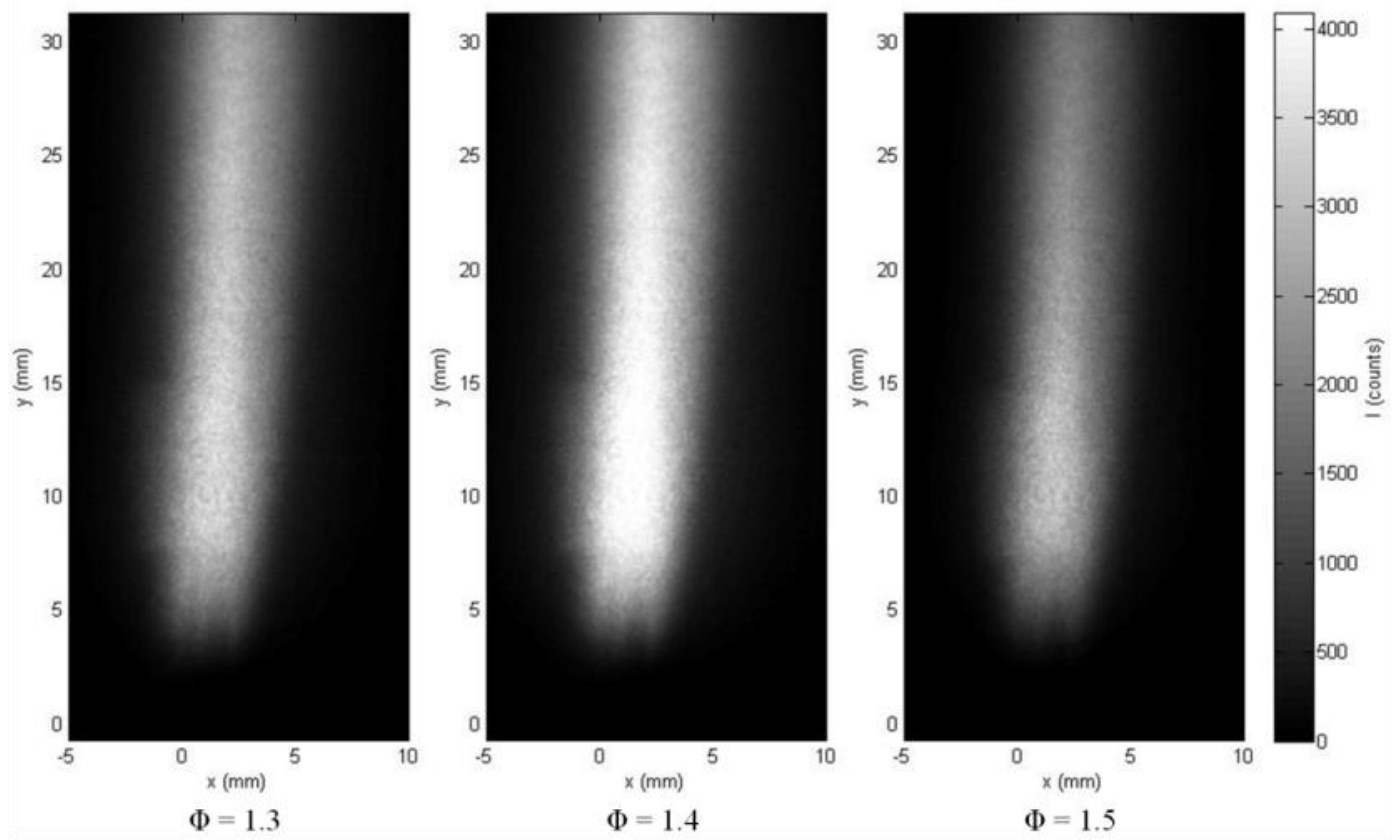

Figure A.9 OH* chemiluminescence images at equivalence ratios, $M=7$, slot 


\section{B. APPENDIX B - CH* IMAGES AND PLOTS}

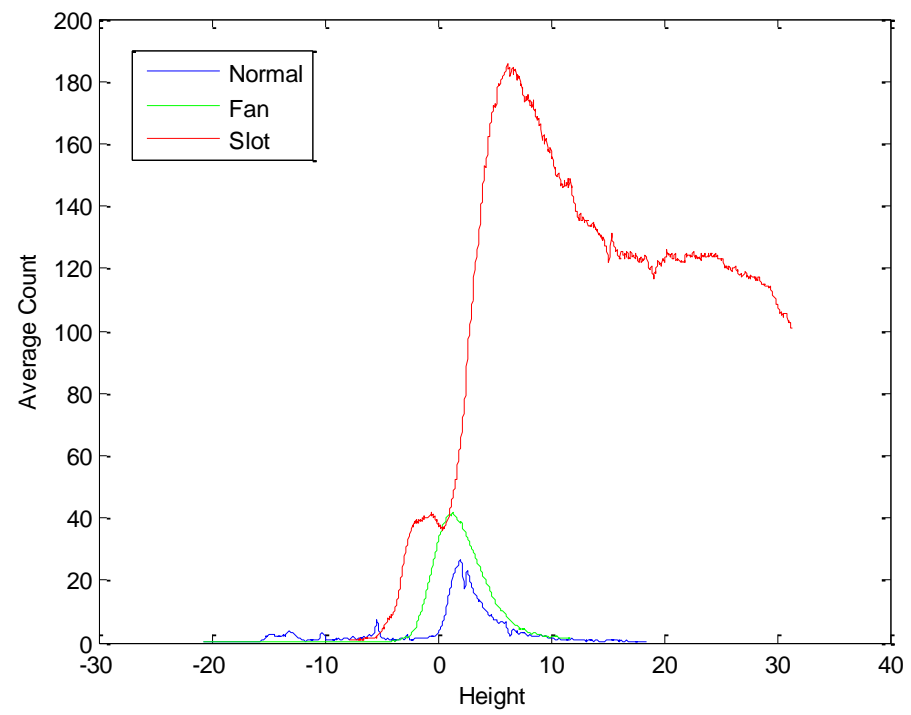

Figure B.1 CH* average photon count for three geometries, $\Phi=1.3, M=1$

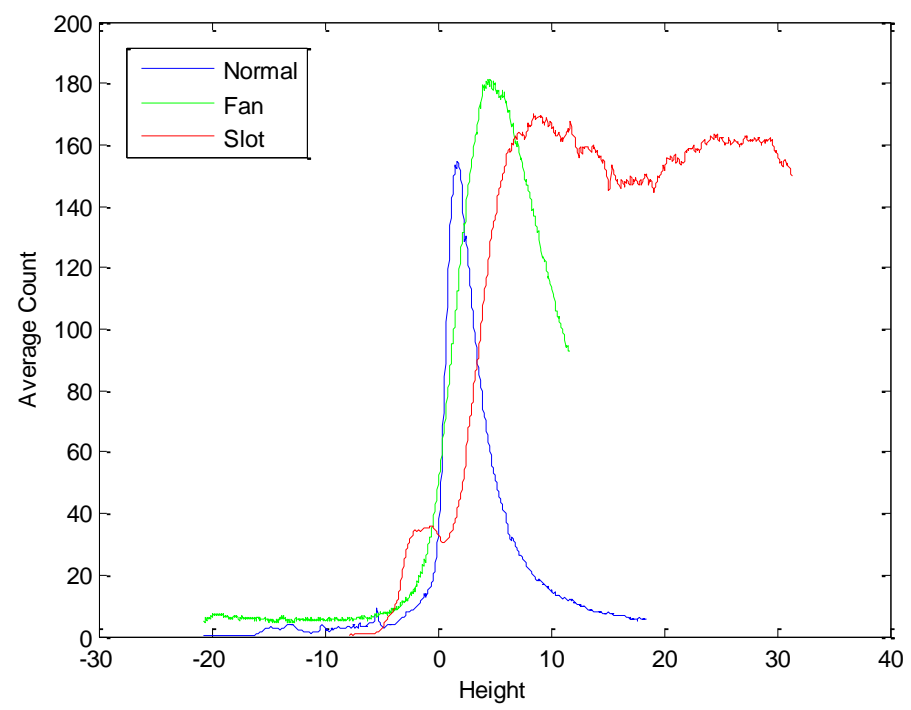

Figure B.2 $\mathrm{CH}^{*}$ average photon count for three geometries, $\Phi=1.3, M=4$ 


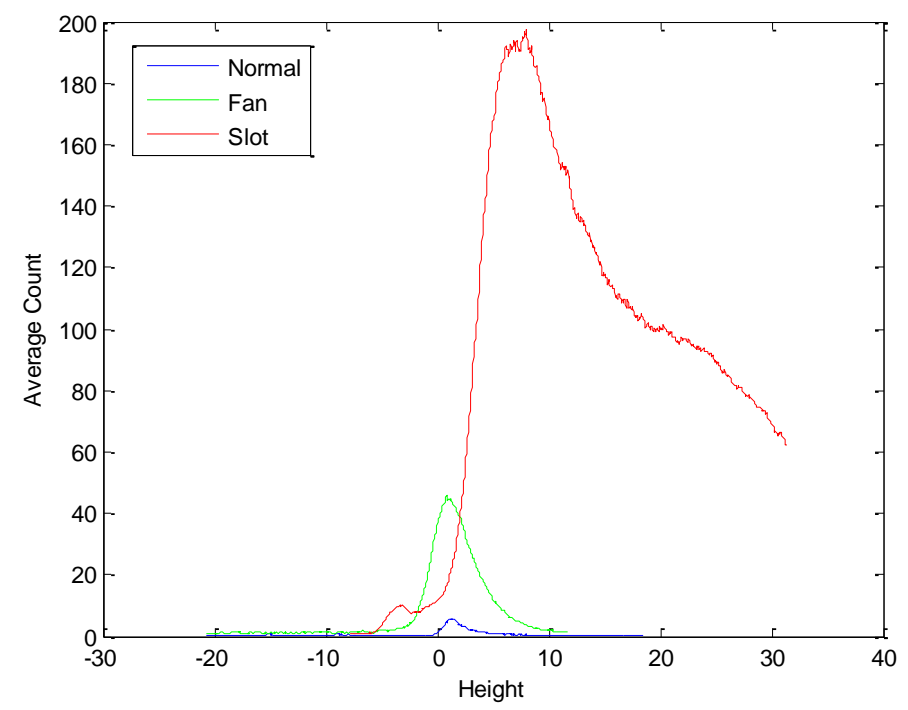

Figure B.3 CH* average photon count for three geometries, $\Phi=1.4, \mathrm{M}=1$

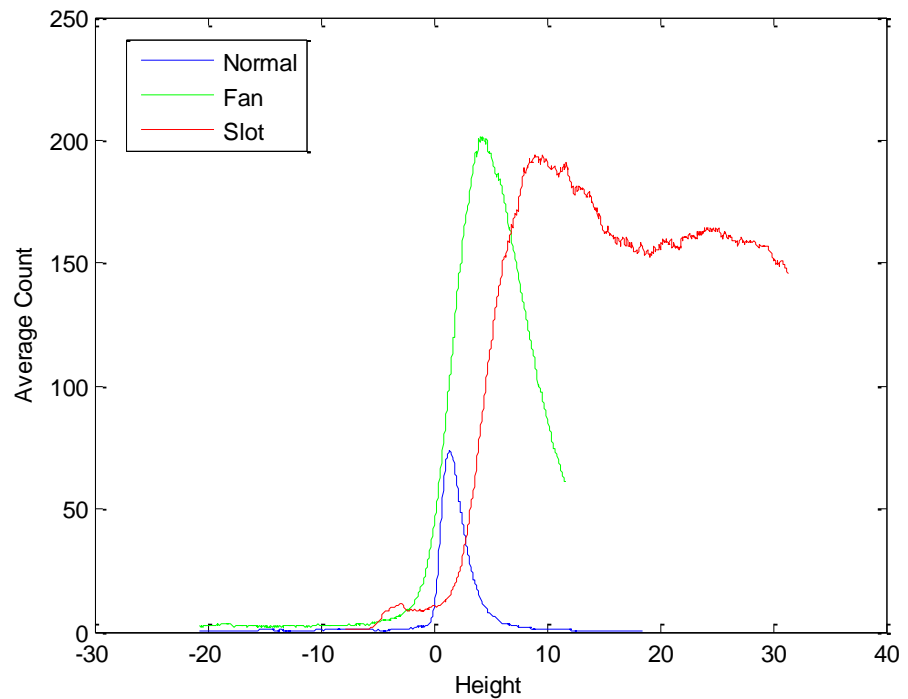

Figure B.4 $\mathrm{CH}^{*}$ average photon count for three geometries, $\Phi=1.4, \mathrm{M}=4$ 


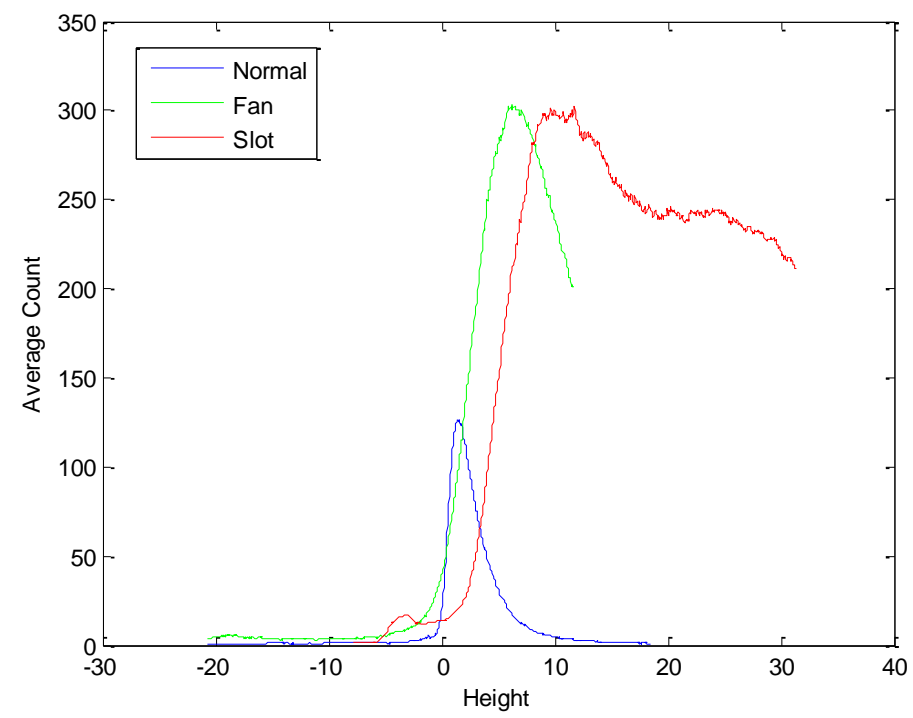

Figure B.5 CH* average photon count for three geometries, $\Phi=1.4, M=7$

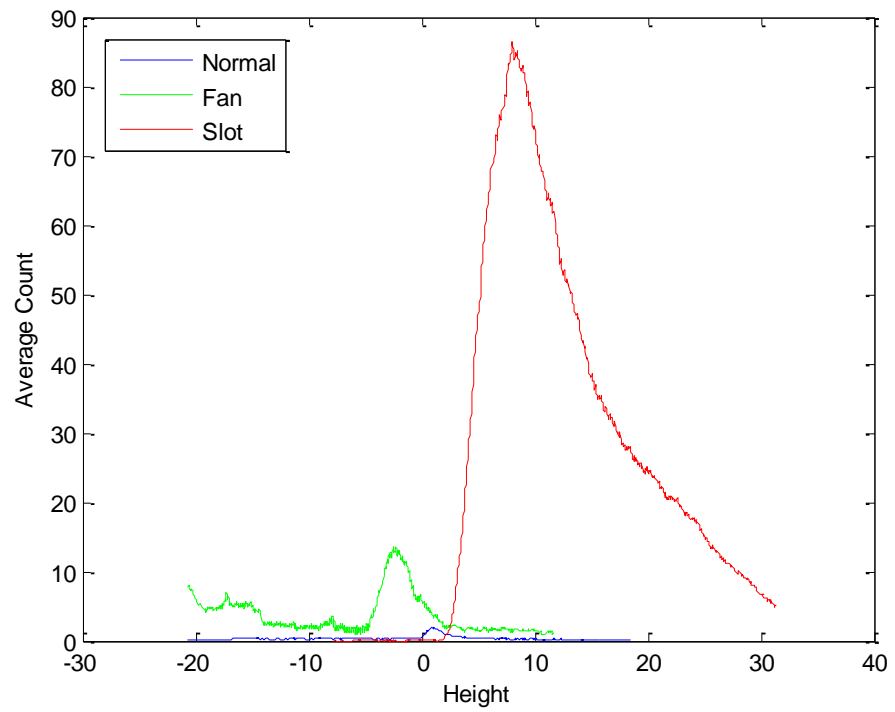

Figure B.6 CH* average photon count for three geometries, $\Phi=1.5, M=1$ 


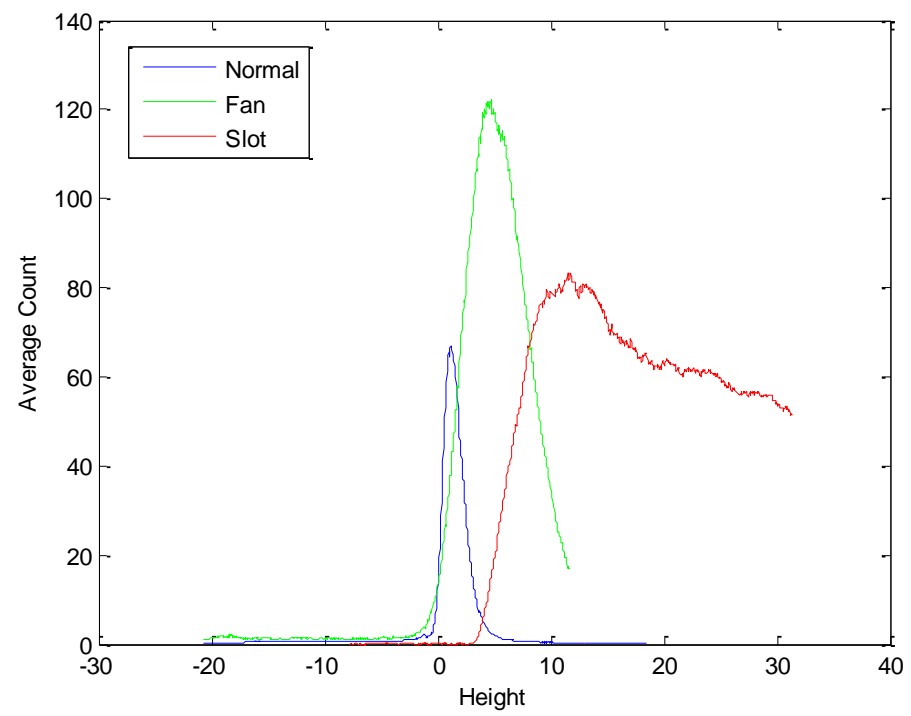

Figure B.7 $\mathrm{CH}^{*}$ average photon count for three geometries, $\Phi=1.5, M=4$

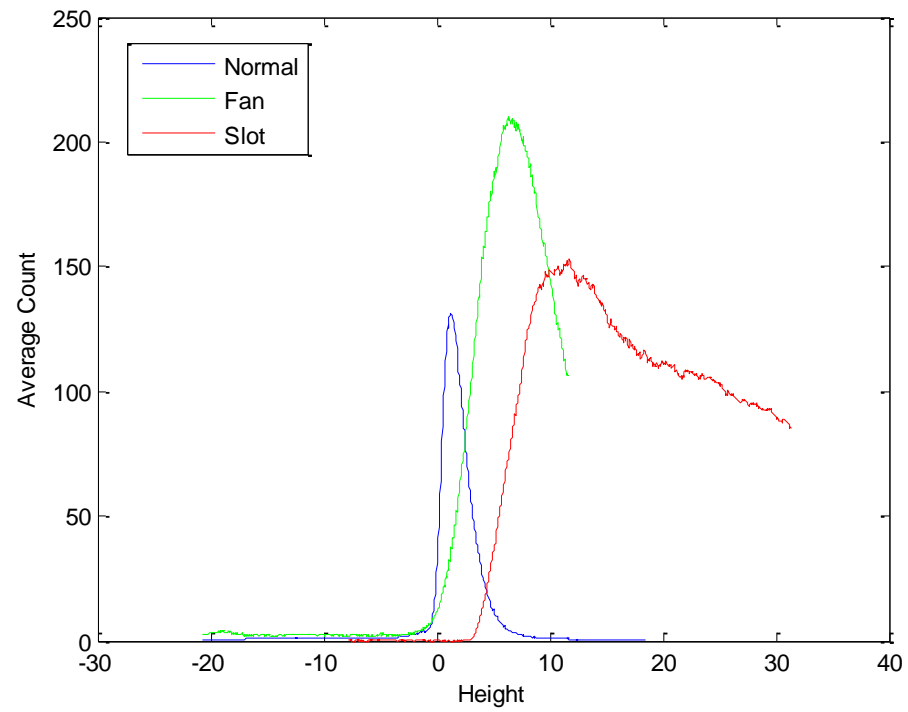

Figure B.8 CH* average photon count for three geometries, $\Phi=1.5, M=7$ 


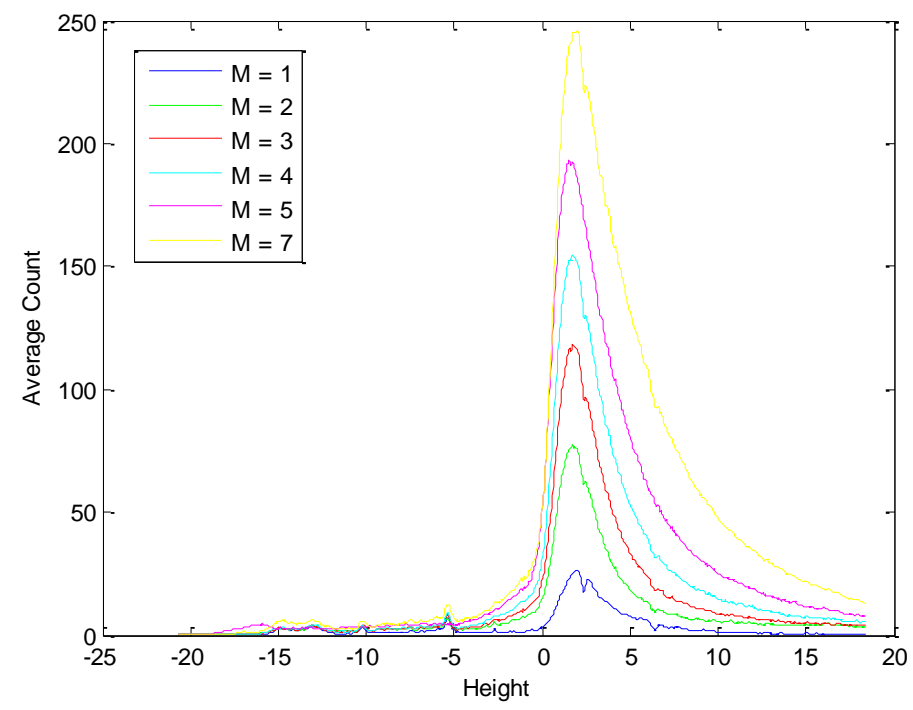

Figure B.9 CH* average photon count at blowing ratios, $\Phi=1.3$, normal holes

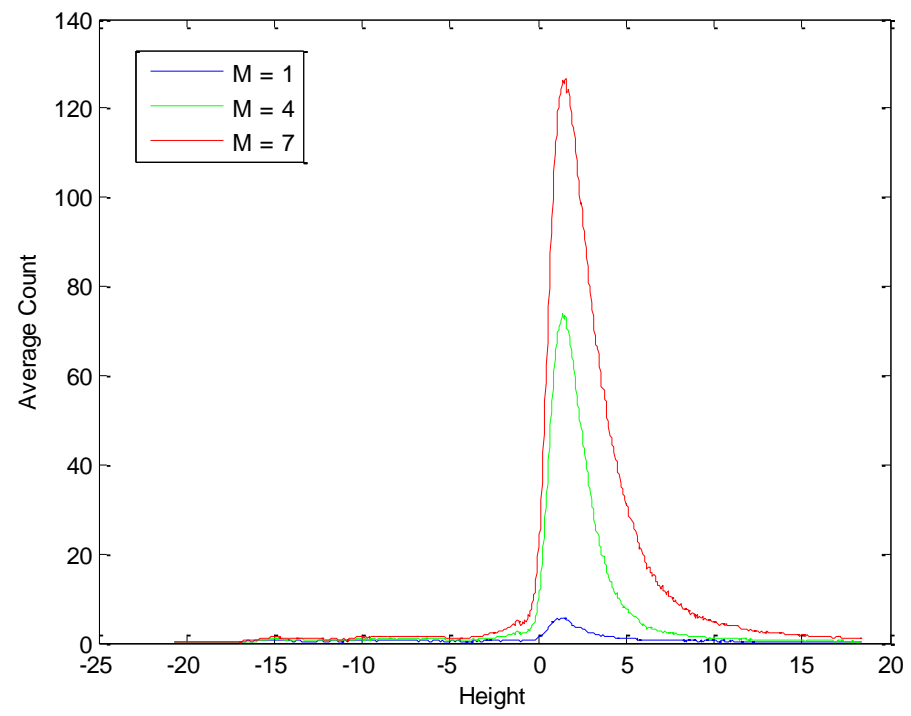

Figure B.10 CH* average photon count at blowing ratios, $\Phi=1.4$, normal holes 


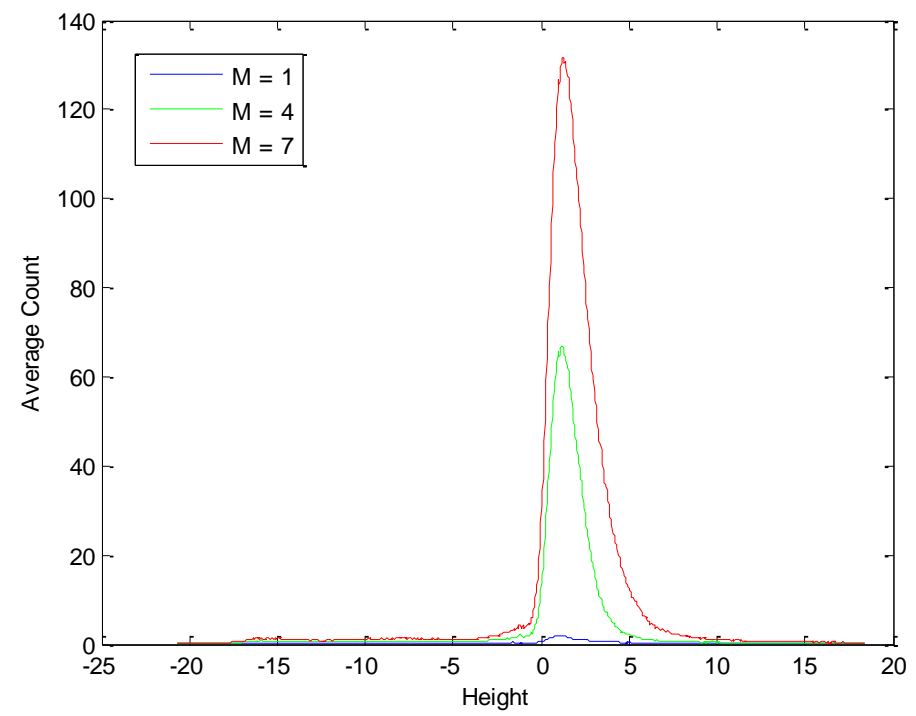

Figure B.11 CH* average photon count at blowing ratios, $\Phi=1.5$, normal holes

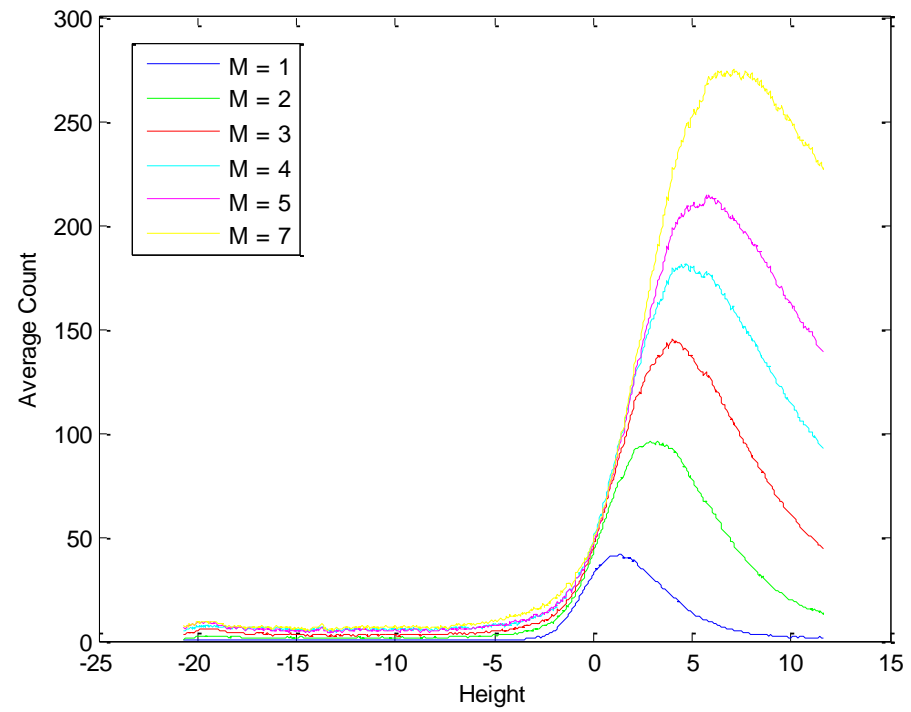

Figure B.12 $\mathrm{CH}^{*}$ average photon count at blowing ratios, $\Phi=1.3$, fan shaped holes 


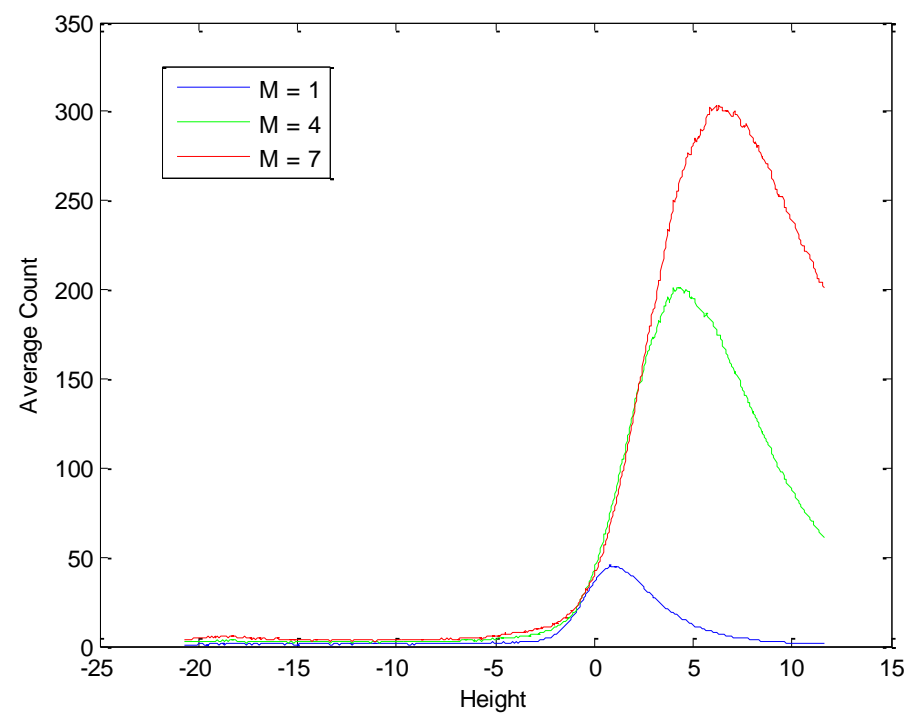

Figure B.13 $\mathrm{CH}^{*}$ average photon count at blowing ratios, $\Phi=1.4$, fan shaped holes

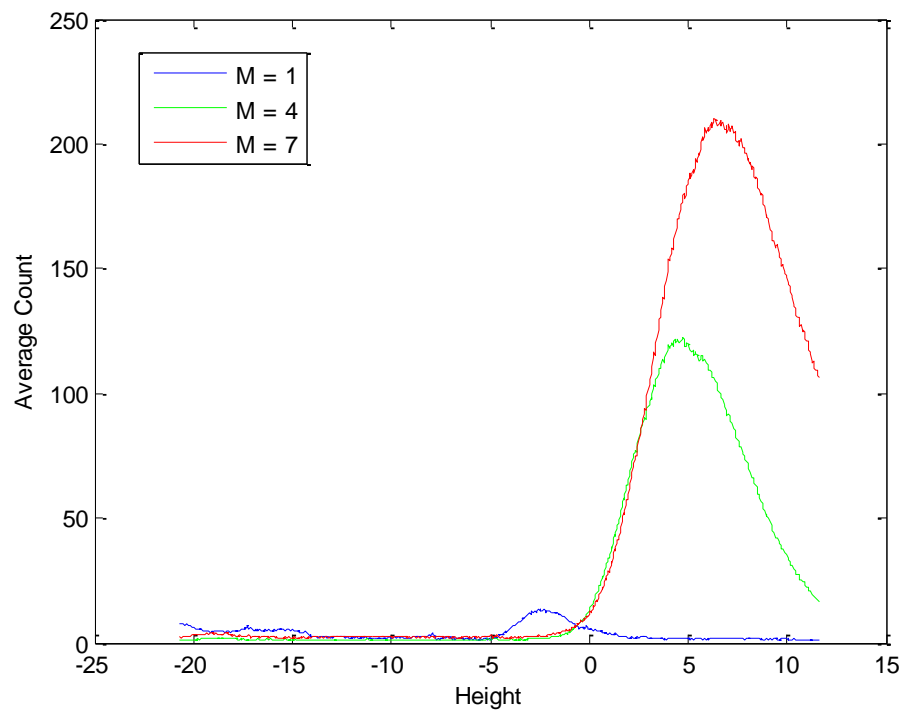

Figure B.14 CH* average photon count at blowing ratios, $\Phi=1.5$, fan shaped holes 


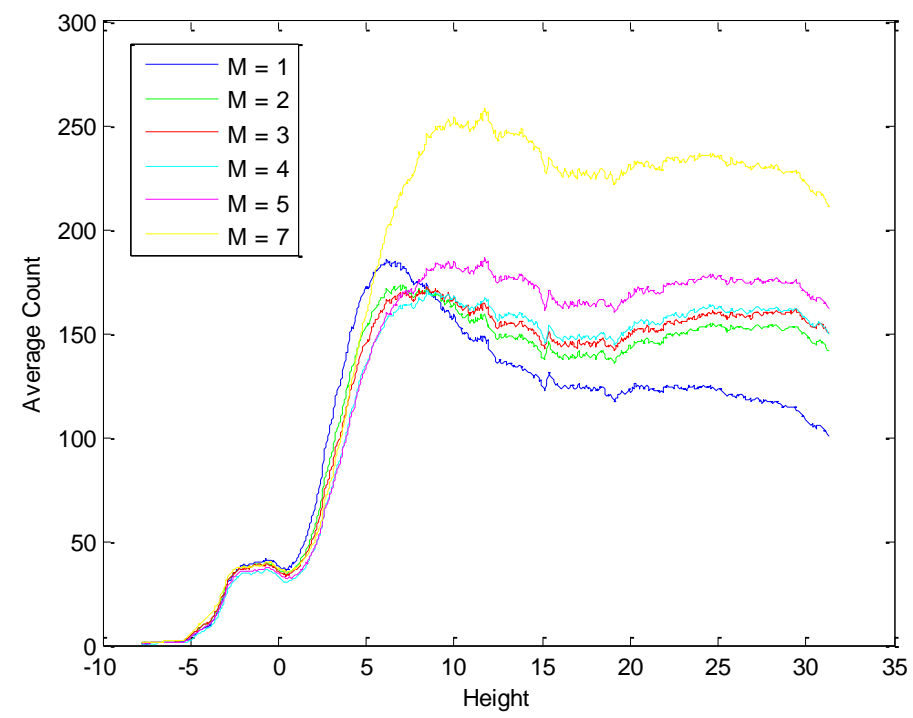

Figure B.15 $\mathrm{CH}^{*}$ average photon count at blowing ratios, $\Phi=1.3$, slot

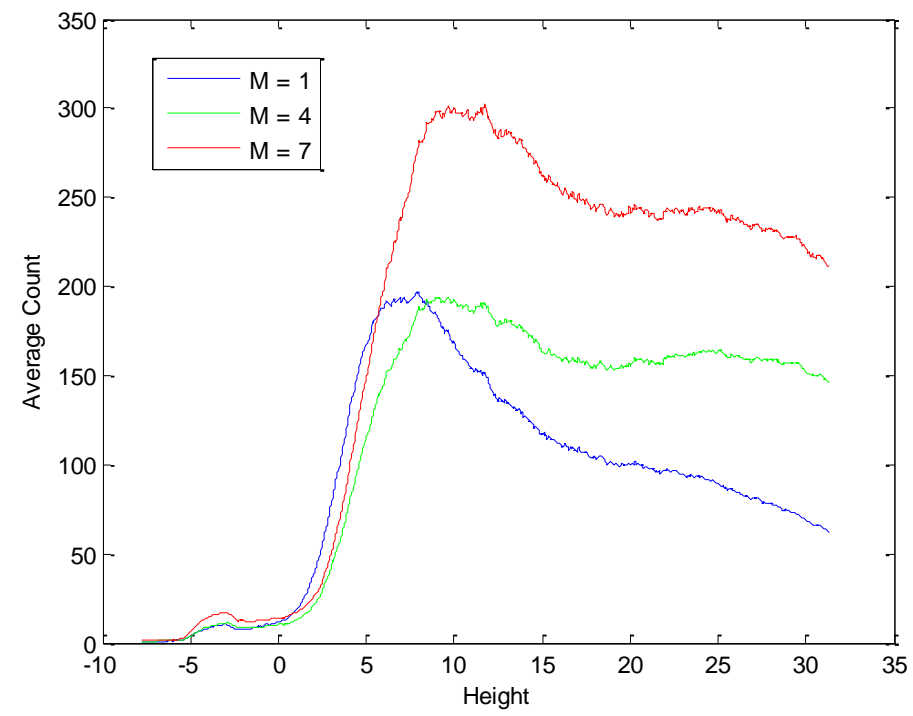

Figure B.16 $\mathrm{CH}^{*}$ average photon count at blowing ratios, $\Phi=1.4$, slot 


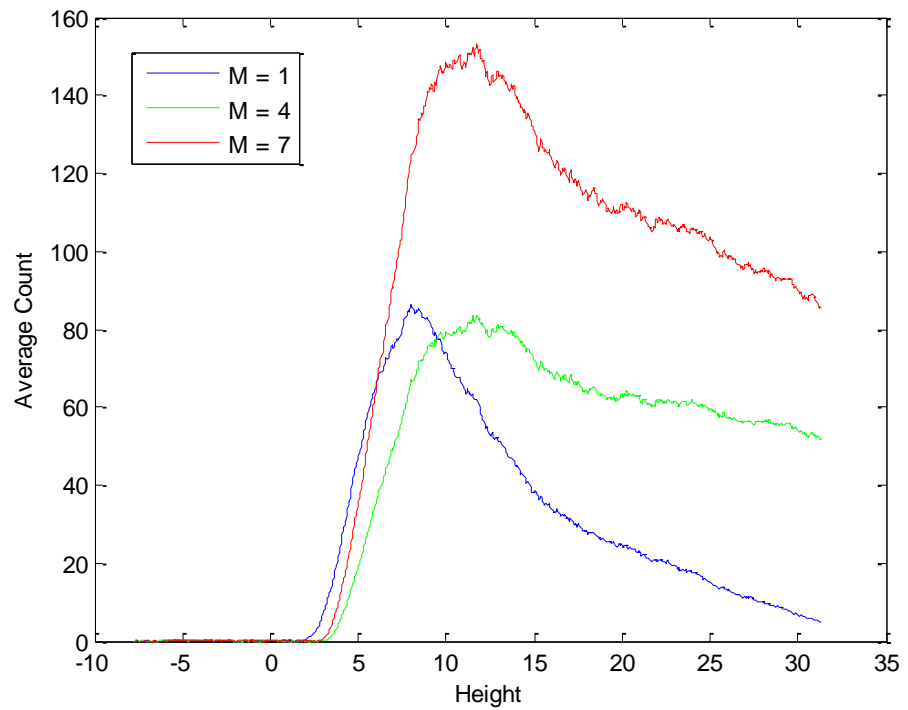

Figure B.17 $\mathrm{CH}^{*}$ average photon count at blowing ratios, $\Phi=1.5$, slot 


\section{APPENDIX C - FILM COOLING INSERTS ENGINEERING DRAWINGS}

The following images are detailed specifications of the film cooling inserts used in this study, as designed by Evans (18). All dimensions are in inches. 


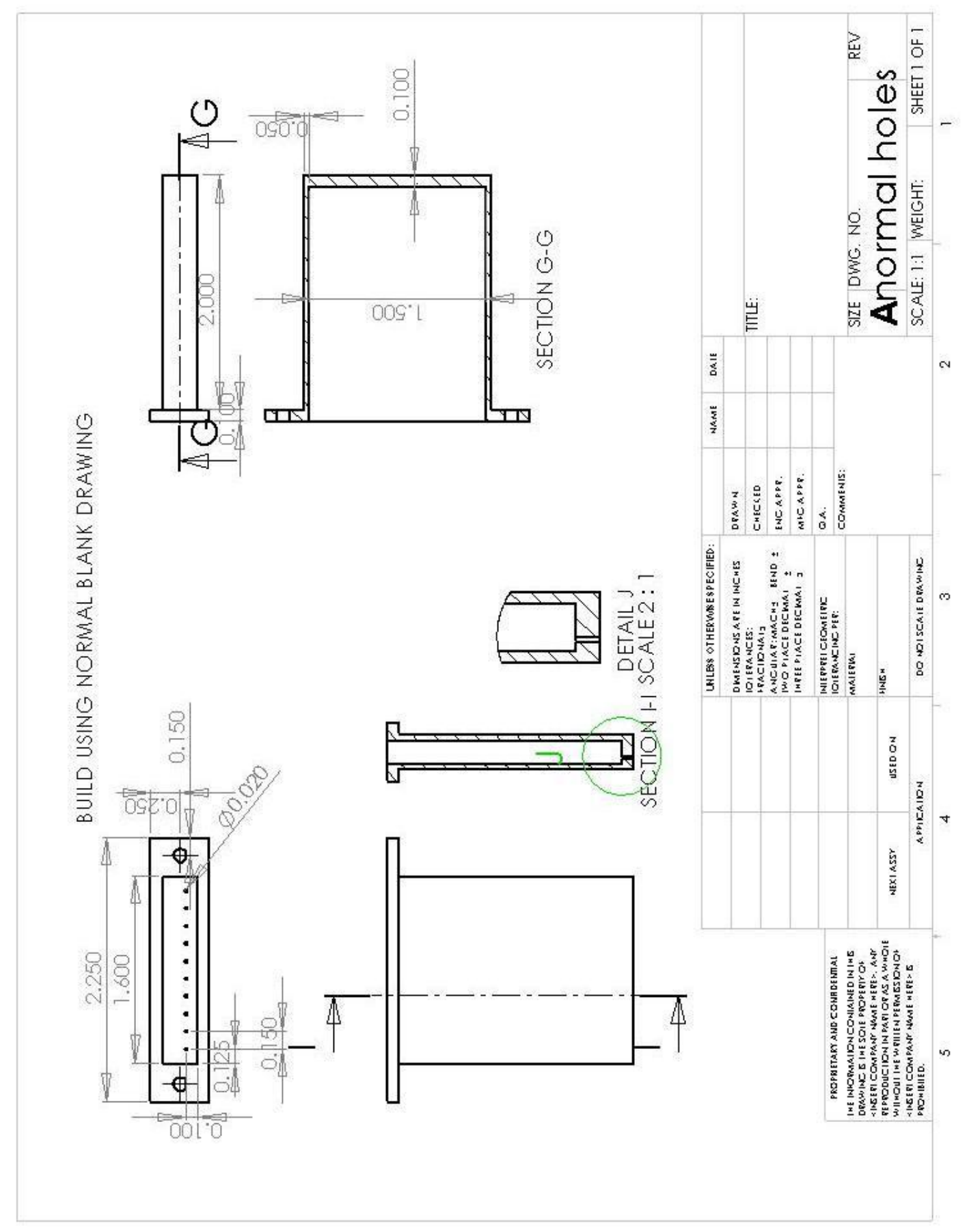

Figure C.1 Normal holes (18) 


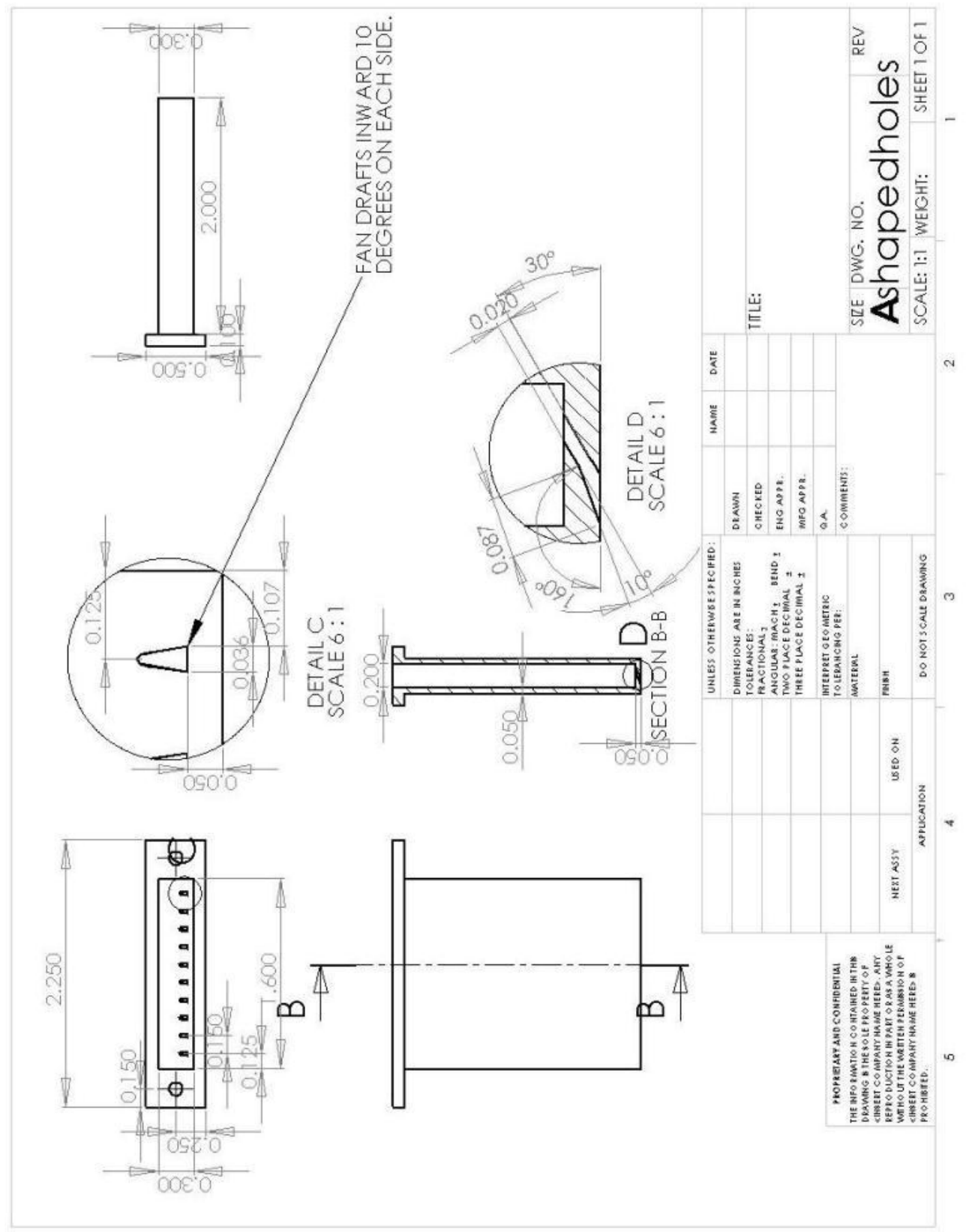

Figure C.2 Fan shaped holes (18) 


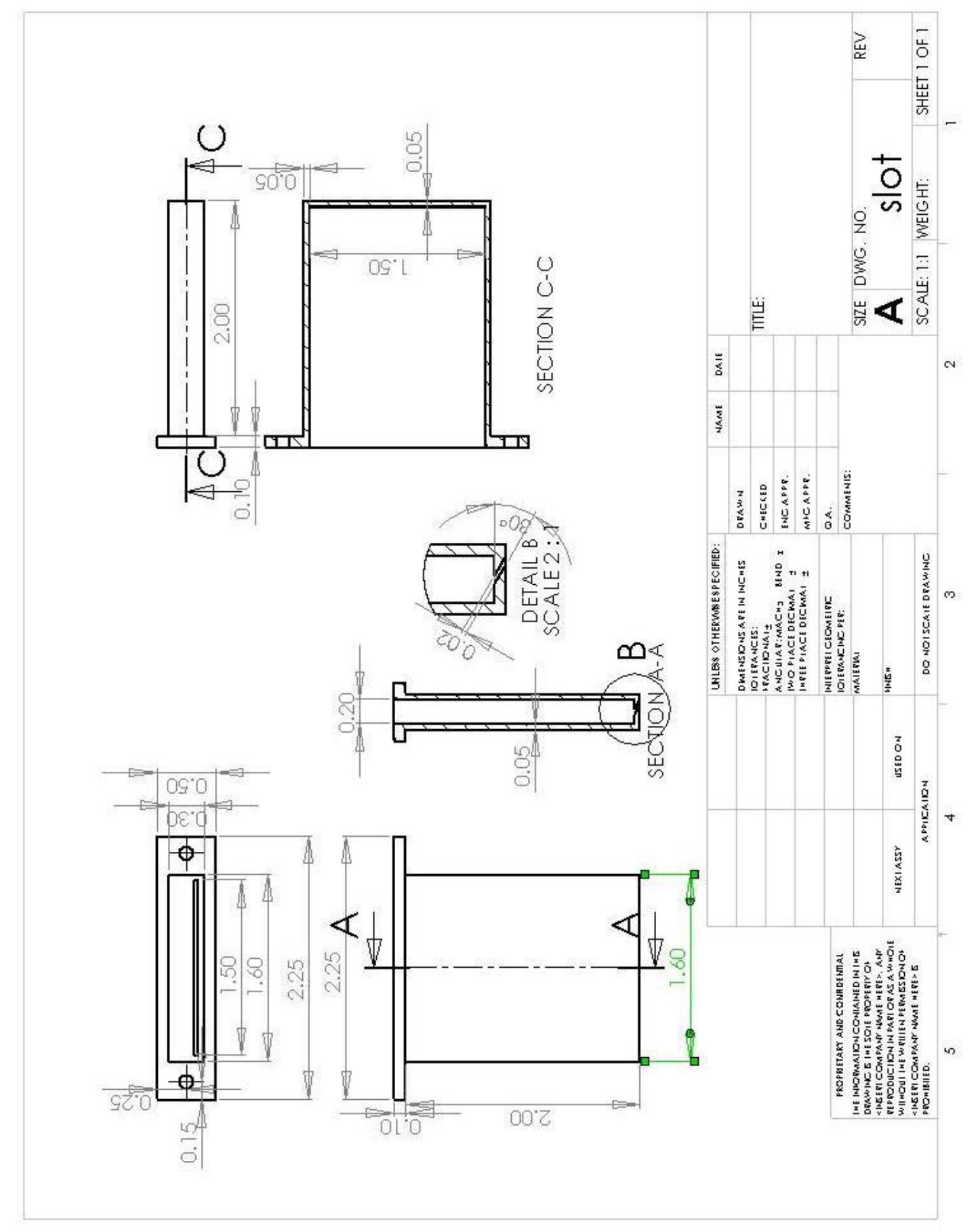

Figure C.3 Slot (18) 


\section{VITA}

Alanna Rose O’Neil was born in Rochester Hills, Michigan on March 10, 1987 to parents, Brian and Krisann O’Neil. She attended Catholic Central High School in Grand Rapids, Michigan. In 2005 she began at the University of Dayton in Dayton, Ohio. She received a bachelor's degree in Mechanical Engineering from the University of Dayton in December 2009. In January 2009 she entered graduate school at the University of Dayton working towards a master's degree in Aerospace Engineering. On September 10, 2011 she married Brian James Abels. 